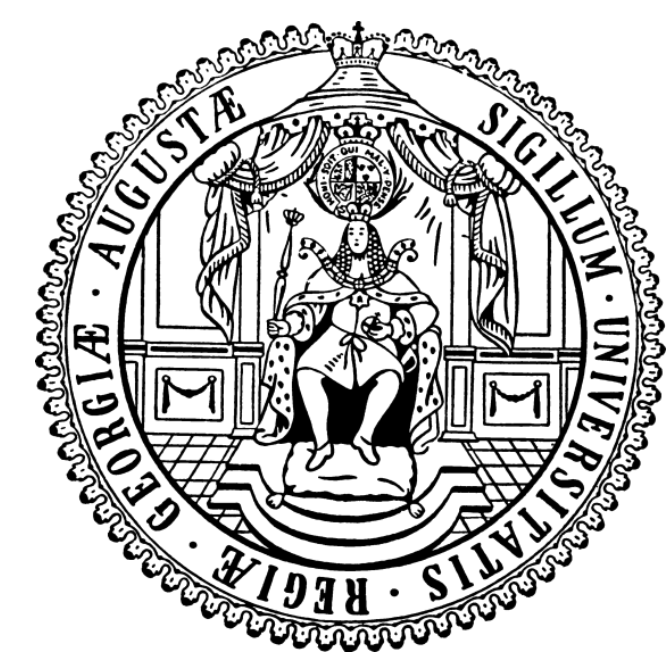

\title{
Kinetics and Mechanism of Cu-Catalyzed Atom Transfer Radical Polymerization
}

\section{Dissertation}

zur Erlangung des mathematisch-naturwissenschaftlichen Doktorgrades

"Doctor rerum naturalium"

der Georg-August-Universität Göttingen

im Promotionsprogramm CaSuS

der Georg-August University School of Science (GAUSS)

vorgelegt von

Nicolai Sörensen

aus Stade

Göttingen 2015 


\section{Betreuungsausschuss}

Prof. Dr. Michael Buback

Prof. Dr. Philipp Vana, MBA

Prof. Dr. Dietmar Stalke
Institut für Physikalische Chemie

Georg-August-Universität Göttingen

Institut für Physikalische Chemie

Georg-August-Universität Göttingen

Institut für Anorganische Chemie

Georg-August-Universität Göttingen

\section{Mitglieder der Prüfungskommission}

\section{Referent}

Prof. Dr. Michael Buback

Institut für Physikalische Chemie

Georg-August-Universität Göttingen

\section{Korreferent}

Prof. Dr. Philipp Vana, MBA

Institut für Physikalische Chemie

Georg-August-Universität Göttingen

\section{Weitere Mitglieder der Prüfungskommission}

Prof. Dr. Dietmar Stalke

Jun.-Prof. Dr. Ricardo Mata

PD Dr. Thomas Zeuch

Dr. Florian Ehlers
Institut für Anorganische Chemie

Georg-August-Universität Göttingen

Institut für Physikalische Chemie

Georg-August-Universität Göttingen

Institut für Physikalische Chemie

Georg-August-Universität Göttingen

Institut für Physikalische Chemie

Georg-August-Universität Göttingen

Tag der mündlichen Prüfung: 26. Mai 2015 




\section{Contents}

1 Abstract 1

2 Introduction 3

$\begin{array}{lll}3 & \text { Theoretical Background } & 7\end{array}$

3.1 Radical Polymerization............................................................... 7

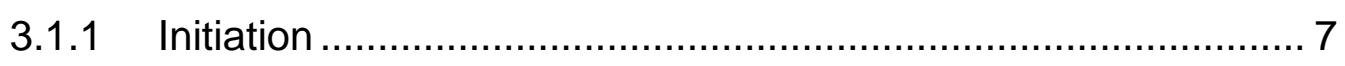

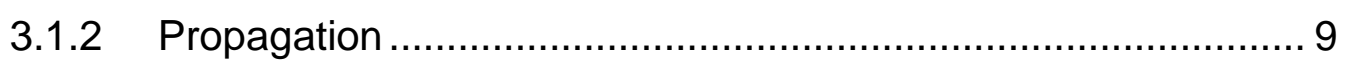

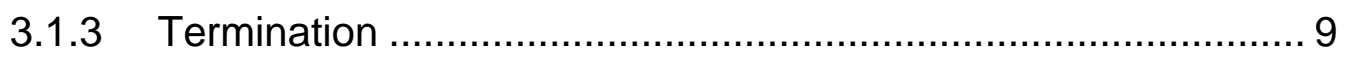

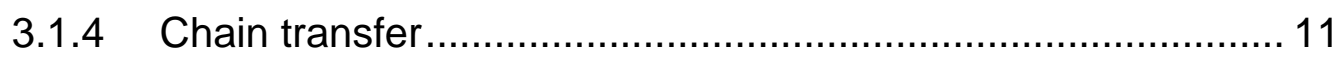

3.2 Variation of Termination Rate Coefficient with Conversion, Chain

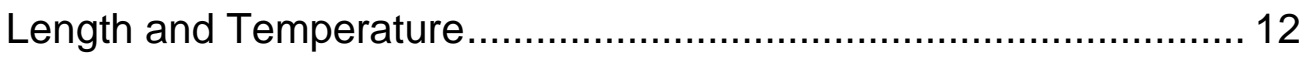

3.2.1 Conversion Dependence....................................................... 14

3.2.2 Chain-Length Dependence ............................................... 15

3.2.3 Temperature Dependence ................................................ 18

3.3 SP-PLP-EPR Technique ....................................................... 19

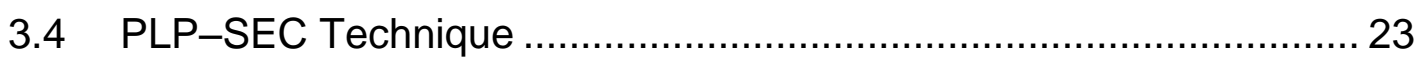

3.5 Atom Transfer Radical Polymerization........................................... 25

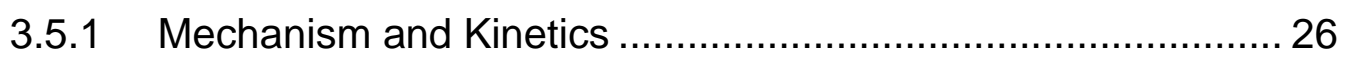

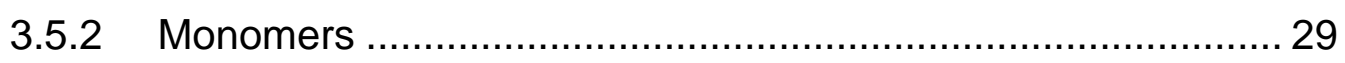

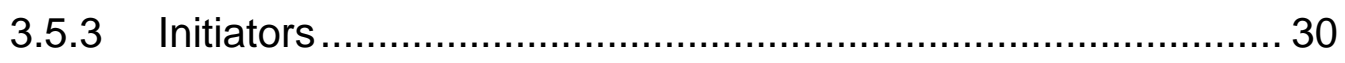

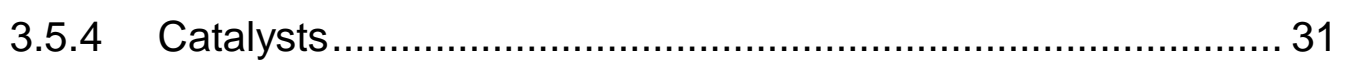

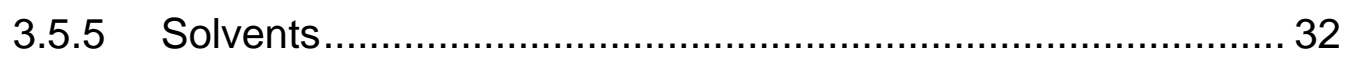

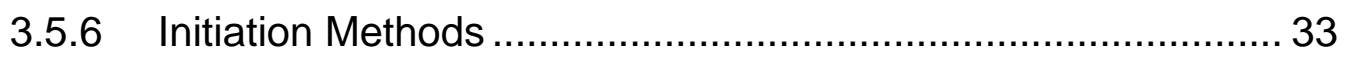

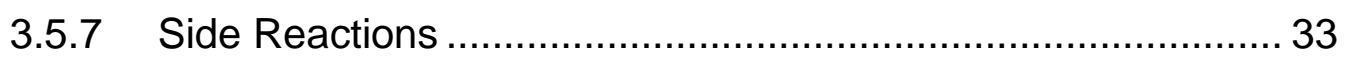

3.6 Determination of ATRP-Related Coefficients …………………...... 34

3.6.1 Determination of Deactivation Rate Coefficient $k_{\text {deact }}$ from Polymerization Kinetics ....................................................... 35 
3.6.2 Equilibrium Constants $K_{\text {ATRP }}$ Determined from Polymerization Kinetics

3.6.3 Determination of Equilibrium Constants $K_{\text {model }}$ in the Absence of Monomer

3.6.4 Determination of the Activation Rate Coefficient $k_{\text {act }}$ in Model Systems

4 Experimental

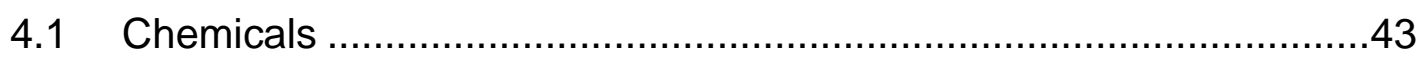

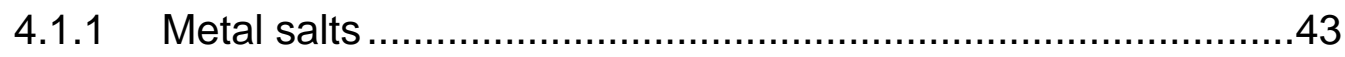

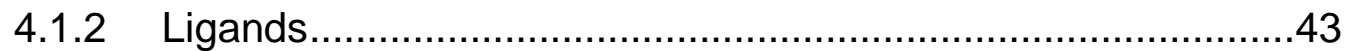

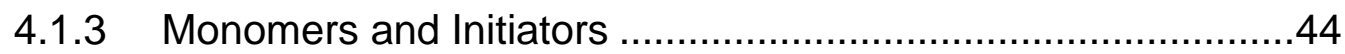

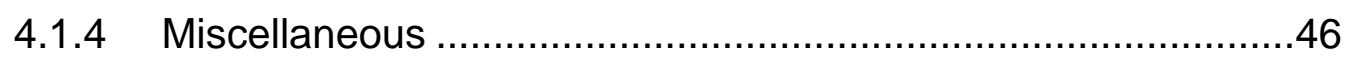

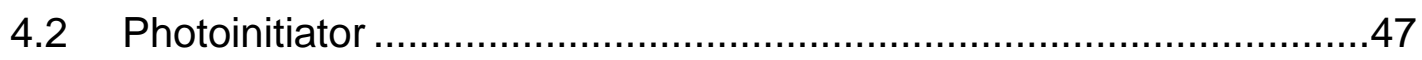

4.3 Electron Paramagnetic Resonance Spectroscopy ...........................48

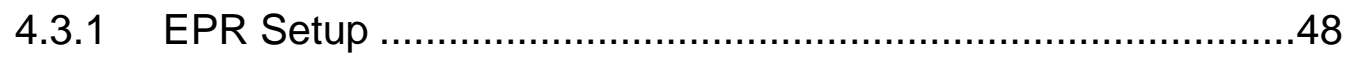

4.3.2 Sample Preparation for EPR Measurements ..........................50

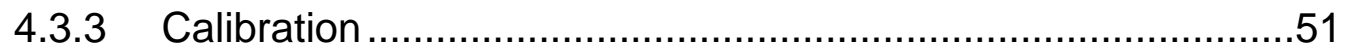

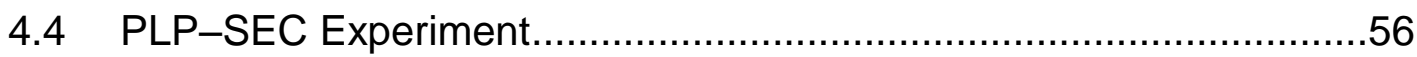

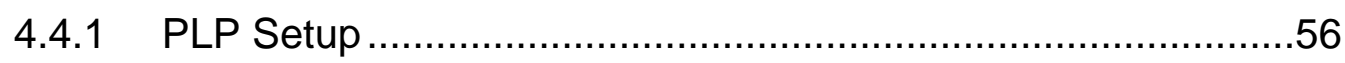

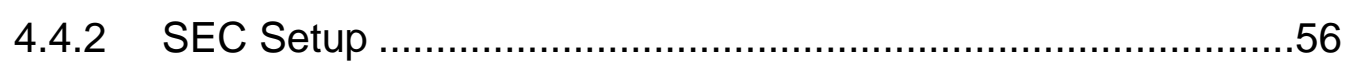

4.4.3 Sample Preparation …………………………………........57

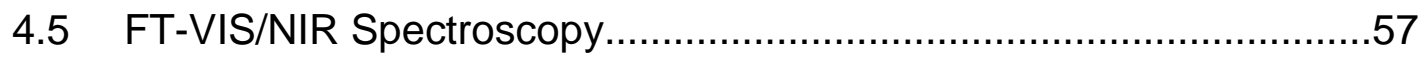

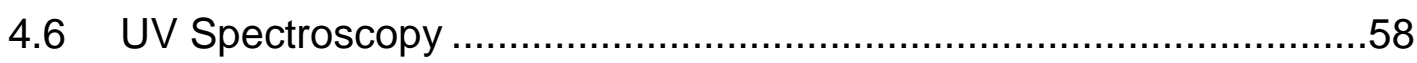

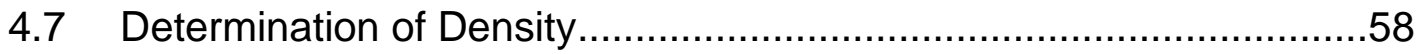

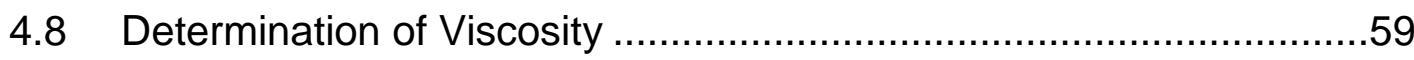

\section{Termination Kinetics of Polymerization of Methacrylate} Monomers

5.1 Splitting Pattern of Methacrylates ...................................................

5.2 Measurement of Chain-length Dependent Termination ....................63 


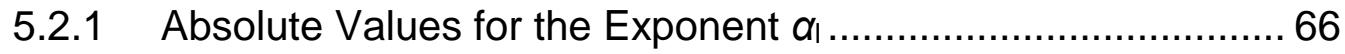

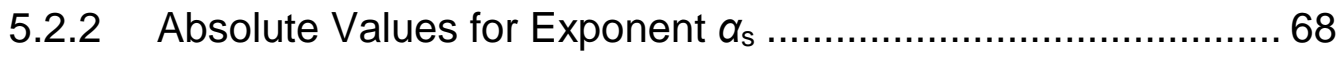

5.2.3 Termination Rate Coefficients .............................................. 71

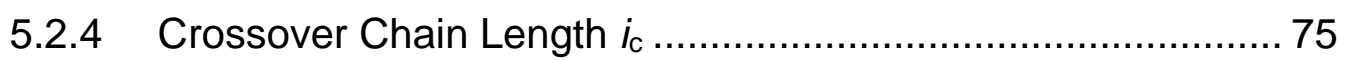

6 SP-PLP-EPR Measurement of ATRP Deactivation Rate for DMA $\quad 81$

6.1 Determination of the Propagation Rate Coefficient, $k_{\mathrm{p}}$, for DMA in $\mathrm{MeCN}$

6.2 Chain-length Dependent Termination of DMA in MeCN …................ 86

6.3 Cull Concentration Measured via EPR ………................................ 92

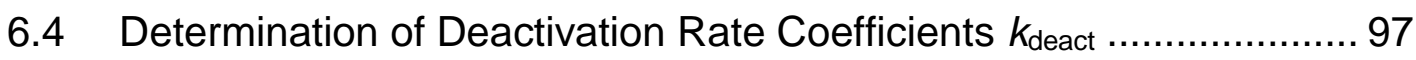

7 ATRP Deactivation of BA Radicals 107

7.1 Deactivation of Radicals at High Conversion of $\mathrm{Cu}^{\prime \prime} \ldots \ldots \ldots \ldots \ldots \ldots \ldots . . . . . . . .113$

8 Interactions of Radicals with Cu' Complexes 117

8.1 Mechanism of $\mathrm{Cu}^{\prime}-$ Induced Termination ....................................... 118

8.2 EPR Detection of Cull Intermediates............................................ 119

8.3 Determination of Rate Coefficients for the Formation of R-Cull..... 125

9 Closing Remarks $\quad 131$

$\begin{array}{ll}\text { Appendix } & 135\end{array}$

$\begin{array}{ll}\text { Abbreviations } & 141\end{array}$

$\begin{array}{ll}\text { Bibliography } & 145\end{array}$ 





\section{Abstract}

The kinetics and mechanism of $\mathrm{Cu}$-mediated atom transfer radical polymerization (ATRP) were investigated with particular emphasis on the ATRP deactivation rate coefficient, $k_{\text {deact. }}$ The method of pulsed laser polymerization (PLP) induced by a laser single pulse (SP-PLP) was applied in conjunction with electron paramagnetic resonance (EPR) for the analysis of radical concentration. As the ATRP equilibrium is superimposed on a conventional radical polymerization scheme, the decay of radical concentration after instantaneous laser-induced production of an intense burst of radicals occurs as a consequence of both deactivation and radical-radical termination. The measurement of $k_{\text {deact }}$ thus consists of two steps: First, termination is measured via SP-PLP-EPR for the $\mathrm{Cu}$-free monomer system. Within a second step, the decay of radical concentration is monitored with the $\mathrm{Cu}^{\mathrm{II}}$ complex being present.

The novel strategy has been applied to homopolymerizations of butyl acrylate (BA) and dodecyl methacrylate (DMA). HMTETA, PMDETA and TPMA were selected as the ligands to $\mathrm{Cu}$. The first two are a linear tri- and a tetradentate ligand, respectively, whereas TPMA is a branched tetradentate ligand.

In the $\mathrm{Cu}$-free DMA system, the crossover chain length $i_{\mathrm{c}}$ showed a strong decrease toward higher temperature. It is the first time that a temperature effect on $i_{\mathrm{c}}$ was observed.

In case of DMA polymerization with TPMA, $k_{\text {deact }}$ was found in close agreement with the number for the monomer-free model systems, whereas with HMTETA and PMDETA, $k_{\text {deact }}$ for the polymerizing system was lower by about one order of magnitude which effect is assigned to steric strain on the polymer chain due to the $\alpha$-methyl group. The values of $k_{\text {deact }}$ for BA polymerization are close to the ones determined for the model system.

With BA, an additional reaction channel occurs in which the $\mathrm{Cu}^{\mathrm{I}}$ species reacts with acrylate radicals. Thus, SP-PLP-EPR experiments on BA in the presence of an ATRP Cu ${ }^{\mathrm{I}}$ catalyst were performed and the produced $\mathrm{Cu}^{\mathrm{II}}$ species was detected. In addition, timeresolved spectra were recorded. The results suggest that the formation of organometallic species mainly depends on the ligand to $\mathrm{Cu}$ and is enhanced for highly active catalysts. 



\section{Introduction}

Biopolymers such as polysaccharides, proteins and DNA are the building blocks of life and natural polymeric products. Wood, wool, rubber, cotton and silk are used for thousands of years as construction material and clothing. These polymers consist of the multiple repetition of small monomer-derived units. The first synthetic polymer "Bakelite" was invented by Baekeland in $1907 .{ }^{1}$ It was followed by fundamental investigations of Staudinger on the formation and structure of macromolecules. ${ }^{2}$ Today, synthetic polymers are as vital to our modern life as biopolymers have been for thousands of years. The European plastics industry had a turnover of 320 billion euro in 2013, and the global production rose to 299 million tons. ${ }^{3}$

The applications of synthetic polymers range from packaging and construction materials, over textiles, electronics, automotive and aircraft parts, to paints, coatings and even cosmetics. The benefits are, e.g., low specific weight, durability and chemical resistance.

Polymers can be synthesized for example by polycondensation, polyaddition or ionic polymerization. However, the major fraction is produced via radical polymerization (RP), particularly mass plastics such as polyethylene (PE), polystyrene (PS), poly(vinyl chloride) (PVC), polyacrylonitrile (PAN) and poly(methyl methacrylate) (PMMA).

The advantages of RP are the insensitivity toward water and the broad availability of functionalized monomers, which can be homo- or copolymerized under variable reaction conditions. ${ }^{4}$ However, conventional radical polymerization is limited in the ability to control chain length and architecture of the resulting polymer. Therefore, reversibledeactivation radical polymerization (RDRP) methods were developed such as nitroxidemediated polymerization (NMP), reversible addition fragmentation chain-transfer (RAFT) polymerization and atom transfer radical polymerization (ATRP). ${ }^{5-9}$ They are based on a dynamic equilibrium between an active radical and a deactivated dormant species, which significantly reduces termination and provide access to polymeric material with narrow molar mass distribution and well-defined architecture. 
ATRP is widely applicable, as halogen functionalities may be easily introduced. $\mathrm{Cu}$ mediated ATRP is one of the most commonly used RDRP methods, since Cu catalysts are highly favored due to their superior properties in terms of versatility and cost. ${ }^{10}$ The large availability of ligands allows to fine-tune the dynamic equilibrium between active and dormant species and thus to achieve good control of polymerization. Styrenes, (meth)acrylate esters and amides, and acrylonitrile have been successfully polymerized. ${ }^{11,12}$

The actual properties of polymers are strongly dependent on the kinetics of the individual reaction steps of overall polymerization. The detailed knowledge of the reaction mechanism and of the associated rate coefficients is essential for modeling and optimizing of the polymerization process. In ATRP an activation-deactivation equilibrium is superimposed on a conventional radical polymerization scheme. The associated activation rate coefficient $k_{\text {act }}$ is easily accessible, whereas the measurement of the deactivation rate coefficient, $k_{\text {deact }}$, is less straight forward.

The primary intention of this work is to study the ATRP deactivation kinetics of $\mathrm{Cu}$ mediated systems. As pulsed laser techniques (PLP) have been widely used for the detailed study of radical polymerization kinetics, it appeared promising to use a laser pulsed method also for the determination of $k_{\text {deact. }}$. The essential advantage of kinetic analyses via PLP methods is the potential of almost instantaneously producing of a significant amount of small radicals. Moreover, the size of growing radicals is proportional to the time $t$ after applying the laser pulse, unless chain-transfer processes come into play. ${ }^{13}$ Rate coefficients derived from PLP are particularly suitable for applications in RDRP, as the radical size distribution in laser single pulse experiments resembles the one in systems with reversible deactivation. ${ }^{14}$

Size-exclusion-chromatographic analysis (SEC) of polymer produced by the application of laser pulses at constant pulse repetition rate yields propagation rate coefficient $k_{\mathrm{p}}$ for bulk and solution homo- and copolymerizations via the PLP-SEC method. ${ }^{15-18}$ PLP carried out in conjunction with highly time-resolved near-infrared spectroscopy allows investigations for the time evolution of monomer concentration after application of a laser pulse. This so-called SP-PLP-NIR technique yields the ratio of termination to propagation rate coefficient $k_{t} / k_{\mathrm{p}}$. An attractive feature of SP-PLP-NIR is that this method 
may be used for measurements up to high degrees of monomer conversion and, as PLPSEC, up to high pressure. ${ }^{19-21}$

Electron paramagnetic resonance (EPR) spectroscopy in conjunction with laser pulsing has turned out to be a highly valuable method for the analysis of radical polymerization kinetics, in which the decay of radical concentration after pulsing is monitored with submillisecond time resolution. In addition, the SP-PLP-EPR method allows for measuring the kinetics of different types of radical species that may evolve after laser-induced production of primary radical fragments. SP-PLP-EPR has already been used for measuring termination rate coefficients as a function of chain length, $k_{\mathrm{t}}^{i, i}$, for monomers, such as methacrylates, methacrylic acid, vinyl acetate and styrene. ${ }^{13,22-27}$ With acrylates and acrylic acid, in addition, time-resolved concentrations of secondary chain-end radicals, SPRs, and of mid-chain radicals, MCRs, produced by intramolecular chain transfer via a 1,5-H shift reaction (backbiting) of SPRs, can be measured. Fitting of the so-obtained radical concentration vs time traces yields the rate coefficients of backbiting and termination reactions as well as of the propagation from MCRs. ${ }^{28-30}$ The potential of EPR-monitoring of two different radical species in one experiment has opened the pathway to studying the kinetics of intermediate radicals and propagating radicals. ${ }^{31,32}$

In the present work, the SP-PLP-EPR technique will be applied to investigations into Cumediated ATRP, in which at least two types of paramagnetic species are present, propagating radicals and the deactivating $\mathrm{Cu}^{\mathrm{II}}$ catalyst.

The method is based on measuring the deactivation of radicals by $\mathrm{Cu}^{\mathrm{II}}$ species. As usual termination occurs in parallel, the chain-length dependent kinetics has to be studied in a first step without the $\mathrm{Cu}$ catalyst being present. Within the second step, the disappearance of radicals is measured in the presence of $\mathrm{Cu}^{\mathrm{II}}$. The novel method will be illustrated for the polymerization of methacrylate and acrylate monomers. Moreover, this study aims at examining side reactions and at detecting intermediate species in $\mathrm{Cu}$-mediated ATRP. 



\section{Theoretical Background}

\subsection{Radical Polymerization}

Radical polymerization consists of initiation, propagation, termination and chain transfer. So-called "ideal polymerization kinetics", which considers the first three reactions, is based on the following assumptions: $:^{33}$

- All reactions are irreversible.

○ The reactivity of radicals are identical, independent of chain length and monomerto-polymer conversion.

- Monomer is solely consumed by propagation of radical species.

$\circ$ Termination of radicals occurs only between 2 growing chains by combination and disproportionation.

\subsubsection{Initiation}

The initiation step can be divided into two separate processes. First an initiator molecule decomposes and generates two primary radicals. Decomposition of the initiator is induced either thermally or photochemically. In a second process a primary radical adds to a monomer molecule and starts a growing chain.

$$
\begin{aligned}
& \text { Initiator decay: } \quad \text { I } \stackrel{k_{\mathrm{d}} \cdot f}{\longrightarrow} 2 \mathbf{R}_{0}^{\bullet} \\
& \text { Initiation: } \quad \mathrm{R}_{0}^{\bullet}+\mathrm{M} \stackrel{k_{\mathrm{i}}}{\longrightarrow} \mathrm{R}_{1}^{\bullet} \\
& \text { I : initiator } \\
& k_{\mathrm{d}} \quad: \quad \text { rate coefficient of initiator decay }
\end{aligned}
$$


$f \quad: \quad$ initiator efficiency

$\mathrm{R}_{i} \quad: \quad$ radical of monomer chain length $i$

M : monomer

$k_{\mathrm{i}} \quad: \quad$ rate coefficient of first monomer addition

Initiator efficiency $f$ describes the ratio of the number of radicals, which initiate chain growth, to the number of produced primary radicals.

The rate of formation of primary radicals, i.e., the increase in radical concentration with time, $t$, can be expressed by a first-order rate law (eq. 3.1).

$$
\frac{\mathrm{d} c_{\mathrm{R}}}{\mathrm{d} t}=2 \cdot k_{\mathrm{d}} \cdot f \cdot c_{\mathrm{I}}
$$

$c_{\mathrm{R}} \quad: \quad$ radical concentration

$c_{\mathrm{I}} \quad: \quad$ initiator concentration

In case of a UV laser-induced photochemical initiation with a pulse width of ca. $20 \mathrm{~ns}$, the formation of primary radicals is instantaneously in comparison to all other reactions.

$$
c_{\mathrm{R}}^{0}=2 \cdot \Phi \cdot \frac{n_{\mathrm{abs}}}{V}
$$

$c_{\mathrm{R}}{ }^{0} \quad: \quad$ initial radical concentration

$\Phi \quad$ : $\quad$ quantum yield

$n_{\text {abs }} \quad: \quad$ amount of absorbed photons

$V \quad$ : $\quad$ sample volume 


\subsubsection{Propagation}

In a propagation reaction a macroradical of chain length $i$ is growing by successive addition of monomer molecules.

Propagation: $\quad \mathrm{R}_{i}^{\bullet}+\mathrm{M} \stackrel{k_{\mathrm{p}}}{\longrightarrow} \mathrm{R}_{i+1}^{\bullet}$

The polymerization rate, i.e., the decrease in monomer concentration with time, $t$, can be described by eq. 3.3 .

$$
\frac{\mathrm{d} c_{\mathrm{M}}}{\mathrm{d} t}=-k_{\mathrm{p}} \cdot c_{\mathrm{M}} \cdot c_{\mathrm{R}}
$$

$k_{\mathrm{p}} \quad: \quad$ propagation rate coefficient

$c_{\mathrm{M}} \quad$ : monomer concentration

\subsubsection{Termination}

Chain termination is characterized by the reaction of two radicals, which can either occur by combination or disproportionation. The ratio of both is mainly monomer dependent. For higher substituted monomers like methacrylates, disproportionation is favored, which gives an unsaturated and a saturated polymer species without change in chain length. In case of less sterically demanding monomers (styrene, acrylates) termination by combination is preferred. ${ }^{34}$ Only one polymer is formed with a chain length which corresponds to the sum of the degrees of polymerization of both radicals.

Combination:

Disproportionation:

$$
\begin{aligned}
\mathrm{R}_{i}^{\bullet}+\mathrm{R}_{j}^{\cdot} \stackrel{k_{\mathrm{tcomb}}}{\longrightarrow} \mathrm{P}_{i+j} \\
\mathrm{R}_{i}^{\bullet}+\mathrm{R}_{j}^{\cdot} \stackrel{k_{\mathrm{tdisp}}}{\longrightarrow} \mathrm{P}_{i}^{=}+\mathrm{P}_{j}^{\mathrm{H}}
\end{aligned}
$$

$k_{\mathrm{t}, \mathrm{comb}}: \quad$ rate coefficient of termination by combination 
$k_{\mathrm{t}, \mathrm{disp}}: \quad$ rate coefficient of termination by disproportionation

$\mathrm{P}_{i+j} \quad$ : $\quad$ polymer formed by combination

$\mathrm{P}_{i}=\quad$ : $\quad$ unsaturated polymer formed by disproportionation

$\mathrm{P}_{j}^{\mathrm{H}} \quad: \quad$ saturated polymer formed by disproportionation

$i, j \quad: \quad$ chain length

The termination rate, i.e., the decrease in radical concentration with time, can be described by a second-order rate law (eq. 3.4) with an overall termination rate coefficient given in eq. 3.5.

$$
\begin{aligned}
& \frac{\mathrm{d} c_{\mathrm{R}}}{\mathrm{d} t}=-2 \cdot k_{\mathrm{t}} \cdot c_{\mathrm{R}}^{2} \\
& k_{\mathrm{t}}=k_{\mathrm{t}, \text { comb }}+k_{\mathrm{t}, \text { disp }}
\end{aligned}
$$

\section{Steady-State Kinetics}

On the assumption of constant radical concentration, the rate of formation of radicals and the rate of consumption must be equal (eq. 3.6).

$$
k_{\mathrm{d}} \cdot f \cdot c_{\mathrm{I}}=k_{\mathrm{t}} \cdot c_{\mathrm{R}}^{2}
$$

Combination of eqs. 3.3 and 3.6 leads to the ideal polymerization rate (eq. 3.7).

$$
-\frac{\mathrm{d} c_{\mathrm{M}}}{\mathrm{d} t}=c_{\mathrm{M}} \cdot \frac{k_{\mathrm{p}}}{\sqrt{k_{\mathrm{t}}}} \cdot \sqrt{k_{\mathrm{d}} \cdot f \cdot c_{\mathrm{I}}}
$$




\subsubsection{Chain transfer}

Under actual polymerization conditions, chain transfer has to be considered. By this process the radical function is transferred to a monomer, initiator or solvent molecule, polymer chain or a chain transfer agent. This occurs primarily by exchange of a hydrogen or halogen atom. The newly formed radical can then add a monomer molecule in a propagation step to start a new polymer chain.

Chain transfer:

$$
\begin{gathered}
\mathrm{R}_{i}^{\bullet}+\mathrm{X} \stackrel{k_{\mathrm{t}, \mathrm{X}}}{\longrightarrow} \mathrm{P}_{i}+\mathrm{X}^{\bullet} \\
\mathrm{X}^{\bullet}+\mathrm{M} \stackrel{k_{\mathrm{p}, \mathrm{X}}}{\longrightarrow} \mathrm{X}-\mathrm{M}^{\bullet}
\end{gathered}
$$

$k_{\mathrm{tr}, \mathrm{X}} \quad: \quad$ transfer rate coefficient to a molecule $\mathrm{X}$

$k_{\mathrm{p}, \mathrm{X}} \quad: \quad$ rate coefficient of the first propagation step after chain transfer

The transfer rate can be expressed by the change in concentration of the transfer agent $\mathrm{X}$ with time (eq. 3.8).

$$
\frac{\mathrm{d} c_{\mathrm{X}}}{\mathrm{d} t}=-k_{\mathrm{tr}, \mathrm{X}} \cdot c_{\mathrm{R}} \cdot c_{\mathrm{X}}
$$

\section{Backbiting}

One of the most important transfer reactions for acrylates and ethylene is the backbiting reaction, which describes an intramolecular 1,5-hydrogen shift from the middle to the end of a chain. ${ }^{35}$ It occurs via a six-membered ring structure. A chain-end radical, the so-called secondary propagating radical (SPR), is transformed into a tertiary radical, a mid-chain radical (MCR). The driving force of this transfer is the higher stability of the MCR in comparison to the SPR.

MCRs may be also undergo propagation or termination but, due to the increased stability, the reactivity is reduced. ${ }^{28}$ 


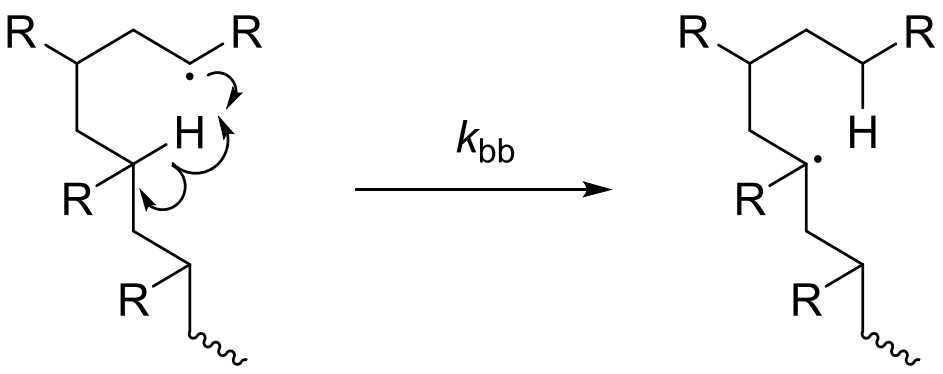

Scheme 3.1. Chain transfer reaction by intramolecular 1,5-hydrogen shift. A chain-end radical (SPR) is transformed into a mid-chain radical (MCR). The corresponding rate coefficient is called $k_{\mathrm{bb}}(\mathrm{bb}=$ backbiting $)$.

\subsection{Variation of Termination Rate Coefficient with Conversion, Chain Length and Temperature}

Bimolecular termination of radicals may be subdivided into three separate steps: First, macroradicals come into contact by center-of-mass diffusion through the reaction mixture, which is referred to translational diffusion (TD). Secondly, the reactive sites have to come into close proximity by reorientation of the chain segments. This process is called segmental diffusion (SD). Finally, the chemical reaction forms the polymer species (CR).

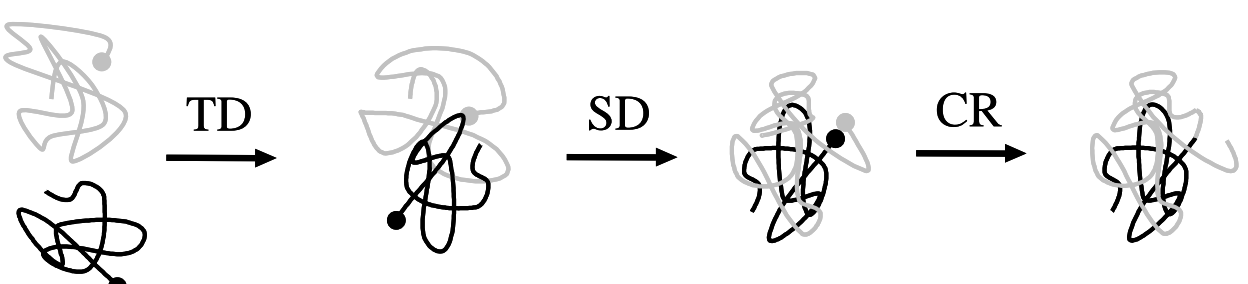

Scheme 3.2. Illustration of macroradical termination subdivided in translational diffusion (TD), segmental diffusion (SD) and chemical reaction (CR). ${ }^{36}$ 
The termination rate coefficient of the described mechanism, which is based on diffusion, can be illustrated by eq. 3.9.

$$
\frac{1}{k_{\mathrm{t}, \mathrm{D}}}=\frac{1}{k_{\mathrm{TD}}}+\frac{1}{k_{\mathrm{SD}}}+\frac{1}{k_{\mathrm{CR}}}
$$

$k_{\mathrm{t}, \mathrm{D}} \quad: \quad$ diffusion controlled termination rate coefficient

$k_{\mathrm{TD}} \quad: \quad$ termination rate coefficient based on translational diffusion

$k_{\mathrm{SD}} \quad: \quad$ termination rate coefficient based on segmental diffusion

$k_{\mathrm{CR}} \quad: \quad$ rate coefficient of the chemical reaction of termination

At low and moderate conversion, $k_{\mathrm{t}}$ is adequately represented by $k_{\mathrm{t}, \mathrm{D}}$, i.e., $k_{\mathrm{t}}=k_{\mathrm{t}, \mathrm{D}}$. Since the chemical reaction of radicals is extremely fast, termination is a diffusion-controlled process from the initial phase of polymerization on. Termination usually depends on the rate-determining diffusion step, denoted by TD- or SD-controlled $k_{\mathrm{t}}$.

At high conversion, the mobility of macroradicals is increasingly hindered. In this case termination occurs to a significant extent via so-called reaction diffusion (RD). By propagation, i.e. addition of monomer, radical species come into spatial proximity to undergo termination. This pathway becomes dominant, when chains are trapped in a polymer environment. Termination by reaction diffusion may be expressed as a function of monomer concentration/conversion and propagation rate coefficient.

$$
k_{\mathrm{t}, \mathrm{RD}}=C_{\mathrm{RD}} \cdot \frac{c_{\mathrm{M}}}{c_{\mathrm{M}}^{0}} \cdot k_{\mathrm{p}}=C_{\mathrm{RD}} \cdot(1-X) \cdot k_{\mathrm{p}}
$$

$k_{\mathrm{t}, \mathrm{RD}} \quad: \quad$ termination rate coefficient based on reaction diffusion

$c_{\mathrm{M}}{ }^{0} \quad$ : initial monomer concentration

$X \quad$ : monomer-to-polymer conversion 
The overall termination rate coefficient can be expressed by eq. 3.11 .

$$
k_{\mathrm{t}}=k_{\mathrm{t}, \mathrm{D}}+k_{\mathrm{t}, \mathrm{RD}}
$$

\subsubsection{Conversion Dependence}

The variation of $k_{\mathrm{t}}$ with monomer conversion may be subdivided into three different regimes shown in Figure 3.1.

With methacrylate monomers, at low degrees of conversion $k_{\mathrm{t}}$ remains almost constant indicating that segmental diffusion is the rate-determining step and that $k_{\mathrm{SD}}$ is much lower than $k_{\mathrm{TD}}$.

Further increase in conversion reduces the translational mobility of macroradicals due to the presence of dead polymer in the polymerizing solution. Hence $k_{\mathrm{TD}}$ decreases and becomes rate-controlling. The induced lower termination rate and thus the higher polymerization rate are also known as the gel effect. ${ }^{37}$

At high conversion, reaction diffusion is the dominant termination step. Since RD is associated to propagation, $k_{\mathrm{t}}$ continuously decreases with monomer consumption. 


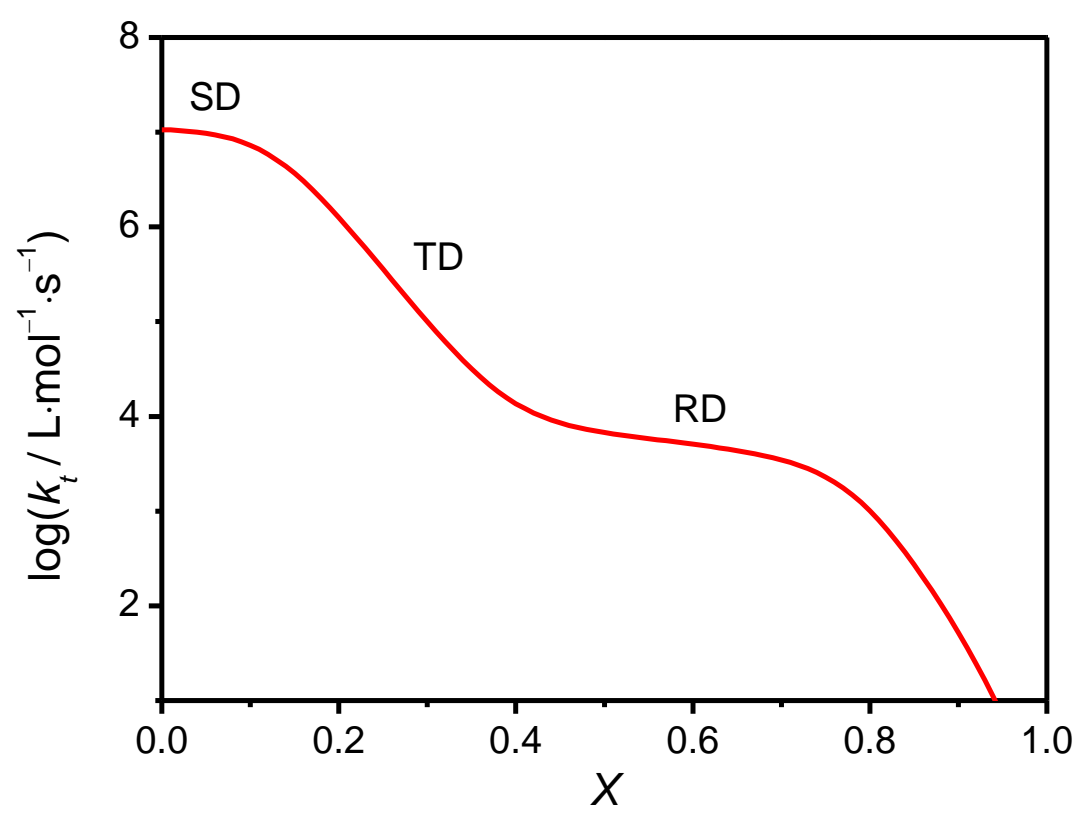

Figure 3.1. Schematic plot of termination rate coefficient $k_{\mathrm{t}}$ as a function of monomer conversion. Expressions $\mathrm{SD}, \mathrm{TD}$ and $\mathrm{RD}$, illustrate the ratedetermining step for the respective regime of monomer-to-polymer conversion as described in the text.

\subsubsection{Chain-Length Dependence}

During radical polymerization under continuous initiation, macroradicals with different chain lengths are formed. The longer the chain, the higher is the hydrodynamic radius and, as expressed by the Stokes-Einstein equation, the lower is the diffusion coefficient (eq 3.12).

$$
D^{i}=\frac{k_{\mathrm{B}} \cdot T}{6 \cdot \pi \cdot r_{i} \cdot \eta}
$$

$D^{i} \quad$ : $\quad$ diffusion coefficient for a macromolecular species of chain length $i$

$k_{\mathrm{B}} \quad$ : boltzmann constant

T : temperature

$r_{i} \quad: \quad$ hydrodynamic radius 
$\eta \quad: \quad$ Viscosity of the reaction mixture

Caused by the diffusion control of termination, the rate coefficient depends on the chain lengths $i$ and $j$ of the associated radicals and should be described by $k_{\mathrm{t}}^{i, j}$.

Three models are commonly used to describe $k_{\mathrm{t}}^{i, j}$ as a function of the individual chain lengths $i$ and $j . k_{\mathrm{t}}{ }^{1,1}$ is associated with the termination rate coefficient of two monomeric radicals and the power-law exponent $\alpha$ quantifies the extent of the chain-length dependence.

The termination rate is supposed to be controlled by center-of-mass diffusion. Thus, the associated diffusion rate coefficient $k_{\text {diff }}$ may be expressed by the Smoluchowski equation: ${ }^{38}$

$$
k_{\mathrm{t}}^{1,1}=k_{\mathrm{diff}}=4 \cdot \pi \cdot P_{\mathrm{Spin}} \cdot N_{\mathrm{A}} \cdot\left(D_{\mathrm{A}} \cdot D_{\mathrm{B}}\right) \cdot R_{\mathrm{c}}
$$

$P_{\text {Spin }}: \quad$ probability of encounter involving a singlet pair

$N_{\mathrm{A}} \quad: \quad$ avogadro constant

$D_{\mathrm{A}}, D_{\mathrm{B}}$ : $\quad$ diffusion coefficient of species A and B

$R_{\mathrm{c}} \quad: \quad$ capture radius

On statistical grounds the value of $P_{\text {Spin }}$ will be $0.25 .{ }^{39,40}$

In case of a laser-induced polymerization all radicals are generated simultaneously and start growing almost at the same time. Therefore, the chain length is proportional to the time after pulsing. As long as chain transfer is negligible, termination occurs between radicals of identical size. All three models (eq. 3.13-3.15) lead to eq. 3.17 if $i=j$.

$$
k_{\mathrm{t}}^{i, i}=k_{\mathrm{t}}^{1,1} \cdot i^{-\alpha}
$$


A disadvantage of this simple model is that it does not consider possible changes in the termination mode during polymerization, i.e., an increase in chain length may induce a change in the power-law exponent $\alpha$. Hence Smith et al. developed the so-called composite model, which is based on eq. 3.17.41

$$
\begin{array}{cc}
k_{\mathrm{t}}^{i, i}=k_{\mathrm{t}}^{1,1} \cdot i^{-\alpha_{\mathrm{s}}} & i \leq i_{\mathrm{c}} \\
k_{\mathrm{t}}^{i, i}=k_{\mathrm{t}}^{1,1} \cdot i_{\mathrm{c}}^{-\alpha_{\mathrm{s}}+\alpha_{1}} \cdot i^{-\alpha_{1}}=k_{\mathrm{t}}^{0} \cdot i^{-\alpha_{1}} & i>i_{\mathrm{c}}
\end{array}
$$

$k_{\mathrm{t}}{ }^{0} \quad: \quad$ termination rate coefficient of two hypothetical coiled radicals of chain length unity

$\alpha_{\mathrm{s}} \quad: \quad$ power-law exponent for short chains

$\alpha_{1} \quad: \quad$ power-law exponent for long chains

$i_{\mathrm{c}} \quad: \quad$ crossover chain length

The model postulates two regimes with different chain-length dependence of termination rate coefficient.

In the short chain regime, $k_{\mathrm{t}}{ }^{i, i}$ strongly decreases with $i$ and termination is controlled by translational diffusion. Whereas in the long-chain regime, when entanglements become important, the dependency is much weaker and is controlled by segmental diffusion.

Thus $k_{\mathrm{t}}^{i, i}$ may be described by the two power-law exponents $\alpha_{\mathrm{s}}$ and $\alpha_{1}$. The transition between both regimes is characterized by the crossover chain length $i_{\mathrm{c}}$ (Figure 3.2). 


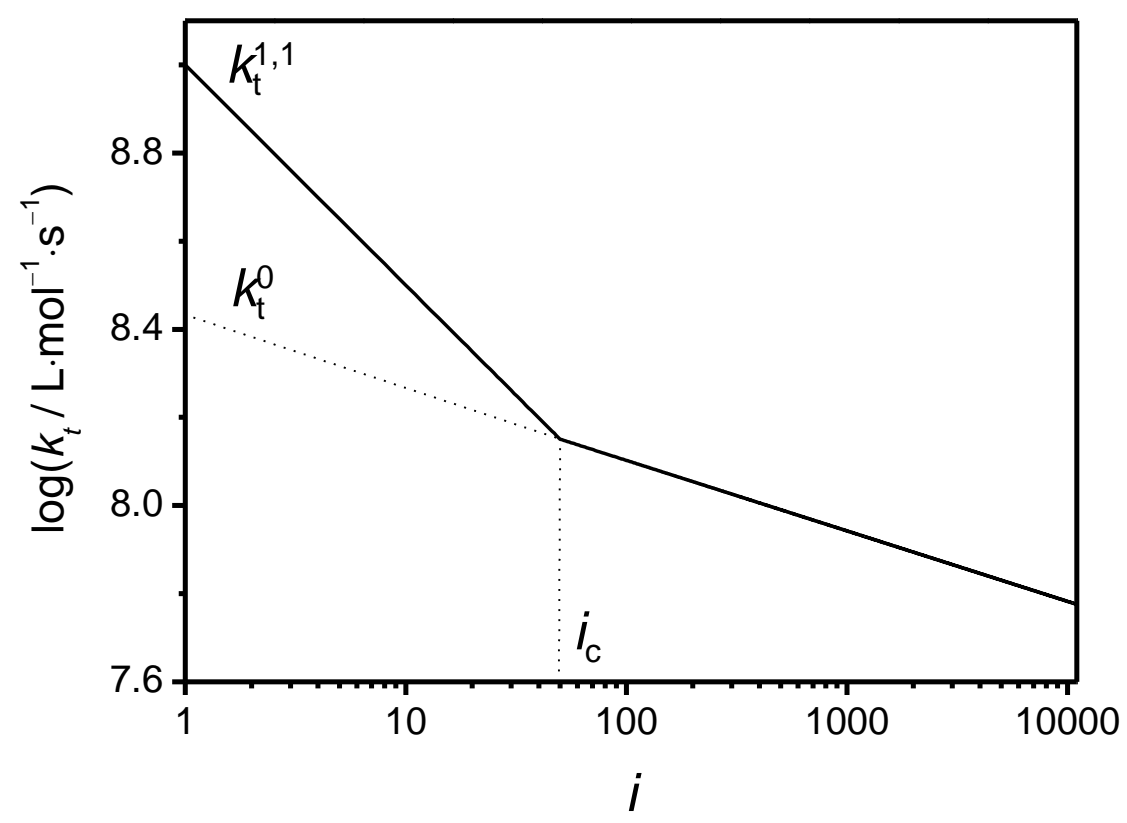

Figure 3.2. Chain-length dependence for the termination rate coefficient of two radicals of identical size according to the composite model described by eqs. 3.18 and 3.19. Extrapolation to chain length unity yields the rate coefficient of termination of two monomeric radicals $k_{\mathrm{t}}^{1,1}$ and $k_{\mathrm{t}}^{0}$ for the short and the long chain regime, respectively. The intersection corresponds to the crossover chain length $i_{\mathrm{c}}$.

\subsubsection{Temperature Dependence}

The temperature dependence of rate coefficients is usually described by the Arrhenius equation. ${ }^{42}$

$$
k=A \cdot \exp \left(\frac{E_{\mathrm{A}}}{R \cdot T}\right)
$$

$$
\begin{array}{lll}
A & : & \text { pre-exponential factor } \\
E_{\mathrm{A}} & : & \text { activation energy } \\
R & : & \text { universal gas constant } \\
T & : & \text { temperature }
\end{array}
$$


Eqs. 3.12 and 3.16 imply that the rate coefficient of a diffusion-controlled process is inversely proportional to the solution viscosity. Therefore, the activation energy of the fluidity (inverse viscosity) should be the activation energy of the diffusion-controlled rate coefficient.

$$
E_{\mathrm{A}}\left(k_{\text {diff }}\right) \approx E_{\mathrm{A}}\left(\eta^{-1}\right)
$$

\subsection{SP-PLP-EPR Technique}

In SP-PLP-EPR experiments, polymerization is initiated by a single laser pulse. The achieved concentration of radicals is directly monitored via on-line EPR detection with a time resolution of less than a microsecond.

As the laser-induced generation of initiator derived primary radicals is assumed to be instantaneously on the timescale of all other reactions, the length of propagating chains is proportional to the time $t$ after pulsing.

$$
i=k_{\mathrm{p}} \cdot c_{\mathrm{M}} \cdot t
$$

$\begin{array}{lll}i & : & \text { kinetic chain length } \\ t & : & \text { time after pulsing }\end{array}$

The average time interval for one propagation step may be described as $t_{\mathrm{p}}$.

$$
t_{\mathrm{p}}=\left(k_{\mathrm{p}} \cdot c_{\mathrm{M}}\right)^{-1}
$$

Due to the immediate formation of radicals in conjunction with the determination of absolute radical concentrations, the SP-PLP-EPR technique is the method of choice for detailed investigations into chain-length dependent termination. 
Figure 3.3 illustrates a characteristic time-resolved EPR concentration-time profile. After irradiation by a single laser pulse at $t=0$, radical generation occurs instantaneously and the decay in radical concentration is recorded over time.

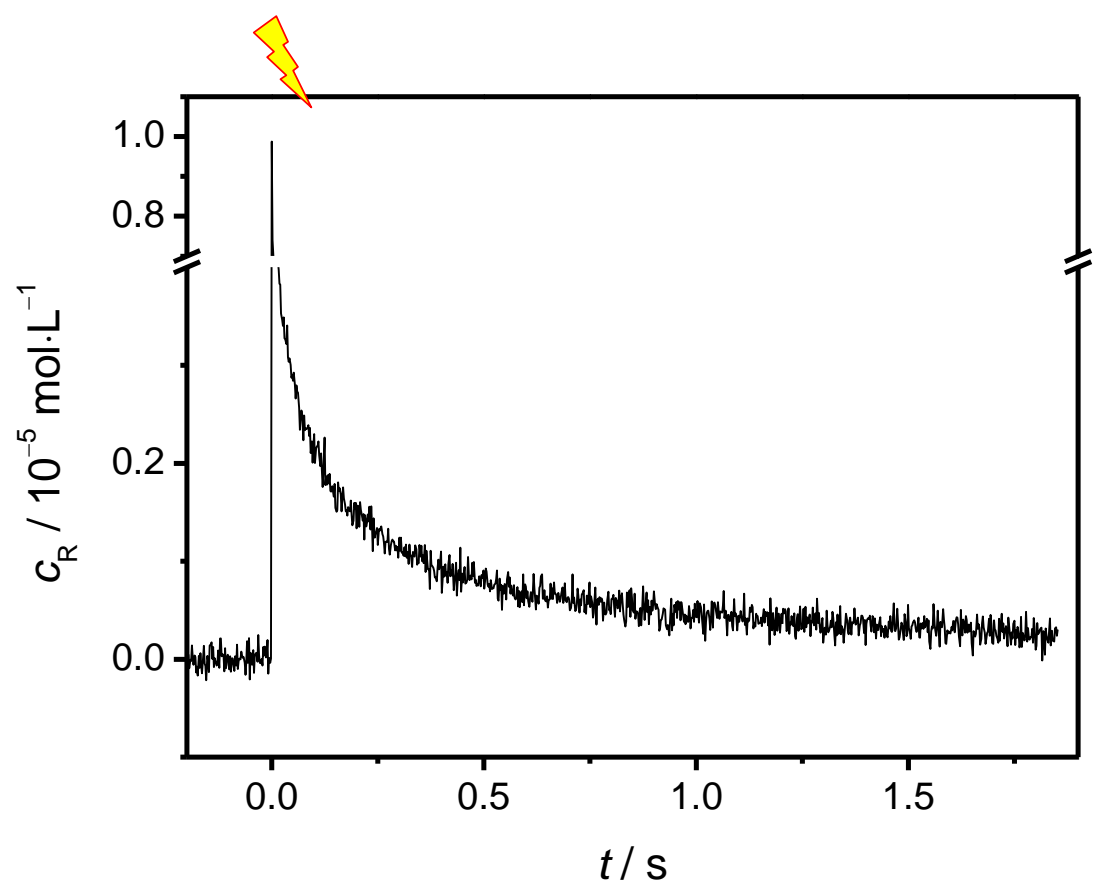

Figure 3.3. Characteristic $c_{\mathrm{R}}(t)$ trace from an SP-PLP-EPR experiment for bulk dodecyl methacrylate at $293 \mathrm{~K}$ recorded at a constant magnetic field value. Irradiation by a single laser pulse occurs at $t=0$ generating a radical concentration of around $10^{-5} \mathrm{~mol} \cdot \mathrm{L}^{-1}$.

The combination of eqs. 3.4, $3.18 / 3.19$, and 3.22 and subsequent integration lead to the following expressions for both short and long chains.

$$
\begin{array}{ll}
\frac{c_{\mathrm{R}}}{c_{\mathrm{R}}^{0}}=\left(\frac{2 \cdot k_{\mathrm{t}}^{1,1} \cdot c_{\mathrm{R}}^{0} \cdot t_{\mathrm{p}}^{\alpha_{\mathrm{s}}}}{1-\alpha_{\mathrm{s}}} \cdot t^{\left(1-\alpha_{\mathrm{s}}\right)}+1\right)^{-1} & 1<i \leq i_{\mathrm{c}} \\
\frac{c_{\mathrm{R}}}{c_{\mathrm{R}}^{0}}=\left(\frac{2 \cdot k_{\mathrm{t}}^{0} \cdot c_{\mathrm{R}}^{0} \cdot t_{\mathrm{p}}^{\alpha_{1}}}{1-\alpha_{1}} \cdot t^{\left(1-\alpha_{1}\right)}+1\right)^{-1} & i>i_{\mathrm{c}}
\end{array}
$$




$$
\log \left(\frac{c_{\mathrm{R}}}{c_{\mathrm{R}}^{0}}-1\right)=\log (C)+(1-\alpha) \cdot \log (t)
$$

In principle, the composite-model parameters $k_{\mathrm{t}}^{1,1}, \alpha_{\mathrm{s}}, \alpha_{\mathrm{l}}, i_{\mathrm{c}}$ should be available by a double-log approach (eq. 3.26), but eq. 3.22 provides a physically incorrect description of chain length at early times $(t=0 \rightarrow i=0)$ resulting in a misinterpretation of the data.

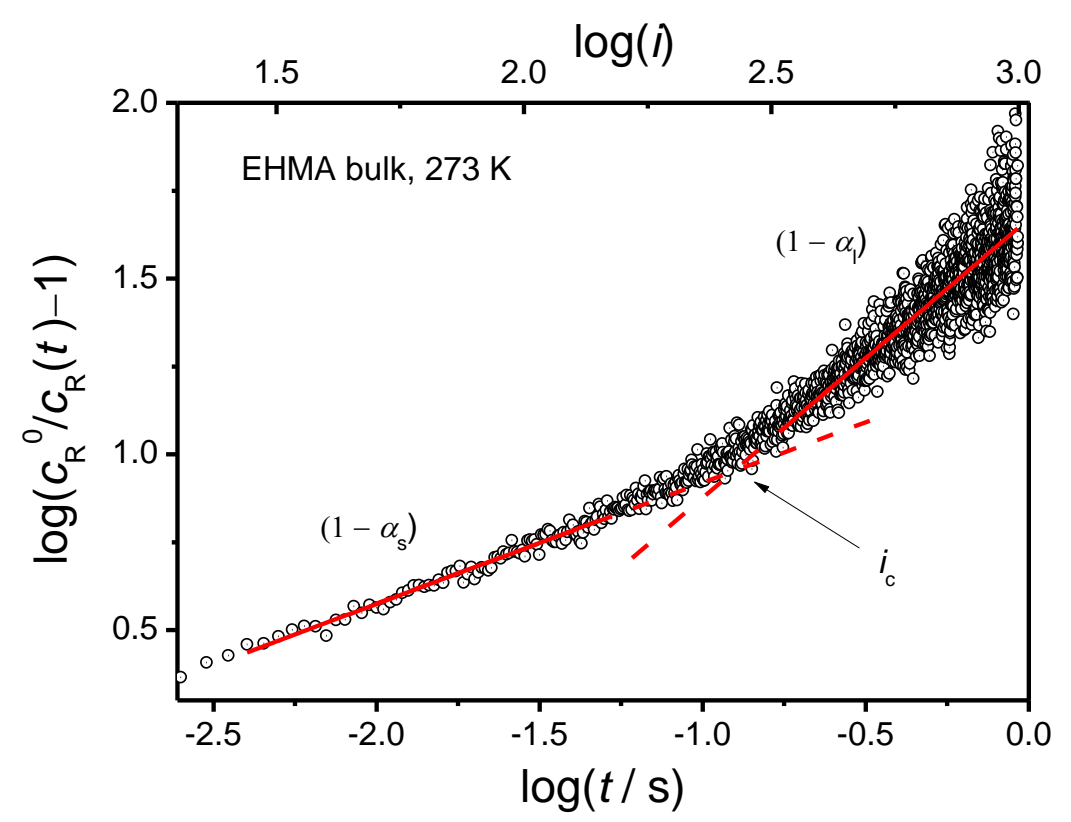

Figure 3.4. Double-log plot of $\left(c_{\mathrm{R}}^{0} / c_{\mathrm{R}}-1\right)$ vs. $t$ for EPR data from single pulse experiments of 2-ethylhexyl methacrylate (EHMA) at 273 K. A straightline fit of the long chain regime yields $\alpha_{1}$. Crossover chain length $i_{\mathrm{c}}$ is obtained from the intersection of the fits for low and for high $t$.

Because of the failure of eq. 3.22 for very small $i$, eq. 3.26 is exclusively used for determination of $\alpha_{1}$ and $i_{\mathrm{c}}$ (eq. 3.25). The power-law exponent is derived from the slope of the straight line fit $(1-\alpha)$ and the crossover chain length is given by the intersection point of both linear regressions (Figure 3.4). 
For the evaluation of $\alpha_{\mathrm{s}}$ and $k_{\mathrm{t}}^{1,1}$, Russell et al. propose a more precise analysis based on eq. 3.27. This approach gives a more realistic description with the chain length being unity at $t=0$, although this model does not distinguish between monomer and initiator.

$$
i=k_{\mathrm{p}} \cdot c_{\mathrm{M}} \cdot t+1
$$

In a similar way to eq. 3.24 the short-chain regime is characterized by eq. 3.28 . The values are obtained from non-linear fitting of the experimental data plotted as $c_{\mathrm{R}}{ }^{0} / c_{\mathrm{R}}-1 \mathrm{vs}$. $t$.

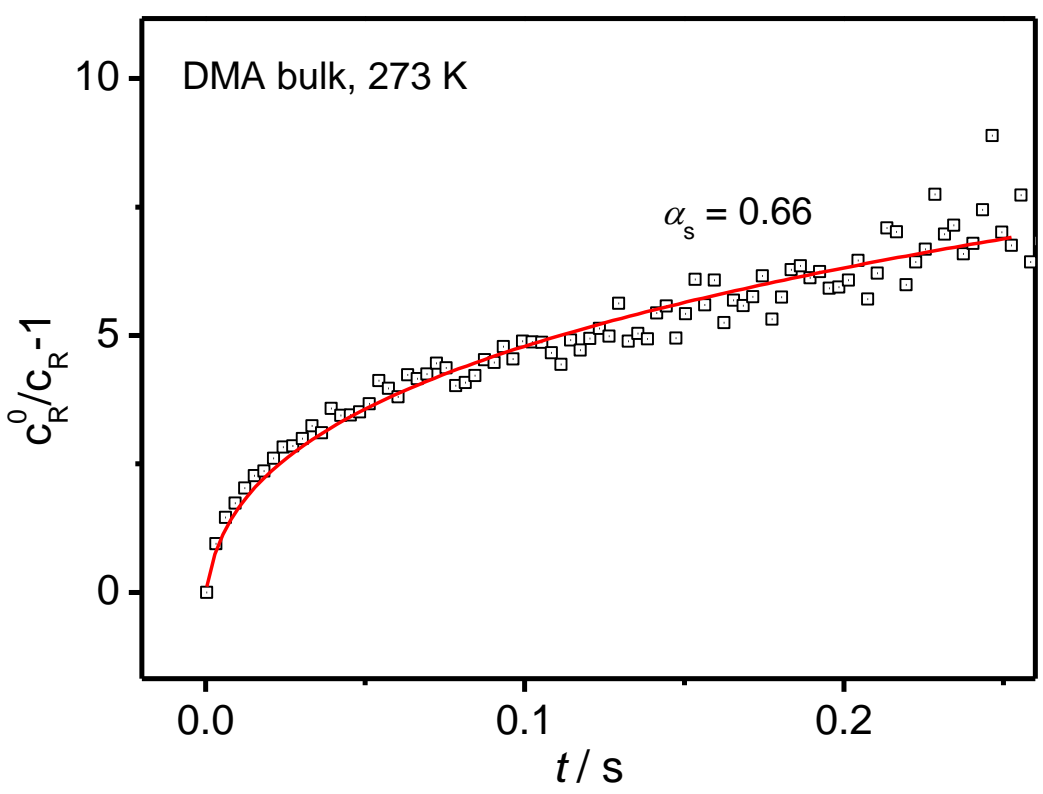

Figure 3.5. Non-linear fit of $\left(c_{\mathrm{R}} / c_{\mathrm{R}}-1\right)$ vs. $t$ for SP-PLP-EPR data of DMA at $273 \mathrm{~K}$ to determine $\alpha_{\mathrm{s}}$ and $k_{\mathrm{t}}^{1,1}$ according to eq. 3.28. The solid line represents the best fit with $\alpha_{\mathrm{s}}=0.66$ and $k_{\mathrm{t}}{ }^{1,1}=1.2 \cdot 10^{7} \mathrm{~L} \cdot \mathrm{mol}^{-1} \cdot \mathrm{s}^{-1}$.

The determination of $k_{\mathrm{t}}^{1,1}$ requires the initial radical concentration to be known, whereas the evaluation of $\alpha_{\mathrm{s}}$ is calibration-free.

$$
\frac{c_{\mathrm{R}}^{0}}{c_{\mathrm{R}}(t)}-1=\frac{2 \cdot k_{\mathrm{t}}^{1,1} \cdot c_{\mathrm{R}}^{0} \cdot\left(\left(k_{\mathrm{p}} \cdot c_{\mathrm{M}} \cdot t+1\right)^{1-\alpha_{\mathrm{s}}}-1\right)}{k_{\mathrm{p}} \cdot c_{\mathrm{M}} \cdot\left(1-\alpha_{\mathrm{s}}\right)} \quad 1<i \leq i_{\mathrm{c}}
$$




\subsection{PLP-SEC Technique}

Pulsed-laser initiated polymerization in conjunction with analysis by size-exclusion chromatography is a powerful tool for determination of the propagation rate coefficient $k_{\mathrm{p}}$.

The system consisting of monomer, solvent and photoinitiator, is irradiated by a sequence of short laser pulses. Each laser pulse instantaneously generates photoinitiator-derived primary radicals, which start chain growth. Termination occurs at any time during the experiment, but due to the enhanced radical concentration immediately after a pulse, the probability of termination of a primary radical and a macroradical generated in a preceding pulse is much higher.

Propagation rate coefficient $k_{\mathrm{p}}$ is described by eq. 3.29 .

$$
L_{b}=b \cdot k_{\mathrm{p}} \cdot c_{\mathrm{M}} \cdot t_{0}=b \cdot k_{\mathrm{p}} \cdot c_{\mathrm{M}} \cdot \frac{1}{v_{\mathrm{L}}}
$$

$L_{b} \quad$ : degree of polymerization

$b \quad: \quad$ number of corresponding maximum in the first derivative of the MMD

$t_{0} \quad$ : time between two laser pulses

$v_{\mathrm{L}} \quad$ : laser repetition rate

The degree of polymerization $L_{1}$ is best identified with the inflection point on the lowmolar-mass side of the first PLP-induced maximum in the molar mass distribution (MMD). Not each chain is terminated by the subsequent laser pulse. Thus a multimodal MMD is obtained in an ideal PLP experiment, which is furthermore a consistency criterion of this method. Several maxima occur at integer multiples of $t_{0}$. 


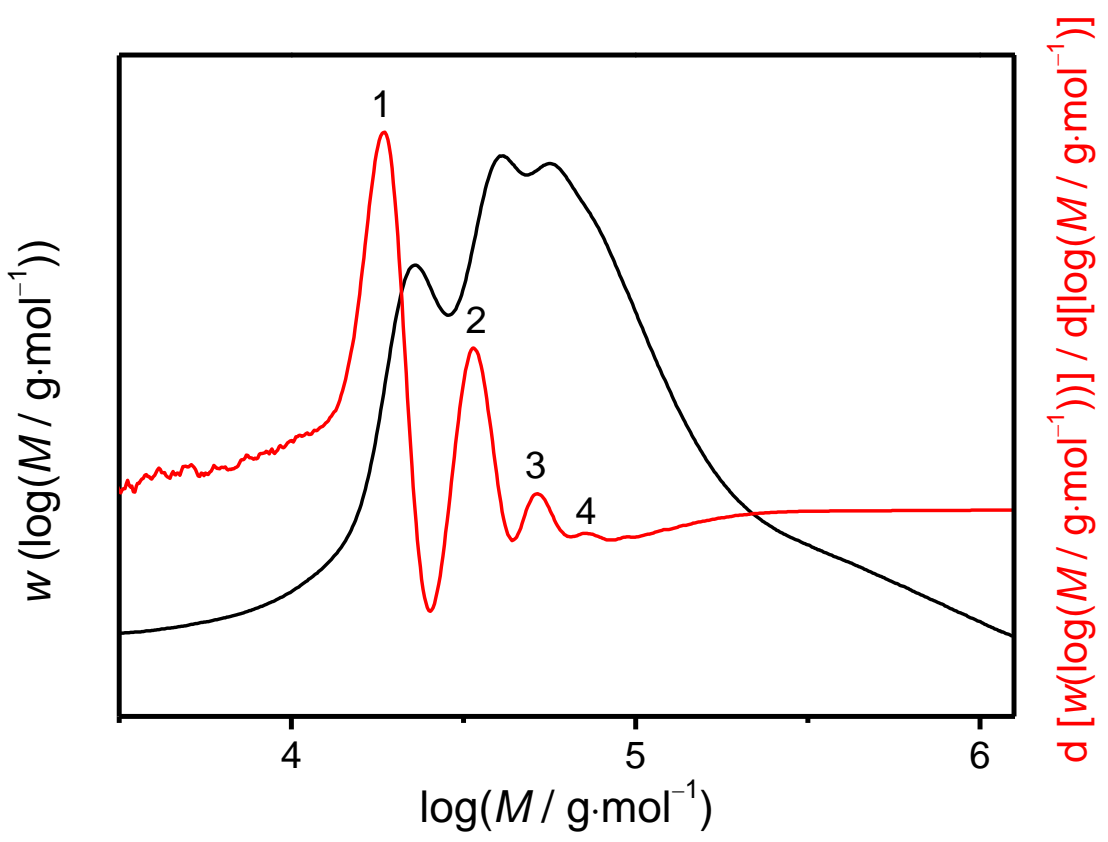

Figure 3.6. Molar mass distribution (black line) and associated first-derivative curve (red line) obtained from polymerization of dodecyl methacrylate (DMA) in $15 \mathrm{wt} \%$ acetonitrile $(\mathrm{MeCN})$ at $293 \mathrm{~K}$ and a laser repetition rate of $15 \mathrm{~Hz}$. The numbers indicate the points of inflection.

Figure 3.6 depicts a typical MMD and the associated first-derivative curve with up to four points of inflection. $L_{b}$ is directly evaluated by means of molar mass of the monomer according to eq. 3.30 .

$$
L_{b}=\frac{M_{b}}{M_{\text {monomer }}}
$$

$M_{b} \quad: \quad$ molar mass at the maximum position $b$ in the first derivative curve $M_{\text {monomer: }} \quad$ molar mass of the monomer 
Monomer concentration $c_{\mathrm{M}}$ is described as the arithmetic mean before and after polymerization, since monomer conversion is kept low during the experiment (eq.3.31). For reliable $k_{\mathrm{p}}$ values, the monomer consumption should be below $5 \%$.

$$
c_{\mathrm{M}}=c_{\mathrm{M}}^{0} \cdot(1-0.5 \cdot X)
$$

$c_{\mathrm{M}}{ }^{0} \quad: \quad$ initial monomer concentration

X : monomer-to-polymer conversion

Monomer-to-polymer conversion was determined by gravimetric analysis.

\subsection{Atom Transfer Radical Polymerization}

Atom-transfer radical polymerization (ATRP) is one of the most important and widely used methods of reversible-deactivated radical polymerization. Easy implementation, a wide range of tolerated monomers and functional groups and a large number of available catalysts have even led to commercial applications of ATRP. ${ }^{43}$

ATRP is based on the atom-transfer radical addition (ATRA) or Kharasch addition, which describes the transition metal-catalyzed addition of an organohalide to a double bondbearing molecule. ${ }^{44}$ The transfer of a halogen atom to the metal complex activates the formation of a radical, which adds to the double bond and is subsequently deactivated by reverse transfer (Scheme 3.3). 


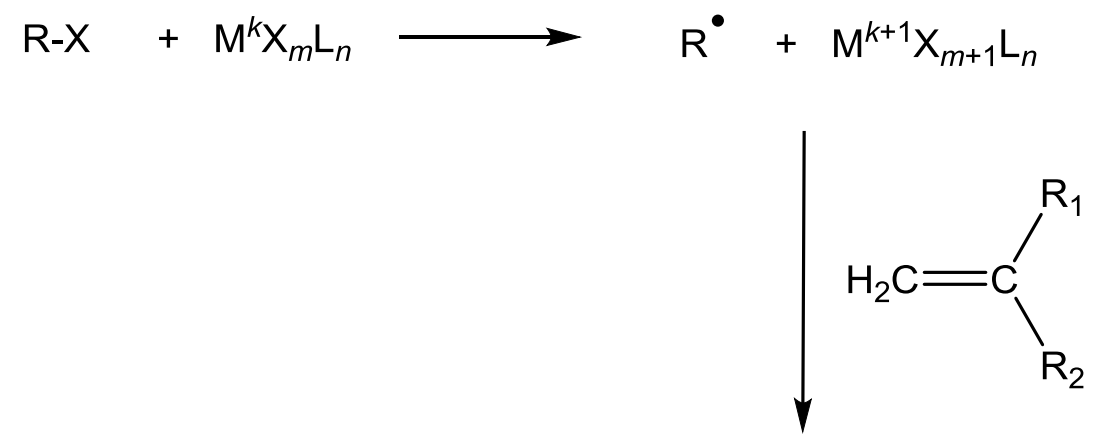<smiles>[R]CC([R])[R]</smiles>

Scheme 3.3. Transition metal-catalyzed radical addition (Kharasch-addition) to a double bond and subsequent deactivation by halogen transfer.

In ATRP, due to a dynamic equilibrium of the transfer and an excess of monomer with each activation/deactivation step, monomer molecules are incorporated into the chain. This method was independently developed by Matyjaszewski and Sawamoto in 1995. 5,45 An effective ATRP system consists of the monomer, a suitable initiator, a catalyst system composed of a transition metal and a ligand, and perhaps a solvent. Additionally the metal complex needs to possess two available oxidation states, which can be reversible converted into each other by a one-electron process.

The following considerations refer to copper-catalyzed ATRP which is within the focus of this work.

\subsubsection{Mechanism and Kinetics}

Scheme 3.4 illustrates the proposed mechanism of copper-catalyzed ATRP which is based on an inner-sphere one-electron transfer.

The reaction starts with the transfer of a halogen atom from an organohalide $\mathrm{R}-\mathrm{X}$ to the $\mathrm{Cu}^{\mathrm{I}}$ complex resulting in the formation of a radical species $\mathrm{R}^{\cdot}$ and the copper catalyst in the higher oxidation state (II). In this initiation step, the formed radical adds to monomer 
with the rate coefficient $k_{\mathrm{i}}$. This step is completed with the reversible deactivation to a dormant organohalide $(\mathrm{RM}-\mathrm{X})$ and the regeneration of the $\mathrm{Cu}^{\mathrm{I}}$ catalyst.

The subsequent dynamic equilibrium of activation and deactivation of the radical $\left(\mathrm{R}_{n}{ }^{*}\right)$ and the corresponding metal complex is characterized by the rate coefficients $k_{\text {act }}$ and $k_{\text {deact. }}$. The ratio of both coefficients determines the equilibrium constant for ATRP $\left(K_{\mathrm{ATRP}}=k_{\mathrm{act}}\right.$ / $\left.k_{\text {deact }}\right)$. The active state may undergo propagation, whereas the dormant radical is prevented from adding monomer. Since the ATRP equilibrium is superimposed on a conventional polymerization, radicals can also terminate by either combination or disproportionation.

\section{Initiation:}

$$
\begin{array}{r}
\mathrm{R}-\mathrm{X}+\mathrm{Cu}^{\mathrm{X} X}(\mathrm{~L})_{n} \longrightarrow \mathrm{R}^{\bullet}+\mathrm{Cu}^{\prime l} \mathrm{X}_{2}(\mathrm{~L})_{n} \\
k_{\mathrm{i}} \\
\mathrm{RM}-\mathrm{X}+\mathrm{Cu}{ }^{\mathrm{X} X}(\mathrm{~L})_{n} \longrightarrow \mathrm{RM}^{\bullet}+\mathrm{Cu}^{\prime l} \mathrm{X}_{2}(\mathrm{~L})_{n}
\end{array}
$$

\section{Propagation:}

$$
\begin{aligned}
& \mathrm{R}_{i}-\mathrm{X}+\mathrm{Cu}^{\mathrm{X} X}(\mathrm{~L})_{n}+\frac{k_{\mathrm{act}}}{k_{\text {deact }}} \underbrace{\mathrm{R}_{i}^{\bullet}}_{k_{\mathrm{p}}}+\mathrm{Cu}^{\prime \prime} \mathrm{X}_{2}(\mathrm{~L})_{n} \\
& \text { Termination: }
\end{aligned}
$$

$$
\mathrm{R}_{i}+\mathrm{R}_{j} \longrightarrow k_{\mathrm{t}} \longrightarrow \mathrm{R}-\mathrm{R} \text { or } \mathrm{R}^{\mathrm{H}}+\mathrm{R}^{=}
$$

Scheme 3.4. Mechanism of the copper-catalyzed atom-transfer radical polymerization involving initiation, propagation and termination. $\mathrm{R}-\mathrm{R}$, radical-radical combination product, $\mathrm{R}^{\mathrm{H}}$ and $\mathrm{R}^{=}$, saturated and unsaturated product of radical-radical disproportionation. 
At the beginning of the reaction, the low concentration of $\mathrm{Cu}^{\mathrm{II}}$ results in a slow deactivation and therefore in termination of a small amount (ca. $5 \%$ ) of the overall number of propagating chains. Each termination step leads to an accumulation of the deactivating $\mathrm{Cu}^{\mathrm{II}}$ complex. The so-called persistent radical effect (PRE), analogous to nitroxidemediated polymerization (NMP), slows down the polymerization. The increase in concentration of the $\mathrm{Cu}^{\mathrm{II}}$ complex shifts the equilibrium to the direction of the dormant species.

Since the radical concentration is reduced, the termination rate is diminished to a larger extent than deactivation. However, the decreased number of activated chains results in a lower rate of polymerization.

The degree of polymerization, $D P$, achieved via ATRP can be predicted by the ratio of consumed monomer and initial concentration of the alkyl halide (eq. 3.32, for reasons of clarity, concentrations are given in brackets).

$$
D P=\frac{[\mathrm{M}]_{0} \cdot X}{[\mathrm{RX}]_{0}}
$$

$[\mathrm{M}]_{0} \quad: \quad$ initial monomer concentration

$X \quad$ : $\quad$ monomer-to-polymer conversion

$[\mathrm{RX}]_{0}: \quad$ initial concentration of the initiator

As already depicted in chapter 3.1.2 the polymerization rate, $R_{\mathrm{p}}$, is expressed as a function of monomer and radical concentration as well as of $k_{\mathrm{p}}$. In terms of ATRP it can be described by means of $K_{\mathrm{ATRP}}$ (eq. 3.33).

$$
R_{\mathrm{p}}=-\frac{\mathrm{dM}}{\mathrm{d} t}=k_{\mathrm{p}} \cdot[\mathrm{M}] \cdot K_{\mathrm{ATRP}} \cdot \frac{\left[\mathrm{Cu}^{\mathrm{I}} \mathrm{X}(\mathrm{L})_{n}\right] \cdot[\mathrm{RX}]}{\left[\mathrm{Cu}^{\mathrm{II}} \mathrm{X}_{2}(\mathrm{~L})_{n}\right]}
$$

$[\mathrm{RX}] \quad: \quad$ concentration of the dormant species

$\left[\mathrm{Cu}^{\mathrm{I} X}(\mathrm{~L})_{n}\right] \quad$ : $\quad$ concentration of $\mathrm{Cu}^{\mathrm{I}}$ complex

$\left[\mathrm{Cu}^{\mathrm{II}} \mathrm{X}_{2}(\mathrm{~L})_{n}\right] \quad: \quad$ concentration of $\mathrm{Cu}^{\mathrm{II}}$ complex 
Accordingly the rate depends on the equilibrium constant and on the ratio of the concentrations of activated and deactivated metal species.

Under ideal conditions, with negligible termination and chain transfer reactions, the radical concentration remains constant during polymerization. Due to first-order kinetics, this situation results in a linear increase of monomer conversion with time on a semilogarithmic scale.

However, termination always occurs to a small extent in real ATRP. Under such conditions, the conversion depicts a linear dependence on $t^{(2 / 3)}$ if chain-length independent termination can be assumed. In addition, due to the PRE, the initial concentration of the activator $\mathrm{Cu}^{\mathrm{I}}$ must exceed the concentration of terminated chains to prevent that the polymerization is stopped at low conversions.

$$
P D I=\frac{M_{\mathrm{w}}}{M_{\mathrm{n}}}=1+\frac{1}{D P}+\left(\frac{k_{\mathrm{p}} \cdot[\mathrm{RX}]_{0}}{k_{\text {deact }} \cdot\left[\mathrm{Cu}^{\mathrm{II}} \mathrm{X}_{2}(\mathrm{~L})_{n}\right]_{0}}\right) \cdot\left(\frac{2}{X}-1\right)
$$

$P D I \quad: \quad$ polydispersity index

$M_{\mathrm{w}} \quad: \quad$ mass-average molar mass

$M_{\mathrm{n}} \quad$ : number-average molar mass

A well-controlled polymerization yielding low dispersities and predictable molar masses depends mainly on the ratio of $k_{\mathrm{p}}$ and $k_{\text {deact }}$ and on monomer-to-polymer conversion. In addition a sufficient amount of the $\mathrm{Cu}^{\mathrm{II}}$ complex is required (eq.3.34).

\subsubsection{Monomers}

In ATRP, monomers are favorable which have substituents next to the double bond to stabilize the radical functionality and activate the alkyl-halogen-bond in the dormant species.

A broad range of different types of functionalities is tolerated leading to a wide variety of applications. Thus diversely substituted styrene derivatives, acrylates and methacrylates 
as well as (meth-)acrylamides, acrylonitriles and vinylpyridines have already been polymerized by copper-mediated ATRP.

However, nitrogen containing monomers may act as a ligand and therefore reduce the activity of the catalyst. Monomers with carboxylic acid groups cannot be polymerized due to a protonation of the amine ligands. In this case the functional group has to be protected or the polymerization has to be performed at high $\mathrm{pH} .{ }^{46}$

\subsubsection{Initiators}

The only structural requirement is a (pseudo)-halogen-carbon bond which is activated by functional groups. For well-controlled ATRP, initiation should be fast in comparison to propagation in order to achieve simultaneous chain growth and narrow molar mass distributions.

The activity of initiators is inversely proportional to the carbon-halogen bond strength. The bond-dissociation energy mainly depends on the leaving group, on the stabilizing group and on the number of substituents at the halogen-bearing carbon atom. ${ }^{47}$ A general order of activity in the initiators may be given by:

Leaving group: iodide $>$ bromide $>$ chloride $>>$ thiocyanate, isothiocyanate Stabilizing group: phenyl ester $>$ cyanide $>$ ester $>$ benzyl $>$ amide

Number of substituents: tertiary $>$ secondary > primary 
It is common to use initiators that are structurally similar to the polymerizing monomer. Scheme 3.5 illustrates suitable monomers in ATRP and the corresponding initiators.<smiles>COC(=O)C(C)(C)Br</smiles>

A<smiles>C=C(C)C(=O)OC</smiles><smiles>COC(=O)C(C)Br</smiles>

B<smiles>C=CC(=O)OC</smiles><smiles>CC(Br)c1ccccc1</smiles>

C<smiles>[R]C(=C)c1ccccc1</smiles><smiles>C=C([N])Br</smiles>

D<smiles>C=CC#N</smiles>

Scheme 3.5. Initiators in ATRP derived from the corresponding monomers: A: methyl 2bromoisobutyrate (MBriB) - methyl methacrylate (MMA); B: methyl 2-bromopropionate (MBrP) - methyl acrylate (MA); C: 1-phenylethyl bromide (PEBr) - subst. styrene (St); D: 2-bromopropionitrile (BrPN) - acrylonitrile (AN).

\subsubsection{Catalysts}

Besides the choice of a suitable initiator, the catalyst is one of the most important parts for a well-controlled ATRP. As stated above, the catalyst has to possess two easily accessible oxidation states for a one-electron process. In addition the deactivation of radicals should be fast to keep its concentration low.

A catalyst consists of a transition metal salt mostly with counter ions similar to halogens of the initiator and a corresponding ligand. Firstly, the ligand regulates the redox potential and thus the activity, secondly it enhances solubility.

ATRP was already performed with a large variety of transition metals. The most investigated metal is copper, but also iron is in the focus of current research.

For copper-mediated ATRP mostly nitrogen-based ligands were used. Some typical ligands, which were partially investigated in this work, are depicted in Scheme 3.6. The activity of a catalyst may be estimated by the structure of the ligand: ${ }^{48}$ 
Denticity: tetradentate $>$ tridentate $>$ bidentate

Structure: cyclic-bridged $>$ branched $>$ cyclic $>$ linear

Type of ligand: alkyl amine $\approx$ pyridine $>$ alkyl imine $>>$ aryl imine $>$ aryl amine<smiles>c1ccc(-c2ccccn2)nc1</smiles>

bipyridine<smiles>CN(C)CCN(C)CCN(C)CCN(C)C</smiles>

HMTETA<smiles>CN(C)CCN(C)CCN(C)C</smiles>

PMDETA<smiles>c1ccc(CN(Cc2ccccn2)Cc2ccccn2)nc1</smiles>

TPMA

Scheme 3.6. Nitrogen-based bi-, tri- and tetradentate ligands. Bipyridine (bpy) was one of the first ligands used in $\mathrm{Cu}$-mediated ATRP. 1,1,4,7,10,10Hexamethyltriethylenetetramine (HMTETA), $N, N, N^{\prime}, N^{\prime \prime}, N^{\prime \prime}$-Pentamethyldiethylenetriamine (PMDETA) and Tris(2-pyridylmethyl(amine) (TPMA) were used in this work.

\subsubsection{Solvents}

ATRP may be performed in bulk as well as in solution or even in heterogeneous systems. ${ }^{49}$ A solvent is needed if the formed polymer is insoluble in the corresponding monomer or if required for achieving solubility of the catalyst. Non-polar (toluene) as well as polar solvent (water, $\mathrm{MeCN}, \mathrm{DMF})^{50}$ can be used.

A proper solvent should not be involved in side reactions. However, ATRP in water leads to an enhanced dissociation of the catalyst complex by solvation of the halide. A competitive coordination of the solvent results in a reduced control of the polymerization. By addition of certain amounts of salt containing the corresponding halide this effect can be compensated. ${ }^{51}$ 


\subsubsection{Initiation Methods}

Besides a proper initiator, catalyst and solvent, a successful and well-controlled ATRP also depends on the appropriate initiation method. The most common ones are briefly depicted in the following section.

Normal ATRP: The mechanism has already been described in chapter 3.5.1. It is primarily suitable for less air-sensitive systems, since the active catalyst is deactivated by oxygen. Reverse ATRP: The polymerization starts with the metal complex in the more stable and higher oxidation state together with a conventional initiator like AIBN. After decomposition, the generated radicals can either be directly deactivated by the catalyst or prior add to monomer. ${ }^{52}$

In-situ generation of activator: The transition metal species is used in combination with an organohalide initiator. The generation of the active form of the catalyst is obtained by either small amounts of conventional initiator (Simultaneous Reverse and Normal Initiation; SR\&NI) or by a non-radical generating reducing agent (Activator Generated by Electron Transfer; AGET). Possible reducing agents are tin 2-ethylhexanoate, ascorbic acid or even metal compounds, for example, zinc, magnesium or copper. This offers an approach for highly active catalysts.

Continuous regeneration of activator: By applying an excess of the reducing agent, the catalyst is continuously regenerated and its amount can be reduced to ppm level. The reduction can again be achieved by a conventional initiator (Initiators for Continuous Activator Regeneration; ICAR) or a non-radical generating reducing agent (Activator ReGenerated by Electron Transfer; ARGET). ${ }^{53,54}$

\subsubsection{Side Reactions}

Due to the transition metal complex a number of side reactions are possible in ATRP. They can both reduce the catalyst efficiency and have an influence on molar masses and chain-end functionalities of the polymer.

In an outer sphere electron transfer, a radical is either reduced to a carbanion by the $\mathrm{Cu}^{\mathrm{I}}$ complex or oxidized to a carbocation via the $\mathrm{Cu}^{\mathrm{II}}$ complex outside the coordination 
sphere. ${ }^{55}$ Moreover, exchange of a halide ion and coordination of a monomer molecule may occur and was already observed for methyl acrylate. ${ }^{56}$

Dissociation of a halide from the metal complex most likely occurs in polar solvents, particularly in aqueous media. By addition of a corresponding halide salt, this effect can be reduced. ${ }^{57}$

The direct reaction of radicals with the $\mathrm{Cu}^{\mathrm{I}}$ complex results either in a formation of an organometallic copper species or leads to a $\beta-\mathrm{H}$ elimination and an unsaturated macromolecule. ${ }^{58}$

\section{Catalytic Radical Termination}

The catalytic radical termination (CRT) describes a $\mathrm{Cu}^{\mathrm{I}}$-induced termination pathway involving a highly reactive copper species. This intermediate is formed by the direct reaction of $\mathrm{Cu}^{\mathrm{I}}$ with radicals. ${ }^{58} \mathrm{It}$ is assumed to be either an organometallic copper species or a copper hydride complex. The evidence of these intermediates could already be provided by EPR spectroscopy. 59

CRT leads to a higher amount of dead chains in ATRP as it is predicted for conventional termination between two radicals. The proposed mechanism and further investigations into CRT will be described in chapter 8 .

\subsection{Determination of ATRP-Related Coefficients}

Besides initiation, propagation and termination, the kinetics in ATRP is primarily influenced by the equilibrium between the copper oxidation states. The important processes are activation and deactivation with the associated rate coefficients $k_{\text {act }}$ and $k_{\text {deact }}$, related by the equilibrium constant, $K_{\mathrm{ATRP}}=k_{\text {act }} / k_{\text {deact }}$.

The equilibrium constant $K_{\mathrm{ATRP}}$ and activation rate coefficient $k_{\text {act }}$ have been investigated as a function of the type of ligand, initiator and solvent via online UV-VIS-NIR spectroscopy. ${ }^{60,61}$ Deactivation rate coefficients are less easily accessible, due to 
difficulties of directly measuring this fast reaction step. So far, $k_{\text {deact }}$ has been measured for monomer-free model systems by simultaneously trapping of radicals by nitroxide species and a $\mathrm{Cu}^{\mathrm{II}}$ deactivator in a competitive reaction. ${ }^{62}$ The most commonly used method for estimating $k_{\text {deact }}$ is via the $K_{\text {ATRP }}$ and $k_{\text {act }}$ values obtained from separate experiments on monomer-free model systems.

However, during polymerization, rate coefficients for activation cannot be obtained from independent experiments. Therefore, a novel method was developed for direct determination of deactivation rate coefficient, $k_{\text {deact }}$, based on the powerful SP-PLP-EPR technique which is presented in the following chapter 3.6.1. ${ }^{63}$ The new strategy allows for measuring ATRP deactivation kinetics taking chain-length dependent termination (CLDT) into account.

An advantage of this method is the measurement of absolute radical concentrations in comparison to investigations via UV-VIS-NIR spectroscopy and the decay of concentration in time-resolved EPR spectra is directly correlated with the occurring reactions. Moreover, EPR detection with a time resolution of less than a millisecond provides access to investigations into such fast reactions.

\subsubsection{Determination of Deactivation Rate Coefficient $\boldsymbol{k}_{\text {deact }}$ from Polymerization Kinetics}

Determination of rate coefficients for deactivation is based on a reverse ATRP-type approach. The system contains monomer, solvent and a conventional photoinitiator as well as a $\mathrm{Cu}^{\mathrm{II}}$ ATRP catalyst.

After applying a single laser pulse, the initiator decomposes and radicals are generated which add to monomer and start chain growth. By means of EPR detection the timeresolved radical concentration may be monitored, like in CLDT experiments. 


$$
\mathrm{Cu}^{\prime} \mathrm{X}(\mathrm{L})_{n}+\mathrm{R}-\mathrm{X} \frac{k_{\text {act }}}{k_{\text {deact }}} \mathrm{Cu}^{\mathrm{I}} \mathrm{X}_{2}(\mathrm{~L})_{n}+\mathrm{R}
$$

Scheme 3.7. Proposed mechanism of Cu-mediated ATRP for determination of deactivation rate coefficient $k_{\text {deact }}$ In this reverse ATRP-type approach radicals were generated by laser-initiated decomposition of a photoinitiator. $\mathrm{R}-\mathrm{R}$, radical-radical combination product, $\mathrm{R}^{\mathrm{H}}$ and $\mathrm{R}^{=}$, saturated and unsaturated product of radical-radical disproportionation.

According to scheme 3.7 the $\mathrm{Cu}^{\mathrm{II}}$ catalyst opens an additional pathway for reaction of radicals besides propagation and termination. By transfer of a halogen atom from the catalyst, the radical is deactivated forming a dormant species.

The decay in radical concentration recorded by EPR should be enhanced due to a further radical consuming step and is described in eq. 3.35.

$$
\frac{\mathrm{d}\left[\mathrm{R}^{\bullet}\right]}{\mathrm{d} t}=-2 \cdot k_{\mathrm{t}}^{i, i} \cdot\left[\mathrm{R}^{\bullet}\right]^{2}-k_{\text {deact }} \cdot\left[\mathrm{Cu}^{\mathrm{II}} \mathrm{X}_{2}(\mathrm{~L})_{n}\right] \cdot\left[\mathrm{R}^{\bullet}\right]+k_{\text {act }} \cdot\left[\mathrm{Cu}^{\mathrm{I} X}(\mathrm{~L})_{n}\right] \cdot[\mathrm{RX}]
$$




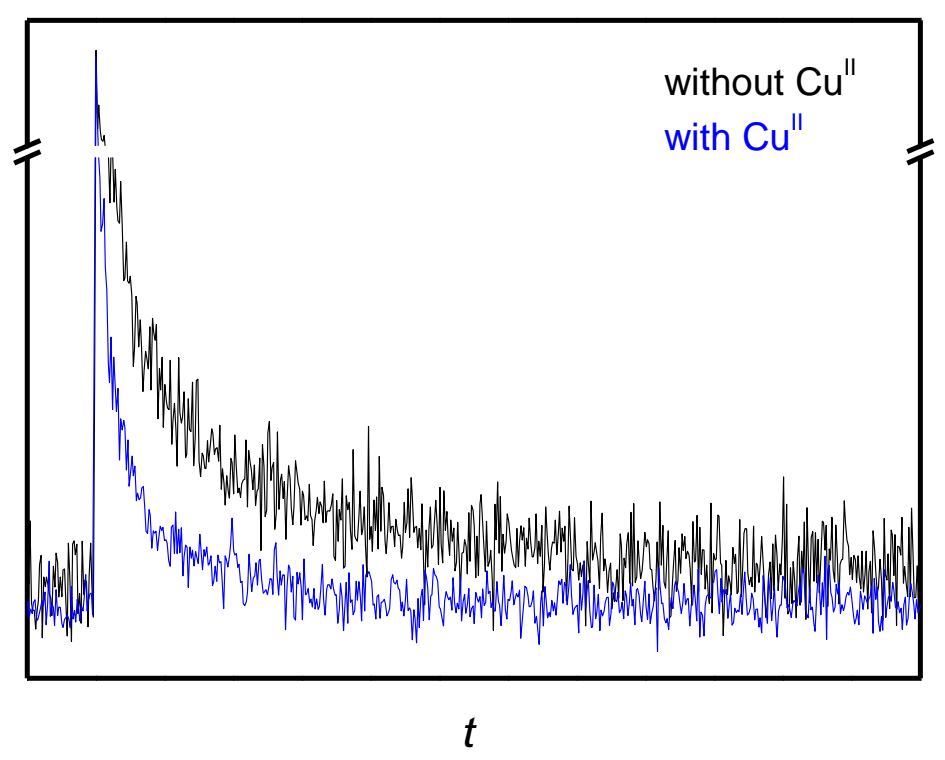

Figure 3.7. EPR concentration-time profiles for the polymerization of butyl acrylate in $15 \mathrm{wt} \%$ acetonitrile at $233 \mathrm{~K}$ with the addition of a small amount of copper ( $0.2 \mathrm{mM}$, blue) and without copper (black).

Figure 3.7 illustrates radical reactions in the presence (blue line) and in the absence (black line) of a $\mathrm{Cu}^{\mathrm{II}}$ catalyst. In the case of a conventional polymerization, the decay of radicals is caused by termination. In case of an ATRP-type reaction, the decay is faster due to the additional deactivation step.

For the sake of completeness it should be mentioned that the back reaction of the ATRP equilibrium increase the concentration of radicals. But since the experiment is performed in the absence of $\mathrm{Cu}^{\mathrm{I}}$ and $\mathrm{R}-\mathrm{X}$ in the beginning and the formed concentrations remain low, the activation step is negligible. In addition, typical values of $k_{\text {act }}$ of $\mathrm{Cu}$ catalysts with the chosen ligands are around five orders of magnitude lower than the corresponding deactivation rate coefficient. For example, even at $50 \%$ conversion of $1 \mathrm{mM}$ of the catalyst and an assumed radical concentration of $1 \cdot 10^{-6} \mathrm{~mol} \cdot \mathrm{L}^{-1}$, the deactivation rate is at least a factor of 200 higher.

According to eq. 3.35 rate coefficients of deactivation are obtained from recorded $c_{\mathrm{R}}(t)$ spectra. Implementing chain-length dependent $k_{\mathrm{t}}^{i, i}$ as described by the composite model, 
eq. 3.18 prevents analytical integration. The experimental data thus needs to be fitted by a kinetic model via PREDICI simulation.

\subsubsection{Equilibrium Constants $K_{\text {ATRP }}$ Determined from Polymerization Kinetics}

The equilibrium constant $K_{\mathrm{ATRP}}$ may be directly obtained from polymerization kinetics. The rate of polymerization is given in eq. 3.36.

$$
R_{\mathrm{p}}=-\frac{\mathrm{dM}}{\mathrm{d} t}=k_{\mathrm{p}} \cdot[\mathrm{M}] \cdot\left[\mathrm{R}^{\cdot}\right]=k_{\mathrm{p}} \cdot[\mathrm{M}] \cdot K_{\mathrm{ATRP}} \cdot \frac{\left[\mathrm{Cu}^{\mathrm{I}} \mathrm{XL}_{n}\right] \cdot[\mathrm{RX}]}{\left[\mathrm{Cu}^{\mathrm{II}} \mathrm{X}_{2} \mathrm{~L}_{n}\right]}
$$

Concentrations of monomer and $\mathrm{Cu}^{\mathrm{II}}$ species can be measured via VIS/NIR spectroscopy and data of $k_{\mathrm{p}}$ is taken from literature. Under the assumption that the $\mathrm{Cu}^{\mathrm{II}}$ complex is solely formed by termination, the actual concentrations of $\mathrm{Cu}^{\mathrm{I}}$ and the dormant species $[\mathrm{RX}]$ are calculated from the increase in $\mathrm{Cu}^{\mathrm{II}}$.

\subsubsection{Determination of Equilibrium Constants $K_{\text {model }}$ in the Absence of Monomer}

The equilibrium constant $K_{\text {model }}$ can be determined for a so-called model system in the absence of monomer. Thereby the elementary reactions are reduced to activation, deactivation and termination. It is assumed that the accumulation of the persistent radical $\left(\mathrm{Y}=\mathrm{Cu}^{\mathrm{II}} \mathrm{X}_{2}(\mathrm{~L})_{n}\right)$ is only due to termination. The rate laws for the concentration of radicals and of $(\mathrm{Y})$ are given in the following eqs. 3.37 and 3.38.

$$
\begin{array}{r}
\frac{\mathrm{d}\left[\mathrm{R}^{\bullet}\right]}{\mathrm{d} t}=k_{\text {act }} \cdot\left[\mathrm{Cu}^{\mathrm{I}} \mathrm{X}(\mathrm{L})_{n}\right] \cdot[\mathrm{RX}]-k_{\text {deact }} \cdot\left[\mathrm{Cu}^{\mathrm{I}} \mathrm{X}_{2}(\mathrm{~L})_{n}\right] \cdot\left[\mathrm{R}^{\bullet}\right]-2 \cdot k_{\mathrm{t}} \cdot\left[\mathrm{R}^{\bullet}\right]^{2} \\
\frac{\mathrm{d}[\mathrm{Y}]}{\mathrm{d} t}=k_{\text {act }} \cdot\left[\mathrm{Cu}^{\mathrm{I} X}(\mathrm{~L})_{n}\right] \cdot[\mathrm{RX}]-k_{\text {deact }} \cdot\left[\mathrm{Cu}^{\mathrm{II}} \mathrm{X}_{2}(\mathrm{~L})_{n}\right] \cdot\left[\mathrm{R}^{\bullet}\right]=\frac{\mathrm{d}[\mathrm{R} \cdot]}{\mathrm{d} t}+2 \cdot k_{\mathrm{t}} \cdot\left[\mathrm{R}^{\bullet}\right]^{2}
\end{array}
$$


The combination of both equations was solved by Fischer, Fukuda and Matyjaszewski analytically to yield eqs. 3.39 and 3.40. The result indicates an increase of the persistent radical proportional to $t^{1 / 3}$. Since termination occurs between two small radicals, $k_{\mathrm{t}}$ is assumed to be diffusion-controlled and is calculated as a function of temperature and viscosity $\left(k_{\mathrm{t}}=R T / 3 \eta\right)$.

$$
\begin{aligned}
& {\left[\mathrm{R}^{\cdot}\right]=\left(\frac{K_{\text {model }} \cdot[\mathrm{RX}]_{0} \cdot\left[\mathrm{Cu}^{\mathrm{I} X}(\mathrm{~L})_{n}\right]_{0}}{6 \cdot k_{\mathrm{t}}}\right)^{\frac{1}{3}} \cdot t^{-\frac{1}{3}}} \\
& {[\mathrm{Y}]=\left(6 \cdot k_{\mathrm{t}} \cdot K_{\text {model }}^{2} \cdot[\mathrm{RX}]_{0}^{2} \cdot\left[\mathrm{Cu}^{\mathrm{I}} \mathrm{X}(\mathrm{L})_{n}\right]_{0}^{2}\right)^{\frac{1}{3}} \cdot t^{\frac{1}{3}}}
\end{aligned}
$$

For equimolar concentrations of initiator and catalyst and at low conversion, the modified Fischer equation 3.40 is applicable towards the determination of $K_{\text {model }}$. However, highly reactive systems differ significantly from the linear dependence of $t^{1 / 3}$. Therefore, Matyjaszewski et al. deduced a modified equation for the equimolar (eq. 3.41) and nonequimolar case (eq. 3.42) which leads to a linear dependence of $F[Y]$ on time.

$$
\begin{gathered}
F([\mathrm{Y}])=\frac{[\mathrm{C}]_{0}^{2}}{3 \cdot\left([\mathrm{C}]_{0}-[\mathrm{Y}]\right)^{3}}-\frac{[\mathrm{C}]_{0}}{\left([\mathrm{C}]_{0}-[\mathrm{Y}]\right)^{2}}-\frac{1}{[\mathrm{C}]_{0}-[\mathrm{Y}]}=2 \cdot k_{\mathrm{t}} \cdot K_{\text {model }}^{2} \cdot t+b_{\mathrm{e}} \\
F([\mathrm{Y}])=\left(\frac{[\mathrm{C}]_{0}[\mathrm{I}]_{0}}{[\mathrm{C}]_{0}-[\mathrm{I}]_{0}}\right)^{2}\left(\frac{1}{[\mathrm{C}]_{0}^{2}\left([\mathrm{I}]_{0}-[\mathrm{Y}]\right)}+\frac{2}{[\mathrm{I}]_{0}[\mathrm{C}]_{0}\left([\mathrm{C}]_{0}-[\mathrm{I}]_{0}\right)} \ln \left(\frac{[\mathrm{I}]_{0}-[\mathrm{Y}]}{[\mathrm{C}]_{0}-[\mathrm{Y}]}\right)+\frac{1}{[\mathrm{I}]_{0}^{2}\left([\mathrm{C}]_{0}-[\mathrm{Y}]\right)}\right) \\
F([\mathrm{Y}])=2 \cdot k_{\mathrm{t}} \cdot K_{\text {model }}^{2} \cdot t+b_{\mathrm{n}}
\end{gathered}
$$

$[\mathrm{C}]_{0} \quad: \quad$ initial concentration of the $\mathrm{Cu}^{\mathrm{I}}$ complex

$[\mathrm{I}]_{0} \quad: \quad$ initial concentration of the organohalide initiator

$b_{\mathrm{e}} \quad: \quad \mathrm{Y}$-intercept of the linearized function $F[\mathrm{Y}]$ (equimolar)

$b_{\mathrm{n}} \quad: \quad \mathrm{Y}$-intercept of the linearized function $F[\mathrm{Y}]$ (non-equimolar) 
The equilibrium constant $K_{\text {model }}$ can be easily determined from the slope of a plot of $F[\mathrm{Y}]$ against time. Concentrations of the $\mathrm{Cu}^{\mathrm{II}}$ species can be measured via VIS/NIR spectroscopy.

\subsubsection{Determination of the Activation Rate Coefficient $\boldsymbol{k}_{\text {act }}$ in Model Systems}

Rate coefficients for activation in ATRP can be determined by a so-called trapping experiment, which was already used for investigations into the dissociation kinetics of alkoxyamines. ${ }^{64}$ This experiment is based on a monomer-free model system containing an ATRP initiator, the catalyst and additionally a trapping agent, for example the stable nitroxide radical (2,2,6,6-tetramethylpiperidine-1-yl)oxyl (TEMPO).

As in normal ATRP, a halogen atom is transferred from the initiator $\mathrm{R}-\mathrm{X}$ to the $\mathrm{Cu}^{\mathrm{I}}$ species. The generated radicals are trapped by reaction with TEMPO. Due to an excess of the trapping agent, this reaction is irreversible and the deactivation by a reverse transfer of a halogen atom is suppressed (Scheme 3.6).

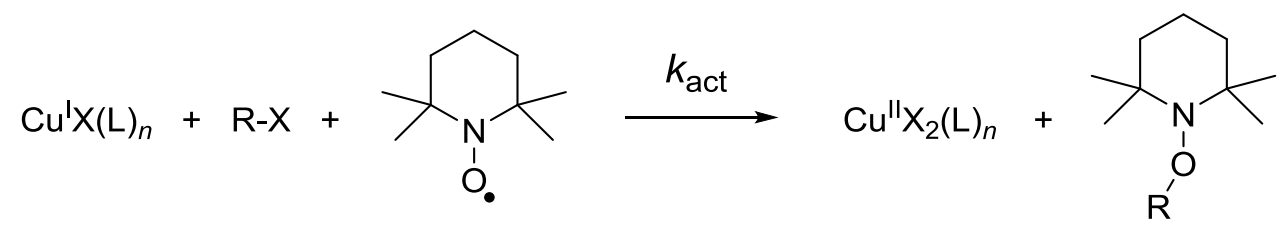

Scheme 3.6. Reaction scheme for determination of $k_{\text {act }}$ by a trapping experiment. Radicals are generated in the activation step and instantaneously trapped by an excess of a stable radical (TEMPO).

Therefore the rate of initiator consumption depends only on the activation step and may be expressed by eq. 3.43 .

$$
\frac{\mathrm{d}[\mathrm{RX}]}{\mathrm{d} t}=-k_{\mathrm{act}} \cdot[\mathrm{R}-\mathrm{X}] \cdot\left[\mathrm{Cu}^{\mathrm{I}} \mathrm{X}(\mathrm{L})_{n}\right]
$$


By using an excess of the $\mathrm{Cu}^{\mathrm{I}}$-activator (ca. 20 equivalents) pseudo-first-order-kinetics are realized and the concentration of the catalyst is assumed to be constant (eq. 3.44).

$$
-\frac{\mathrm{d} \ln ([\mathrm{RX}])}{\mathrm{d} t}=k_{\mathrm{act}} \cdot\left[\mathrm{Cu}^{\mathrm{I}} \mathrm{X}(\mathrm{L})_{n}\right]_{0}
$$

By means of VIS/NIR spectroscopy, the increase in $\mathrm{Cu}^{\mathrm{II}}$-concentration can be recorded. The actual initiator concentration results from the difference of the initial amount of initiator and the time-dependent $\mathrm{Cu}^{\mathrm{II}}$ concentration.

$$
-\frac{\mathrm{d} \ln \left([\mathrm{RX}]_{0}-\left[\mathrm{Cu}^{\mathrm{II}} \mathrm{X}_{2}(\mathrm{~L})_{n}\right]_{t}\right)}{\mathrm{d} t}=k_{\mathrm{act}} \cdot\left[\mathrm{Cu}^{\mathrm{I}} \mathrm{X}(\mathrm{L})_{n}\right]_{0}
$$

The activation rate coefficient is achieved from the slope of a log-plot of the $\mathrm{Cu}^{\mathrm{II}}$ concentration versus time. 



\section{$4 \quad$ Experimental}

\subsection{Chemicals}

\subsubsection{Metal salts}

\section{Copper(II) bromide}

Copper(II) bromide $\left(\mathrm{Cu}^{\mathrm{II}} \mathrm{Br}_{2}, M=223.35 \mathrm{~g} \cdot \mathrm{mol}^{-1}\right.$, Aldrich, $\left.99 \%\right)$ was used as received.

\section{Copper(I) bromide}

Copper(I) bromide $\left(\mathrm{Cu}^{\mathrm{I}} \mathrm{Br}, M=143.45 \mathrm{~g} \cdot \mathrm{mol}^{-1}\right.$, Aldrich, $99.999 \%$ metals basis $)$ was used as received.

\section{Tetrakis(acetonitrile)copper(I) hexafluorophosphate}

Tetrakis(acetonitrile)copper(I) hexafluorophosphate $\quad\left(\mathrm{Cu}^{\mathrm{I} P F} 6, \quad M=372.72 \mathrm{~g} \cdot \mathrm{mol}^{-1}\right.$, Aldrich, $97 \%$ ) was used as received.

\subsubsection{Ligands}

\section{$1,1,4,7,10,10-$ Hexamethyltriethylenetetramine}

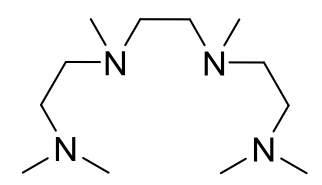


1,1,4,7,10,10-Hexamethyltriethylenetetramine (HMTETA, $M=230.39 \mathrm{~g} \cdot \mathrm{mol}^{-1}$, Aldrich, $97 \%$ ) was used without further purification.

\section{$\boldsymbol{N}, \boldsymbol{N}, \boldsymbol{N}, \boldsymbol{N}^{\prime}, \boldsymbol{N}^{\prime}$ '-Pentamethyldiethylenetriamine}<smiles>CN(C)CCN(C)CCN(C)C</smiles>

$N, N, N$ ', $N$ ',$N$ ' '-Pentamethyldiethylenetriamine (PMDETA, $M=173.30 \mathrm{~g} \cdot \mathrm{mol}^{-1}$, Aldrich, $99 \%$ ) was used as received.

\section{Tris(2-pyridylmethyl(amine)}<smiles>c1ccc(CN(Cc2ccccn2)Cc2ccccn2)nc1</smiles>

Tris(2-pyridylmethyl(amine) (TPMA, $M=290.36 \mathrm{~g} \cdot \mathrm{mol}^{-1}$, Aldrich, $98 \%$ ) was used without further purification.

\subsubsection{Monomers and Initiators}

\section{Butyl acrylate}

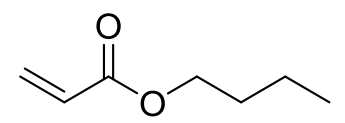

Butyl acrylate $\left(\mathrm{BA}, M=128.17 \mathrm{~g} \cdot \mathrm{mol}^{-1}\right.$, Aldrich, $99.5 \%$, stabilized by $10 \mathrm{ppm}$ hydrochinone monomethylether) was purified by passing through a column filled with inhibitor remover. 


\section{Dodecyl methacrylate}

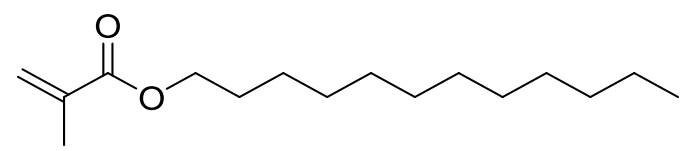

Dodecyl methacrylate (DMA, lauryl methacrylate, $M=254.41 \mathrm{~g} \cdot \mathrm{mol}^{-1}$, Aldrich, $96 \%$, stabilized by 500 ppm hydrochinone monomethylether) was purified by passing through a column filled with inhibitor remover.

\section{2-Ethylhexyl methacrylate}

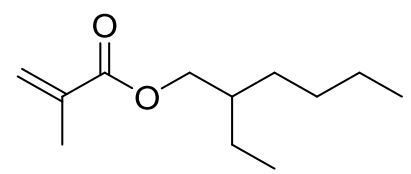

2-Ethylhexyl methacrylate (EHMA, $M=198.30 \mathrm{~g} \cdot \mathrm{mol}^{-1}$, Aldrich, $98 \%$, stabilized by $50 \mathrm{ppm}$ hydrochinone monomethylether) was purified by passing through a column filled with inhibitor remover.

\section{Butyl methacrylate}

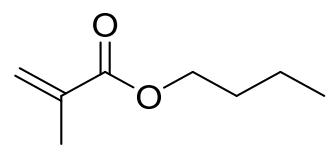

Butyl methacrylate (BMA, $M=142.20 \mathrm{~g} \cdot \mathrm{mol}^{-1}$, Aldrich, $99 \%$, stabilized by $10 \mathrm{ppm}$ hydrochinone monomethylether) was purified by passing through a column filled with inhibitor remover. 


\section{Methyl methacrylate}

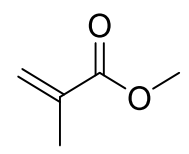

Methyl methacrylate (MMA, $M=100.12 \mathrm{~g} \cdot \mathrm{mol}^{-1}$, Fluka, >99 \%, stabilized by $50 \mathrm{ppm}$ hydrochinone monomethylether) was purified by passing through a column filled with inhibitor remover.

$\alpha$-Methyl-4-(methylmercapto)- $\alpha$-morpholinopropiophenone<smiles>CSc1ccc(C(=O)C(C)(C)N2CCOCC2)cc1</smiles>

$\alpha$-Methyl-4-(methylmercapto)- $\alpha$-morpholinopropiophenone (MMMP, Aldrich, $\left.M=279.40 \mathrm{~g} \cdot \mathrm{mol}^{-1}, 98 \%\right)$ was used received.

\subsubsection{Miscellaneous}

\section{(2,2,6,6-Tetramethylpiperidine-1-yl)oxyl}

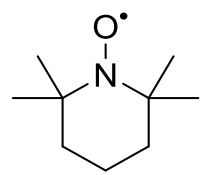

(2,2,6,6-Tetramethylpiperidine-1-yl)oxyl (TEMPO, $M=156.25 \mathrm{~g} \cdot \mathrm{mol}^{-1}$, Aldrich, $98 \%$ ) was used without further purification. 


\section{Hydroquinone}<smiles>Oc1ccc(O)cc1</smiles>

The inhibitor hydroquinone $\left(M=110.11 \mathrm{~g} \cdot \mathrm{mol}^{-1}\right.$, Fluka, $\left.>99 \%\right)$ was used without further purification.

\section{Solvents}

The solvents acetonitrile (MeCN, Aldrich, $99.8 \%$, anhydrous), tetrahydrofuran (THF, Fisher Chemicals, $99.99 \%$ ) and toluene (Acros Organics, $>99.85 \%$, extra dry) were used as received.

\subsection{Photoinitiator}

Pulsed laser experiments are based on the correlation of kinetic chain length with time after pulsing. Therefore an appropriate photoinitiator has to be chosen, which fulfills several requirements.

First, the initiator has to absorb and decompose at the wavelength of $351 \mathrm{~nm}$ applied by irradiation with a $\mathrm{XeF}$ laser. The decomposition should be fast compared to chain initiation and the reactivity of the generated primary radicals should be almost identical to ensure uniform initiation of chain growth. In addition, the photoinitiator has to be thermally stable, which is particularly important in single pulse experiments at higher temperatures.

Commonly used photoinitiator for PLP experiments are carbonyl compounds, which may undergo Norrish type I photodissociation. 


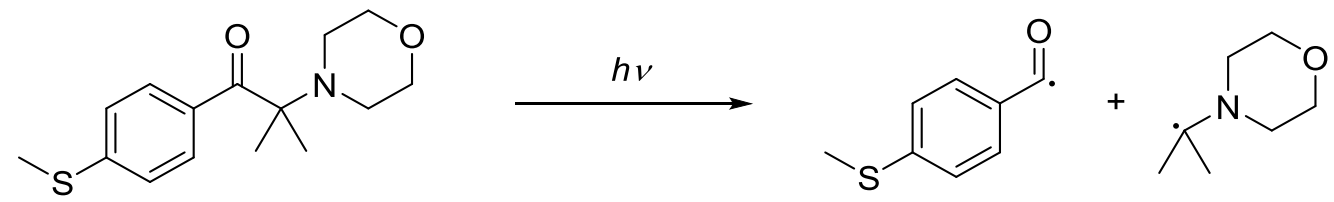

Scheme 4.1. Photo-induced decomposition of $\alpha$-methyl-4-(methylmercapto)- $\alpha$ morpholinopropiophenone.

Investigations into the polymerization of methyl acrylate showed that MMMP fulfills the stated requirements and is a close to an ideal photoinitiator. Since MMMP is soluble in the applied monomer-solvent mixtures, all pulsed laser experiments were performed using MMMP.

\subsection{Electron Paramagnetic Resonance Spectroscopy}

\subsubsection{EPR Setup}

Within the present thesis, experiments were performed on two different EPR setups. An overall schematic view is illustrated in Figure 4.1.

The microwave bridge houses the electromagnetic radiation source and the detector. The cavity resonator is equipped in the front with a grid for irradiation of the sample with UV light. The cavity amplifies weak signals from the sample and is characterized by its quality factor $Q$, which indicates how efficiently the cavity stores microwave energy. As $Q$ is inversely proportional to the amount of energy lost during one microwave period, an increasing $Q$ enhances the spectrometer sensitivity.

Both setups use an ADC signal channel (SC) for recording EPR intensity vs. magnetic field as well as intensity vs. time at constant magnetic field after laser pulse initiation. The maximum resolution of the time-dependent spectra is $10 \mu \mathrm{s}$.

The laser source and the spectrometer are synchronized using a Quantum Composers 9314 pulse generator (Scientific Instruments). Temperature control was achieved by an ER 4131VT unit (Bruker) and by purging the cavity with nitrogen. 
The console consists of signal processing units and control electronics. Recording of the primary data and control of the spectrometer settings was done by the software XEPR (Bruker).

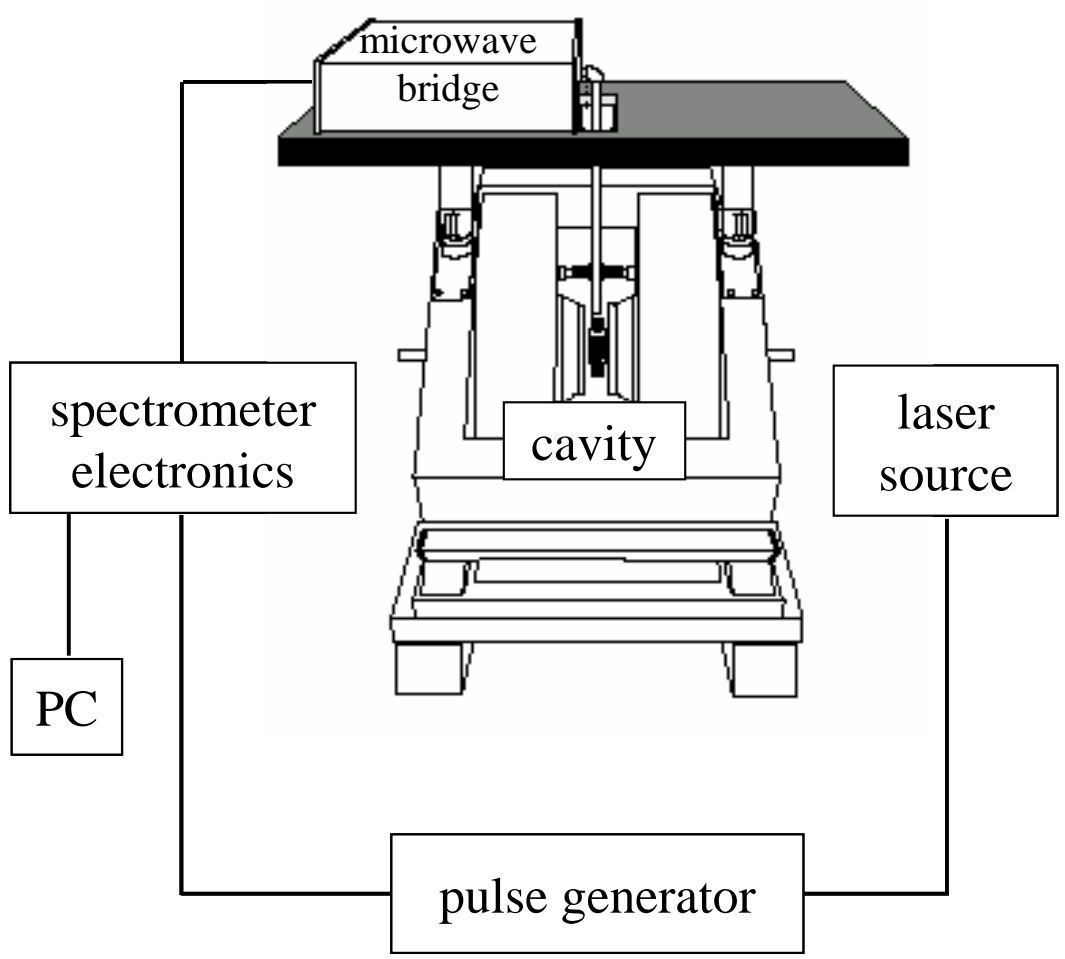

Figure 4.1. Schematic setup of the SP-PLP-EPR experiment. The microwave bridge houses the microwave source and the detector. The samples are placed into the cavity. Control and signal processing is performed via a PC.

\section{Setup A}

Measurements were carried out on a Bruker Elexsys E 500 series cw-EPR spectrometer operating at the X-band frequency. Setup A uses a SHQE-W1 cavity and a XeF excimer laser (Lambda Physik, COMPex 102, maximum repetition rate of $20 \mathrm{~Hz}$ ) operating at a wavelength of $351 \mathrm{~nm}$ for irradiation. Besides the ADC signal channel (SC), the instrument is equipped with a fast digitizer acquisition board (FD), which increases the resolution for time-resolved spectra at constant magnetic field. The maximum time 
resolution of the FD is $500 \mathrm{~ns}$. The spectrometer is located in the institute of inorganic chemistry.

\section{Setup B}

EPR spectra were also recorded on a Bruker Elexsys II E 500T series cw-EPR spectrometer operating at the X-band frequency. Irradiation of the samples with UV light was done using a XeF excimer laser (351 nm, Lambda Physik, LPX 210i with a maximum repetition rate of $100 \mathrm{~Hz}$ ). In comparison to setup A it is equipped with a ER 41122SHQELC cavity, which has a higher $Q$ factor and provides spectra with better signal-to-noise ratio.

\subsubsection{Sample Preparation for EPR Measurements}

The purified monomer, solvents and ligands were degassed by several freeze-pump-thaw cycles. All EPR samples were prepared under an argon atmosphere in a glove box.

In case of metal-free measurements, the initiator was added to the monomer and the monomer-solvent mixture, respectively. The solution $(0.05 \mathrm{~mL})$ was filled into EPR quartz tubes of $2 \mathrm{~mm}$ inner and $3 \mathrm{~mm}$ outer diameter with a syringe. The sample tubes were closed with a plastic cap, sealed with PARAFILM and protected from light prior to the experiment.

For copper-containing samples a stock solution of the complex was prepared by dissolving the copper salt and an equimolar amount of ligand in acetonitrile. The initiator and the stock solution were added to the monomer. EPR tubes of the same dimensions were filled with the solution and handled as described above.

Calibration solutions of $10^{-5}$ to $10^{-6} \mathrm{~mol} \cdot \mathrm{L}^{-1}$ of TEMPO in the corresponding monomersolvent mixture were prepared by stepwise dilution starting with $10^{-2} \mathrm{~mol} \cdot \mathrm{L}^{-1}$ TEMPO.

For enhanced signal-to-noise quality a modulation frequency of $100 \mathrm{kHz}$ was used. The modulation amplitude was $10 \mathrm{G}$ for $\mathrm{Cu}^{\mathrm{II}}$-containing samples and was varied between 1 and $3 \mathrm{G}$ in case of macroradicals. The microwave energy was in the range 2 to $20 \mathrm{~mW}$ depending on the attenuation. 
EPR spectra of TEMPO calibration and macroradicals were recorded at a conversion time (time per data point) of $10.24 \mathrm{~ms}$, while spectra of $\mathrm{Cu}^{\mathrm{II}}$-species were taken at $40.96 \mathrm{~ms}$. For PLP-initiation, a laser pulse energy of 20 to $100 \mathrm{~mJ}$ was chosen.

The spectrometer cavity is brought to reaction temperature and the sample is placed into the resonator. First, an EPR spectrum is recorded under continuous laser initiation at a p.r.r. typically of $20 \mathrm{~Hz}$ to identify a suitable characteristic line for time-resolved tracing (field scan). Afterwards single-pulse experiments were carried out at this fixed magnetic field (time scan). To improve signal quality, usually 20 to 100 traces were co-added for one $c_{\mathrm{R}}(t)$ curve. In case of measurements with $\mathrm{Cu}^{\mathrm{II}}$ a new sample was used after the field scan. Also the number of single pulses per sample was reduced to 3 to 5 to lower the conversion of the $\mathrm{Cu}^{\mathrm{II}}$ species.

EPR spectrometer and laser are synchronized with a delay for firing the laser pulse at around 10 per cent of the full recording time. Thus a baseline, where no radicals are present, is obtained to subtract the offset. To ensure complete decay in radical concentration, a suitable dark time between two laser pulses is chosen.

\subsubsection{Calibration}

Electron paramagnetic resonance is the only technique for the direct detection and quantification of radicals.

Comparable to other methods, such as IR or NMR spectroscopy, the integral of an EPR spectrum is proportional to the concentration of the species. Since in EPR the first derivative of the absorbance is recorded, spectra have to be double-integrated to find the concentration.

This correlation is independent of the type of radical. It depends only on the total amount of radicals. Therefore it is possible to determine the proportionality factor $h_{1}$ (eq. 4.1) by calibrating the setup with samples of different concentrations of TEMPO, which is soluble in all investigated monomer/solvent mixtures. For an accurate calibration, the EPR spectra of TEMPO have to be measured under exactly the same conditions as used in the single pulse experiment. 


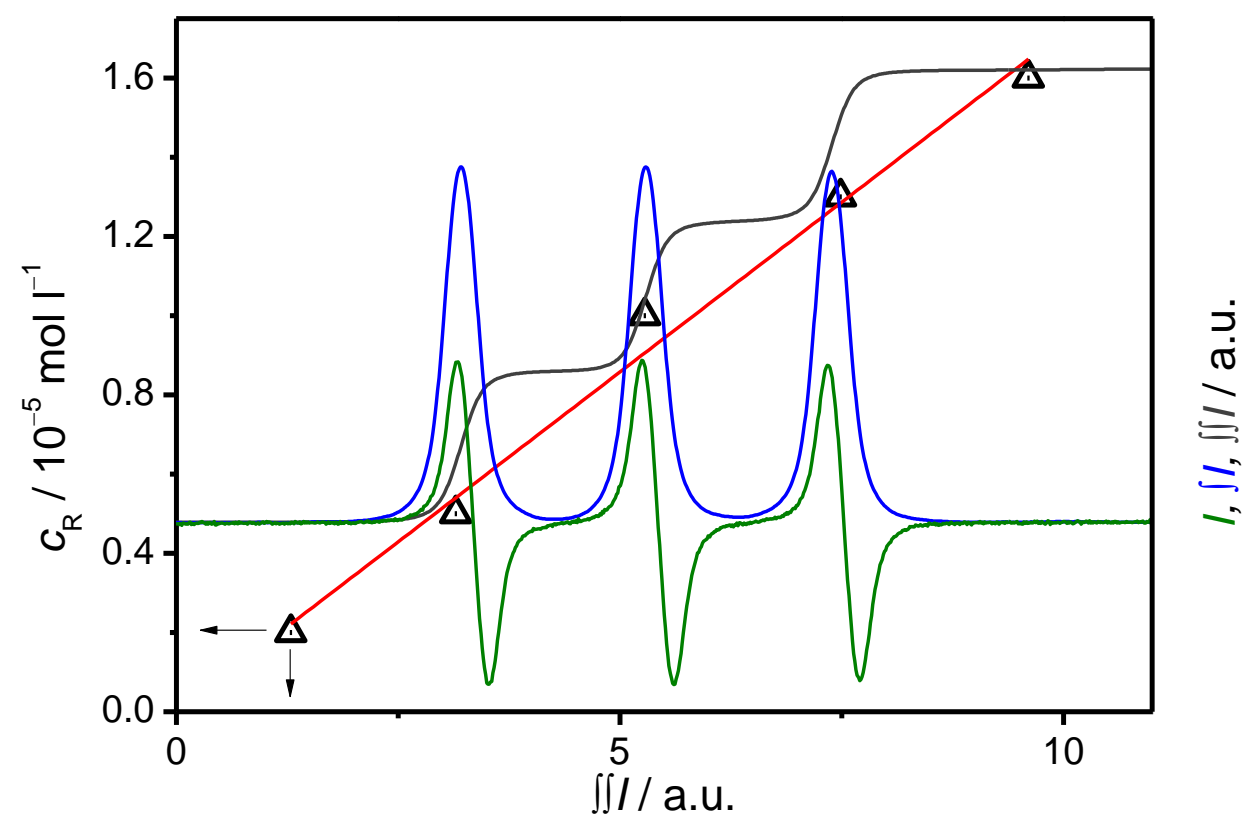

Figure 4.2. TEMPO concentrations between $2 \cdot 10^{-6}$ and $1.6 \cdot 10^{-5} \mathrm{~mol} \cdot \mathrm{L}^{-1}$ are plotted vs. the associated measured double integral in DMA bulk polymerization at $273 \mathrm{~K}$ (black triangle). A typical EPR spectrum of $1 \cdot 10^{-5} \mathrm{~mol} \cdot \mathrm{L}^{-1}$ TEMPO is shown in green, with integral (blue) and double integral (grey). The slope of linear regression yields the calibration constant $h_{1}$.

Figure 4.2 shows a typical EPR spectrum (green line) of a solution of TEMPO in DMA at $273 \mathrm{~K}\left(c \approx 10^{-5} \mathrm{~mol} \cdot \mathrm{L}^{-1}\right)$, its integral (blue line) and the double integral (grey line). By plotting the TEMPO concentration vs. the associated double integral (black triangles) $h_{1}$ is obtained from the slope of the linear regression.

$$
c_{\mathrm{R}}=c_{\mathrm{R}, \mathrm{ref}} \cdot \frac{\iint I_{\mathrm{SC}}}{\iint I_{\mathrm{SC}, \mathrm{ref}}}=h_{1} \cdot \iint I_{\mathrm{SC}}
$$


Since in SP-PLP-EPR experiments the time-resolved signal intensity of a propagating radical is recorded at constant magnetic field value $\left(B_{\mathrm{X}}\right)$, the measured peak intensity of the scan has to be correlated with the double integral of the full spectrum. The proportionality given by $h_{2}$ is expressed by eq. 4.2 .

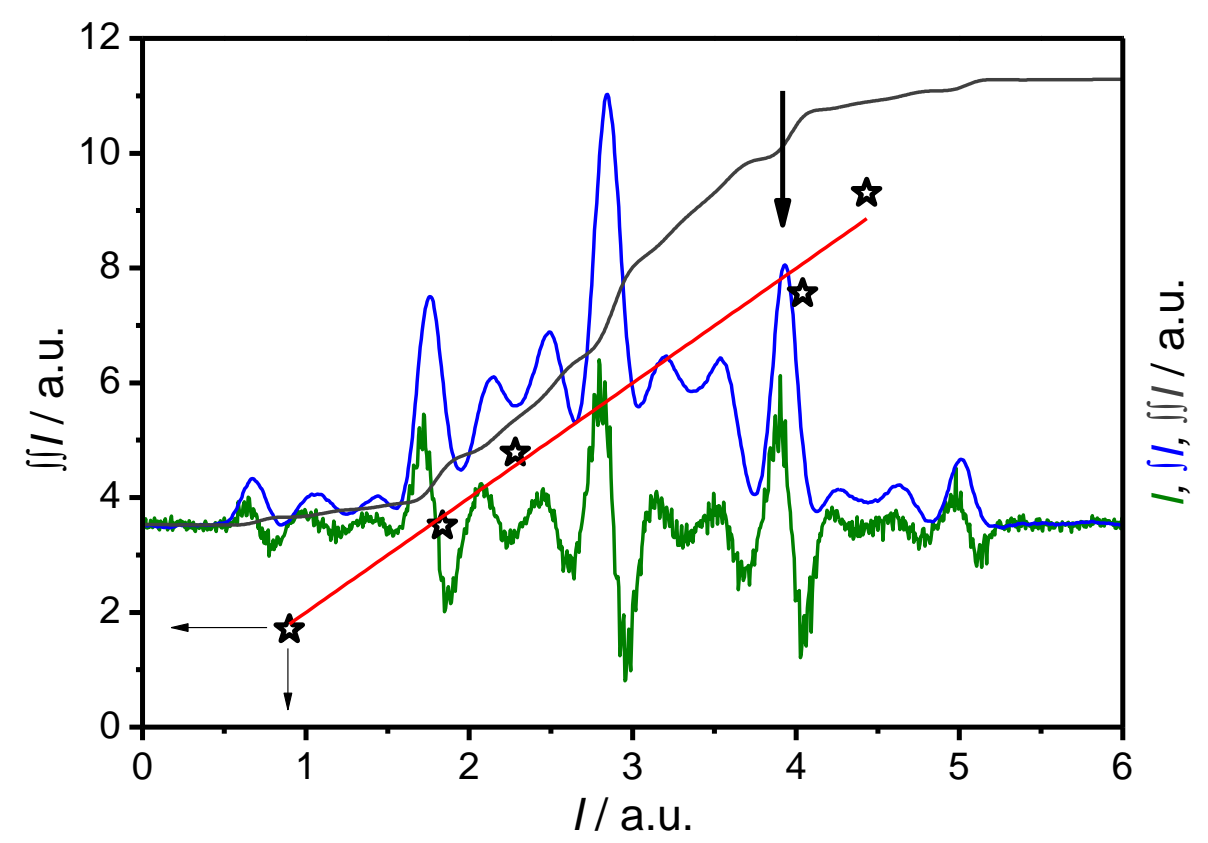

Figure 4.3. Correlation between the double integral of the EPR spectrum and the intensity of the peak indicated by the arrow for DMA polymerization at $273 \mathrm{~K}$ yielding $h_{2}$ as the slope. The green line represent the EPR spectrum of DMA radicals under continuous laser initiation with $20 \mathrm{~Hz}$ under such conditions with the associated integral (blue) and the double integral (grey).

Figure 4.3 illustrates the full EPR spectrum of a propagating DMA radical (green line) under continuous laser initiation $(20 \mathrm{~Hz}, 273 \mathrm{~K})$, its integral (blue line) and double integral (grey line). For several concentrations, the double integral is plotted vs. the intensity of the signal to yield $h_{2}$.

$$
\iint I_{\mathrm{SC}}=h_{2} \cdot I_{\mathrm{SC}}\left(B_{X}\right)
$$


In time-resolved experiments recorded on setup A (see above) a fast digitizer (FD) was used, which has a different sensitivity compared to the signal channel detection (SC). Hence, a third constant $h_{3}$ is needed for measurements with setup A. Figure 4.4 shows the intensity of a TEMPO sample for both acquisition boards. The proportional factor of SC to $\mathrm{FD}$ is about 2.

$$
I_{\mathrm{SC}}\left(B_{\mathrm{X}}\right)=h_{3} \cdot I_{\mathrm{FD}}\left(B_{\mathrm{X}}\right)
$$

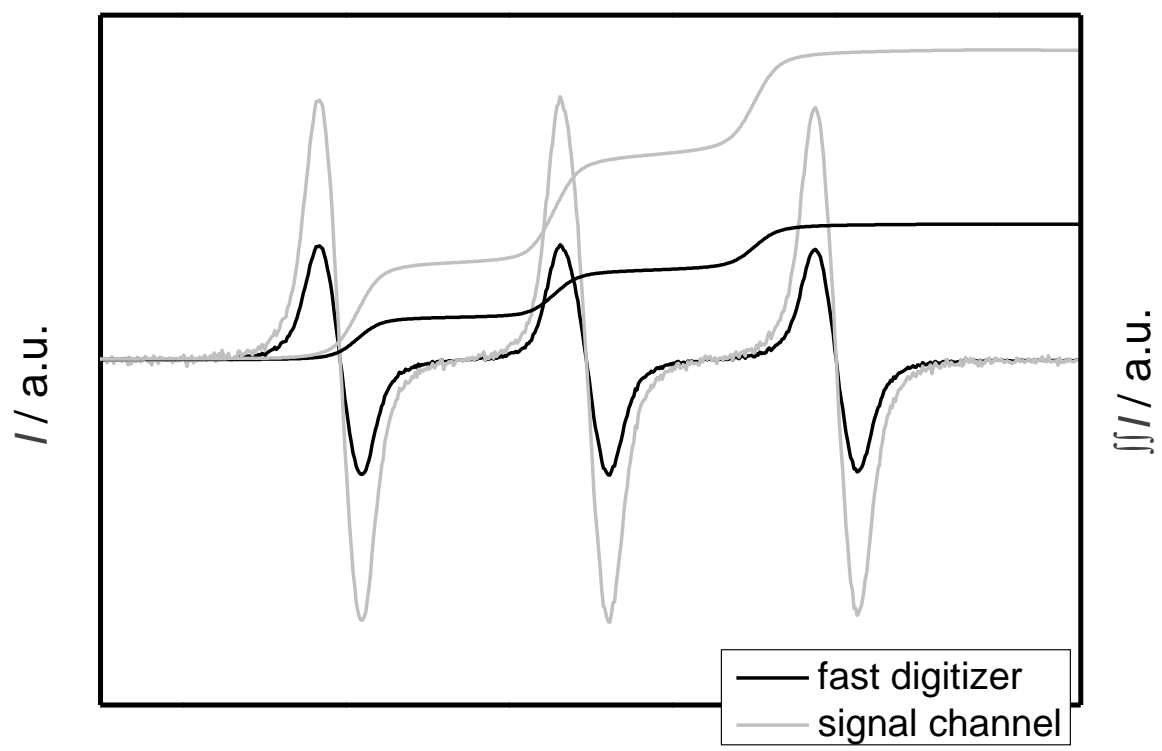

Figure 4.4. Plot of EPR spectra and corresponding double integrals of $1 \cdot 10^{-5} \mathrm{~mol} \cdot \mathrm{L}^{-1}$ TEMPO solution in DMA at $273 \mathrm{~K}$ recorded on both detection modes (signal channel and fast digitizer).

The proportionality constants depend on several factors such as temperature or polarity and dielectricity of the sample. Thus, the calibration with TEMPO was carried out at identical conditions. Sample and reference were prepared in monomer/solvent mixture of the same composition. They were measured in EPR tubes of identical material and diameter. Moreover, the same sample volume was used. To minimize uncertainties the same spectrometer settings (modulation frequency and amplitude, microwave energy, conversion time) were chosen. 


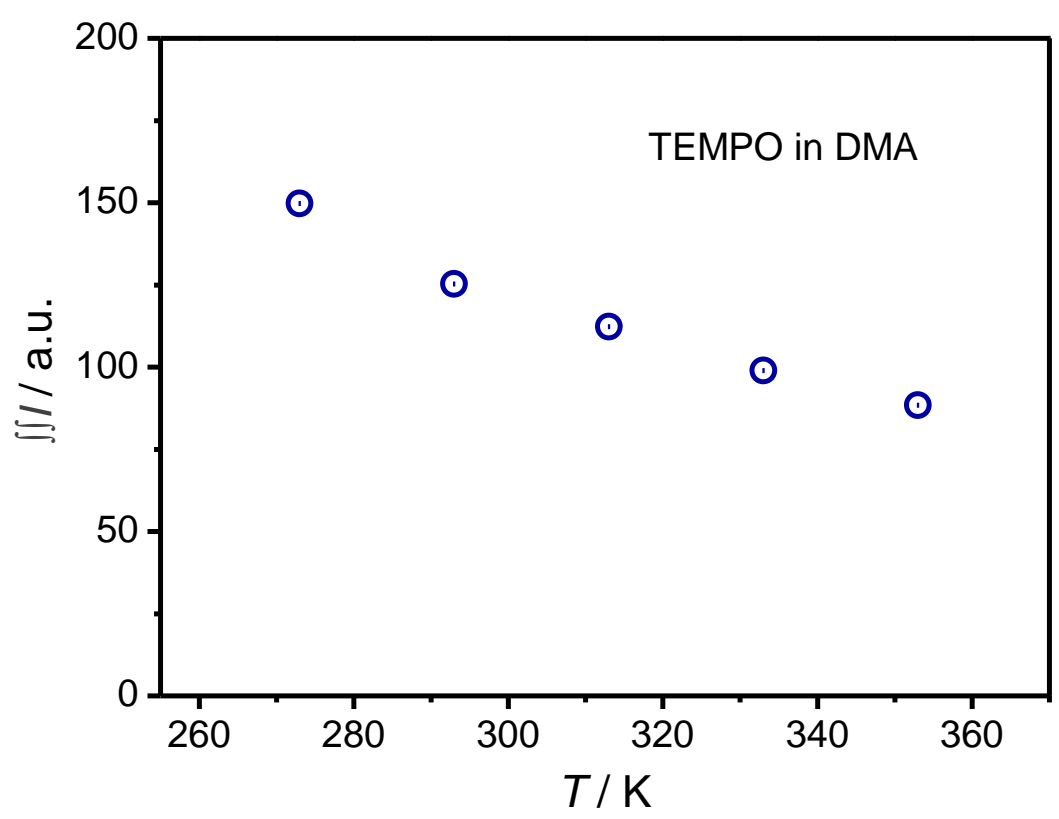

Figure 4.5. Temperature dependence of spectrometer sensitivity expressed by the double integral of a spectrum of $10^{-5} \mathrm{~mol} \cdot \mathrm{L}^{-1}$ TEMPO dissolved in DMA. The higher the double integral, the better is the sensitivity.

Depicted in Figure 4.5 is the spectrometer sensitivity as a function of temperature. According to the Boltzmann distribution, the sensitivity and the corresponding double integral of the signal decrease with increasing temperature as the population difference between the spin levels in the magnetic field is reduced. On the other hand, the dielectricity of monomer and solvent is lower at higher temperature, which enhances sensitivity in organic solvents. In the systems studied here, the first effect is dominant. Therefore, experiments were performed preferably at low temperatures.

By combination of the calibration constants, the radical concentration in single pulse experiments is directly accessible from the peak intensity at the selected (peak maximum) magnetic field. Eqs. 4.4 and 4.5 are associated with the detection modes described above, when using the setups A and B, respectively.

$$
c_{\mathrm{R}}(t)=h_{1} \cdot h_{2} \cdot h_{3} \cdot I_{\mathrm{FD}}\left(B_{\mathrm{X}}\right)(t)
$$

$$
c_{\mathrm{R}}(t)=h_{1} \cdot h_{2} \cdot I_{\mathrm{SC}}\left(B_{\mathrm{X}}\right)(t)
$$




\subsection{PLP-SEC Experiment}

\subsubsection{PLP Setup}

PLP-SEC experiments were performed using a XeF exciplex laser (Coherent, LPXpro 240 , max. pulse energy of $120 \mathrm{~mJ}$ ) operating at a wavelength of $351 \mathrm{~nm}$. The maximum repetition rate is $400 \mathrm{~Hz}$ with a pulse width of $20 \mathrm{~ns}$.

The laser beam is focused on the sample (S) by means of four lenses (L) resulting in a maximum pulse energy of $40 \mathrm{~mJ} \cdot \mathrm{cm}^{-2}$. For safety reasons, a beam dumb (BD) is used to absorb light, which passes the sample. The entire optical pathway is set up in a box.

Figure 4.6 gives an overview on the setup. A detailed illustration may be found in the $\mathrm{PhD}$ thesis of J. Schrooten. ${ }^{65}$

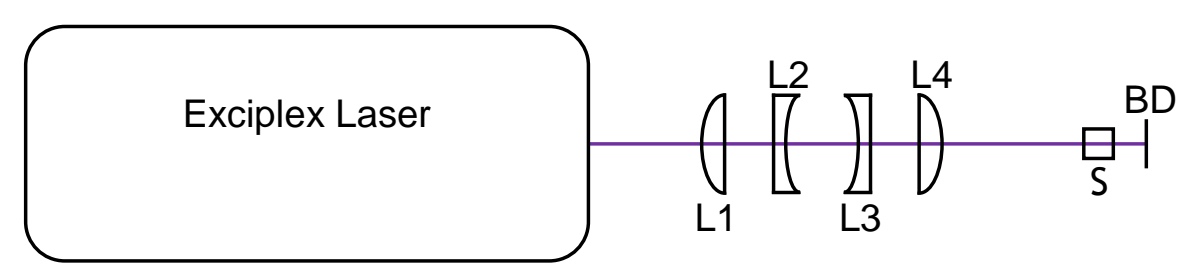

Figure 4.6. PLP setup consisting of an exciplex laser, lenses (L1-4), a sample (S) and a beam dumb (BD).

\subsubsection{SEC Setup}

Polymer samples from PLP experiments were analyzed by size-exclusion chromatography. The setup contains a Waters 515 HPLC pump, an autosampler (JASCO AS-2055-plus), a PSS SDV (styrene-divinylbenzene copolymer-network) precolumn ( $8 \times$ $50 \mathrm{~mm})$, three PSS SDV separation columns $(8 \times 300 \mathrm{~mm}$; particle size $=5 \mu \mathrm{m}$; pore size $=10^{5}, 10^{3}$, and $10^{2} \AA$ ) and a Waters 2410 refractive index detector. The SEC device was operated at $35^{\circ} \mathrm{C}$ with a flow rate of $1 \mathrm{~mL} \cdot \mathrm{min}^{-1}$. THF was used as the eluent and toluene as the internal standard. Each sample was measured twice. 
The system was calibrated against polystyrene and polyMMA standards of low dispersities manufactured by PSS. As the Mark-Houwink parameters for polyDMA, $K=5.18 \cdot 10^{-5} \mathrm{dL} \cdot \mathrm{g}^{-1}$ and $\alpha=0.72$ were used. ${ }^{66}$

\subsubsection{Sample Preparation}

For the PLP-SEC experiments the initiator was dissolved in a mixture of monomer and solvent. The reaction solution was filled into a heatable cuvette of $1 \mathrm{~cm}$ path length (Starna, 65.14/Q/10, Spectrosil fused quartz) and purged with nitrogen for $5 \mathrm{~min}$ to remove oxygen.

The cuvette was closed with a PTFE stopper and protected from light until starting laser irradiation. To achieve reaction temperature, the cuvette was connected to a cryostat (Haake, 001-4202) for about 10 min prior to laser pulsing.

After the experiment, the solution was transferred into a sample vial containing hydroquinone to prevent from further polymerization. Residual monomer and solvent were removed in a vacuum oven at $40^{\circ} \mathrm{C}$ until constant weight of the sample was reached. Monomer-to-polymer conversion was determined by gravimetric analysis.

\subsection{FT-VIS/NIR Spectroscopy}

VIS/NIR spectra were recorded with a Fourier transform infrared spectrometer (IFS 88, Bruker) equipped with a tungsten halogen lamp, a silicon-coated calcium fluoride beam splitter and a liquid-nitrogen-cooled MCT detector. The optical system and the sample compartment were continuously flushed with compressed dry air.

To measure monomer-to-polymer conversion the EPR tube was directly positioned into the sample chamber of the spectrometer. Monomer conversion was determined by monitoring the first overtone of the alkene $\mathrm{C}-\mathrm{H}$ stretching mode. Integration of the absorption spectra was carried out via the software package Opus (Bruker). 


\subsection{UV Spectroscopy}

Measurements of the stability of the copper complexes under UV irradiation were performed on a Cary 300 UV-VIS spectrometer. The spectra were processed via the spectrometer software (Varian).

\subsection{Determination of Density}

A density meter, which is based on the oscillating U-tube principle, was used in this thesis. The instrument consists of a data acquisition unit, DMA 60, (Anton Paar), a measuring unit, DMA 602TP, (Anton Paar) and a high-temperature cell, DMA 602 H (DURAN® 50, $-10-150^{\circ} \mathrm{C}$, Anton Paar).

The sample is filled into an U-shaped glass tube, which is electronically excited into undamped oscillation. The natural frequency of the tube depends on the mass and thus on the density of the solution. The densities of two substances A and B are related via eq. 4.1.

$$
\rho_{\mathrm{A}}-\rho_{\mathrm{B}}=\kappa \cdot\left(f_{\mathrm{A}}^{-2}-f_{\mathrm{B}}^{-2}\right)
$$

$$
\begin{array}{lll}
\rho & : & \text { density of substances A and B } \\
\kappa & : & \text { instrument constant } \\
f & : & \text { oszillator frequency of A and B }
\end{array}
$$

The instrumental constant was determined by calibration with two samples of well-known density, water and air. 


\subsection{Determination of Viscosity}

Viscosity measurements were performed by means of an AMVn instrument (Anton Paar, 1569). It is a falling/rolling sphere viscometer. Each data point is measured twice at positive and negative angle. Two glass capillaries with different diameters $(1.6 \mathrm{~mm}$, $1.8 \mathrm{~mm}$ ) were used to cover a viscosity range of about $0.3-20 \mathrm{mPa} \cdot \mathrm{s}$. The equipment is calibrated by means of viscosity standards (water, N10, S60, S600, Sigma Aldrich) for a temperature range of $10-80^{\circ} \mathrm{C}$ at a constant angle of $20^{\circ}$.

Density values were taken from literature in case of pure substances and measured, as described in chapter 4.7, for solutions. Recording and evaluation of the data were carried out by the viscometer software Rheoplus. 



\section{Termination Kinetics of Polymerization of Methacrylate Monomers}

In this chapter, the kinetics of chain-length dependent termination (CLDT) of dodecyl methacrylate (DMA) and 2-ethylhexyl methacrylate (EHMA) is investigated via the SP-PLP-EPR technique. CLDT is well described by the composite model with the associated $k_{\mathrm{t}}{ }^{1,1}$ value and the model parameters $\alpha_{\mathrm{s}}, \alpha_{1}$ and $i_{\mathrm{c}}$ (cf. chapter 3.2.2). ${ }^{41}$ The main focus is on the temperature dependence of these parameters. Using DMA and EHMA for the investigations into CLDT has some advantages:

Due to the long alkyl side chain, both monomers are less polar than MMA, which increases the signal-to-noise quality of the recorded EPR spectra because polarity unfavorably affects the sensitivity of EPR spectroscopy.

Furthermore, DMA and EHMA have a relatively low $k_{\mathrm{t}}$ and high $k_{\mathrm{p}}$. Therefore, the radical concentration is relatively high which further enhances the signal quality, especially for investigations into the long-chain regime.

The better quality of EPR spectra permits determination of CLDT parameters in a wide range of temperature. In addition, due to the $\alpha$-methyl group, the rotation around the $\quad \mathrm{C}-$ $\mathrm{C}$ backbone is hindered which may result in a higher activation energy for chain flexibility. This stronger temperature dependence should be reflected in $i_{\mathrm{c}}$.

\subsection{Splitting Pattern of Methacrylates}

The EPR spectra of methacrylates may be distinguished by a characteristic splitting pattern whose distinctiveness mainly results from interactions of the unpaired electron with the hydrogen atoms and the presence of different conformers. Figure 5.1 shows the spectrum of the radical in 2-ethylhexyl methacrylate bulk polymerization. It consists of 13 lines, 5 lines at an identical distance of ca. $22 \mathrm{G}$ (marked with an asterisk) and 8 inner 
lines within these field ranges. This shape is typical of many methacrylate (chain-end) radicals (DMA, methyl/butyl methacrylate). ${ }^{22,29,67}$

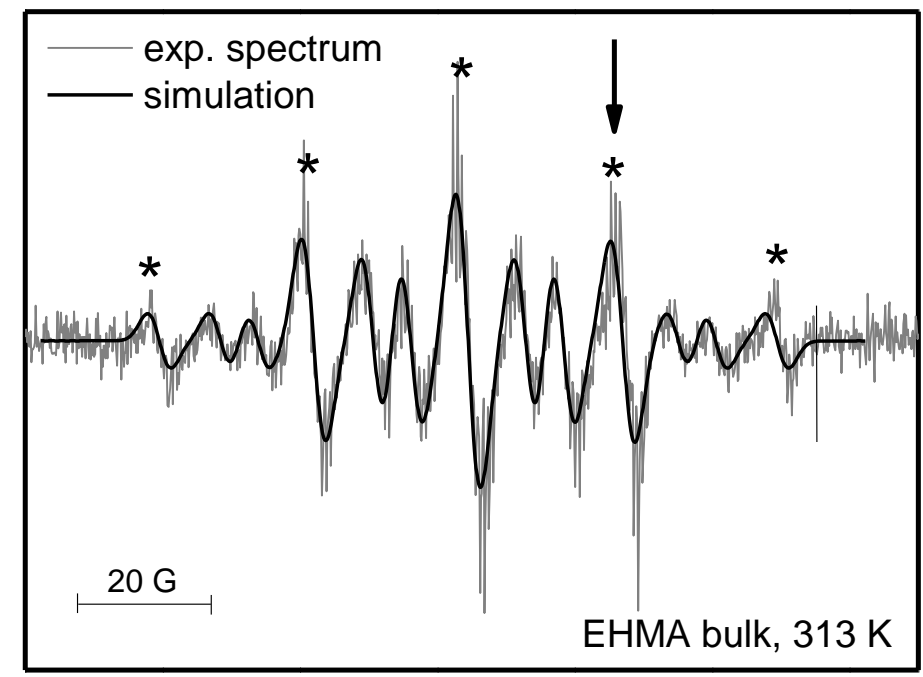

Figure 5.1. Characteristic 13-line EPR spectrum of propagating radical in EHMA polymerization at $313 \mathrm{~K}$ recorded with a modulation amplitude of $3 \mathrm{G}$, a scan time of $10 \mathrm{~s}$ and under pseudostationary conditions by continuous laser initiation at a p.r.r. of $20 \mathrm{~Hz}$. The black line represents the best fit by simulation with hyperfine coupling constants of $22.2,14.4$ and $9.7 \mathrm{G}$, respectively.

The spectrum may be adequately simulated by the WINEPR software (Bruker) as depicted by the bolt black line in Figure 5.1. The coupling constants are $22.2 \mathrm{G}$ for the three equivalent methyl hydrogen atoms, and $14.4 \mathrm{G}$ and $9.7 \mathrm{G}$ for the two non-equivalent methylene hydrogen atoms. These values are very similar to reported constants in literature, but may vary slightly for different monomers. ${ }^{68}$

The intensities and widths of the inner 8 lines are strongly temperature dependent. With increasing temperature, the signals decrease and become broader as expressed by Figure 5.2. Simulations at these conditions based on only one conformation provide inadequate agreement with the recorded spectra. Due to hindrance of the rotation around the $\mathrm{C}_{\alpha}-\mathrm{C}_{\beta}$ 
backbone axis, two conformations with different coupling constants of the methylene hydrogen atoms coexist and contribute to the overall EPR spectrum.

These observations were also made for systems in which internal rotation is significantly hindered, i.e. for monomers with sterically demanding side groups like tert-butyl methacrylate or at high monomer-to-polymer conversion. ${ }^{22,68,69}$

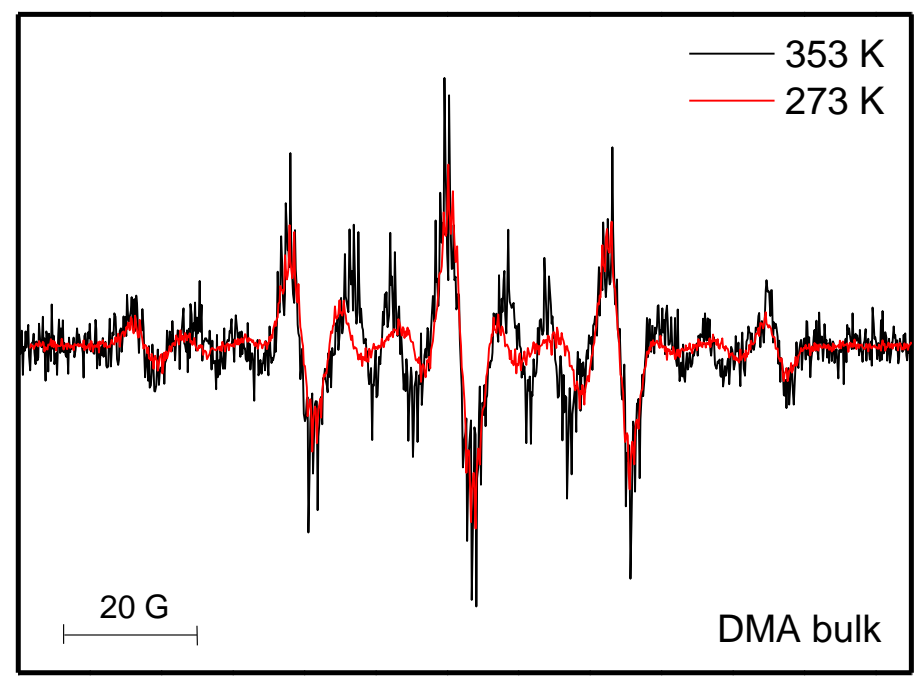

Figure 5.2. Temperature dependence of the splitting pattern of dodecyl methacrylate radicals. EPR spectra were recorded at 273 (red line) and $353 \mathrm{~K}$ (black line) with a modulation amplitude of $3 \mathrm{G}$ and under continuous laser irradiation at a p.r.r. of $20 \mathrm{~Hz}$.

\subsection{Measurement of Chain-length Dependent Termination}

As shown in chapter 4.3.3, a better signal-to-noise ratio of EPR spectra is obtained at lower temperature for all systems. In general, the temperature range of investigation is limited by the melting and boiling points of the sample. To determine the temperature dependence of the composite-model parameters, DMA and EHMA bulk polymerizations were investigated in the temperature range $273-373 \mathrm{~K}$ and $233-333 \mathrm{~K}$, respectively. 
The overall monomer-to-polymer conversion for both systems during the experiment was below $10 \%$ as checked by FT-VIS/NIR spectroscopy. The monomer concentration is assumed to be constant. Data of $k_{\mathrm{p}}$ are taken from literature. ${ }^{66}$

Single laser pulse experiments were carried out at constant magnetic field. No interference of signals from the initiator fragment and the propagating radicals were observed due to a very fast initiation and first propagation step. In order to minimize uncertainties resulting from a potential overlap with the EPR spectrum of initiator fragments, the second highest line (indicate by an arrow in Figure 5.1) was used for the time-resolved measurements. MMMP was chosen as the photoinitiator at concentrations of $0.02 \mathrm{~mol} \cdot \mathrm{L}^{-1}$ which led to an initial radical concentration of about $1 \cdot 10^{-5} \mathrm{~mol} \cdot \mathrm{L}^{-1}$. Further increase in signal quality of the $c_{\mathrm{R}}(t)$ trace was achieved by co-adding up to 40 single scans.

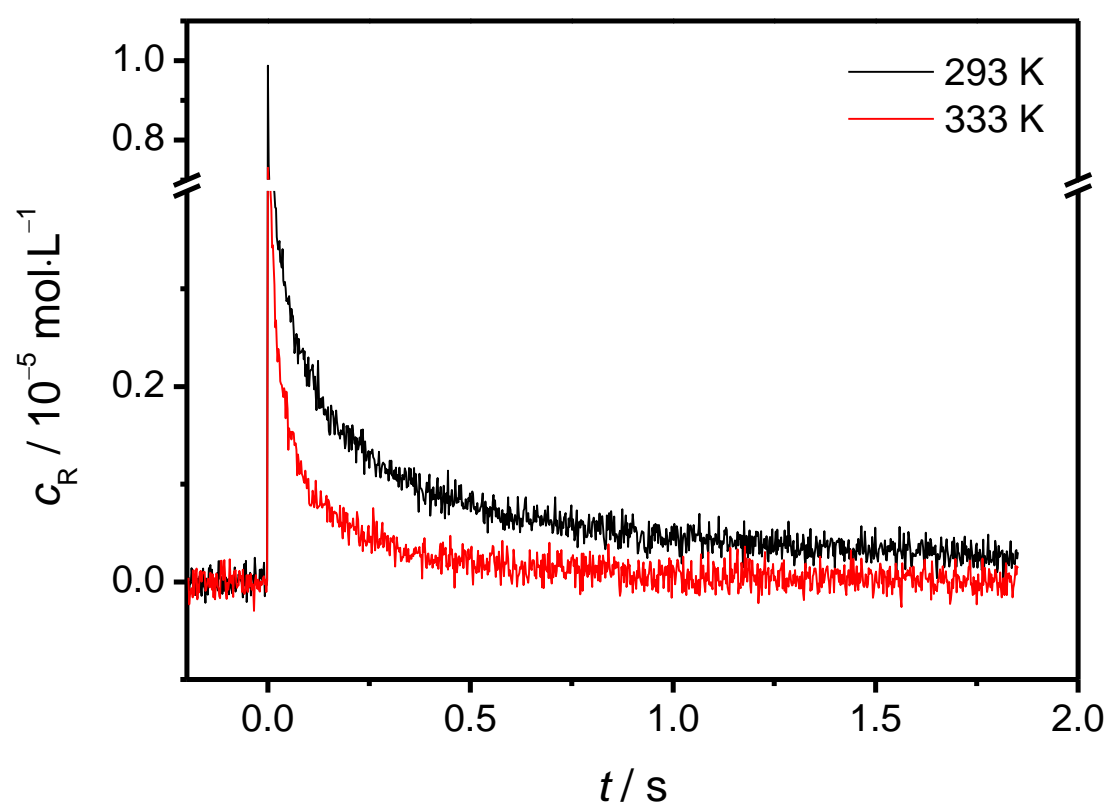

Figure 5.3. Time-resolved EPR spectra of DMA radicals recorded at a constant magnetic field at $273 \mathrm{~K}$ (black line) and $333 \mathrm{~K}$ (red line). Initiation by a single laser pulse occured at $t=0$. Because of an increased termination rate at higher temperatures the decay in radical concentration is faster. 
Figure 5.3 illustrates a typical time-resolved EPR signal, which shows the decay in radical concentration after single laser pulse initiation at two temperatures. Due to an enhanced termination at $333 \mathrm{~K}$, the decay is faster (red line) as compared to $273 \mathrm{~K}$. From the $\mathrm{SP}-$ PLP-EPR-deduced $c_{\mathrm{R}}(t)$ traces composite-model parameters are investigated by a twostep analysis.

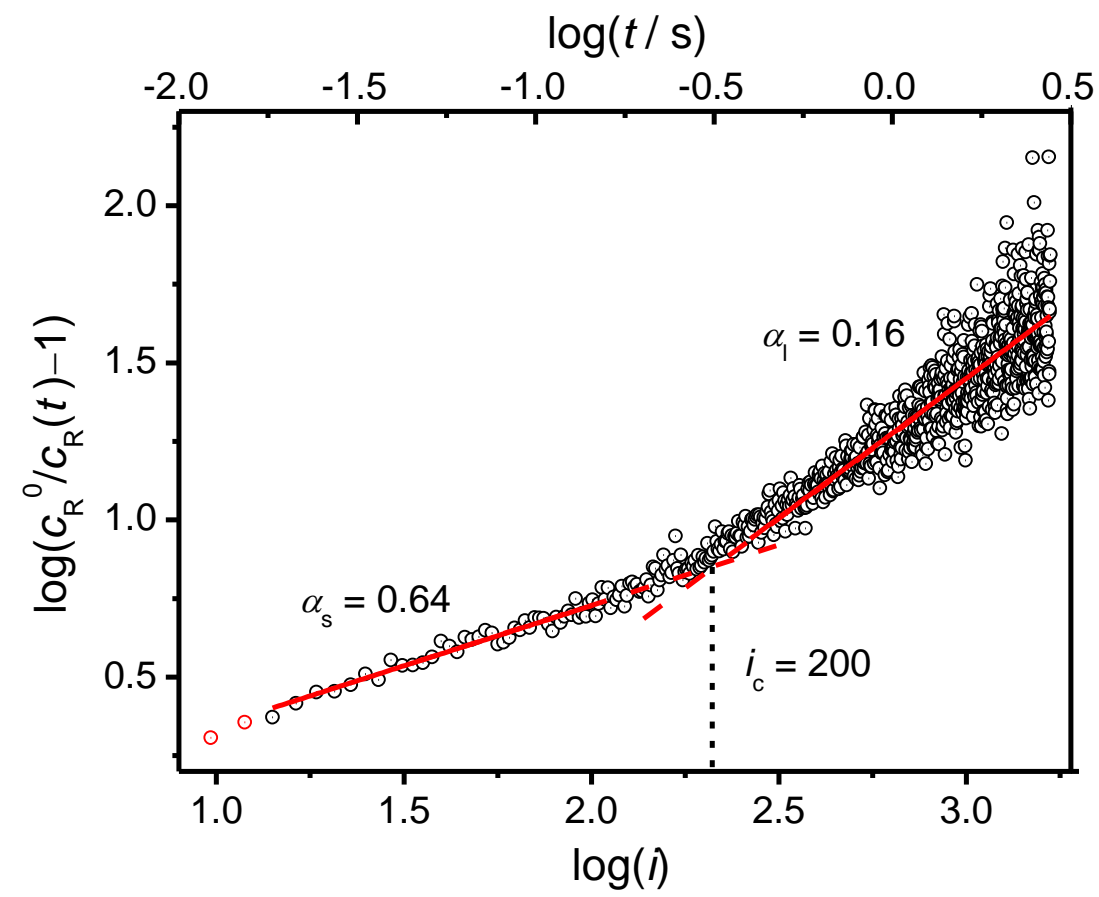

Figure 5.4. Double-log plot of $\left(c_{\mathrm{R}}^{0} / c_{\mathrm{R}}-1\right)$ vs. $t$ for EPR data from single pulse experiments for DMA at $273 \mathrm{~K}$. Analysis of the long-chain regime yields $\alpha_{1}$. The crossover chain length $i_{\mathrm{c}}$ is obtained from the intersection of the two straight line fits for low and high $t$.

First, the power-law exponent $\alpha_{1}$ and the crossover chain length $i_{\mathrm{c}}$ are determined from a double-log plot of $c_{\mathrm{R}}{ }^{0} / c_{\mathrm{R}}-1$ vs. $t$ (Figure 5.4). According to the composite model and as expressed by eqs. 3.17 and 3.18, two regimes are present, one of shorter and one of longer radicals. Two independent linear fits are applied yielding $1-\alpha_{\mathrm{s}}$ and $1-\alpha_{1}$ from the slopes (see chapter 3.3). As the double-log approach yields an inaccurate description for very short chains, the first data points are excluded from the fit (data points in red in Figure 5.4). 
The intersection of both fits yields the crossover chain length $i_{\mathrm{c}}$ which is found from the crossover time $t_{\mathrm{c}}$ and the propagating rate coefficient $k_{\mathrm{p}}$. By means of the propagation rate coefficient and monomer concentration, the kinetic chain length at the crossover point is calculated. Since the transition point between the regimes is not sharp, this crossover regime is excluded from the fitting (dashed lines in Figure 5.4). The results and discussion of $i_{\mathrm{c}}$ are presented in chapter 5.2.4

\subsubsection{Absolute Values for the Exponent $\alpha_{1}$}

Figure 5.5-A illustrates the measured $\alpha_{1}$ exponents of DMA (red triangle) and EHMA (blue squares) bulk polymerization for different temperatures. For both DMA and EHMA the data show no significant dependence on temperature and differ only slightly. This finding is in agreement with reported data. ${ }^{22,29,69}$ The mean values are $\alpha_{1}(\mathrm{DMA})=(0.17 \pm 0.04)$ and $\alpha_{1}($ EHMA $)=(0.19 \pm 0.05)($ Figure $5.5-B)$. In case of DMA, $\alpha_{1}$ is in full agreement with the reported exponent of $\alpha_{1}=0.18$ for $273 \mathrm{~K} .{ }^{22}$

Shown in Figure 5.5-B are the mean values of $\alpha_{1}$ averaged over the experimental temperature range for various methacrylate monomers. ${ }^{22,29,67}$ No dependence on the size and structure of the ester side chain may be found within the methacrylate family. 

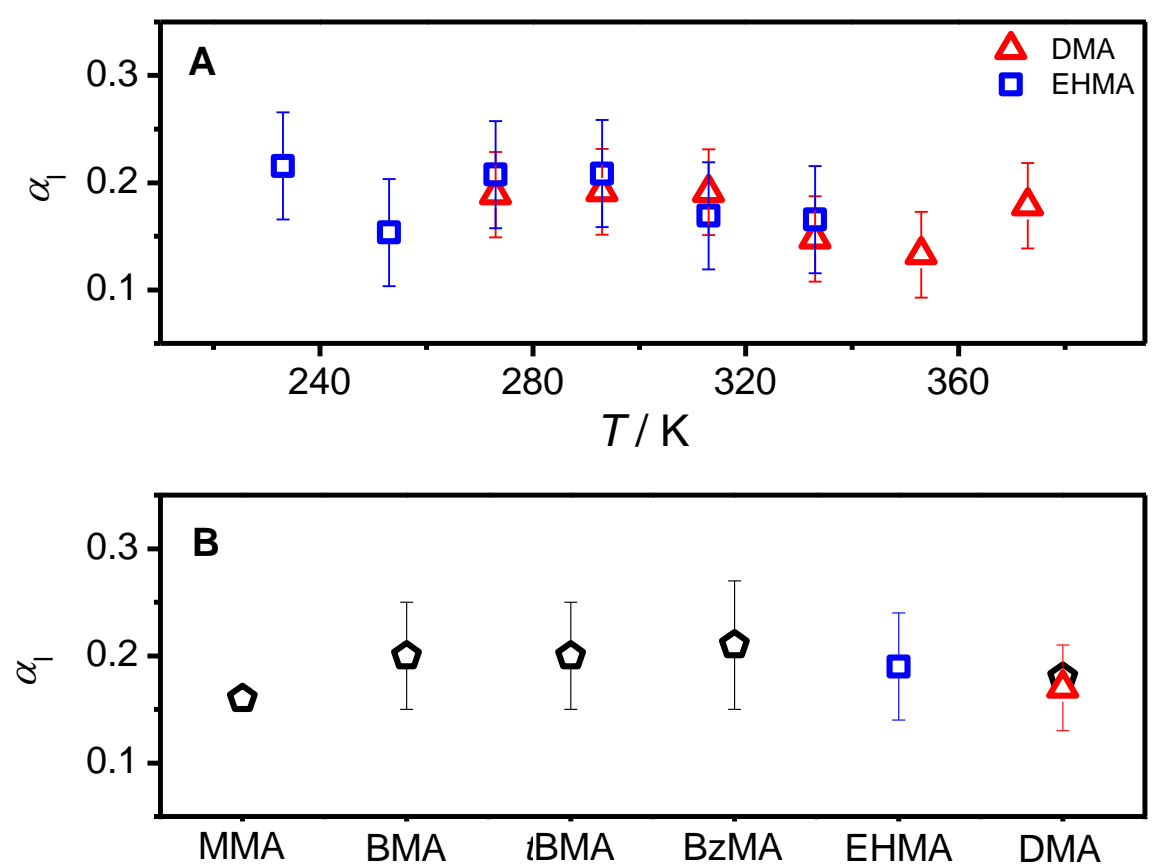

Figure 5.5. A: Power-law exponents $\alpha_{1}$ for long-chain radicals between 233 and $373 \mathrm{~K}$ of DMA (red triangle) and EHMA (blue square). The exponent $\alpha_{1}$ is obtained from a double-log plot according to eq. 3.25. B: Temperatureaveraged values of $\alpha_{1}=0.17$ for DMA (red) and $\alpha_{1}=0.19$ for EHMA (blue). The literature data is illustrated in black..$^{22,29,67}$

Long-chain exponents for methacrylate monomers as well as for acrylates are listed in Table 5.1 (chapter 5.2.2). Although the monomers differ in structure and by several orders of magnitude in termination rate coefficient, the power-law exponent for long chains is in all cases quite similar with an average value of about 0.18 . No systematic effect of the size of the alkyl group is observed.

For the termination of two chain-end radicals theory predicts a power-law exponent for the long chain regime of 0.16 , whereas for the reaction of chain-end/mid-chain and midchain/mid-chain radicals the value increases to 0.27 and 0.43 , respectively. ${ }^{70}$ The prediction for the termination of two chain-end radicals is in good agreement with the average value for methacrylates of $\alpha_{1}=0.18$. 


\subsubsection{Absolute Values for Exponent $\alpha_{\mathrm{s}}$}

As mentioned in chapter 3.3, the double-log approach does not adequately represent termination kinetics at short chain lengths. Hence, power-law exponents $\alpha_{\mathrm{s}}$ and termination rate coefficients $k_{\mathrm{t}}^{1,1}$ are determined by means of eq. 3.28 which represents an adequate expression for very small chain lengths.

In the second step, the measured EPR $c_{\mathrm{R}}(t)$ traces are plotted as $c_{\mathrm{R}}{ } / c_{\mathrm{R}}-1$ vs. $t$. By leastsquares fitting of the data for $i<i_{\mathrm{c}}, \alpha_{\mathrm{s}}$ and the coupled parameter $c_{\mathrm{R}}{ }^{0} k_{\mathrm{t}}^{1,1}$ are obtained. From calibration with TEMPO, as described in chapter 4.3.3, the initial radical concentration $c_{\mathrm{R}}{ }^{0}$ is accessible and thus $k_{\mathrm{t}}^{1,1}$ values are obtained.

Figure 5.6 represents a typical least-squares fit of an EPR trace for EHMA polymerization at $253 \mathrm{~K}$. Data points were fitted up to $i_{\mathrm{c}}$ at about $0.4 \mathrm{~s}$ yielding an exponent of $\alpha_{\mathrm{s}}=0.63$ and a termination rate coefficient of $k_{\mathrm{t}}^{1,1}=1.0 \cdot 10^{7} \mathrm{~L} \cdot \mathrm{mol}^{-1} \cdot \mathrm{s}^{-1}$. In addition, the sensitivity of the analysis is demonstrated by plotting curves for constant $k_{\mathrm{t}}^{1,1}$ upon variation of $\alpha_{\mathrm{s}}$.

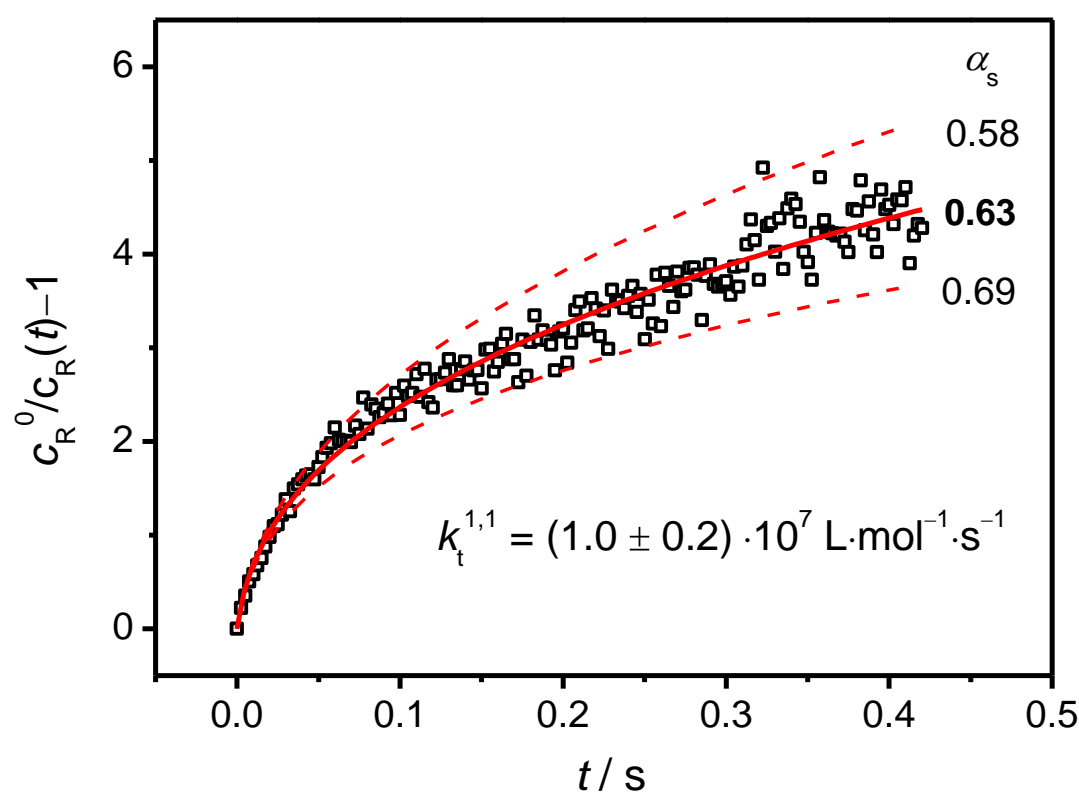

Figure 5.6. Least-squares fit of $\left(c_{\mathrm{R}}{ }^{0} c_{\mathrm{R}}-1\right)$ vs. $t$ for SP-PLP-EPR data of EHMA at $273 \mathrm{~K}$ to determine $\alpha_{\mathrm{s}}$ and $k_{\mathrm{t}}^{1,1}$ according to eq. 3.28. The solid line represents the best fit with $\alpha_{\mathrm{s}}=0.63$ and $k_{\mathrm{t}}{ }^{1,1}=1.0 \cdot 10^{7} \mathrm{~L} \cdot \mathrm{mol}^{-1} \cdot \mathrm{s}^{-1}$. Dashed lines constructed for constant $k_{\mathrm{t}}^{1,1}$ may be considered as lower and upper bounds of $\alpha_{\mathrm{s}}$. 
Shown in Figure 5.7-A are the individually measured values of $\alpha_{\mathrm{s}}$ determined for DMA (red triangle) and for EHMA (blue square) bulk polymerization. Neither in DMA nor in EHMA bulk polymerization, the power-law exponent of the short-chain regime showed any temperature dependency. This observation agrees with the findings for other monomers, i.e., for MMA or for $t$-BMA, which were also investigated in a wide temperature range. ${ }^{29,67}$
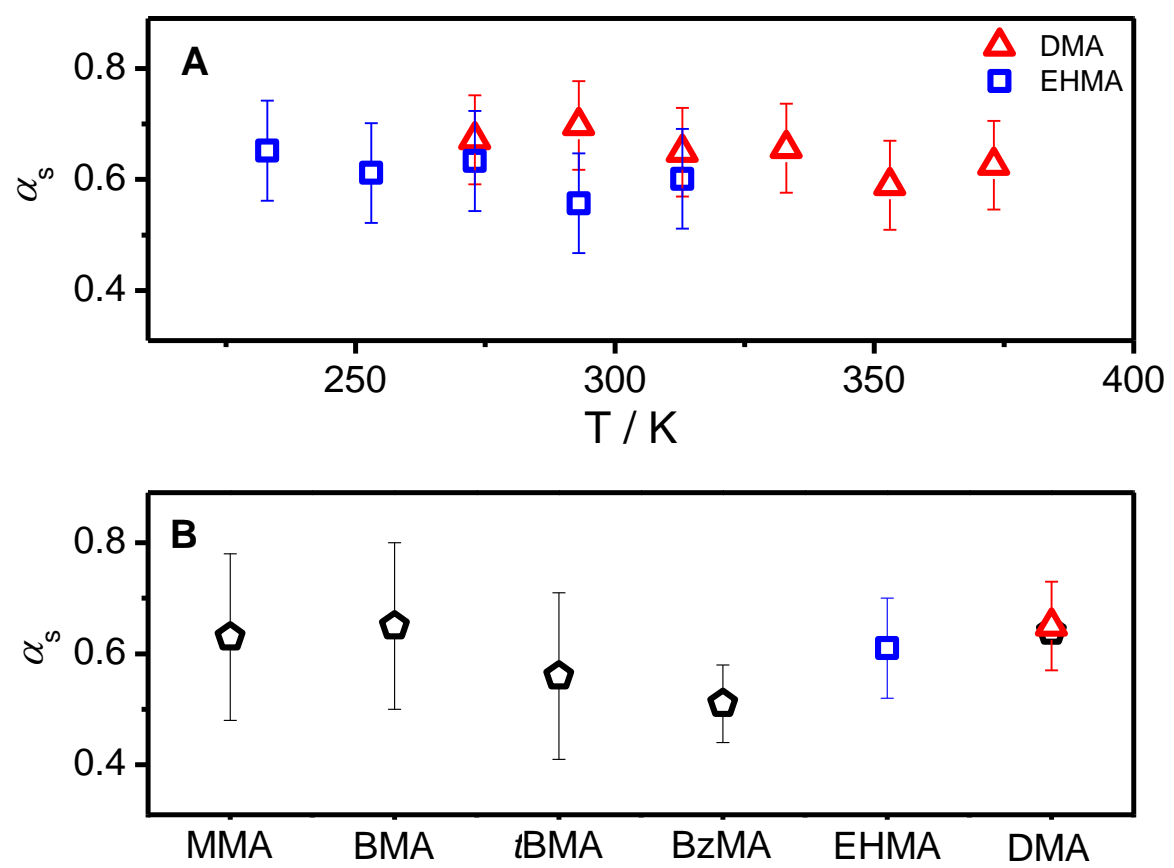

Figure 5.7. A: Individual values of power-law exponents $\alpha_{\mathrm{s}}$ for short-chain radicals between 233 and $373 \mathrm{~K}$ of DMA (red triangle) and EHMA (blue square). The exponent $\alpha_{\mathrm{s}}$ results from a least-squares fit according to eq. 3.28. B: Temperature-averaged values of $\alpha_{\mathrm{s}}=0.65$ for DMA (red) and $\alpha_{\mathrm{s}}=0.61$ for EHMA (blue). The literature data is illustrated in black. ${ }^{22,67,71}$

The arithmetic mean values for both systems are $\alpha_{\mathrm{s}}=(0.65 \pm 0.08)$ in case of DMA and $\alpha_{\mathrm{s}}=(0.61 \pm 0.09)$ for EHMA. In a previous study into DMA, $\alpha_{\mathrm{s}}$ was determined for $273 \mathrm{~K}$ to be $0.64 .^{22}$ This is in perfect agreement with the result presented here.

In the group of methacrylates bearing a linear side chain, no effect of the size of the alkyl chain on $\alpha_{\mathrm{s}}$ is observed. In case of branched ester side groups, the $\alpha_{\mathrm{s}}$ values are slightly 
reduced, as shown for tert-butyl or benzyl in Figure 5.7-B. By contrast, $\alpha_{\mathrm{s}}$ in acrylate polymerization is higher, of the order of 0.8 . The exponents for short and long-chain radicals as well as the investigated temperature range are summarized in Table 5.1.

Table 5.1. Power-law exponents $\alpha_{\mathrm{s}}$ and $\alpha_{1}$ determined via SP-PLP-EPR for bulk homopolymerizations of different types of monomers, unless otherwise indicated. $(\mathrm{BA}=$ butyl acrylate; DA = dodecyl acrylate)

\begin{tabular}{ccccc}
\hline monomer & $\alpha_{\mathrm{s}}$ & $\alpha_{\mathrm{l}}$ & $\boldsymbol{T} / \mathbf{K}$ & ref. \\
\hline DMA & $0.65 \pm 0.08$ & $0.17 \pm 0.04$ & $273-373$ & this work \\
DMA & 0.64 & 0.18 & 273 & 22 \\
BMA & $0.65 \pm 0.15$ & $0.20 \pm 0.05$ & $243-333$ & 29 \\
MMA & $0.63 \pm 0.15$ & $0.15^{a}$ & $283-323$ & 67,72 \\
\hline EHMA & $0.61 \pm 0.09$ & $0.19 \pm 0.05$ & $233-353$ & this work \\
$t$-BMA & $0.56 \pm 0.15$ & $0.20 \pm 0.05$ & $243-333$ & 29 \\
BzMA & $0.51 \pm 0.07$ & $0.21 \pm 0.06$ & 273 & 22 \\
\hline BA & $0.71 \pm 0.15$ & $0.26 \pm 0.07$ & 233 & 28 \\
DA & $0.87 \pm 0.15^{b}$ & $0.19 \pm 0.07^{b}$ & 233 & 73 \\
\hline
\end{tabular}

${ }^{a}$ only for $353 \mathrm{~K}$ and from RAFT-CLD-T; ${ }^{b} 1.5 \mathrm{M}$ in toluene

Diffusion-controlled termination rate coefficients are well described by the Smoluchowski equation (eq. 3.16) which depends on the capture radius $R_{\mathrm{c}}$ and the diffusion coefficient $D^{i}$. From quenching experiments on polystyrene it was deduced that $R_{\mathrm{c}}$ is almost independent of the degree of polymerization in the short-chain regime. ${ }^{74}$ Therefore, the chain-length dependence of the termination rate coefficient $k_{\mathrm{t}}^{i, i}$ is induced by $D^{i}$.

From theory $\alpha_{\mathrm{s}}$ is related to the decrease of the radical center-of-mass diffusion coefficient $D^{i}$. In dilute solution, the exponent $\alpha_{\mathrm{s}}$ is predicted to be 0.5 for random coils. If the excluded volume is considered, $\alpha_{\mathrm{s}}$ increases to $0.6{ }^{75}$ For rod-like chains an exponent even of 1.0 is proposed. ${ }^{76}$ 
Experimental investigations on chain-length dependent diffusion coefficients were performed by pulsed-field-gradient NMR. For MMA and BMA oligomers an exponent of 0.66 was determined, which demonstrates the validity of $D^{i} \sim i^{-\alpha_{\mathrm{s}} .}{ }^{77}$

\subsubsection{Termination Rate Coefficients}

Termination rate coefficients $k_{\mathrm{t}}^{1,1}$ are deduced from the coupled $c_{\mathrm{R}}{ }^{0} \cdot k_{\mathrm{t}}{ }^{1,1}$ parameter of the least-squares fit to eq. 3.28 by calibration with TEMPO dissolved in the respective monomer as described in chapter 4.3.3. The initial radical concentration is obtained from the peak maximum at $t=0$ directly after firing the laser pulse.

For DMA polymerization, values of $k_{\mathrm{t}}{ }^{1,1}$ vary between $(1.2 \pm 0.2) \cdot 10^{7} \mathrm{~L} \cdot \mathrm{mol}^{-1} \cdot \mathrm{s}^{-1}$ for $273 \mathrm{~K}$, which is in close agreement with literature value of $k_{\mathrm{t}}{ }^{1,1}=1.1 \cdot 10^{7} \mathrm{~L} \cdot \mathrm{mol}^{-1} \cdot \mathrm{s}^{-1}$, and $(1.3 \pm 0.3) \cdot 10^{8} \mathrm{~L} \cdot \mathrm{mol}^{-1} \cdot \mathrm{s}^{-1}$ for $373 \mathrm{~K}$. The dependency is well described by the following Arrhenius relation.

$$
\ln \left(k_{\mathrm{t}}^{1,1} / \mathrm{L} \cdot \mathrm{mol}^{-1} \cdot \mathrm{S}^{-1}\right)=25.09-2391 \cdot\left(T^{-1} / \mathrm{K}^{-1}\right)
$$

Since termination is a diffusion-controlled process, $k_{\mathrm{t}}{ }^{1,1}$ should be inversely proportional to solution viscosity according to the Smoluchowski and Stokes-Einstein relations. Therefore, activation energies of $k_{\mathrm{t}}^{1,1}$ and of the fluidity (inverse viscosity) are expected to be similar. Figure 5.8 illustrates the temperature dependence of both quantities. The slopes of linear fits corresponding to the associated activation energies are in satisfactory agreement: $E_{\mathrm{A}}\left(k_{\mathrm{t}}{ }^{1,1}\right)=(20 \pm 2) \mathrm{kJ} \cdot \mathrm{mol}^{-1}$ and $E_{\mathrm{A}}\left(\eta^{-1}\right)=(18.5 \pm 0.5) \mathrm{kJ} \cdot \mathrm{mol}^{-1}$. The viscosity of bulk DMA was determined from independent measurements performed between 283 and $333 \mathrm{~K}$. The close correlation of $E_{\mathrm{A}}\left(k_{\mathrm{t}}{ }^{1,1}\right)$ and $E_{\mathrm{A}}\left(\eta^{-1}\right)$ was also observed for other methacrylate monomers as well as for other monomer families e.g. acrylates, vinyl esters and styrene. ${ }^{28,29,67,25,26}$ 


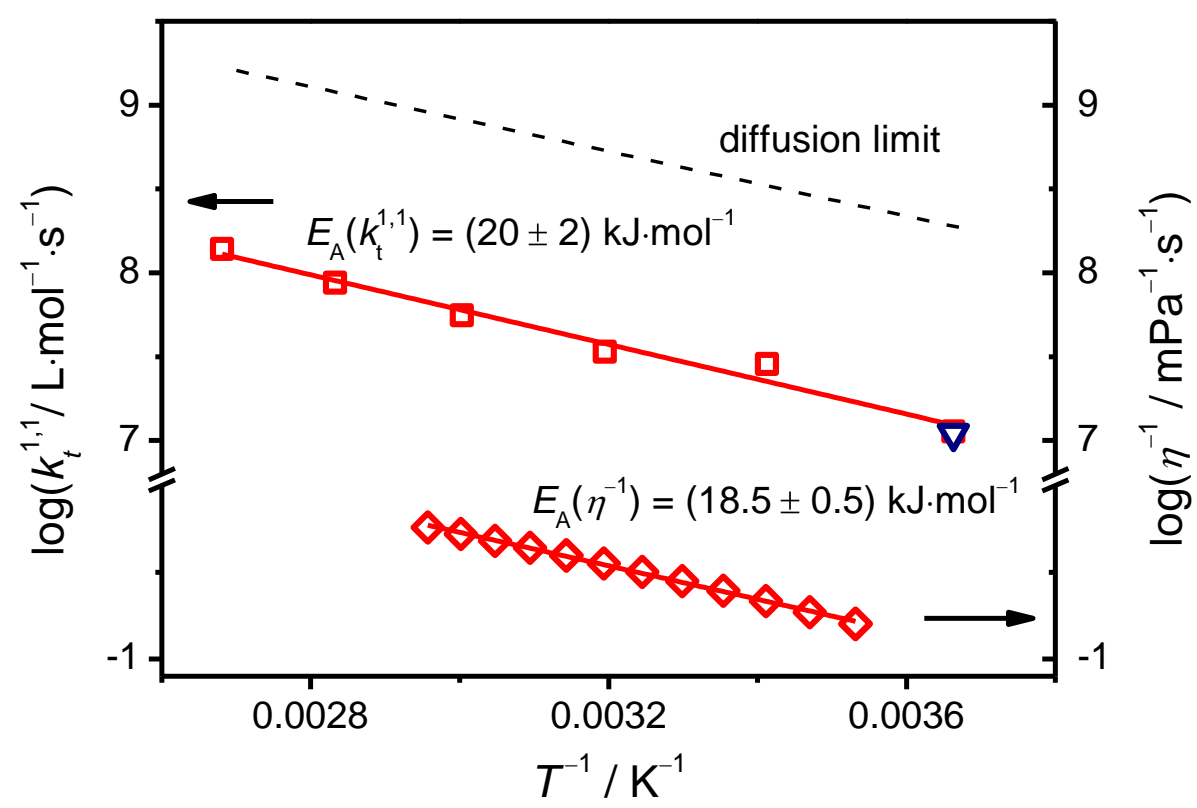

Figure 5.8. Arrhenius plot of the rate coefficient for termination of monomeric radicals $k_{\mathrm{t}}^{1,1}$ and of fluidity $\eta^{-1}$ in DMA bulk polymerization. Data of $k_{\mathrm{t}}{ }^{1,1}$ were obtained by fitting the radical concentration traces from SP-PLP-EPR experiments to eq. 3.28. The full lines represent the Arrhenius fits to the $k_{\mathrm{t}}{ }^{1,1}$ and $\eta^{-1}$ data. The dashed line illustrates the diffusion limit. Literature data for $273 \mathrm{~K}$ is marked with a blue triangle. ${ }^{22}$

The rate coefficient for termination of two monomeric radicals in EHMA bulk polymerization was investigated between 233 and $313 \mathrm{~K}$. The $k_{\mathrm{t}}{ }^{1,1}$ value at $273 \mathrm{~K}$ is by about a factor of 2 above the one for DMA which is $k_{\mathrm{t}}^{1,1}(273 \mathrm{~K})=$ $(1.9 \pm 0.3) \cdot 10^{7} \mathrm{~L} \cdot \mathrm{mol}^{-1} \cdot \mathrm{s}^{-1}$. 


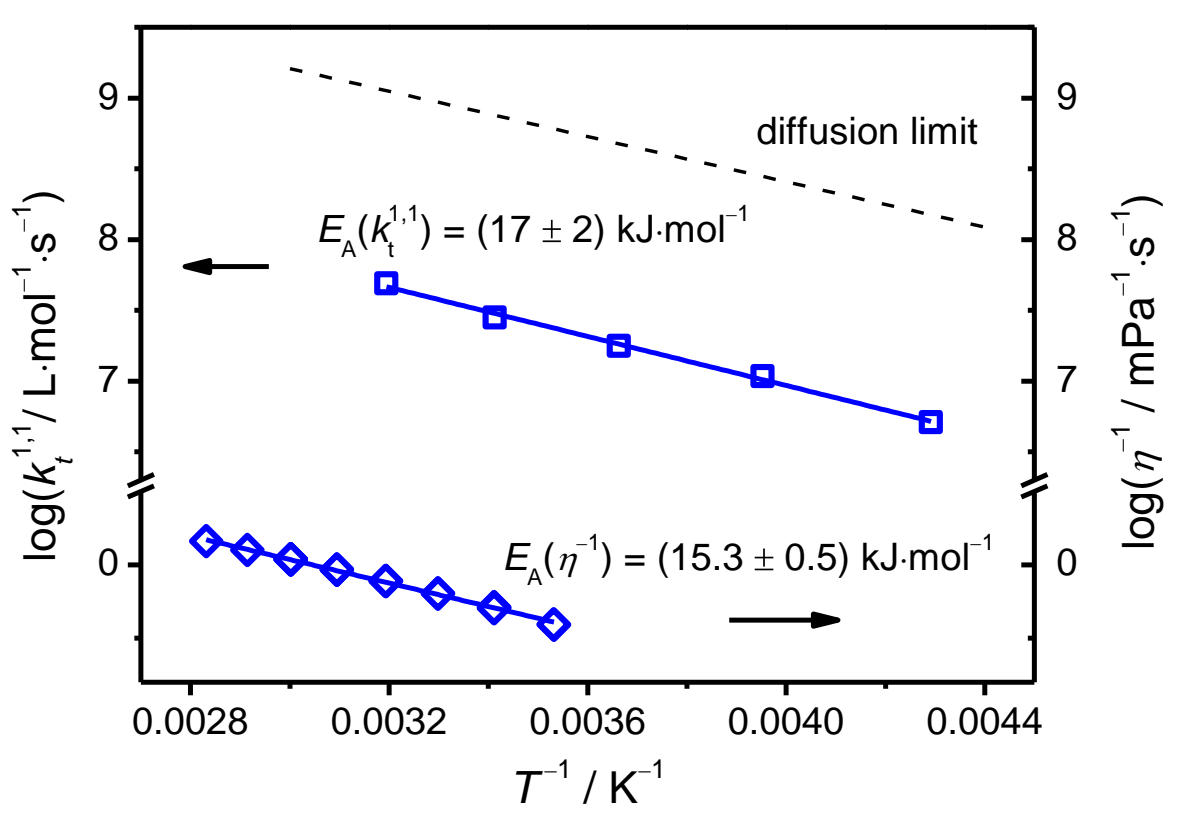

Figure 5.9. Arrhenius plot of the termination rate coefficient of two radicals of chain length unity, $k_{\mathrm{t}}{ }^{1,1}$, and of fluidity $\eta^{-1}$ in EHMA bulk polymerization. Data of $k_{\mathrm{t}}^{1,1}$ were obtained by fitting the radical concentration traces to eq. 3.28. The full lines represent the Arrhenius fits to the $k_{\mathrm{t}}{ }^{1,1}$ and $\eta^{-1}$ data. The dashed line illustrates the diffusion limit.

Figure 5.9 shows the temperature dependence of the termination rate coefficient, $k_{\mathrm{t}}{ }^{1,1}$, and of the fluidity of the monomer. Viscosity measurements were performed between 283 and $353 \mathrm{~K}$. The activation energy of $k_{\mathrm{t}}{ }^{1,1}$ with $E_{\mathrm{A}}=(17 \pm 2) \mathrm{kJ} \cdot \mathrm{mol}^{-1}$ is close to $E_{\mathrm{A}}\left(\eta^{-1}\right)=(15.3 \pm 0.5) \mathrm{kJ} \cdot \mathrm{mol}^{-1}$ and leads to the Arrhenius expression for EHMA:

$$
\ln \left(k_{\mathrm{t}}^{1,1} / \mathrm{L} \cdot \mathrm{mol}^{-1} \cdot \mathrm{S}^{-1}\right)=24.03-1997 \cdot\left(T^{-1} / \mathrm{K}^{-1}\right)
$$

The maximum value of $k_{\mathrm{t}}{ }^{1,1}$ is given by the so-called diffusion limit assuming the capture radius $R_{\mathrm{c}}$ to be two times the hydrodynamic radius $\left(R_{\mathrm{c}}=2 \cdot r_{i}\right)$. The monomer viscosities (see appendix) yield $k_{\mathrm{t}}^{1,1}{ }_{\max }(\mathrm{DMA})=1.8 \cdot 10^{8} \mathrm{~L} \cdot \mathrm{mol}^{-1} \cdot \mathrm{s}^{-1}$ and $k_{\mathrm{t}}{ }^{1,1}{ }_{\max }(\mathrm{EHMA})=$ $4.8 \cdot 10^{8} \mathrm{~L} \cdot \mathrm{mol}^{-1} \cdot \mathrm{s}^{-1}$ for $273 \mathrm{~K}$. These diffusion limiting values exceed the measured $k_{\mathrm{t}}{ }^{1,1}$ by almost one order of magnitude, which indicates that the capture radius is not given by size of the entire radical but by the reactive center of the radical $\left(R_{\mathrm{c}}<r_{i}\right)$ with a major part of 
the radical surface being non-reactive. The influence of hydrodynamic radius and shielding of the radical site may be expressed by the following relationship which is based on eqs. 3.12 and 3.16 .

$$
k_{\mathrm{t}}^{1,1} \cdot \eta \sim \frac{R_{\mathrm{c}}}{r_{i}}
$$

As the activation energy of $k_{\mathrm{t}}^{1,1}$ and of fluidity are close to each other, the product $k_{\mathrm{t}}{ }^{1,1} \cdot \eta$ should not be sensitive toward temperature. The individual values of $k_{\mathrm{t}}^{1,1} \cdot \eta$ for DMA and EHMA, calculated according to the data presented in Figure 5.8 and 5.9, differ from the extrapolated value (cf. Table 5.2) only by about $10 \%$ and exhibit no temperature dependence. Shown in Table 5.2 are the $k_{\mathrm{t}}^{1,1}$ values, bulk viscosities and the associated product $k_{\mathrm{t}}^{1,1} \cdot \eta$ for several monomers at $353 \mathrm{~K}$.

Table 5.2. Comparison of $k_{\mathrm{t}}^{1,1} \cdot \eta$ for bulk polymerization of several monomers. The activation energies required for extrapolation to $353 \mathrm{~K}$ were taken from the cited literature.

\begin{tabular}{|c|c|c|c|c|}
\hline monomer & $\begin{array}{c}\boldsymbol{k}_{\mathbf{t}}^{\mathbf{1 , 1}}(353 \mathrm{~K}) / \\
\left(\mathrm{L} \cdot \mathrm{mol}^{-1} \cdot \mathrm{s}^{-1}\right) \times 10^{8}\end{array}$ & $\begin{array}{l}\boldsymbol{\eta ( 3 5 3 ~ K )} \\
/(\mathrm{mPa} \cdot \mathrm{s})\end{array}$ & $\begin{array}{c}\boldsymbol{k}_{\mathbf{t}}^{\mathbf{1}, \mathbf{1}} \cdot \boldsymbol{\eta} \\
/\left(\mathrm{L} \cdot \mathrm{mPa} \cdot \mathrm{mol}^{-1}\right) \times 10^{8}\end{array}$ & ref \\
\hline MMA & $(11 \pm 3)$ & 0.34 & 3.7 & 67,78 \\
\hline MA & $(12 \pm 3)^{a}$ & $0.31^{b}$ & 3.7 & 73 \\
\hline VAc & $(15 \pm 3)$ & 0.24 & 3.6 & 26 \\
\hline $\mathrm{St}$ & $(8.3 \pm 0.5)$ & 0.39 & 3.2 & 25 \\
\hline BMA & $(3.6 \pm 0.7)$ & 0.43 & 1.5 & 29 \\
\hline VPi & $(4.1 \pm 0.5)$ & 0.33 & 1.4 & 26 \\
\hline$t$-BMA & $(3 \pm 1)$ & 0.45 & 1.3 & 29,79 \\
\hline DMA & $(0.88 \pm 0.15)$ & 1.29 & 1.1 & this work \\
\hline BzMA & $(1.1 \pm 0.2)^{c}$ & 0.89 & 0.9 & 22,80 \\
\hline EHMA & $(0.94 \pm 0.16)$ & 0.68 & 0.6 & this work \\
\hline
\end{tabular}


As is illustrated by the upper four entries in Table 5.2, almost the same value of $k_{\mathrm{t}}{ }^{1,1} \cdot \eta$ is obtained for styrene, vinyl acetate, and the "first" (methyl ester) members of the acrylate and methacrylate families. The close agreement of the four entries suggest that, with these small radicals, most of the diffusional encounters result in reaction. ${ }^{25}$

Toward larger size and thus larger unreactive surface of the radicals, $k_{\mathrm{t}}{ }^{1,1} \cdot \eta$ should decrease due to an enhancement of both hydrodynamic radius and shielding of the radical site. This is indeed what the entries for BMA and DMA suggest. It should however be noted that going from MMA to BMA reduces $k_{\mathrm{t}}^{1,1} \cdot \eta$ by more than a factor of 2 , whereas this product is lowered by only $25 \%$ in passing from BMA to DMA.

Interestingly, substitution of the linear butyl group by a more bulky tert-butyl side chain has only a small effect. On the other hand, the values of $k_{\mathrm{t}}^{1,1} \cdot \eta$ for BzMA and EHMA, which both bear an ester side group with a ternary substituted branching point at the second carbon atom, are lower than the value of DMA, which may indicate an even stronger shielding of the radical site.

\subsubsection{Crossover Chain Length $i_{\mathrm{c}}$}

The crossover chain lengths of DMA and EHMA were determined from a double-log plot of $c_{\mathrm{R}}{ }^{0} / c_{\mathrm{R}}-1$ vs. $t$ as the intersection point of both linear fits with the slopes being given by the power-law exponents. The major advantage of this analysis is that $i_{\mathrm{c}}$ values are direct accessible from the recorded data and no calibration of the spectrometer is required. The temperatures, at which $i_{\mathrm{c}}$ was evaluated, were 273 to $373 \mathrm{~K}$ for DMA and 233 to $333 \mathrm{~K}$ for EHMA.

Figure 5.10 illustrates the strong shift in crossover chain length for DMA polymerization. The transition from short-chain to long-chain regime at $273 \mathrm{~K}(\mathbf{A})$ is located at a time after the laser pulse which corresponds to a chain length of 220 . In contrast, at $373 \mathrm{~K}(\mathbf{B})$ an $i_{\mathrm{c}}$ value of 35 is determined. 

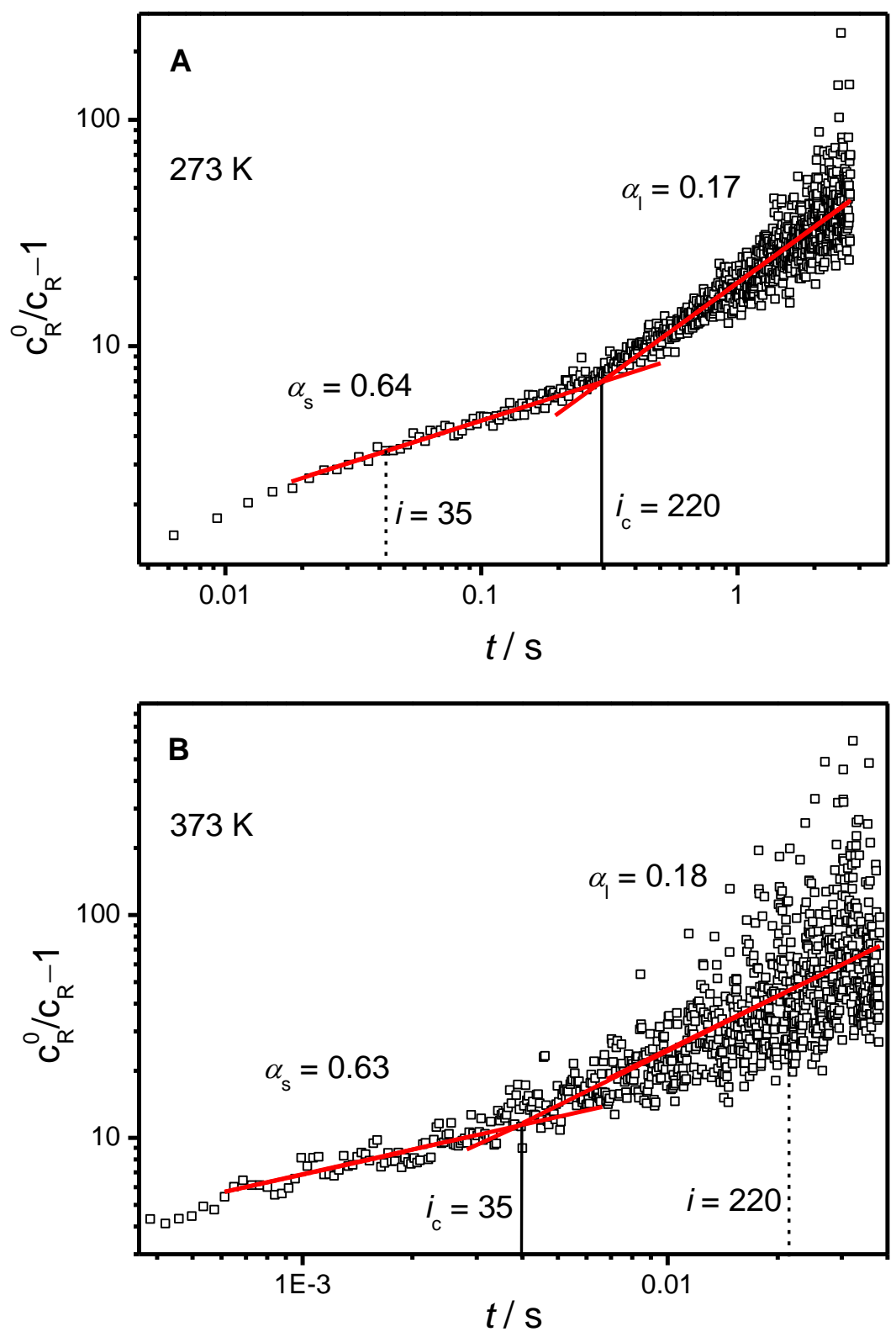

Figure 5.10. Double-log plots of $\left(c_{\mathrm{R}}^{0} / c_{\mathrm{R}}-1\right)$ vs. $t$ for DMA polymerization at 273 (A) and $373 \mathrm{~K}$ (B). Crossover chain lengths were determined from the intersection of the linear fits at short and long time. Both pictures illustrate the strong shift in $i_{\mathrm{c}}$ with temperature. 
Figure 5.11 shows the data for $i_{\mathrm{c}}$ in DMA (red) and EHMA (blue) bulk polymerization. Actually, the numbers are mean values from multiple determinations. The values of $i_{\mathrm{c}}$ for DMA and EHMA show a strong temperature effect. At low temperature, the crossover chain length is about $(220 \pm 30)$, whereas at high $T$ it drops significantly to $(35 \pm 15)$. Investigations into EHMA show a similar trend.

The strong temperature dependence of $i_{\mathrm{c}}$ is remarkable, because a temperature dependence of the crossover chain length was not observed so far. On the other hand, as $i_{\mathrm{c}}$ is assumed to depend on chain flexibility, one would expect that with increasing temperature the motion of chain segments is enhanced. This results in a better flexibility and $i_{\mathrm{c}}$ should be reduced.

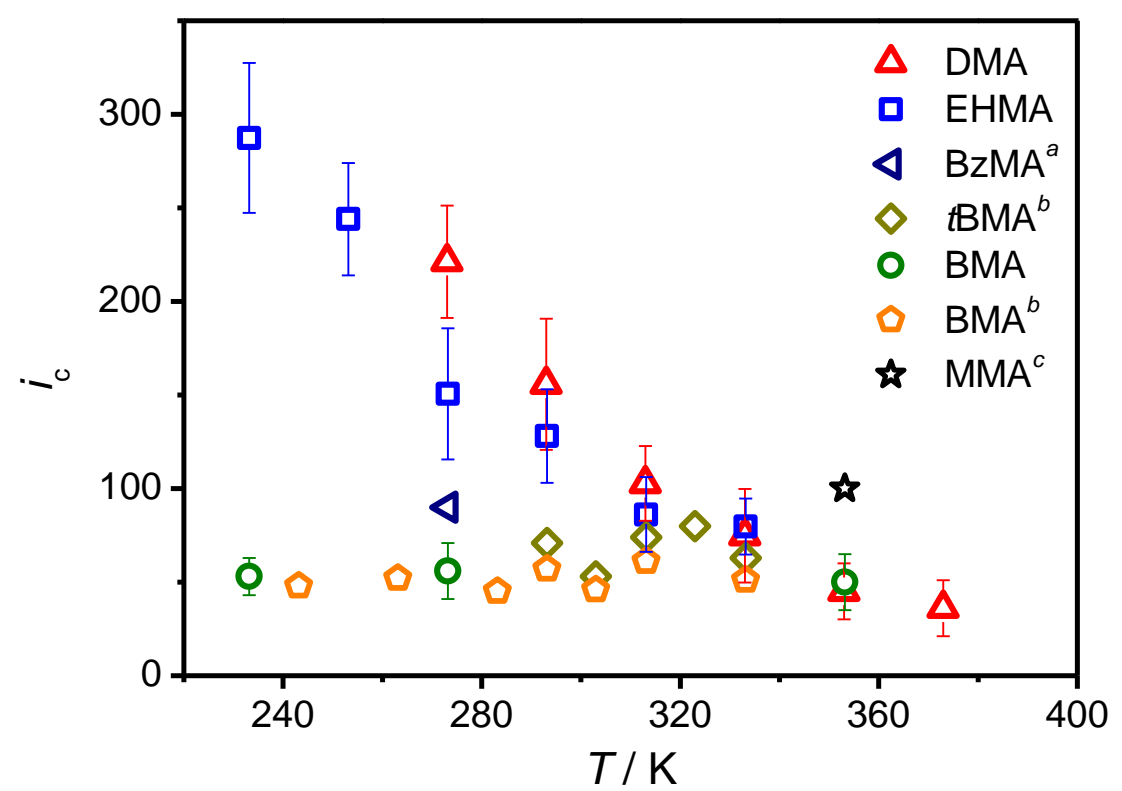

Figure 5.11. Crossover chain length $i_{\mathrm{c}}$ for methacrylate monomers as a function of temperature. The data were obtained from double-log plots of $\left(c_{\mathrm{R}}{ }^{0} / c_{\mathrm{R}}-1\right)$ vs. $t$ by the intersection of linear fits for short-chain and long-chain regime via SP-PLP-EPR, unless otherwise indicated. ${ }^{a}$ from ref..$^{22}{ }^{b}$ from ref. ${ }^{29}$; ${ }^{c}$ via RAFT-CLD-T from ref. ${ }^{72}$.

One might argue that the differences in $i_{\mathrm{c}}$ are caused by chain-length dependent propagation which would result in a lower $\alpha_{\mathrm{s}}$ value at high temperatures. However, this is 
indeed not the case as $\alpha_{\mathrm{s}}$ is temperature independent and in good agreement with the literature..$^{22}$

Additional to the measurements of DMA and EHMA, the crossover chain length of BMA (green) was determined to be 50, which is in good agreement with the reported values (orange). ${ }^{29}$ Since $i_{\mathrm{c}}$ of BMA shows no significant temperature dependence, the $\alpha$-methyl group at the double bond is no adequate explanation for the temperature effect.

However, the $i_{\mathrm{c}}$ values of methacrylates were mostly determined to be between 300 and 50 depending on monomer structure and temperature, whereas $i_{\mathrm{c}}$ values of acrylates were mostly below 50 even at $233 \mathrm{~K}^{73}$ Since $i_{\mathrm{c}}$ is related to chain flexibility, the missing $\alpha$-methyl group in case of acrylates may enhance segment mobility and reduce chain stiffness

Within the methacrylate family and at low temperatures, the crossover chain length is increasing towards larger size of the alkyl side chain. A larger alkyl chain enhances the steric hindrance to rotational motion and thus increases $i_{\mathrm{c}}$ (cf. Figure 5.11). According to this, $i_{\mathrm{c}}$ at $273 \mathrm{~K}$ was determined to be 50 for BMA, 90 and 160 for BzMA and EHMA, respectively, and reached a value of 220 for DMA. An increasing crossover chain length with larger alkyl side chain was also found for vinyl acetate and vinyl pivalate as well as for acrylates. ${ }^{73,26}$

On the other hand, it may be assumed that at high temperatures methacrylate-type monomers approach a lower limit of $i_{\mathrm{c}}$ below 100. In this case the motion of segments should be enhanced and restrictions due to steric demand be reduced. Moreover, the data at $353 \mathrm{~K}$ may suggest that long alkyl side chains solubilize the stiff methacrylate backbone structure and thus even lower $i_{\mathrm{c}}$. However, the differences of $i_{\mathrm{c}}$ for DMA and BMA at $353 \mathrm{~K}$ are within experimental accuracy.

Crossover chain length describes the transition between translational diffusion control of short chains and segmental diffusion control of long chains. A temperature dependence of $i_{\mathrm{c}}$ implies that the activation energies of termination rate coefficients for both regimes are different. This is illustrated in Figure 5.12. The termination rate coefficient $k_{\mathrm{t}}^{i, i}$ is calculated for 273 and $313 \mathrm{~K}$ with constant $\alpha_{\mathrm{s}}$ and $\alpha_{1}$ values. Extrapolation to chain length 
unity gives rate coefficients for termination of two hypothetical coiled $\left(k_{\mathrm{t}}{ }^{0}\right)$ and uncoiled chains $\left(k_{\mathrm{t}}{ }^{1,1}\right)$, respectively. The difference in activation energies is obvious from the different separation between both lines in the short-chain and long-chain regime.

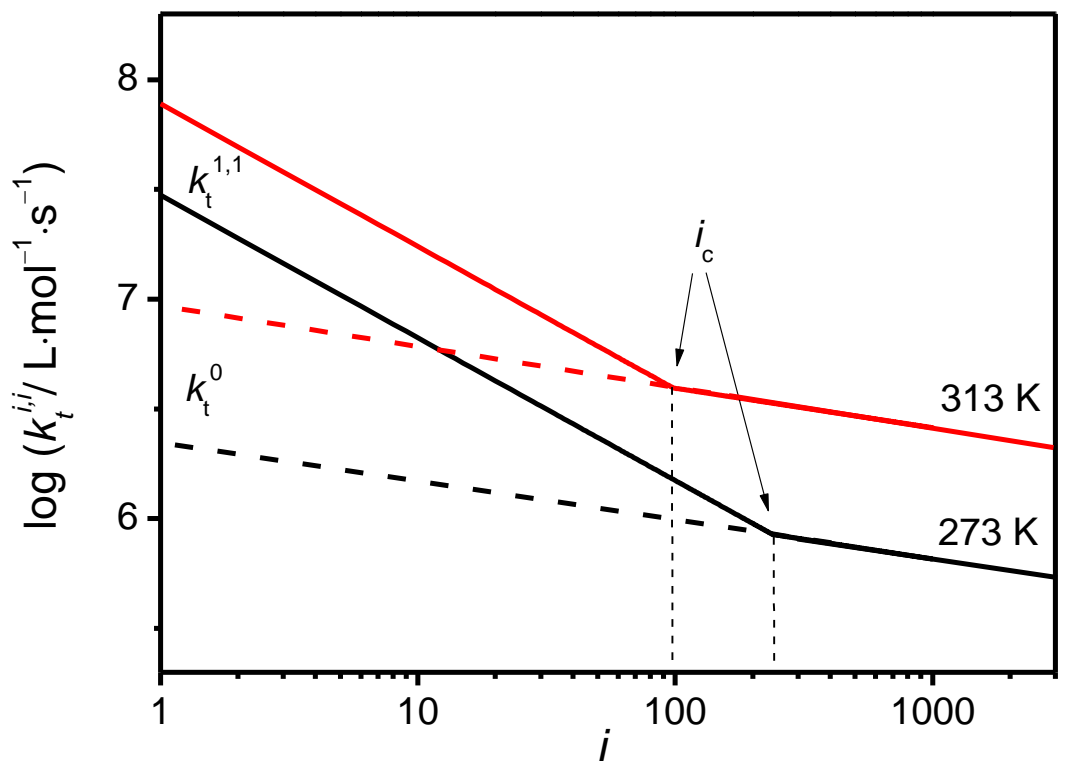

Figure 5.12. Calculated termination rate coefficient as a function of chain length $i$ for DMA at 273 and $313 \mathrm{~K} . k_{\mathrm{t}}^{1,1}$ values are taken from eq. 5.1 with $\alpha_{\mathrm{s}}=0.65$ and $\alpha_{1}=0.19$. Different crossover chain length of $i_{\mathrm{c}}(273 \mathrm{~K})=220$ and $i_{\mathrm{c}}(313 \mathrm{~K})=100$ were used. The dashed lines represent extrapolation of the long-chain regime to $i=1$ to obtain $k_{\mathrm{t}}{ }^{0}$.

The relation of $k_{\mathrm{t}}^{0}$ and $k_{\mathrm{t}}^{1,1}$ is deduced from eq. 3.19.

$$
k_{\mathrm{t}}^{0}=k_{\mathrm{t}}^{1,1} \cdot i_{\mathrm{c}}^{-\alpha_{\mathrm{s}}+\alpha_{1}}
$$

Eq. 5.5 arises from substitution of both coefficients by the Arrhenius equation. Hence the activation energy of $k_{\mathrm{t}}{ }^{0}$ can be estimated from a plot of $\ln \left(i_{\mathrm{c}}\right)$ vs. $T^{-1}$.

$$
\ln \left(i_{\mathrm{c}}\right)=\frac{E_{\mathrm{A}}\left(k_{\mathrm{t}}^{1,1}\right)-E_{\mathrm{A}}\left(k_{\mathrm{t}}^{0}\right)}{R \cdot T \cdot\left(-\alpha_{\mathrm{s}}+\alpha_{1}\right)}+\frac{\ln \left(A\left(k_{\mathrm{t}}^{0}\right) / A\left(k_{\mathrm{t}}^{1,1}\right)\right)}{\alpha_{\mathrm{s}}+\alpha_{1}}
$$


For DMA, with $E_{\mathrm{A}}\left(k_{\mathrm{t}}^{1,1}\right)=19.9 \mathrm{~kJ} \cdot \mathrm{mol}^{-1}$, eq. 5.5 yields $E_{\mathrm{A}}\left(k_{\mathrm{t}}^{0}\right)=27.3 \mathrm{~kJ} \cdot \mathrm{mol}^{-1}$, which represents the same trend as shown in Figure 5.12. Since there is only a few data for $k_{t}^{0}$ in literature, a direct comparison is difficult. However from single-pulse experiments in combination with NIR detection (SP-PLP-NIR) the chain-length averaged rate coefficient is available $\left.\left(<k_{\mathrm{t}}\right\rangle\right)$. As $<k_{\mathrm{t}}>$ contains short-chain and long-chain behavior, $E_{\mathrm{A}}$ of $\left\langle k_{\mathrm{t}}\right\rangle$ is assumed to be in-between the separate values. This in good agreement with the determined activation energy of $E_{\mathrm{A}}\left(<k_{\mathrm{t}}>\right)=22.4 \mathrm{~kJ} \cdot \mathrm{mol}^{-1} .81$

Table 5.3. Summary of composite-model parameters $k_{\mathrm{t}}^{1,1}, \alpha_{\mathrm{s}}, \alpha_{1}$ and $i_{\mathrm{c}}$ for dodecyl and 2-ethylhexyl methacrylate.

\begin{tabular}{ccccc}
\hline monomer & $\begin{array}{c}\boldsymbol{k}_{\mathbf{t}}^{\mathbf{1}, \mathbf{1}}(\mathbf{2 7 3 ~ K )} \\
/ \mathbf{L} \cdot \mathbf{m o l}^{-\mathbf{1}} \cdot \mathbf{s}^{-\mathbf{1}}\end{array}$ & $\alpha_{\mathbf{s}}$ & $\alpha_{\mathbf{l}}$ & $\boldsymbol{i}_{\mathbf{c}}$ \\
\hline \multirow{2}{*}{ DMA } & $1.2 \cdot 10^{7}$ & $0.65 \pm 0.08$ & $0.19 \pm 0.04$ & $\begin{array}{c}320 \pm 30(273 \mathrm{~K}) \\
\end{array}$ \\
\hline \multirow{2}{*}{ EHMA } & $1.8 \cdot 10^{7}$ & $0.61 \pm 0.09$ & $0.17 \pm 0.05$ & $285 \pm 40(233 \mathrm{~K})$ \\
& & & & $80 \pm 15(333 \mathrm{~K})$ \\
\hline
\end{tabular}

In this chapter, the temperature dependence of composite-model parameters was investigated for the polymerization of DMA and EHMA. The values of $k_{\mathrm{t}}^{1,1}$ are well described by the variation of the fluidity of the solution with temperature. The exponents $\alpha_{\mathrm{s}}$ and $\alpha_{1}$ were determined to be temperature independent. However, the crossover chain length shows are large effect in that $i_{\mathrm{c}}$ is enhanced toward lower temperature. 


\section{SP-PLP-EPR Measurement of ATRP Deactivation Rate for DMA}

The kinetics of an ATRP reaction is described by two coefficients, $k_{\text {act }}$ and $k_{\text {deact }}$ for activation and deactivation, respectively. They are included in the description of the equilibrium constant $K_{\mathrm{ATRP}}=k_{\mathrm{act}} / k_{\text {deact }}$. This relationship has the benefit that one quantity may be estimated whenever the other two are known.

The equilibrium constant and the activation rate coefficient for model systems together with the equilibrium constant in polymerization systems are accessible via online UVVIS-NIR spectroscopy according to methods described in chapter $3.6 .{ }^{60,61}$ In principle, $k_{\text {act }}$ during polymerization might be determined by a trapping experiment with macroinitiators in the same way as for model systems (cf. chapter 3.6.4). However, one difficulty of this approach is that during the preparation of the macroinitiators termination occurs which leads to dead polymer instead of the desired molecules. In addition due to transfer reactions, a significant amount of molecules which bears a halogen atom in the middle of the chain instead of the required terminal halogen atom is formed.$^{82}$

The direct measurement of ATRP deactivation rate is particularly challenging, since the deactivation rate coefficient is much larger than the one of activation.

It has been attempted to estimate the $\mathrm{Cu}$-mediated $k_{\text {deact }}$ for styrene and butyl acrylate (BA) polymerization at $110^{\circ} \mathrm{C}$ via stationary polymerization rate data. ${ }^{83}$ These approaches, however, are based on the assumption of a chain-length independent termination rate. Moreover, transfer reactions, for example the backbiting reaction in case of BA, have been neglected.

The potential of EPR in monitoring radical polymerization kinetics thus should be applied for measuring $k_{\text {deact }}$ in ATRP. Within the present work, a novel SP-PLP-EPR method has been developed which directly monitors radical concentration as a function of time after applying a laser single pulse. This method allows for measuring ATRP deactivation 
kinetics while, at the same time, chain-length dependent termination (CLDT) is taken into account. ${ }^{63}$ The process consists of two steps:

First, $k_{\mathrm{t}}^{i, i}$ is determined from measurements on the copper-free monomer system according to the procedure illustrated in chapter $5 .{ }^{29,67,25,26,30} k_{\mathrm{t}}{ }^{1,1}$ is measured on the same system, i.e., at almost identical viscosity and polarity, with only the copper-ligand species being absent. One particular advantage of pulsed-laser-initiated polymerization is that the kinetics is close to the one of reversible deactivation polymerization in that the size of a narrowly distributed radical population increases linearly with time. Within the second step, the decay of radical concentration after laser pulsing is again measured, but in the presence of $\mathrm{Cu}^{\mathrm{II}}$. The concentration of $\mathrm{Cu}^{\mathrm{II}}$ may also be determined by means of EPR spectroscopy. The method will first be illustrated for the simpler case of methacrylate ATRP with HMTETA, PMDETA and TPMA as ligands of the catalyst, respectively.

Scheme 6.1 illustrates the relevant reaction steps. The decay in radical concentration recorded via EPR spectroscopy in the presence of an ATRP catalyst is due to termination and deactivation.

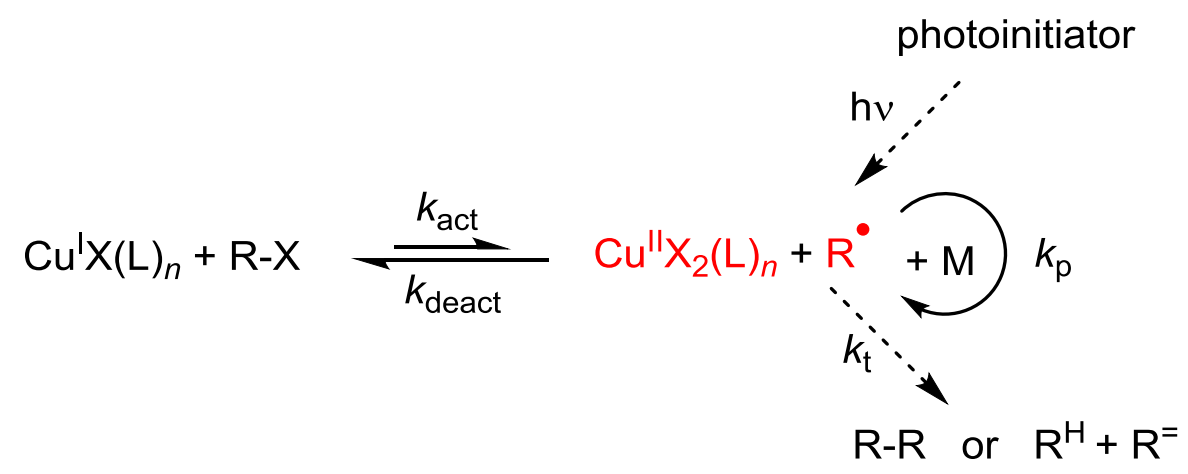

Scheme 6.1. Proposed mechanism for $\mathrm{Cu}$-mediated ATRP initiated by applying laser pulses to induce the decomposition of a photoinitiator. $\mathrm{R}-\mathrm{X}$ and $\mathrm{R}^{\cdot}$ denote the dormant and active radical species, respectively. $\mathrm{Cu}^{\mathrm{I}} \mathrm{X}(\mathrm{L})_{n}$ and $\mathrm{Cu}^{\mathrm{II}} \mathrm{X}_{2}(\mathrm{~L})_{n}$ refer to the catalyst in both oxidation states. $\mathrm{R}-\mathrm{R}$ refers to the radical-radical combination product and $\mathrm{R}^{\mathrm{H}}$ and $\mathrm{R}^{=}$to the saturated and unsaturated product of radical-radical disproportionation, respectively. EPR-active species are marked in red. 
The reaction steps shown in Scheme 6.1 and their relative importance for ATRP kinetics have been studied via several independent methods which will be shown in the following.

\subsection{Determination of the Propagation Rate Coefficient, $k_{\mathrm{p}}$, for DMA in MeCN}

Precise $k_{\mathrm{p}}$ data are essential for an accurate description of chain-length dependency, since the kinetic chain length after pulsing is directly proportional to $k_{\mathrm{p}}$, unless transfer or termination come into play.

PLP-SEC was used to determine $k_{\mathrm{p}}$ of DMA in $15 \mathrm{wt} \% \mathrm{MeCN}$ at $293 \mathrm{~K}$. The monomer mass fraction was $w_{\mathrm{DMA}}=0.85 \mathrm{~g} \cdot \mathrm{g}^{-1}(85 \mathrm{wt} \%)$, which corresponds to a monomer concentration of $c_{\mathrm{M}}=2.85 \mathrm{~mol} \cdot \mathrm{L}^{-1}$. The number of applied laser pulses was between 1000 and 1500 for each sample at a constant repetition rate of $15 \mathrm{~Hz}$. The initiator concentration was chosen to be $2.9 \mathrm{~mol} \cdot \mathrm{L}^{-1}$.

Shown in Figure 6.1 is a typical molar mass distribution of a sample from PLP (black line) and the associated first derivative (red line). Three distinct points of inflection may be seen. The corresponding molar masses at these points as well as the $M_{1} / M_{2}$ ratios and the resulting $k_{\mathrm{p}}$ data are listed in Table 6.1. 


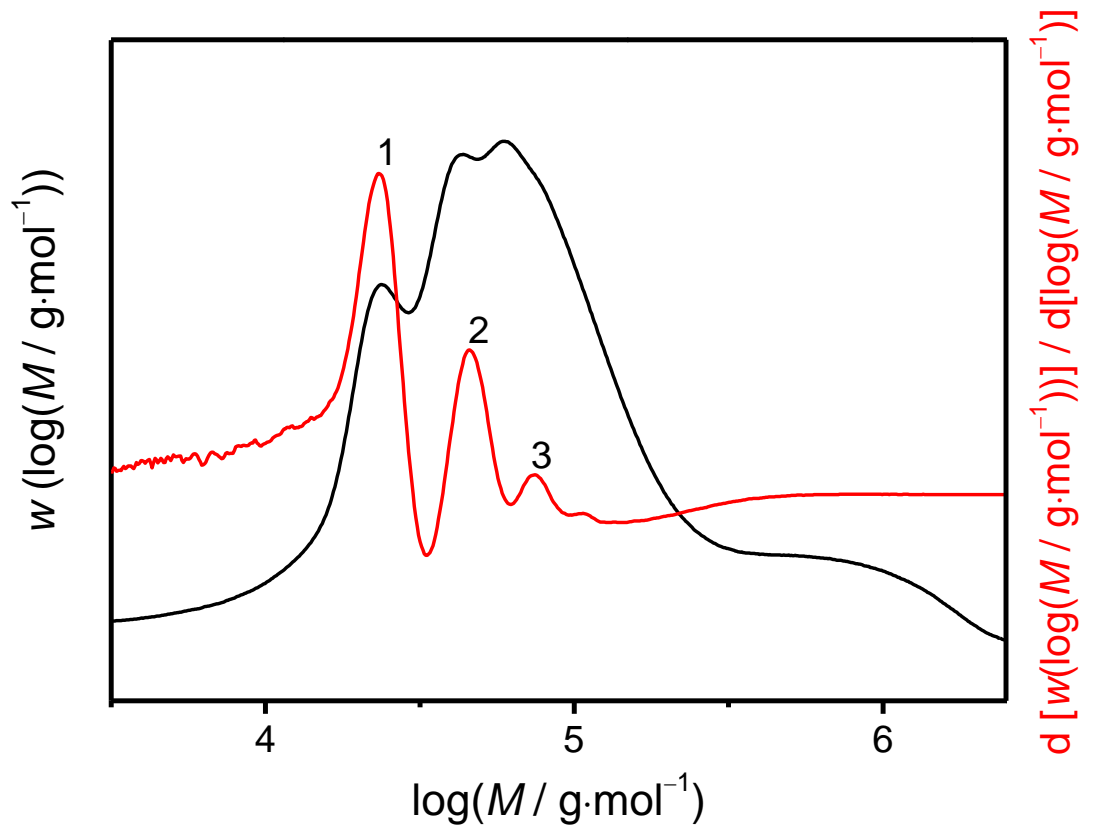

Figure 6.1. Molar mass distribution (black line) and the associated firstderivative (red line) for a sample from PLP of dodecyl methacrylate (DMA) in $15 \mathrm{wt} \%$ acetonitrile $(\mathrm{MeCN})$ at $293 \mathrm{~K}$ and a pulse repetition rate of $15 \mathrm{~Hz}$. The numbers indicate the points of inflection (POI).

Propagation rate coefficients are calculated according to eq. 3.29. The individual data slightly scatter around the average value, which amounts to $k_{\mathrm{p}}=428 \mathrm{~L} \cdot \mathrm{mol}^{-1} \cdot \mathrm{s}^{-1}$ at $293 \mathrm{~K}$. The $M_{1} / M_{2}$ ratios are close to the theoretical value of 0.5 . According to the theory in chapter $3.4, M_{2}$ should be twice as large as $M_{1}$ (for the propagation time being $2 \cdot t_{0}$ ).

The rate coefficients for bulk DMA and in solution are listed in Table 6.1. No significant dependence on monomer concentration and solvent was observed, since the average value for DMA in $15 \mathrm{wt} \% \mathrm{MeCN}$ is within experimental accuracy and in good agreement with the value for bulk polymerization and for polymerization in toluene solution, which is no surprise at such high monomer concentration. ${ }^{66,84,85}$ 
Table 6.1. Individual values of propagating rate coefficient $k_{\mathrm{p}}$ for DMA in $\mathrm{MeCN}$ at $293 \mathrm{~K}$ with the associated molar masses at the first inflection point $M_{1}$ and the ratio of first and second POI $M_{1} / M_{2}$. Average value for DMA in $\mathrm{MeCN}$ as well as literature data for DMA polymerization are depicted in the lower part.

\begin{tabular}{|c|c|c|c|c|c|}
\hline & $\begin{array}{c}w_{\text {DMA }} / \\
{\mathrm{g} \cdot \mathrm{g}^{-1}}^{-1}\end{array}$ & $\begin{array}{c}M_{1} / \\
\mathrm{g} \cdot \mathrm{mol}^{-1}\end{array}$ & $M_{1} / M_{2}$ & $\begin{array}{l}k_{\mathrm{p}}\left(20^{\circ} \mathrm{C}\right) / \\
\mathrm{L} \cdot \mathrm{mol}^{-1} \cdot \mathrm{s}^{-1}\end{array}$ & method \\
\hline \multirow{4}{*}{$\begin{array}{c}\text { DMA in MeCN } \\
\text { (individual } \\
\text { values) }\end{array}$} & 0.85 & 18035 & 0.55 & 401 & \multirow{4}{*}{ this work } \\
\hline & 0.85 & 18568 & 0.55 & 413 & \\
\hline & 0.85 & 18980 & 0.54 & 451 & \\
\hline & 0.85 & 18905 & 0.54 & 449 & \\
\hline DMA in $\mathrm{MeCN}$ & 0.85 & & & 428 & this work \\
\hline DMA in toluene & 0.70 & & & 425 & $\mathrm{EPR}^{84}$ \\
\hline DMA bulk & 1.00 & & & 453 & PLP-SEC 66 \\
\hline
\end{tabular}

The values for $k_{\mathrm{p}}$ of DMA in MeCN were measured only for $293 \mathrm{~K}$ and the difference to DMA bulk polymerization is only by about $10 \%$. The propagation rate coefficients for the modeling procedure may therefore be taken from literature bulk data, i.e., from the following Arrhenius relation: ${ }^{66}$

$$
\operatorname{In}\left(k_{\mathrm{p}} / \mathrm{L} \cdot \mathrm{mol}^{-1} \cdot \mathrm{s}^{-1}\right)=14.74-2525 \cdot\left(T^{-1} / \mathrm{K}^{-1}\right)
$$




\subsection{Chain-length Dependent Termination of DMA in MeCN}

SP-PLP-EPR experiments were performed to determine the composite-model parameters for DMA in $15 \mathrm{wt} \% \mathrm{MeCN}$. The decay in the concentration of propagating radicals has been recorded between 263 and $333 \mathrm{~K}$ with a modulation amplitude of $3 \mathrm{G}$ and a microwave power of $3 \mathrm{~mW}$.

The full EPR spectrum of DMA radicals in solution is identical in shape to the spectra recorded for bulk polymerization. Thus for radical detection, the same field position was chosen (cf. Figure 5.1). However, the signal-to-noise ratio is decreased due to the addition of a highly polar solvent. Therefore up to 50 individual traces were added and averaged to yield one $c_{\mathrm{R}}(t)$ spectrum.

The parameters $\alpha_{\mathrm{s}}, \alpha_{\mathrm{l}}, i_{\mathrm{c}}$ and $k_{\mathrm{t}}^{1,1}$ were determined from the recorded $c_{\mathrm{R}}(t)$ traces according to the procedure described in chapter 5.2. $\alpha_{1}$ and $i_{\mathrm{c}}$ are derived from a double-log plot of $\left(c_{\mathrm{R}}{ }^{0} / c_{\mathrm{R}}-1\right)$ vs. $t$, whereas data of $\alpha_{\mathrm{s}}$ and $k_{\mathrm{t}}^{1,1}$ were obtained from a least-squares fit of $\left(c_{\mathrm{R}}{ }^{0} / c_{\mathrm{R}}-1\right)$ vs. $t$.

Figure 6.2 illustrates the double-log plot (upper part) and least-squares fits (lower part) of $\left(c_{\mathrm{R}}{ }^{0} c_{\mathrm{R}}-1\right)$ vs. $t$ for SP-PLP-EPR experiments of DMA in $15 \mathrm{wt} \% \mathrm{MeCN}$. 

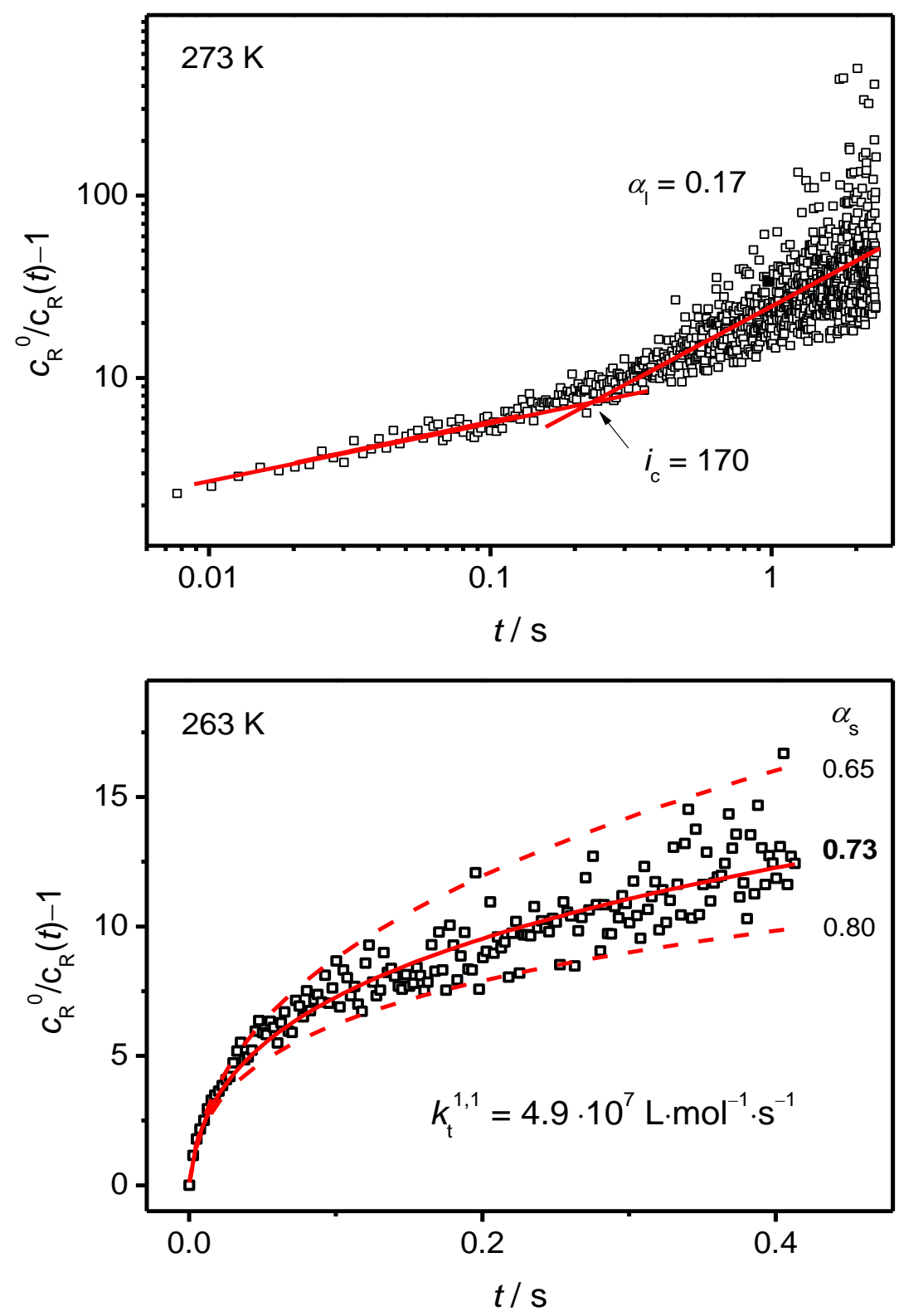

Figure 6.2. Double-log plot (upper part) and least-squares fits (lower part) of $\left(c_{\mathrm{R}}{ }^{0} c_{\mathrm{R}}-1\right)$ vs. $t$ for SP-PLP-EPR experiments of DMA in $15 \mathrm{wt} \% \mathrm{MeCN}$, to determine the composite-model parameters according to eqs. 3.25 and 3.28. The solid lines represent best fits with $\alpha_{\mathrm{s}}=0.73, \alpha_{1}=0.17, i_{\mathrm{c}}=170$ and $k_{\mathrm{t}}{ }^{1,1}=4.9 \cdot 10^{7} \mathrm{~L} \cdot \mathrm{mol}^{-1} \cdot \mathrm{s}^{-1}$. Dashed lines in the lower figure may be considered as lower and upper bounds of $\alpha_{\mathrm{s}}$ determined for constant $k_{\mathrm{t}}^{1,1}$. 
Shown in Figures 6.3-A are the individual values of $\alpha_{1}$ for each of the six measured temperatures. The mean value with $\alpha_{1}(\mathrm{DMA} / \mathrm{MeCN})=(0.17 \pm 0.07)$ exhibits no significant effect of temperature. ${ }^{63}$

Within the limits of experimental accuracy, the number fully agrees with the power-law exponents reported in chapter 5.2 for DMA (red) and EHMA (blue) bulk polymerization as well as for MMA and BMA (black) (Figure 6.3-B). ${ }^{67,30,86}$
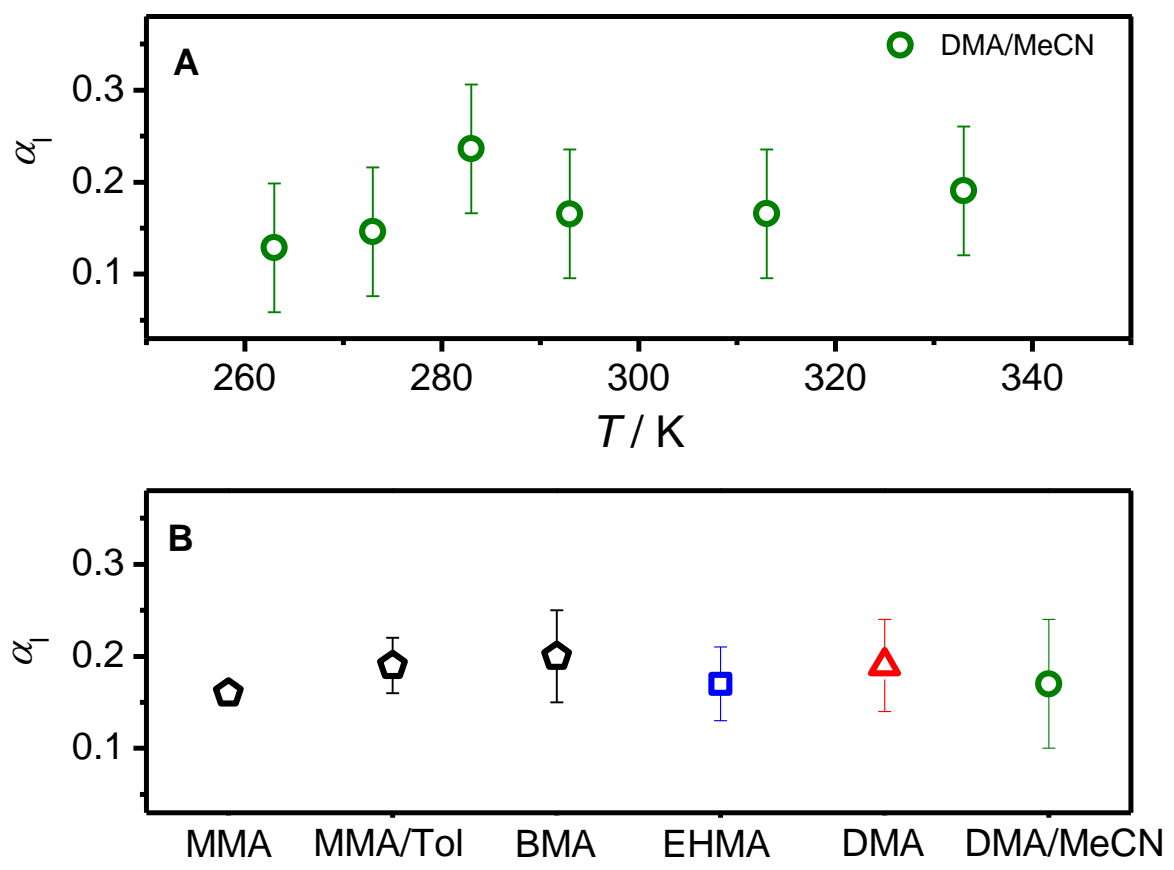

Figure 6.3. A: Individual values of $\alpha_{1}$ for DMA with $15 \mathrm{wt} \% \mathrm{MeCN}$ between 263 and $333 \mathrm{~K}$. B: The temperature-averaged value of $\alpha_{1}=0.17$ for DMA/MeCN (green), data for bulk DMA (red) and bulk EHMA (blue) from this work and literature data for MMA and BMA (black) $29,67,86$ are depicted.

Figure 6.4-C illustrates the individual values for $\alpha_{\mathrm{s}}$ which show no temperature effect within the limits of experimental accuracy. ${ }^{63}$ The temperature independent average of $\alpha_{\mathrm{s}}=(0.72 \pm 0.15)$ is depicted in Figure 6.4-D with literature bulk data of BMA and MMA as well as bulk DMA and bulk EHMA from the present work. ${ }^{67,30}$ 

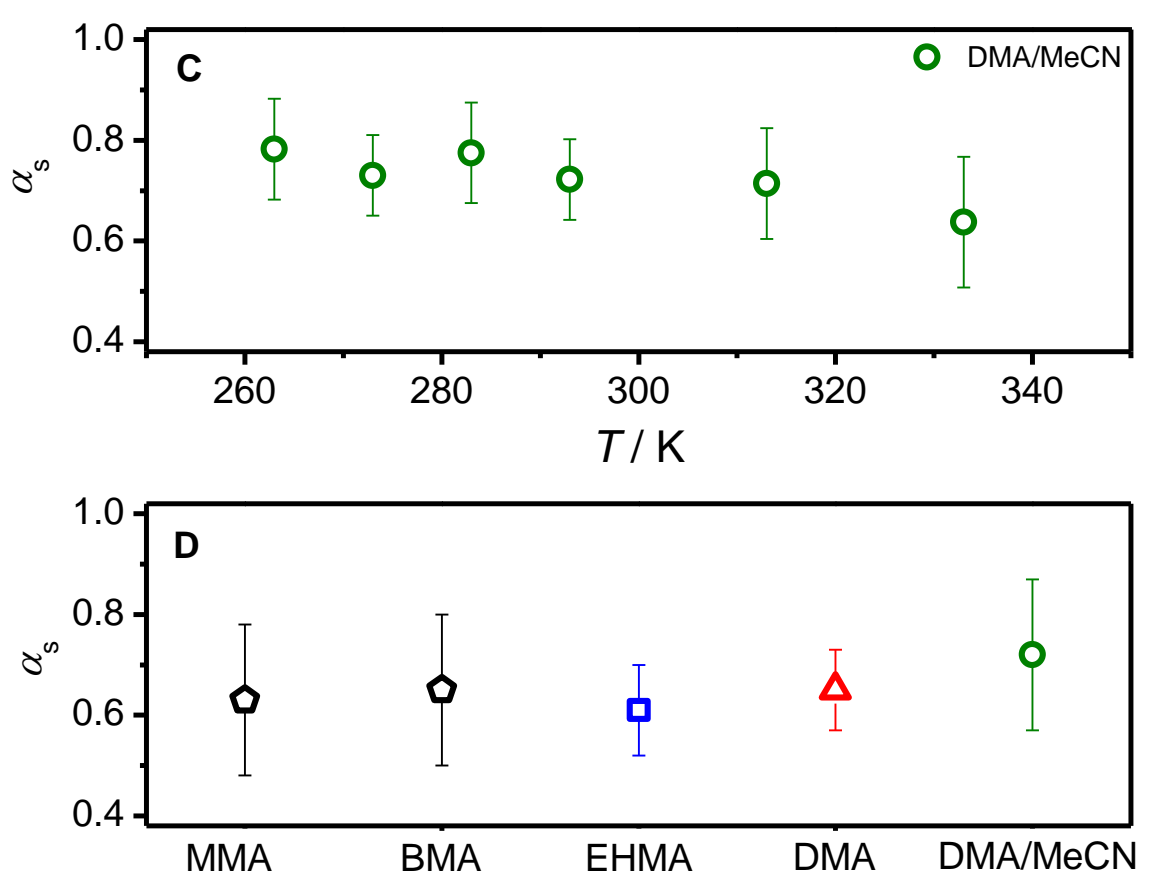

Figure 6.4. C: Individual values of $\alpha_{\mathrm{s}}$ for DMA with $15 \mathrm{wt} \% \mathrm{MeCN}$ between 263 and $333 \mathrm{~K}$. D: The temperature-averaged value of $\alpha_{1}=0.72$ for DMA/MeCN (green), data for bulk DMA (red) and bulk EHMA (blue) determined within this work and literature data for MMA and BMA (black) ${ }^{29,67}$ are depicted.

Termination rate coefficients $k_{\mathrm{t}}{ }^{1,1}$ determined for DMA between 263 and $333 \mathrm{~K}$ in the presence of $15 \mathrm{wt} \%$ acetonitrile are depicted in Figure 6.5. The data are well fitted by an Arrhenius line associated with an activation energy of $E_{\mathrm{A}}\left(k_{\mathrm{t}}^{1,1}\right)=(13 \pm 2) \mathrm{kJ} \cdot \mathrm{mol}^{-1}$. This activation energy is rather close to the one deduced from the fit of fluidity for the DMA mixture with $15 \mathrm{wt} \% \mathrm{MeCN}$, i.e., of reciprocal viscosity, $E_{\mathrm{A}}\left(\eta^{-1}\right)=(14.2 \pm 0.5) \mathrm{kJ} \cdot \mathrm{mol}^{-1}$. The close similarity of these two activation energies is indicative of center-of-mass diffusion controlling the termination of short radicals. 


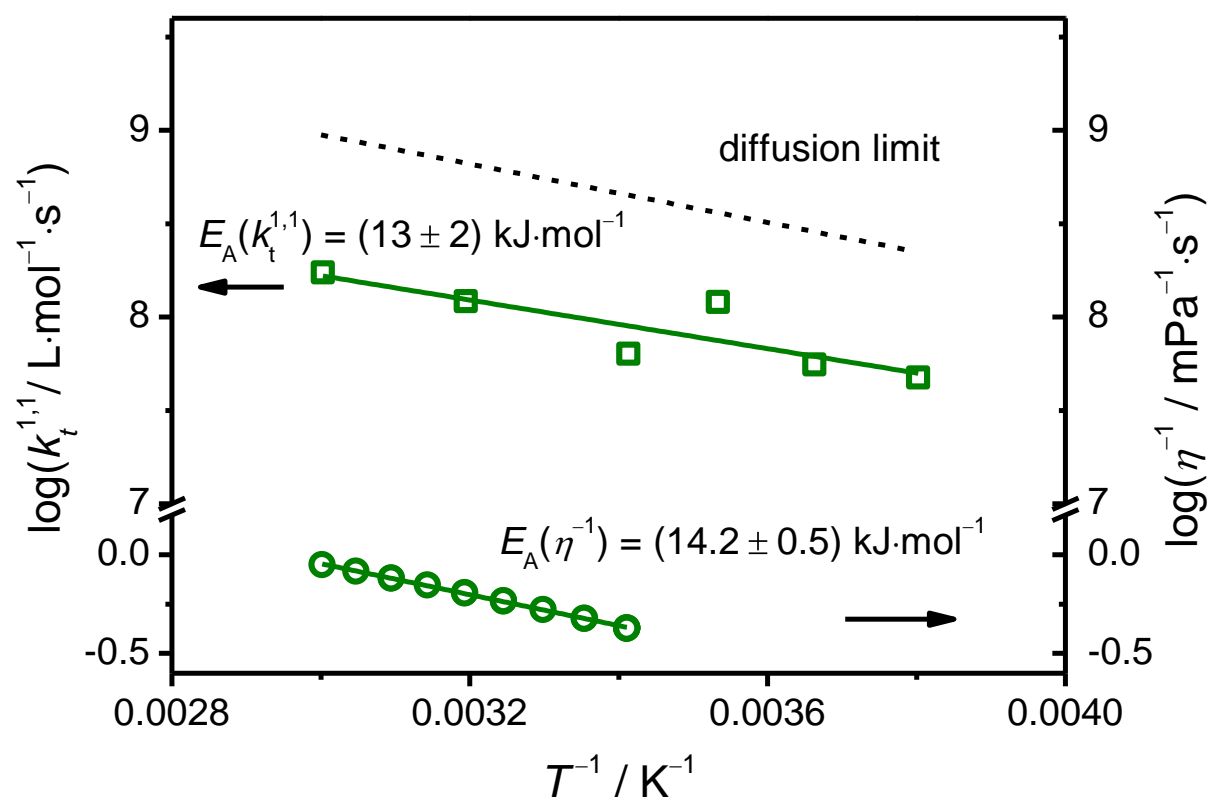

Figure 6.5. Temperature dependence of $k_{\mathrm{t}}^{1,1}$ (squares) and $\eta^{-1}$ (circles) for solutions of DMA with $15 \mathrm{wt} \% \mathrm{MeCN}$. Each data point represents the mean value from 5 to 10 independent measurements at identical temperature. The full lines refer to Arrhenius fits of the data associated with activation energies of $(13 \pm 2) \mathrm{kJ} \cdot \mathrm{mol}^{-1}$ and $(14.2 \pm 0.5) \mathrm{kJ} \cdot \mathrm{mol}^{-1}$ for $k_{\mathrm{t}}{ }^{1,1}$ and $\eta^{-1}$, respectively.

The values for $k_{\mathrm{t}}^{1,1}$ in $\mathrm{DMA} / \mathrm{MeCN}$ are adequately represented by the Arrhenius expression:

$$
\ln \left(k_{\mathrm{t}}^{1,1} / \mathrm{L} \cdot \mathrm{mol}^{-1} \cdot \mathrm{s}^{-1}\right)=23.49-1515 \cdot\left(T^{-1} / \mathrm{K}^{-1}\right)
$$

Absolute $k_{\mathrm{t}}^{1,1}$ in DMA/MeCN $(85: 15)=6.2 \cdot 10^{7} \mathrm{~L} \cdot \mathrm{mol}^{-1} \cdot \mathrm{s}^{-1}$ at $273 \mathrm{~K}$ exceeds the associated value for DMA bulk polymerization, $k_{\mathrm{t}}{ }^{1,1}=1.2 \cdot 10^{7} \mathrm{~L} \cdot \mathrm{mol}^{-1} \cdot \mathrm{s}^{-1}$, by a factor of $5 .^{22}$ This difference should primarily be due to the viscosity of the acetonitrilecontaining solution which is by a factor of 3 below the one of bulk DMA. However, particularly the determination of the initial radical concentration largely depends on the polarity of the solution. Therefore, the quality of the calibration may be reduced by the addition of $\mathrm{MeCN}$. Moreover, the small and highly polar solvent may lower the shielding of the radical center and thus increase $k_{\mathrm{t}}^{1,1} \cdot{ }^{27}$ 
The crossover chain length $i_{\mathrm{c}}$ was determined from a double-log plot of $\left(c_{\mathrm{R}}{ }^{0} / c_{\mathrm{R}}-1\right)$ vs. $t$ (Figure 6.2). This parameter exhibits a strong temperature dependence with $i_{\mathrm{c}}$ being around 220 at $263 \mathrm{~K}$ and dropping to $i_{\mathrm{c}}=100$ at $333 \mathrm{~K}$. Shown in Figure 6.6 are the solution values together with the associated $i_{c}$ values of DMA and EHMA in bulk polymerization. The data for DMA in solution are consistent with bulk data. For DMA, $i_{\mathrm{c}}$ does not significantly depend on the addition of $15 \mathrm{wt} \% \mathrm{MeCN}$. Moreover, the numbers for all three systems are close to each other and show more or less the same temperature dependence. The crossover chain length for DMA in $15 \mathrm{wt} \% \mathrm{MeCN}$ may be described by following expression:

$$
i_{\mathrm{c}}=6.9 \cdot \exp \left(875 \cdot\left(T^{-1} / \mathrm{K}^{-1}\right)\right)
$$

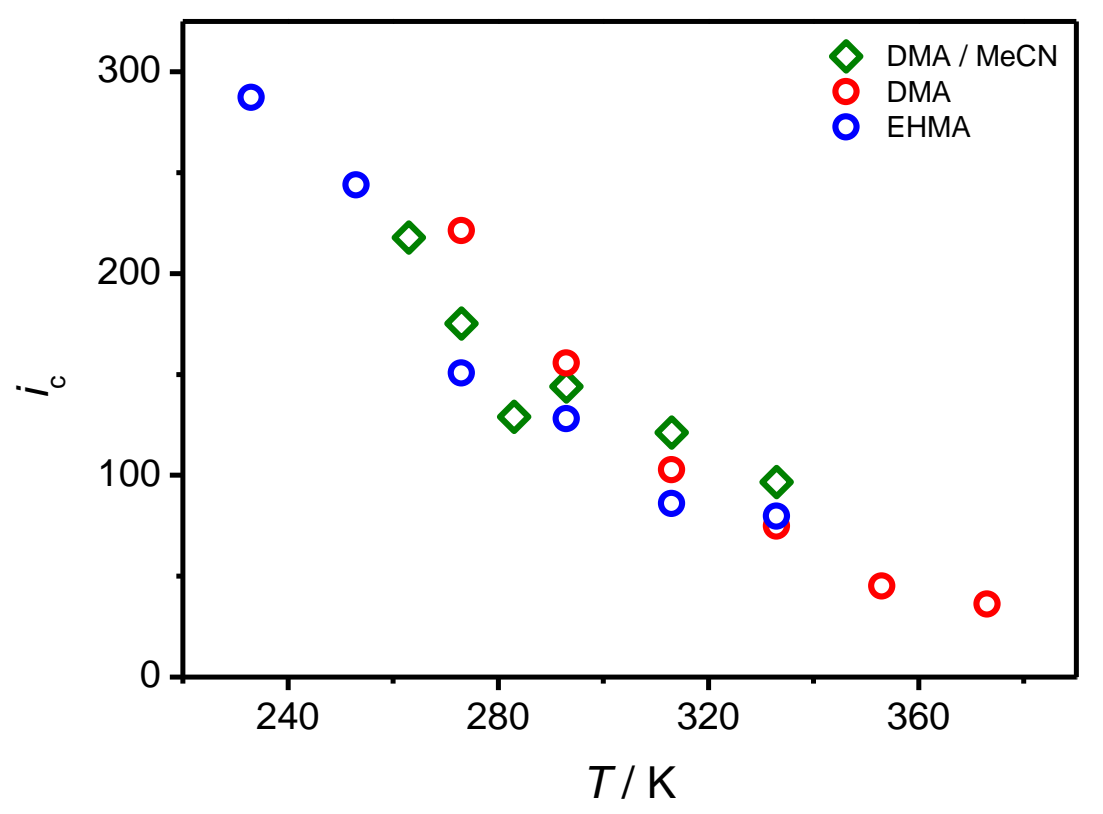

Figure 6.6. Temperature dependence of crossover chain length $i_{\mathrm{c}}$ for DMA$15 \mathrm{wt} \%$ acetonitrile solutions (green), DMA bulk (red) and EHMA bulk (blue) between 233 and $373 \mathrm{~K}$. Each data point represents the mean value from independent measurements at identical temperature.

The composite-model parameters determined for the copper-free system were implemented into the PREDICI model for analyzing $k_{\text {deact }}$. 


\subsection{Cu"l Concentration Measured via EPR}

The $\mathrm{Cu}^{\mathrm{II}}$ species is paramagnetic and thus also EPR active. Figure 6.7 illustrates the characteristic spectra of $\mathrm{Cu}^{\mathrm{II}}$ in solution at three temperatures. At $353 \mathrm{~K}$ the signal turns out to be a broad singlet, whereas a distinct hyperfine splitting is seen at lower temperatures. The splitting pattern is probably due to interactions of the unpaired electron with the copper and bromine nuclear spin. A similar spectral pattern was also reported for other $\mathrm{Cu}^{\mathrm{II}}$ ATRP catalysts. ${ }^{87,88}$

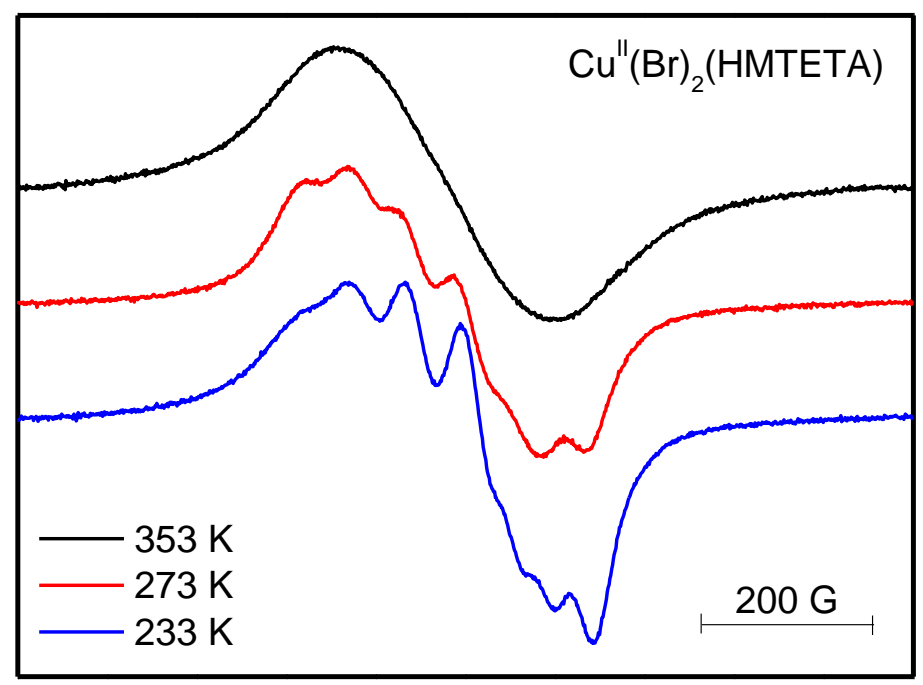

Figure 6.7. $\mathrm{EPR}$ signal of $\mathrm{Cu}^{\mathrm{II}}(\mathrm{Br})_{2}(\mathrm{HMTETA})$ in $\mathrm{BMA}$ with $15 \mathrm{wt} \% \mathrm{MeCN}$ measured at three temperatures with a modulation amplitude of $10 \mathrm{G}$ at a scan time of $40 \mathrm{~s}$.

The EPR spectra shown in Figure 6.7 were measured in a mixture of butyl methacrylate with $15 \mathrm{wt} \% \mathrm{MeCN}$. BMA was used instead of DMA due to BMA having a lower melting point which allows to investigate a larger temperature range. The splitting pattern is almost independent of the type of methacrylate monomer and the type of ligand (Figure 6.8). 


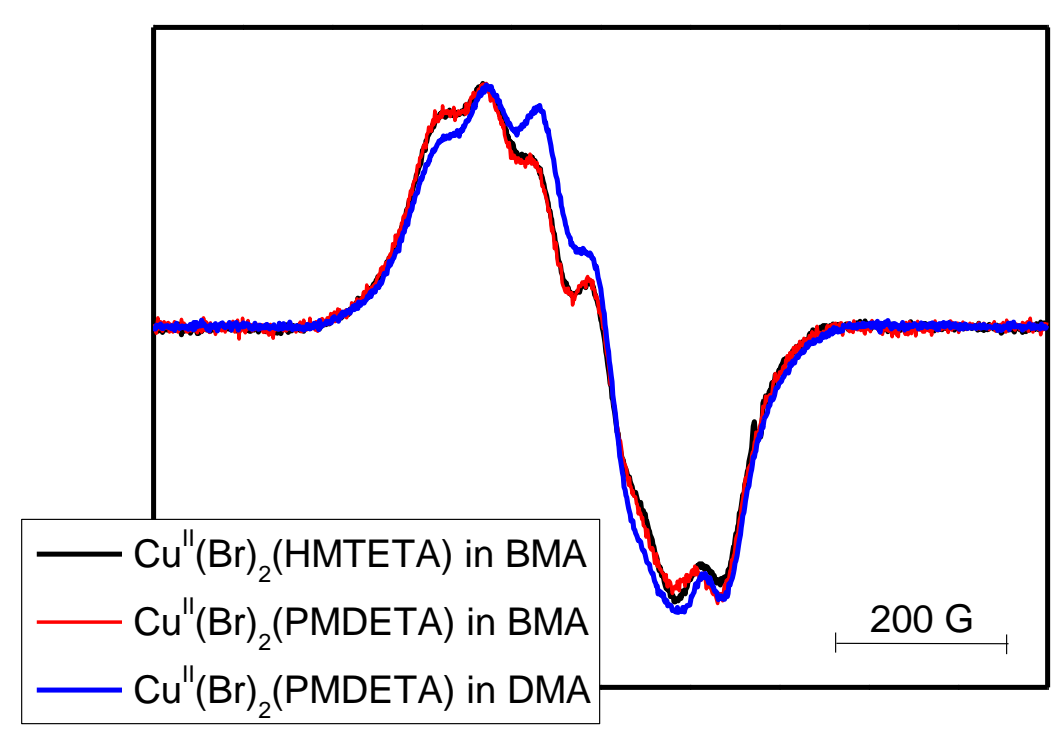

Figure 6.8. EPR spectra of different $\mathrm{Cu}^{\mathrm{II}}$ catalysts with HMTETA or PMDETA being the ligand and with DMA or BMA being the monomer in solution of $15 \mathrm{wt} \% \mathrm{MeCN}$. The signals were recorded at $273 \mathrm{~K}$ with a modulation amplitude of $10 \mathrm{G}$ at a scan time of $40 \mathrm{~s}$.

Shown in Figure 6.9 are combined spectra of both the copper-centered (red line) and the propagating radical signal (black line). The EPR signals are overlapping, which, however, has only a negligible influence on the time-resolved EPR traces, because the concentration of both species may be determined independently.

For better illustration, the spectrum of $\mathrm{Cu}^{\mathrm{II}}$ in Figure 6.9 is multiplied by a factor of 20 . $\mathrm{Cu}^{\mathrm{II}}$ may be recorded in between laser pulsing such that no $\mathrm{R}^{\cdot}$ is present. The spectra of propagating radicals were recorded at around $3350 \mathrm{G}$. Due to the broad $\mathrm{Cu}^{\mathrm{II}}$ signal, the variation of the copper signal during laser pulse application is small, such that no significant change between 3300 and $3400 \mathrm{G}$ occurs. 


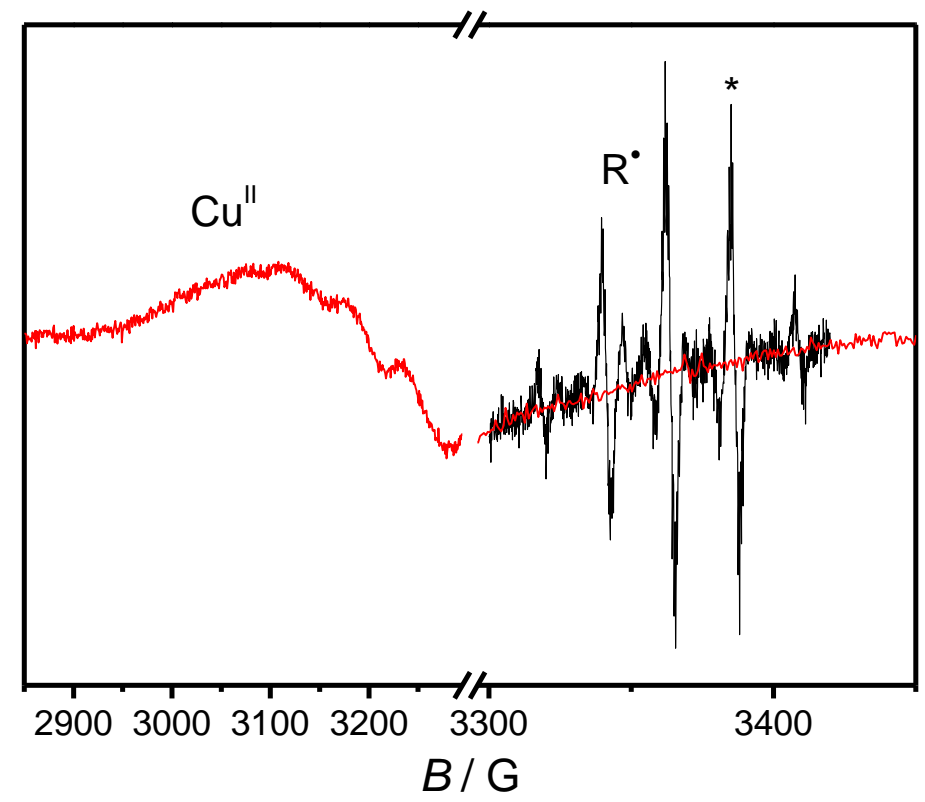

Figure 6.9. EPR spectra of $\mathrm{Cu}^{\mathrm{II}}(\mathrm{Br})_{2}$ (HMTETA) (red) recorded with a modulation amplitude of $10 \mathrm{G}$. The spectrum for DMA propagating radicals (black) was measured under continuous laser initiation at $273 \mathrm{~K}$ with a modulation amplitude of $3 \mathrm{G}$. The $\mathrm{Cu}^{\mathrm{II}}$ signal (red) was increased in intensity by a factor of 20 .

For the correct determination of the $\mathrm{Cu}^{\mathrm{II}}$ concentration, the double integral of the $\mathrm{Cu}^{\mathrm{II}} \mathrm{EPR}$ signal must be proportional to the $\mathrm{Cu}^{\mathrm{II}}$ concentration. Therefore, four samples with 0.2 to $3.5 \mathrm{mmol} \cdot \mathrm{L}^{-1} \mathrm{Cu}^{\mathrm{II}}(\mathrm{Br})_{2}(\mathrm{PMDETA})$ were measured in the DMA/MeCN mixture. Figure 6.10 illustrates the proportionality of the double integral vs. $\mathrm{Cu}^{\mathrm{II}}$ concentration. 


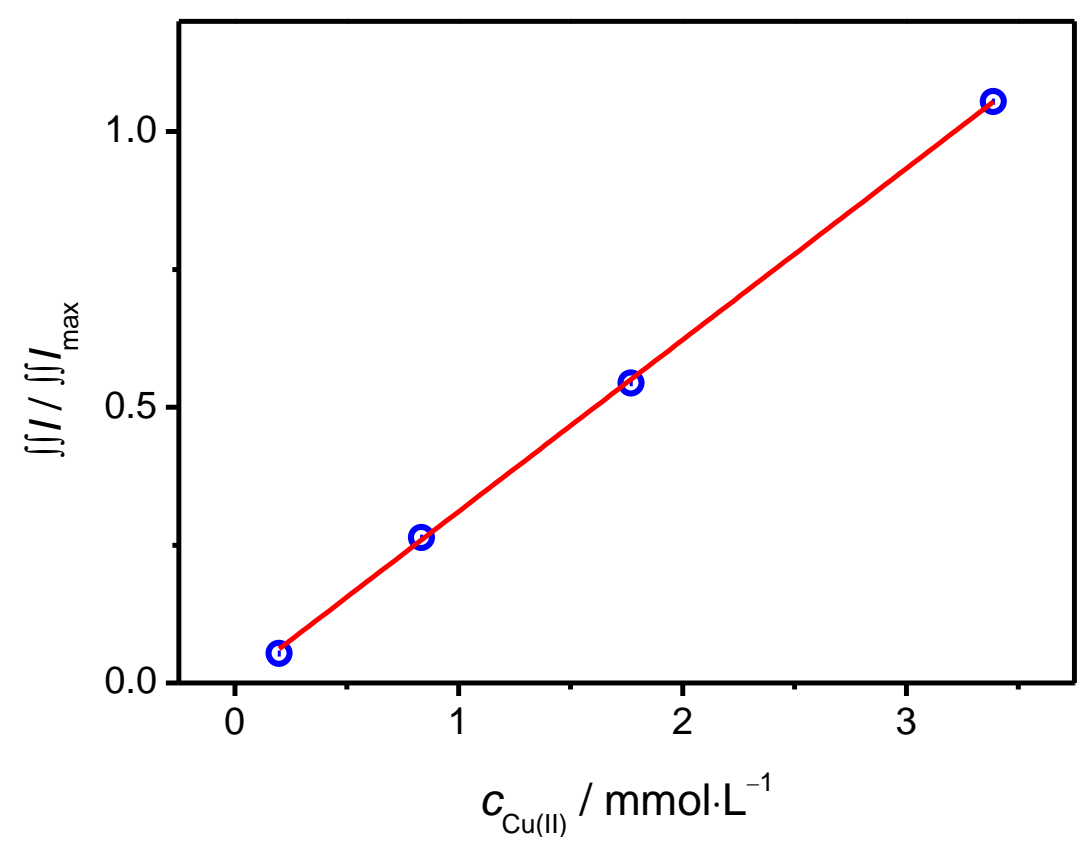

Figure 6.10. Plot of the double integral, $\iint I$, of the $\mathrm{Cu}^{\mathrm{II}} \mathrm{EPR}$ signal vs. $\mathrm{Cu}^{\mathrm{II}}$ concentration. The samples contain different concentrations of $\mathrm{Cu}^{\mathrm{II}}(\mathrm{Br})_{2}(\mathrm{PMDETA})$ in a mixture of DMA with $15 \mathrm{wt} \% \mathrm{MeCN}$. The spectra were recorded at $293 \mathrm{~K}$.

The concentration of $\mathrm{Cu}^{\mathrm{II}}$ decreases with the applied number of laser pulses. Shown in Figure 6.11 is the progressive decrease in $\mathrm{Cu}^{\mathrm{II}}$ concentration with an increasing number of applied laser pulses. The EPR spectra of $\mathrm{Cu}^{\mathrm{II}}(\mathrm{Br})_{2}$ (TPMA) were recorded in DMA with $15 \mathrm{wt} \% \mathrm{MeCN}$ at $293 \mathrm{~K}$. The overall number of laser pulses was 60. 


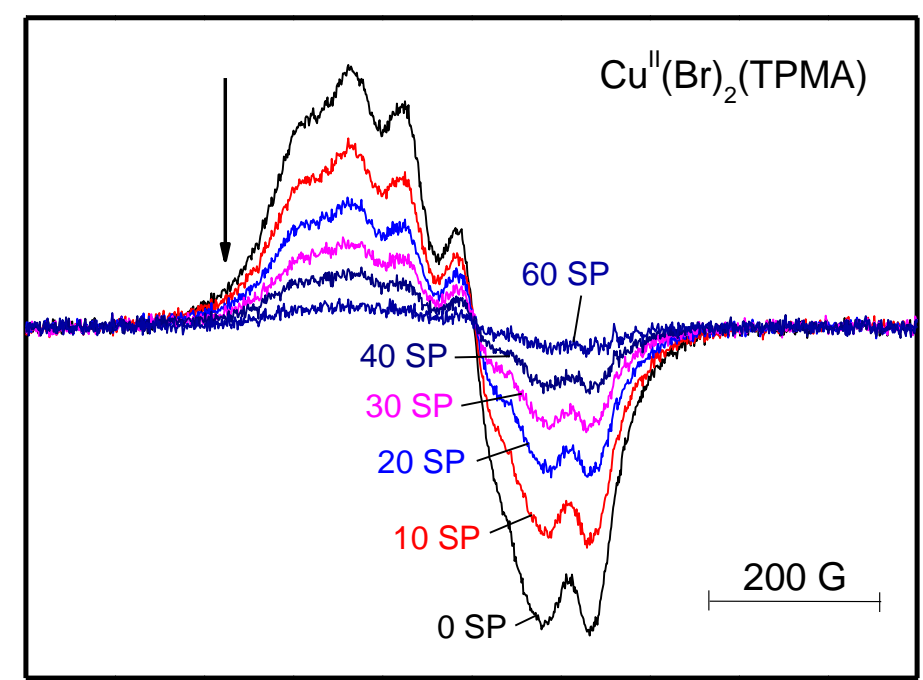

Figure 6.11. Decrease of the concentration of the $\mathrm{Cu}^{\mathrm{II}}(\mathrm{Br})_{2}(\mathrm{TPMA})$ catalyst measured at $293 \mathrm{~K}$ with a modulation amplitude of $10 \mathrm{G}$ and an overall number of 60 laser pulses.

It would be desirable to determine the concentration of $\mathrm{Cu}^{\mathrm{II}}$ directly during irradiation. This is, however, complicated due to for the following reasons:

(i) The EPR line of $\mathrm{Cu}^{\mathrm{II}}$ extends over a range of $600 \mathrm{G}$, which reduces the signal-to-noise (S/N) quality of the spectrum. The absolute change in EPR intensity at given magnetic field is far below the signal of $\mathrm{R}^{\bullet}$ after applying the laser single pulse.

(ii) $\mathrm{S} / \mathrm{N}$ does not increase by adding several individual curves to achieve one $c_{\mathrm{R}}(t)$ trace, since no relaxation of $c_{\mathrm{Cu}(\mathrm{II})}$ to its initial value occurs after SP.

The best option is to measure an overall EPR spectrum before and after the experiment. The average value of $\mathrm{Cu}^{\mathrm{II}}$ was then used for the analysis of $k_{\text {deact }}$ via modeling.

To minimize the conversion of $\mathrm{Cu}^{\mathrm{II}}$, the number of applied laser pulses was kept below 10. The entire experiment was repeated several times and the obtained traces were averaged to increase $\mathrm{S} / \mathrm{N}$. 


\subsection{Determination of Deactivation Rate Coefficients $\boldsymbol{k}_{\text {deact }}$}

In what follows, the method is demonstrated for the polymerization of DMA in acetonitrile with three different ligands to $\mathrm{Cu}^{\mathrm{II}}$. The analysis of the deactivation rate coefficient $k_{\text {deact }}$ proceeds via PREDICI modeling. The employed model and the associated rate coefficients are depicted in Scheme 6.2.

\section{Initiation:}

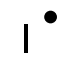

Propagation:

$\mathrm{R}_{i}^{\bullet}$

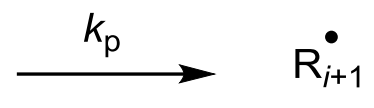

Deactivation:

$$
\mathrm{R}_{i}^{\bullet}+\mathrm{Cu}^{\prime \prime} \mathrm{X}_{2}(\mathrm{~L})_{n} \stackrel{k_{\text {deact }}}{\longrightarrow} \mathrm{R}_{i} \mathrm{X}+\mathrm{Cu}^{\prime} \mathrm{X}(\mathrm{L})_{n}
$$

\section{Termination:}

$$
\mathrm{R}_{i}+\mathrm{R}_{i} \stackrel{k_{\mathrm{t}}^{i, i}}{\longrightarrow} \mathrm{R}-\mathrm{R} \text { or } \mathrm{R}^{\mathrm{H}}+\mathrm{R}^{=}
$$

Scheme 6.2. Relevant reactions for PREDICI modeling. Primary radicals (I*) are generated by laser-induced decomposition of a photoinitiator.

The four relevant reaction steps are initiation, propagation, deactivation and termination. The decomposition of the initiator and potential side reactions of the primary radicals do not have to be considered, since the measured $c_{\mathrm{R}}$ vs. $t$ data refers to the propagating radicals only. The initiation step cannot be resolved on the experimental time scale. The associated rate coefficient $k_{\mathrm{i}}$ is assumed to be $100 \cdot k_{\mathrm{p}}$. This fast initiation ensures instantaneous generation of propagating chains. 
The rate for the activation step by $\mathrm{Cu}^{\mathrm{I}}$ may be ignored, since the associated activation rate coefficient is far below $k_{\text {deact. }}{ }^{89}$ No significant activation should thus occur as explained in detail in chapter 3.6.1. Termination and propagation rate coefficients were determined in independent experiments (chapters 6.1 and 6.2) thus achieving highly accurate values for $k_{\text {deact. }}$ The determination of the $\mathrm{Cu}^{\mathrm{II}}$ concentration was performed by using EPR spectroscopy as outlined in chapter 6.3 .

The ATRP deactivation rate coefficient was measured by applying laser single pulses for radical production in conjunction with subsequent time-resolved detection of the decay of radical concentration. The recorded $c_{\mathrm{R}}(t)$ traces were fitted via PREDICI modeling to obtain $k_{\text {deact }}$ according to Scheme 6.2.

DMA has been chosen due to the low termination rate coefficient, because the sensitivity of the $c_{\mathrm{R}}(t)$ traces towards deactivation increases when deactivation is much faster than termination. ${ }^{63}$ The long alkyl side chain reduces the polarity of the monomer which enhances the quality of the data.

The relative amounts of $\mathrm{Cu}^{\mathrm{II}}, \mathrm{MeCN}$ and monomer have to be selected carefully. If the copper concentration is too high, the decay of $c_{\mathrm{R}}(t)$ is too fast to be properly detected. Also a large proportion of the initiator fragments $I^{\bullet}$ may be deactivated even before adding to monomer. In the opposite case, the difference of the traces between copper-free and copper-containing systems is too small. The best traces were obtained at $\mathrm{Cu}^{\mathrm{II}}$ concentrations between 1.5 and $0.1 \mathrm{mM}$. Up to four different concentrations were measured for each ligand system.

The three selected ligands represent important types of common compounds of $\mathrm{Cu}^{\mathrm{II}}$ complexes. HMTETA is a tetradentate ligand, PMDETA a tridentate one and TPMA is a branched ligand (Scheme 6.3). ${ }^{90,10}$ 


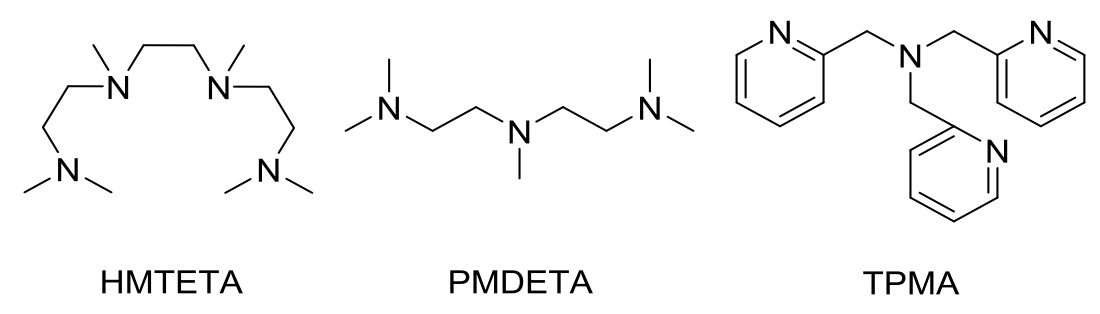

Scheme 6.3. Nitrogen-based tri- and tetradentate ligands: 1,1,4,7,10,10Hexamethyltriethylenetetramine (HMTETA), $N, N, N^{\prime}, N^{\prime \prime}, N^{\prime \prime}-$ Pentamethyldiethylenetriamine (PMDETA) and Tris(2-pyridylmethyl(amine) (TPMA)

A prediction for the rate coefficients of deactivation of the three ligands is rather difficult, because deactivation depends on different aspects such the $\mathrm{Cu}-\mathrm{Br}$ bond strength and the energy for reorganization of the ligand sphere. ${ }^{89,91}$ Previous studies showed that the complex stability with TPMA is much higher than for complexes with PMDETA as the ligand. ${ }^{55,92}$ Therefore, the ability to transfer the halogen should be reduced in case of TPMA. It may be thus expected that the deactivation rate coefficient is lowered as compared to $k_{\text {deact }}$ for PMDETA.

Shown in Figure 6.12 is the absolute concentration of propagating radicals measured after the laser single pulse at $t=0$ for DMA polymerization at $293 \mathrm{~K}$. The upper curve (green) refers to the experiment without copper, whereas the curves in blue and red have been measured in the presence of 0.07 and $0.3 \mathrm{mM} \mathrm{Cu}^{\mathrm{II}}(\mathrm{Br})_{2}$ (TPMA), respectively. The $\mathrm{Cu}^{\mathrm{II}}$ concentrations refer to the average value from measurements before and after applying the sequence of single pulses. The decay of $c_{\mathrm{R}}(t)$ is significantly faster with $\mathrm{Cu}^{\mathrm{II}}$ being present. The full lines illustrate the PREDICI fits based on Scheme 6.2. 


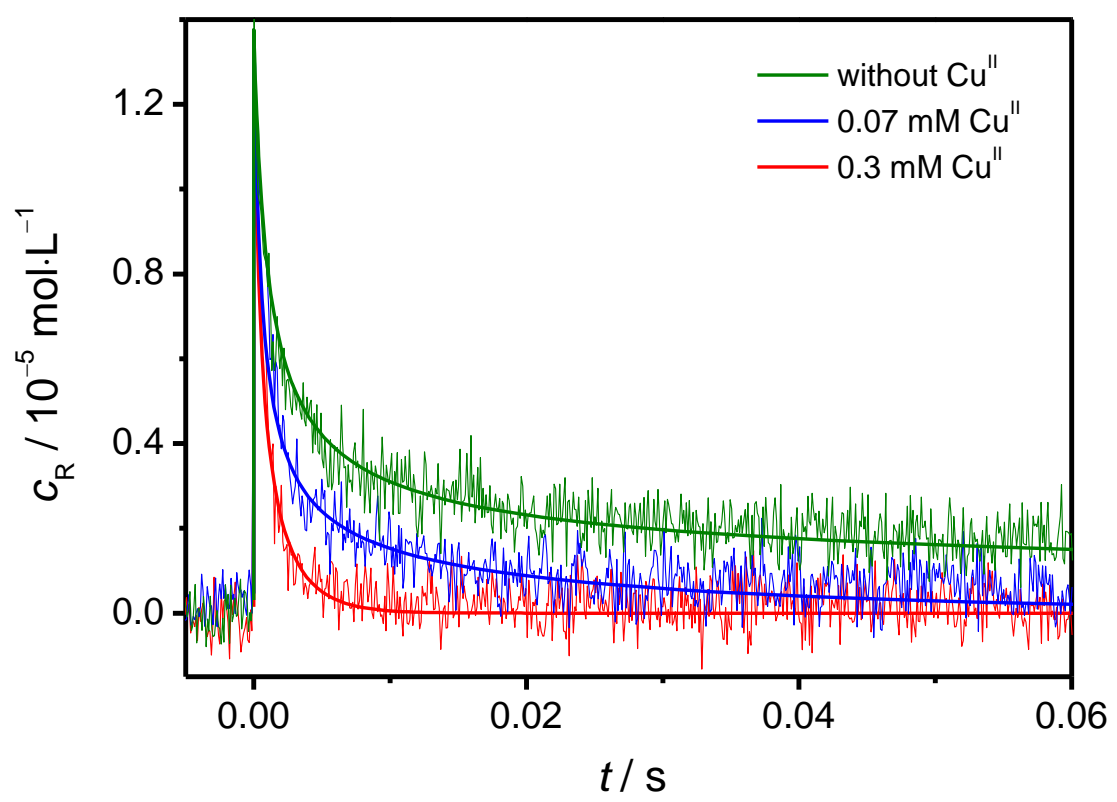

Figure 6.12. Time-resolved concentration of propagating radicals after single laser pulse initiation at $t=0$ in DMA polymerization with $15 \mathrm{wt} \% \mathrm{MeCN}$. The upper curve is measured in the absence of copper (green), both lower ones (blue, red) are recorded in the presence of $\mathrm{Cu}^{\mathrm{II}}(\mathrm{Br})_{2}$ (TPMA) at different concentrations. The full lines represent the PREDICI modeling.

Up to 6 individual traces per sample were co-added to increase S/N-ratio, but no more to minimize the consumption of $\mathrm{Cu}^{\mathrm{II}}$. To achieve a further enhancement of the signal quality, the experiment was repeated up to 10 times for each condition and the obtained data were averaged. The results for the three copper-ligand systems are summarized in Table 6.3.

Literature data of $k_{\text {deact }}$ from ATRP experiments of DMA are not available. Thus, data deduced from monomer-free model systems with initiators of similar functionality may serve for comparison. 
Table 6.2. Deactivation rate coefficient, $k_{\text {deact }}$, for three ligands in the presence (DMA) and in the absence of monomer (Model 1+2). The values for ethyl 2-bromoisobutyrate (EtBriB) and methyl 2-bromoisobutyrate (MBriB) were measured at $295 \mathrm{~K}$, the values for DMA were determined at $293 \mathrm{~K}$.

\begin{tabular}{ccccc}
\hline system & ligand & $\begin{array}{c}\text { MeCN } \\
/ \mathbf{w t} \%\end{array}$ & $\begin{array}{c}\text { deactivated } \\
\text { species }\end{array}$ & $\begin{array}{c}\boldsymbol{k}_{\text {deact }}{ }^{89} \\
/ \mathbf{L}^{\circ} \mathbf{m o l}^{-\mathbf{1}} \cdot \mathbf{s}^{-\mathbf{1}}\end{array}$ \\
\hline DMA & HMTETA & 15 & $(\mathrm{DMA})_{n}-\mathrm{Br}$ & $(8 \pm 3) \cdot 10^{5}$ \\
Model 1 & HMTETA & 100 & EtBriB & $6.4 \cdot 10^{6}$ \\
Model 2 & HMTETA & 100 & MBriB & $3.3 \cdot 10^{6}$ \\
\hline DMA & PMDETA & 15 & $(\mathrm{DMA})_{n}-\mathrm{Br}$ & $(2.0 \pm 0.6) \cdot 10^{6}$ \\
Model 1 & PMDETA & 100 & EtBriB & $1.7 \cdot 10^{7}$ \\
Model 2 & PMDETA & 100 & $\mathrm{MBriB}$ & $9.6 \cdot 10^{6}$ \\
\hline DMA & TPMA & 15 & $(\mathrm{DMA})_{n}-\mathrm{Br}$ & $(1.0 \pm 0.3) \cdot 10^{6}$ \\
Model 1 & TPMA & 100 & EtBriB & $3.3 \cdot 10^{6}$ \\
Model 2 & TPMA & 100 & $\mathrm{MBriB}$ & $1.7 \cdot 10^{6}$ \\
\hline
\end{tabular}

The values for $k_{\text {deact }}$ with HMTETA and PMDETA as a ligand are lower than the ones for the model systems by almost one order of magnitude. The essential reason behind this difference in $k_{\text {deact }}$ is most likely the back-strain (B) effect. ${ }^{93-95}$ The B-effect reduces the deactivation rate of the propagating radical as compared to the model systems.

In a polymerization this means that the $\alpha$-methyl group of the penultimate monomer unit of the chain may induce a steric strain on the $s p^{3}$ carbon atom of the deactivated species which bears the halogen atom. This strain is released by dissociation of a halogen and by associated formation of a $s p^{2}$-hybridized radical species (lhs, Scheme 6.4).

In a model system, which corresponds to radicals of chain length unity, the penultimate unit is missing that no steric strain may occur (rhs, Scheme 6.4). Thus, the activation for model systems should be slower as compared to the polymerizing system. ${ }^{94,96}$

Vice versa, for the deactivation step one would expect that the halogen transfer to the radical is slower for polymerization than for model systems. 

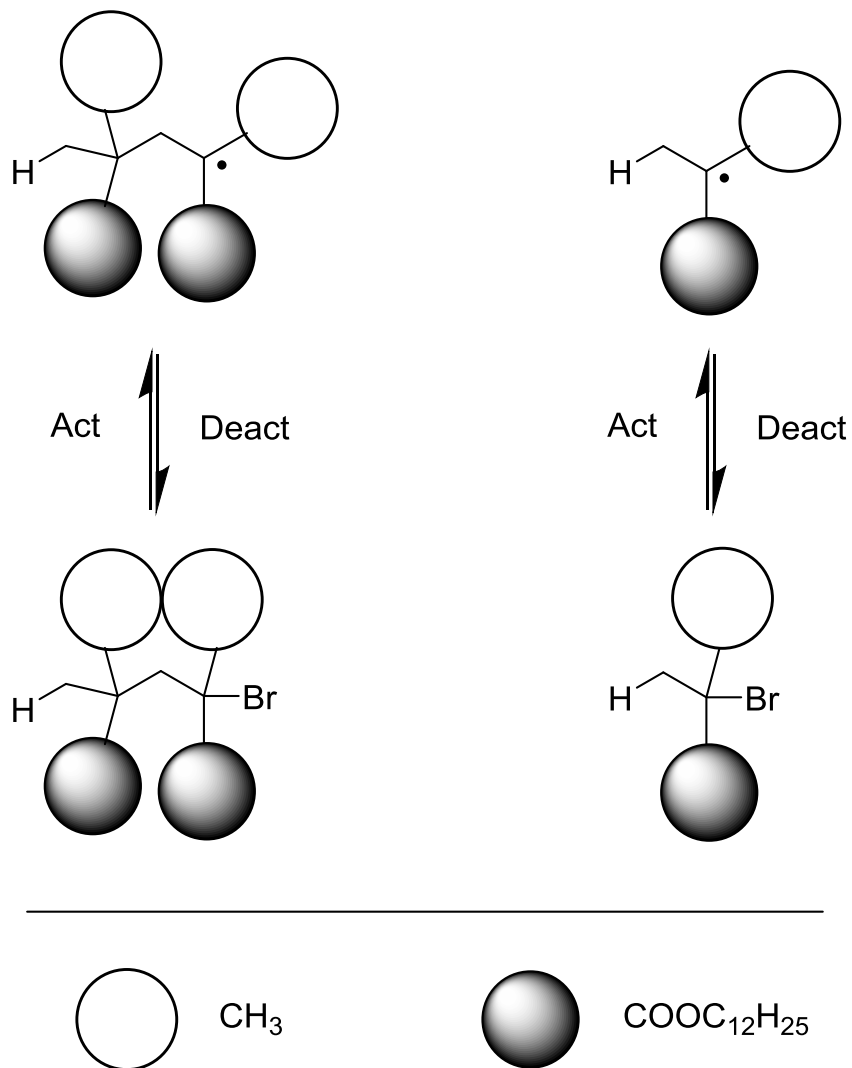

$\mathrm{COOC}_{12} \mathrm{H}_{25}$

Scheme 6.4. Back strain effect induced by the $\alpha$-methyl group $(\bigcirc)$ of the penultimate monomer unit (lhs). In the model system no B-effect is expected to occur (rhs). ${ }^{97}$

The size of the side chain should not contribute to this difference, as the increasing size of the substituent, i.e., passing from methyl to ethyl, has the opposite effect. ${ }^{89}$ This is also seen for $k_{\mathrm{p}}$, where bulk $k_{\mathrm{p}}$ increases towards larger ester size for both the acrylate and methacrylate families. ${ }^{98,14}$

The amount of acetonitrile in the two systems has no effect on $k_{\text {deact. }}$ This was evidenced in previous studies of model systems performed with an addition of saturated monomer which showed no difference with respect to investigations in the pure solvent. ${ }^{82}$

To validate the B-effect, the rate coefficients and equilibrium constants were determined both for the polymerizing system with DMA and for the model system with dodecyl 2bromoisobutyrate (DoBriB). ${ }^{63,82}$ HMTETA was used as the ligand. The results are listed 
in Table 6.3. The experiments show that the activation during polymerization is increased as compared to the model system. Vice versa, the deactivation for the polymerizing system is decreased by almost the same factor. These findings confirm the expected B-effect.

Table 6.3. Equilibrium constants and rate coefficients for the polymerization of DMA ( $\left.K_{\text {ATRP, }} k_{\text {act,poly }}, k_{\text {deact,poly }}\right)$ and for the model system with dodecyl 2-bromoisobutyrate ( $\left.K_{\text {model, }} k_{\text {act,model }}, k_{\text {deact,model }}\right)$, respectively. ${ }^{63,82}$ HMTETA was used as the ligand. The experiments were performed at $298 \mathrm{~K}$, except $k_{\text {deact,poly }}$ which was determined at $293 \mathrm{~K}$. The second line illustrates the ratio of rate coefficients for polymerization as compared to the model system.

\begin{tabular}{|c|c|c|c|c|c|}
\hline$K_{\text {ATRP }}$ & $K_{\text {model }}$ & $\begin{array}{c}k_{\text {act,poly }} / \\
\mathbf{L} \cdot \mathbf{m o l}^{-1} \cdot \mathbf{s}^{-1}\end{array}$ & $\begin{array}{c}k_{\text {act,model }} / \\
\mathbf{L} \cdot \mathrm{mol}^{-1} \cdot \mathbf{s}^{-1}\end{array}$ & $\begin{array}{c}k_{\text {deact,poly }} / \\
\mathbf{L} \cdot \mathrm{mol}^{-1} \cdot \mathbf{s}^{-1}\end{array}$ & $\begin{array}{l}k_{\text {deact,model }} / \\
\mathbf{L} \cdot \mathbf{m o l}^{-1} \cdot \mathbf{s}^{-1}\end{array}$ \\
\hline $2.6 \cdot 10^{-6}$ & $7.6 \cdot 10^{-9}$ & $2.1 \cdot 10^{0}$ & $6.9 \cdot 10^{-2}$ & $8 \cdot 10^{5}$ & $9.2 \cdot 10^{6}$ \\
\hline \multicolumn{2}{|c|}{300} & \multicolumn{2}{|c|}{30} & \multicolumn{2}{|c|}{0.1} \\
\hline
\end{tabular}

It should be noted that the values of $k_{\text {deact }}$ for DMA with TPMA as the ligand differ only by a factor of 3 from the results for the model systems (Table 6.2). The reason for this difference is probably due to deactivation being controlled primarily by two effects: ${ }^{89,99}$ (i) bond formation of the $\mathrm{R}-\mathrm{X}$ species and (ii) formation of the $\mathrm{Cu}^{\mathrm{I}}$ complex.

Where (ii) dominates, as seems to be the case for (TPMA), the similarity of the $\mathrm{Cu}^{\mathrm{I}}$ species in both model and ATRP systems leads to a similarity of $k_{\text {deact. }}$ In cases of weaker $\mathrm{Cu}^{\mathrm{I}}$ complexation (HMTETA, PMDETA), ATRP rate may be controlled by (i). ${ }^{100}$ Under such conditions, the bond-formation step matters and contributions from back-strain are important. In those cases, $k_{\text {deact }}$ shows a much larger difference between model and ATRP system. That implies that at least for PMDETA and HMTETA the values of $k_{\text {deact }}$ obtained from model systems cannot be used to adequately describe the kinetics of DMA polymerization.

Shown in Table 6.4 are the equilibrium constants for the polymerization of MMA and for

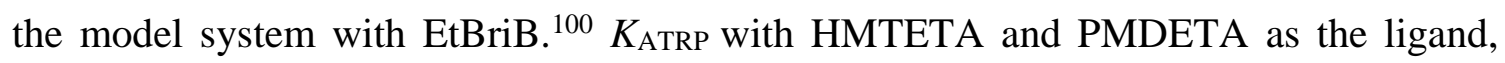


respectively, is more than two orders of magnitude higher than $K_{\text {model }}$. Whereas for the system with TPMA, the difference is only a factor of 5 . Assuming a consistent change of activation and deactivation, the difference of $k_{\text {deact }}$ between ATRP and model system should be roughly the square root of the difference in the equilibrium constants. This would lead to almost one order of magnitude higher values of $k_{\text {deact }}$ for HMTETA and PMDETA and to a factor of 2 higher ones for TPMA. This is in good agreement with the differences for DMA already presented in Table 6.2.

Table 6.4. Equilibrium constants for the polymerization of MMA and for the model system with EtBriB, respectively. ${ }^{100}$ The experiments were performed at $298 \mathrm{~K}$.

\begin{tabular}{cccc}
\hline ligand & $\boldsymbol{K}_{\text {ATRP }}$ & $\boldsymbol{K}_{\text {model }}$ & $\boldsymbol{K}_{\text {ATRP }} / \boldsymbol{K}_{\text {model }}$ \\
\hline HMTETA & $3.8 \cdot 10^{-6}$ & $3.1 \cdot 10^{-8}$ & 122 \\
PMDETA & $1.6 \cdot 10^{-5}$ & $9.8 \cdot 10^{-8}$ & 160 \\
TPMA & $9.4 \cdot 10^{-5}$ & $2.0 \cdot 10^{-5}$ & 4.7 \\
\hline
\end{tabular}

The temperature dependency of $k_{\text {deact }}$ was investigated for the system $\mathrm{Cu}^{\mathrm{II}} \mathrm{Br}_{2}$ (HMTETA) in DMA between 273 and $313 \mathrm{~K}$ (Figure 6.13). ${ }^{63}$ The slope of the Arrhenius line corresponds to an activation energy for $k_{\text {deact }}$ of $E_{\mathrm{A}}\left(k_{\text {deact }}\right)=(22 \pm 4) \mathrm{kJ} \cdot \mathrm{mol}^{-1}$. The dependency is described by the following Arrhenius relation.

$$
\ln \left(k_{\text {deact }} / \mathrm{L} \cdot \mathrm{mol}^{-1} \cdot \mathrm{S}^{-1}\right)=22.41-2606 \cdot\left(T^{-1} / \mathrm{K}^{-1}\right)
$$




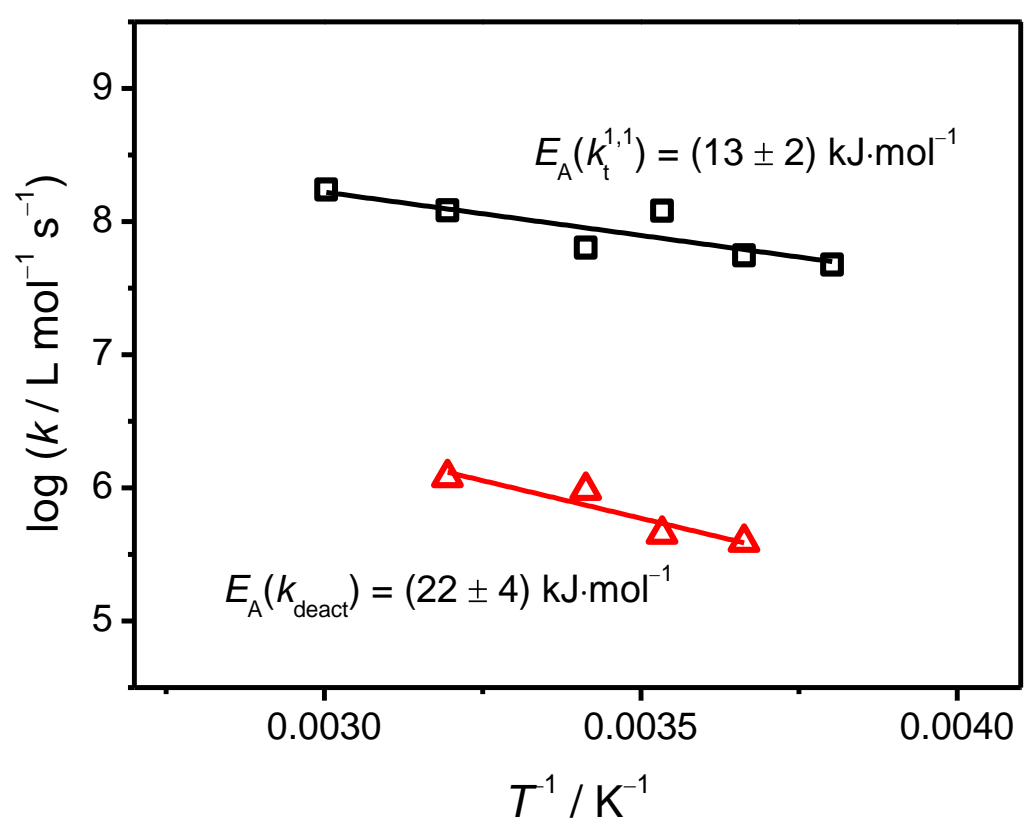

Figure 6.13. Temperature dependence of $k_{\mathrm{t}}{ }^{1,1}$ (black) and of deactivation rate coefficient (red). The values for $k_{\mathrm{t}}^{1,1}$ were determined in the copper-free system (see chapter 6.2). Deactivation rate coefficients were measured between 273 and $313 \mathrm{~K}$ in the presence of $\mathrm{Cu}^{\mathrm{II}}(\mathrm{Br})_{2}(\mathrm{HMTETA})$.

The data of $k_{\mathrm{t}}{ }^{1,1}$ (chapter 6.2) deduced from copper-free polymerization of DMA in MeCN is also shown in Figure 6.13. The deactivation rate coefficient for the system $\mathrm{Cu}^{\mathrm{II}}(\mathrm{Br})_{2}$ (HMTETA) is by two orders of magnitude below the termination rate coefficient $k_{\mathrm{t}}{ }^{1,1}{ }^{63}$ This difference demonstrates that deactivation does not occur under diffusion control, at least not at low degrees of monomer conversion. Deactivation is a chemically controlled process which encompasses structural reorganization of the complex and changes in the copper-halogen bonding. ${ }^{99,101}$

In this chapter, a novel method for the direct determination of deactivation rate coefficients was presented. The required rate coefficients and concentrations for the analysis of $k_{\text {deact }}$ via SP-PLP-EPR were deduced from independent measurements. Furthermore, it was shown that a large difference in $k_{\text {deact }}$ occurs between model and ATRP system in DMA polymerization mainly due to steric strain of the polymer backbone. The method will be extended to acrylate monomers in the next chapter to demonstrate the broad applicability of this SP-PLP-EPR strategy. 



\section{$7 \quad$ ATRP Deactivation of BA Radicals}

The previous chapter demonstrated the efficacy of the SP-PLP-EPR technique for measuring ATRP deactivation rate coefficients $k_{\text {deact }}$ for methacrylate monomers. In this chapter, the method is applied to measurements involving an acrylate monomer. Measuring the associated polymerization kinetics is particularly challenging, since, in general, secondary chain-end radicals (SPRs) are more reactive than methacrylates due to the radical being located at a secondary instead of a tertiary carbon atom. ${ }^{71,102}$ Thus, the propagation rate coefficient for BA was determined to be $k_{\mathrm{p}}=8.5 \cdot 10^{3} \mathrm{~L} \cdot \mathrm{mol}^{-1} \cdot \mathrm{s}^{-1}$ at $273 \mathrm{~K}$ which is by more than one order of magnitude higher than the associated value for DMA, $k_{\mathrm{p}}=2.4 \cdot 10^{3} \mathrm{~L} \cdot \mathrm{mol}^{-1} \cdot \mathrm{s}^{-1} \cdot{ }^{66,18,103}$ The $k_{\mathrm{t}}^{1,1}$ value for $\mathrm{BA}$ at $273 \mathrm{~K}$ with $k_{\mathrm{t}}^{1,1}=$ $2.6 \cdot 10^{8} \mathrm{~L} \cdot \mathrm{mol}^{-1} \cdot \mathrm{s}^{-1}$ also exceeds the corresponding value of $k_{\mathrm{t}}^{1,1}=1.2 \cdot 10^{7} \mathrm{~L} \cdot \mathrm{mol}^{-1} \cdot \mathrm{s}^{-1}$ for DMA. ${ }^{22,73,30}$

For the deactivation in ATRP, one would expect that the rate coefficient $k_{\text {deact }}$ is also significantly enhanced for acrylates as compared to methacrylates due to the higher reactivity. The influence of the back strain effect on $k_{\text {deact }}$ should be small in contrast to the results for DMA due to the missing $\alpha$-methyl group (cf. chapter 6). Therefore, differences between model and polymerizing systems should be less pronounced.

The kinetics of acrylates is rather complicated due to the generation of MCRs. ${ }^{104,18,105,106}$ These tertiary radicals are produced via intramolecular transfer to polymer involving a 1,5-H-shift from SPRs by the so-called backbiting reaction. ${ }^{73}$ The occurrence and the mechanism of backbiting in acrylate polymerization has been proven by EPR. ${ }^{107,108}$ It is well known that MCRs are far less reactive towards propagation. ${ }^{30,109}$ In terms of termination, the kinetics of acrylates is much more complex due to three reactions contributing to the overall termination rate: SPR and MCR homotermination, respectively, as well as SPR-MCR cross-termination. ${ }^{73}$ 
The reaction temperature for determination of $k_{\text {deact }}$ was chosen to be $233 \mathrm{~K}$. Shown in Figure 7.1 is the EPR spectrum of butyl acrylate in $15 \mathrm{wt} \% \mathrm{MeCN}$ recorded at $233 \mathrm{~K}$ with MMMP as the photoinitiator under continuous irradiation at a p.r.r. of $20 \mathrm{~Hz}$. The spectrum which depicts four broad lines is very similar to the reported one for BA polymerization in toluene at $233 \mathrm{~K} .{ }^{104}$ The spectrum is indicative of only SPRs being present. ${ }^{102}$ The radical functionality couples with the $\alpha$-proton and with two equivalent $\beta$ methylene protons. The expected doublet of triplet signals overlap to result in a four-line spectrum. ${ }^{104}$

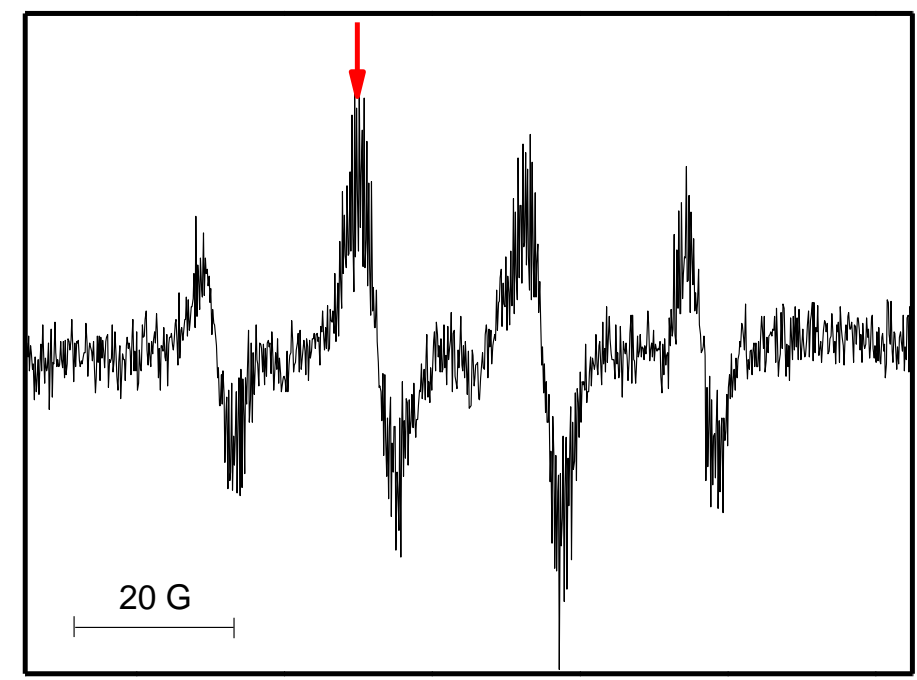

Figure 7.1. Characteristic 4-line EPR spectrum of propagating radicals in BA polymerization at $233 \mathrm{~K}$ recorded with a modulation amplitude of $3 \mathrm{G}$, a scan time of $10 \mathrm{~s}$ under pseudostationary conditions by continuous laser initiation at a p.r.r. of $20 \mathrm{~Hz}$. The arrow marks the magnetic field position used for the single pulse experiments.

The reverse ATRP-type approach in SP-PLP-EPR provides the initial absence of $\mathrm{Cu}^{\mathrm{I}}$. The conversion of $\mathrm{Cu}^{\mathrm{II}}$ to $\mathrm{Cu}^{\mathrm{I}}$ during the experiment was kept below $15 \%$ by applying only up to 5 single pulses per sample. Potential side reactions with $\mathrm{Cu}^{\mathrm{I}}$ may thus be ignored.

Figure 7.2 illustrates the characteristic EPR spectrum of $\mathrm{Cu}^{\mathrm{II}}(\mathrm{Br})_{2}$ (TPMA) in BA/MeCN $(85: 15, \mathrm{~g} / \mathrm{g})$ at $233 \mathrm{~K}$ before irradiation (black line) and after 10 laser single pulses (red 
line). The shape, the splitting pattern as well as the linewidth is similar to the $\mathrm{Cu}^{\mathrm{II}}$ spectra in solution of DMA illustrated in chapter 6. A distinct hyperfine splitting is seen at this temperature which is probably due to interactions of the unpaired electron with the copper and bromine nuclear spin.

The actual measurements of ATRP deactivation rate were carried out at up to three levels of $\mathrm{Cu}^{\mathrm{II}}$, between 0.5 and $0.05 \mathrm{mM}$. The three selected ligands for formation of $\mathrm{Cu}^{\mathrm{II}}$ complexes were HMTETA, PMDETA and TPMA (cf. Scheme 6.3).

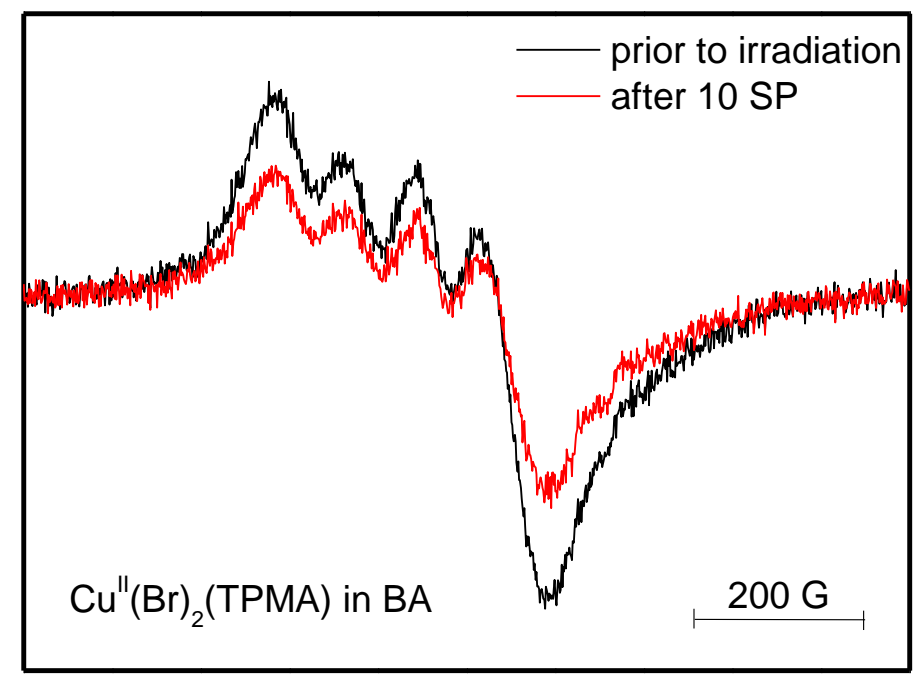

Figure 7.2. EPR spectrum of $\mathrm{Cu}^{\mathrm{II}}(\mathrm{Br})_{2}$ (TPMA) catalyst before (black line) and after laser irradiation (red line) in solution of the monomer BA with $15 \mathrm{wt} \% \mathrm{MeCN}$ recorded at $233 \mathrm{~K}$ with a modulation amplitude of $10 \mathrm{G}$.

The magnetic field for single pulse experiments is indicated by the red arrow in Figure 7.1. Shown in Figure 7.3 are the measured $c_{\mathrm{R}}(t)$ traces for BA polymerization at $233 \mathrm{~K}$. The upper curve (green) refers to the experiment carried out in the absence of copper, whereas the curves in blue and red have been measured in the presence of 0.06 and $0.2 \mathrm{mM}$ $\mathrm{Cu}^{\mathrm{II}}(\mathrm{Br})_{2}$ (HMTETA), respectively. The indicated $\mathrm{Cu}^{\mathrm{II}}$ concentrations refer to the average value from measurements before and after applying the sequence of single pulses. The decay of $c_{\mathrm{R}}(t)$ is significantly faster in the presence of $\mathrm{Cu}^{\mathrm{II}}$. The full lines illustrate the PREDICI fits as detailed further below. 


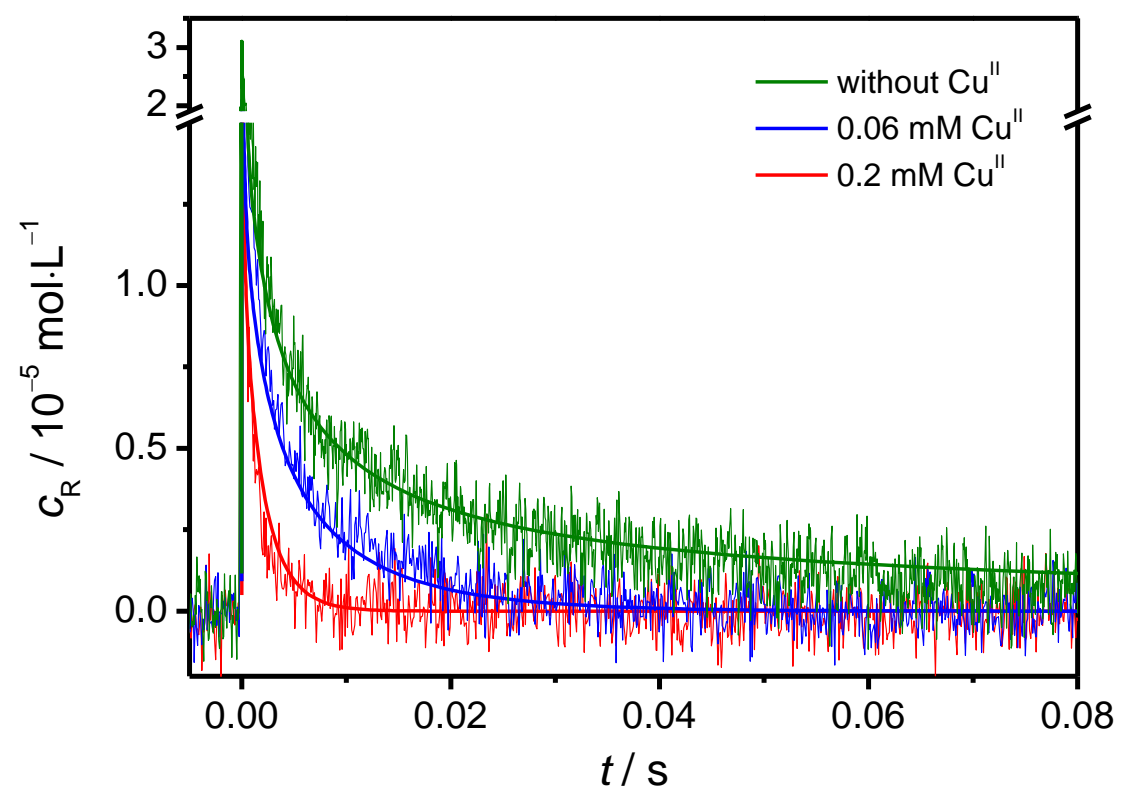

Figure 7.3. Time-resolved concentration of BA radicals after single laser pulse initiation at $t=0$ in $15 \mathrm{wt} \% \mathrm{MeCN}$. The upper curve was measured in the absence of copper (green), both lower curves (blue, red) were recorded in the presence of $\mathrm{Cu}^{\mathrm{II}}(\mathrm{Br})_{2}$ (TPMA). The full lines represent PREDICI modeled curves.

The recorded $c_{\mathrm{R}}(t)$ traces were fitted via PREDICI to obtain $k_{\text {deact. }}$. Due to only one type of radical species being present, the four relevant reaction steps are initiation, propagation, deactivation and termination (cf. Scheme 6.2), as in the investigations with methacrylates.

The analysis of ATRP deactivation rate via the modeling procedure requires precise rate coefficients of propagation and termination for BA polymerization in $15 \mathrm{wt} \% \mathrm{MeCN}$. Contrary to other acrylates, the value of $k_{\mathrm{p}}$ for BA polymerization in organic solvents (1.5 to $2.5 \mathrm{~mol} \cdot \mathrm{L}^{-1}$ ) is close to the value for bulk polymerization. ${ }^{14,110}$ Therefore, the reported $k_{\mathrm{p}}$ data for bulk BA is assumed to hold for BA in $15 \mathrm{wt} \% \mathrm{MeCN} .{ }^{111}$ This approximation should be particularly justified for the solutions under investigation, as the BA concentration $\left(5.8 \mathrm{~mol} \cdot \mathrm{L}^{-1}\right)$ is close to the bulk concentration $\left(7 \mathrm{~mol} \cdot \mathrm{L}^{-1}\right)$.

The variation of solvent is expected to predominantly influence the $k_{\mathrm{t}}{ }^{1,1}$ parameter due to the associated variation in solvent viscosity. ${ }^{73,30}$ However, in case of BA in $15 \mathrm{wt} \%$ 
$\mathrm{MeCN}$, the viscosity of the solution only varies by $10 \%$ as compared to the value for bulk BA (cf. appendix). Therefore, the composite-model parameters for CLDT of bulk BA were used. ${ }^{73}$

Literature data of $k_{\text {deact }}$ from ATRP experiments with BA and the associated ligands is not available. Thus the reported data deduced for monomer-free model systems based on initiators of similar functionality may serve for comparison.

Table 7.1. Deactivation rate coefficient $k_{\text {deact }}$ for BA and DMA polymerization in $15 \mathrm{wt} \%$ $\mathrm{MeCN}$ at $233 \mathrm{~K}$. The values for DMA were already presented in chapter 6 and were extrapolated to $233 \mathrm{~K}$ via the associated activation energy of $22 \mathrm{~kJ} \cdot \mathrm{mol}^{-1}$. The coefficients for the model system with methyl 2-bromopropionate (MBrP) were measured at $295 \mathrm{~K} .{ }^{89}$ Data of $k_{\text {deact }}$ for BA polymerization at $295 \mathrm{~K}$ were extrapolated assuming the same activation energy as compared to DMA polymerization.

\begin{tabular}{c|cccc|c}
\hline \multirow{2}{*}{ ligand } & \multicolumn{5}{|c|}{$\boldsymbol{k}_{\text {deact }} /{\mathbf{L} \cdot \mathbf{m o l}^{-\mathbf{1}} \cdot \mathbf{s}^{-\mathbf{1}}}^{(\mathbf{B A}) /}$} \\
& $\mathbf{B A}$ & $\mathbf{M B r P}$ & $\mathbf{B A}^{a}$ & $\mathbf{D M A}^{\boldsymbol{b}}$ & $(\mathbf{D M A})$ \\
& $\mathbf{2 3 3} \mathbf{K}$ & $\mathbf{2 9 5 K}$ & $\mathbf{2 9 5} \mathbf{K}$ & $\mathbf{2 3 3} \mathbf{K}$ & $\mathbf{2 3 3 K}$ \\
\hline HMTETA & $(2.0 \pm 0.5) \cdot 10^{6}$ & $2.3 \cdot 10^{7}$ & $2 \cdot 10^{7}$ & $7 \cdot 10^{4}$ & 29 \\
PMDETA & $(6 \pm 2) \cdot 10^{6}$ & $4.3 \cdot 10^{7}$ & $6 \cdot 10^{7}$ & $2 \cdot 10^{5}$ & 30 \\
TPMA & $(9 \pm 2) \cdot 10^{5}$ & $1.2 \cdot 10^{7}$ & $1 \cdot 10^{7}$ & $8 \cdot 10^{4}$ & 11 \\
\hline
\end{tabular}

${ }^{a}$ Data of $k_{\text {deact }}$ measured at $233 \mathrm{~K}$ were extrapolated to $295 \mathrm{~K}$ assuming the activation energy of $22 \mathrm{~kJ} \cdot \mathrm{mol}^{-1}$ for DMA polymerization from chapter 6 .

$b$ The deactivation data measured at $293 \mathrm{~K}$ were extrapolated to $233 \mathrm{~K}$ via $E_{\mathrm{A}}=$ $22 \mathrm{~kJ} \cdot \mathrm{mol}^{-1}$.

The measured $k_{\text {deact }}$ values for BA polymerization at $233 \mathrm{~K}$ are listed in Table 7.1. The highest coefficients were obtained for $\mathrm{Cu}$ complexes with PMDETA as the ligand, the lowest for complexes with TPMA. The values of $k_{\text {deact }}$ for the model system with methyl 2-bromopropionate $(\mathrm{MBrP})$, which were calculated from $k_{\text {act }}$ and $K_{\mathrm{ATRP}}$, reflect the same 
trend. However, the experiments with $\mathrm{MBrP}$ were performed at $295 \mathrm{~K}$ instead of $233 \mathrm{~K}$. The coefficients thus exceed the associated values for BA by one order of magnitude.

Since $k_{\text {deact }}$ for BA polymerization was only measured at $233 \mathrm{~K}$, no activation energy is available. Therefore, it was assumed that the activation energy of $k_{\text {deact }}$ for BA is similar to the one obtained for DMA (cf. chapter 6). Shown in Table 7.1 are the extrapolated values which are in close agreement with the $k_{\text {deact }}$ data for the model system with MBrP. Even a variation of the activation energy by $30 \%$ would only lead to a difference between model and polymerizing system of a factor of 2. This is still far below the differences obtained between model and DMA polymerization.

The reported equilibrium constants for BA polymerization, $K_{\mathrm{ATRP}}$, and for the model system with methyl 2-bromopropionate $(\mathrm{MBrP}), K_{\text {model }}$, were measured with PMDETA and TPMA being the ligands (Table 7.2). ${ }^{82}$ The values for both systems shown in Table 7.2 are in close agreement which furthermore support the similarity of $k_{\text {deact. }}$.

Table 7.2. Equilibrium constants $K_{\mathrm{ATRP}}$ for BA polymerization and $K_{\text {model }}$ for the model system with methyl 2-bromopropionate $(\mathrm{MBrP})$ being the initiator measured at $295 \mathrm{~K} .{ }^{82}$

\begin{tabular}{ccc}
\hline ligand & $\boldsymbol{K}_{\text {ATRP }}(\mathbf{B A})$ & $\boldsymbol{K}_{\text {model }}(\mathbf{M B r P})$ \\
\hline PMDETA & $1.8 \cdot 10^{-9}$ & $4.4 \cdot 10^{-9}$ \\
TPMA & $2.3 \cdot 10^{-7}$ & $3.1 \cdot 10^{-7}$ \\
\hline
\end{tabular}

It should be noted that the $k_{\text {deact }}$ values for all three ligands in BA polymerization at $233 \mathrm{~K}$ exceed the associated coefficients for DMA polymerization by at least one order of magnitude. The expected increase in $k_{\text {deact }}$ should be due to the enhanced reactivity of the secondary radicals in acrylate polymerization.

The coefficients for BA with HMTETA and PMDETA being the ligand are by a factor of 30 higher, whereas with TPMA as the ligand, the coefficient differs by only about one order of magnitude. The differences in the relative values of $k_{\text {deact }}$ in BA as compared to DMA polymerization should be due the back strain effect in DMA polymerization. The 
B-effect influences $k_{\text {deact }}$ of $\mathrm{Cu}$ (TPMA) complexes with DMA less significantly, thus resulting in higher values for $k_{\text {deact }}$ and a smaller difference as compared to BA polymerization with the same catalyst.

The control in ATRP polymerization yielding low dispersities and predictable molar masses depends mainly on the ratio of $k_{\mathrm{p}}$ and $k_{\text {deact. }}$. Since $k_{\mathrm{p}}$ for acrylates is significantly higher than for methacrylates, $k_{\text {deact }}$ must also increase to achieve similar control.

In this part, the SP-PLP-EPR method for determination of $k_{\text {deact }}$ from ATRP kinetics was successfully applied to butyl acrylate polymerization. For dodecyl methacrylate, a difference between model and polymerizing system was observed due to the back-strain effect. As such an effect is not operative in BA polymerization, both the reported data for ATRP model systems and for the polymerization system as obtained via the SP-PLP-EPR approach are in close agreement. Because of the close similarity of $k_{\text {deact, }}$ data from model systems are suitable to describe the kinetics in acrylate polymerization to a good approximation.

\subsection{Deactivation of Radicals at High Conversion of $\mathrm{Cu}^{\prime \prime}$}

The overall conversion of $\mathrm{Cu}^{\mathrm{II}}$ to $\mathrm{Cu}^{\mathrm{I}}$ was kept low for measuring $k_{\text {deact }}$ to avoid potential reactions with $\mathrm{Cu}^{\mathrm{I}}$ as described above. Such reactions may, however, become evident at significantly higher degrees of $\mathrm{Cu}^{\mathrm{II}}$ conversion. Shown in Figure 7.4 is an EPR spectrum of $0.5 \mathrm{mM} \mathrm{Cu}{ }^{\mathrm{II}}(\mathrm{Br})_{2}$ (TPMA) in a mixture of BA/MeCN (85:15) (black). After 60 single pulses (SP) the signal almost completely disappeared (grey) indicating that $\mathrm{Cu}^{\mathrm{II}}$ has almost quantitatively been converted into $\mathrm{Cu}^{\mathrm{I}}$. 


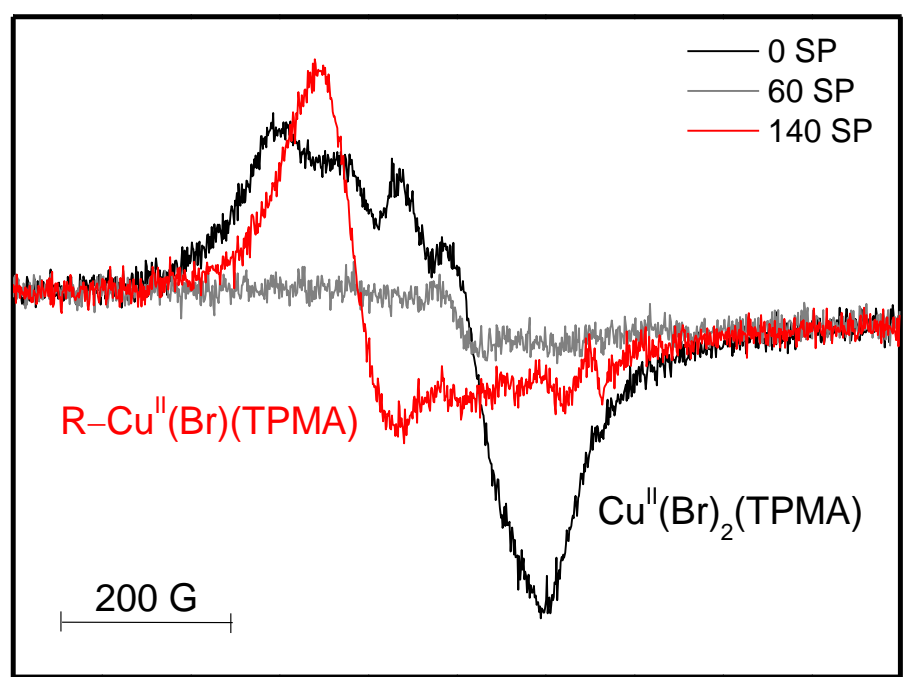

Figure 7.4. EPR signal of $0.5 \mathrm{mM} \mathrm{Cu}{ }^{\mathrm{II}}(\mathrm{Br})_{2}$ (TPMA) before laser irradiation (black line). After 60 single pulses the signal almost entirely disappeared (grey line). After applying further $80 \mathrm{SP}$, the signal of a different $\mathrm{Cu}^{\mathrm{II}}$ species appeared (red line). The signals were recorded at $233 \mathrm{~K}$ using a modulation amplitude of $10 \mathrm{G}$.

Upon the application of additional laser pulses, the EPR signal of a second species appeared, which should be associated to the formation of a different type of $\mathrm{Cu}^{\mathrm{II}}$ species. The advantage of SP-PLP-EPR over other methods for determination of ATRP kinetics is due to the possibility of avoiding significant concentration of $\mathrm{Cu}^{\mathrm{I}}$. In other spectroscopic methods, much higher concentrations of $\mathrm{Cu}^{\mathrm{I}}$ were simultaneously used in the presence of radicals. Therefore, potential reactions with $\mathrm{Cu}^{\mathrm{I}}$ cannot generally be excluded. To obtain further insight into the reactions of $\mathrm{Cu}^{\mathrm{I}}$ with BA radicals, SP-PLP-EPR should be carried out starting directly with the associated $\mathrm{Cu}^{\mathrm{I}}$ complex in the absence of the $\mathrm{Cu}^{\mathrm{II}}$ ATRP deactivator. Such experiments will be presented in chapter 8 . 


$$
\begin{aligned}
& \mathrm{Br}-\mathrm{Cu}{ }^{\prime \prime}(\mathrm{Br})(\mathrm{TPMA})+\mathrm{R}^{\bullet} \\
& \stackrel{k_{\text {deact }}}{\longrightarrow} \mathrm{Cu}(\mathrm{Br})(\mathrm{TPMA})+\mathrm{R}-\mathrm{Br} \\
& \stackrel{+\mathrm{R}^{\bullet}}{\longrightarrow} \mathrm{R}-\mathrm{Cu}^{\prime \prime}(\mathrm{Br})(\mathrm{TPMA})
\end{aligned}
$$

Scheme 7.1. Reaction scheme of the experiment illustrated in Figure 7.4. By applying laser pulses, radicals were generated which were subsequently deactivated by the $\mathrm{Cu}^{\mathrm{II}}(\mathrm{Br})_{2}$ (TPMA) species and the associated $\mathrm{Cu}^{\mathrm{I}}$ species is formed. After applying further laser pulses, the radicals react with $\mathrm{Cu}^{\mathrm{I}}$ to a different $\mathrm{Cu}^{\mathrm{II}}$ species $\left(\mathrm{R}-\mathrm{Cu}^{\mathrm{II}}(\mathrm{Br})(\mathrm{TPMA})\right.$. 



\section{$8 \quad$ Interactions of Radicals with Cu' Complexes}

In the previous chapter, a potential interaction of radicals with the $\mathrm{Cu}^{\mathrm{I}}(\mathrm{Br})(\mathrm{TPMA})$ complex in BA polymerization was observed forming a different $\mathrm{Cu}^{\mathrm{II}}$ species. An interaction between $\mathrm{Cu}^{\mathrm{I}}$ species and radicals was previously reported, however, the effect on ATRP was not quantified. ${ }^{58,112,113}$ In this chapter, these interactions are analyzed via EPR spectroscopy and the importance and influence on ATRP is investigated.

In the $\mathrm{Cu}$-mediated ATRP process, the alkyl halide $(\mathrm{R}-\mathrm{Br})$ is activated by $\mathrm{Cu}(\mathrm{Br})(\mathrm{L})(\mathrm{L}$ : ligand) to generate radicals and the higher oxidized $\mathrm{Cu}^{\mathrm{II}}(\mathrm{Br})_{2}(\mathrm{~L})$ state. After addition of one or a few monomer units, the radicals react with $\mathrm{Cu}^{\mathrm{II}}(\mathrm{Br})_{2}(\mathrm{~L})$ to regenerate $\mathrm{R}-\mathrm{Br}$ as the dormant species. ${ }^{5}$ Concurrently, two radicals may react with each other to form dead chains.

Assuming that the loss of chain-end functionality (CEF) is caused exclusively by termination between two radicals, the molar percentage of dead chains $\left(T_{\mathrm{mol}} \%\right)$ may be correlated with the targeted degree of polymerization $\left(\mathrm{DP}_{\mathrm{T}}\right)$, reaction time $t$ and conversion of monomer $X$ (eq 8.1). ${ }^{114}$ However, the actual loss of CEF could also result from irreversible chain transfer to monomer, solvent or catalyst which would increase the observed value of $T_{\mathrm{mol} \%}{ }^{59}$

$$
T_{\mathrm{mol} \%}=\frac{2 k_{\mathrm{t}}}{k_{\mathrm{p}}^{2}} \cdot \frac{\ln ^{2}\left(\frac{1}{1-X}\right)}{t \cdot[\mathrm{RX}]_{0}}=\frac{2 k_{\mathrm{t}}}{k_{\mathrm{p}}^{2}} \cdot \frac{\mathrm{DP}_{\mathrm{T}} \cdot \ln ^{2}\left(\frac{1}{1-X}\right)}{t \cdot[\mathrm{M}]_{0}}
$$

Several ATRP studies into methyl acrylate and butyl acrylate, respectively, showed that the experimental values of $T_{\mathrm{mol} \%}$ are in all cases much higher than the predicted values assuming termination exclusively between two radicals. ${ }^{115-117}$ For example, in normal ATRP of methyl acrylate (MA) with $[\mathrm{MA}]_{0}:[\mathrm{EtBrP}]_{0}:\left[\mathrm{Cu}{ }^{\mathrm{I} B r}\right]_{0}:\left[\mathrm{Cu}^{\mathrm{II}} \mathrm{Br}_{2}\right]_{0}:[\mathrm{TPMA}]_{0}=$ 200:1:0.1:0.1:0.24 in $\mathrm{MA} / \mathrm{MeCN}=1 / 1(\mathrm{v} / \mathrm{v})$ at $313 \mathrm{~K}$ (conversion of $62.5 \%$ after $6.5 \mathrm{~h}$ ) 
the molar percentage of dead chains was $T_{\mathrm{mol}} \%=1.9 \%$, while the predicted value was $T_{\mathrm{mol} \%}=0.05 \%{ }^{115}$ These experiments indicate that some additional termination reactions occur in the ATRP process which caused a more significant loss of CEF than predicted by the values for termination of two radicals. ${ }^{59}$

Furthermore, three normal ATRP experiments of MA were performed with different initial amounts of $\mathrm{Cu}^{\mathrm{I}}$ under identical reaction conditions. Since the initial ratio of $\mathrm{Cu}^{\mathrm{I}}$ to $\mathrm{Cu}^{\mathrm{II}}$ was the same in all three experiments, they should give the same value for $T_{\text {mol }} \%$ according to eq. 8.1, if the loss of CEF occurred mainly due to termination between two radicals. However, the value for $T_{\mathrm{mol}} \%$ increased with the initial concentration of $\mathrm{Cu}^{\mathrm{I}} .^{59}$ These findings suggest a reaction between radicals and the $\mathrm{Cu}^{\mathrm{I}}$ species, which supports the observations from chapter 7.1.

\subsection{Mechanism of Cu'-Induced Termination}

It was shown for the normal ATRP of MA in $\mathrm{MeCN}$ with $\mathrm{Cu}^{\mathrm{I}}(\mathrm{Br})$ (TPMA) that each $\mathrm{R}-\mathrm{X}$ oxidizes one $\mathrm{Cu}^{\mathrm{I}}$ to $\mathrm{Cu}^{\mathrm{II}}{ }^{59} \mathrm{No}$ further $\mathrm{Cu}^{\mathrm{II}}$ was generated during the polymerization. Thus, the $\mathrm{Cu}^{\mathrm{I}}$-induced termination should be a catalytic process, in which $\mathrm{Cu}^{\mathrm{I}}$ reacts with a radical to form an intermediate which can then react with another radical to regenerate the $\mathrm{Cu}^{\mathrm{I}}$ species and form dead chains.

The most probable reaction between $\mathrm{Cu}^{\mathrm{I}}(\mathrm{Br})(\mathrm{L})$ (L: TPMA) and a radical should be the formation of either $\mathrm{R}-\mathrm{Cu}^{\mathrm{II}}(\mathrm{Br})(\mathrm{L})$ and/or $\mathrm{H}-\mathrm{Cu}^{\mathrm{II}}(\mathrm{Br})(\mathrm{L})$ species (Scheme 8.1). These species should be very reactive and may quickly terminate with another radical to regenerate $\mathrm{Cu}^{\mathrm{I}}(\mathrm{Br})(\mathrm{L})$ and form dead chains.

A direct reaction between $\mathrm{R}-\mathrm{Cu}^{\mathrm{II}}(\mathrm{Br})(\mathrm{L})$ and a polymeric radical may be sterically hindered. Hence, it is plausible that $\mathrm{R}-\mathrm{Cu}{ }^{\mathrm{II}}(\mathrm{Br})(\mathrm{L})$ undergoes a $\beta$-H elimination to form an unsaturated polymer chain and $\mathrm{H}-\mathrm{Cu}^{\mathrm{II}}(\mathrm{Br})(\mathrm{L})$. Alternatively, the polymeric radical may react with $\mathrm{Cu}^{\mathrm{I}}(\mathrm{Br})(\mathrm{L})$ to form an unsaturated dead chain $\left(\mathrm{R}^{=}\right)$and $\mathrm{H}-\mathrm{Cu}^{\mathrm{II}}(\mathrm{Br})(\mathrm{L})$ directly without intermediates. The generated $\mathrm{H}-\mathrm{Cu}{ }^{\mathrm{II}}(\mathrm{Br})(\mathrm{L})$ species reacts rapidly with another radical to reform $\mathrm{Cu}^{\mathrm{I}}(\mathrm{Br})(\mathrm{L})$ and a saturated dead chain $\left(\mathrm{R}^{\mathrm{H}}\right)$. 
The low proportion of termination products formed by coupling, which are favored in conventional termination between two radicals for acrylates, supports the formation of $\mathrm{H}-$ $\mathrm{Cu}^{\mathrm{II}}(\mathrm{Br})(\mathrm{L}){ }^{34}$

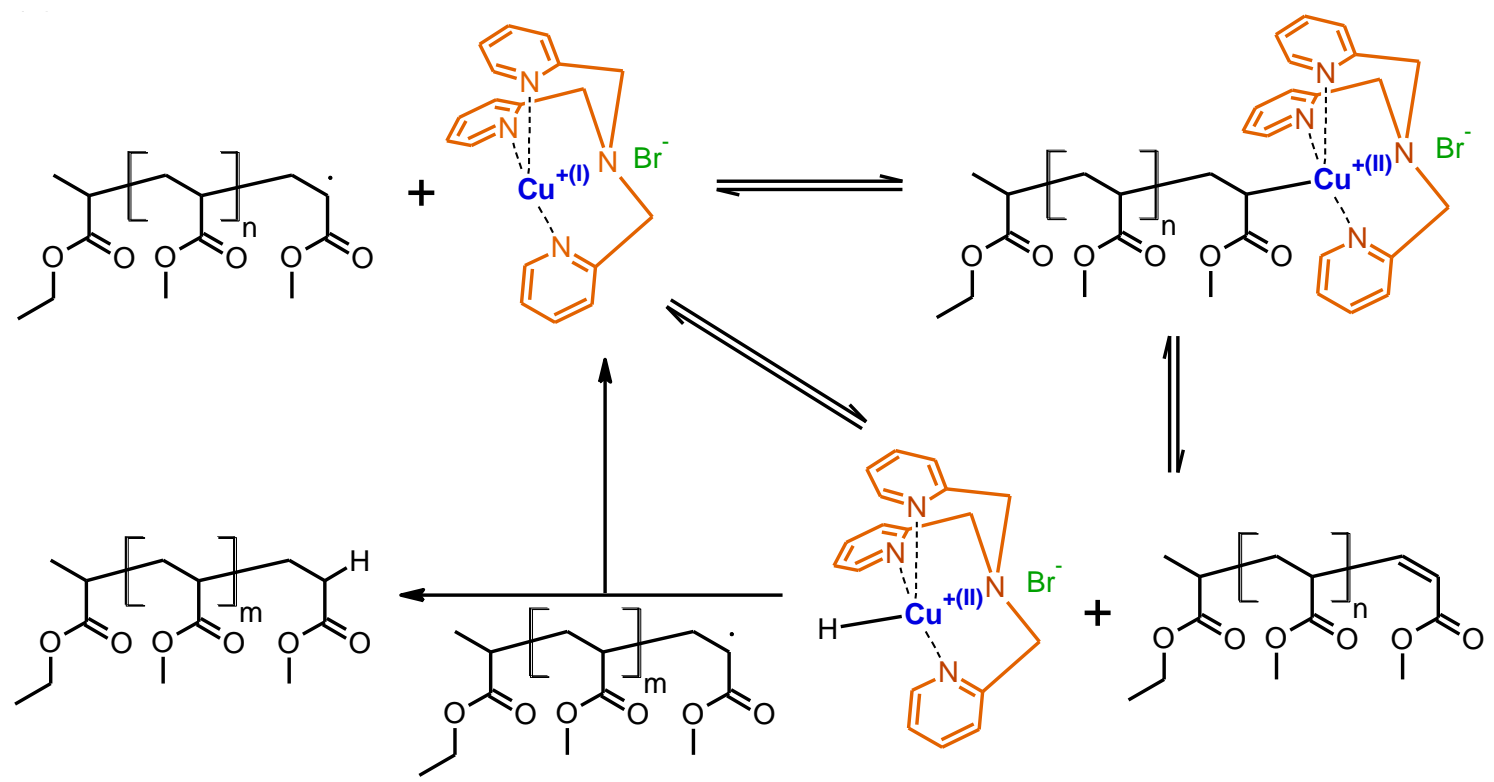

Scheme 8.1. Proposed mechanism of $\mathrm{Cu}^{\mathrm{I}}$-induced termination illustrated for $\mathrm{MA}$ polymerization with EtBrP as initiator and TPMA as the ligand of the $\mathrm{Cu}$ complex. ${ }^{59} \mathrm{~A}$ detailed description of the mechanism is included in chapter 8.1.

\subsection{EPR Detection of Cu" Intermediates}

EPR measurements were carried out in order to directly observe the formation of $\mathrm{R}-$ $\mathrm{Cu}^{\mathrm{II}}(\mathrm{Br})(\mathrm{TPMA})$ and/or $\mathrm{H}-\mathrm{Cu}^{\mathrm{II}}(\mathrm{Br})(\mathrm{TPMA})$ species. Figure 8.1-A illustrates the EPR signals for laser-induced BA polymerization in $15 \mathrm{wt} \% \mathrm{MeCN}$ with $3 \mathrm{mM}$ $\mathrm{Cu}^{\mathrm{I}}(\mathrm{Br})(\mathrm{TPMA})$ measured at $233 \mathrm{~K}$. Thus, the mixture contained the $\mathrm{Cu}^{\mathrm{I}}$-active catalyst. However, due to the absence of an ATRP initiator $\mathrm{R}-\mathrm{X}$, formation of the $\mathrm{Br}-$ $\mathrm{Cu}^{\mathrm{II}}(\mathrm{Br})(\mathrm{TPMA})$ species via halogen transfer did not occur. Therefore, radicals were generated by laser-induced decomposition of MMMP. 

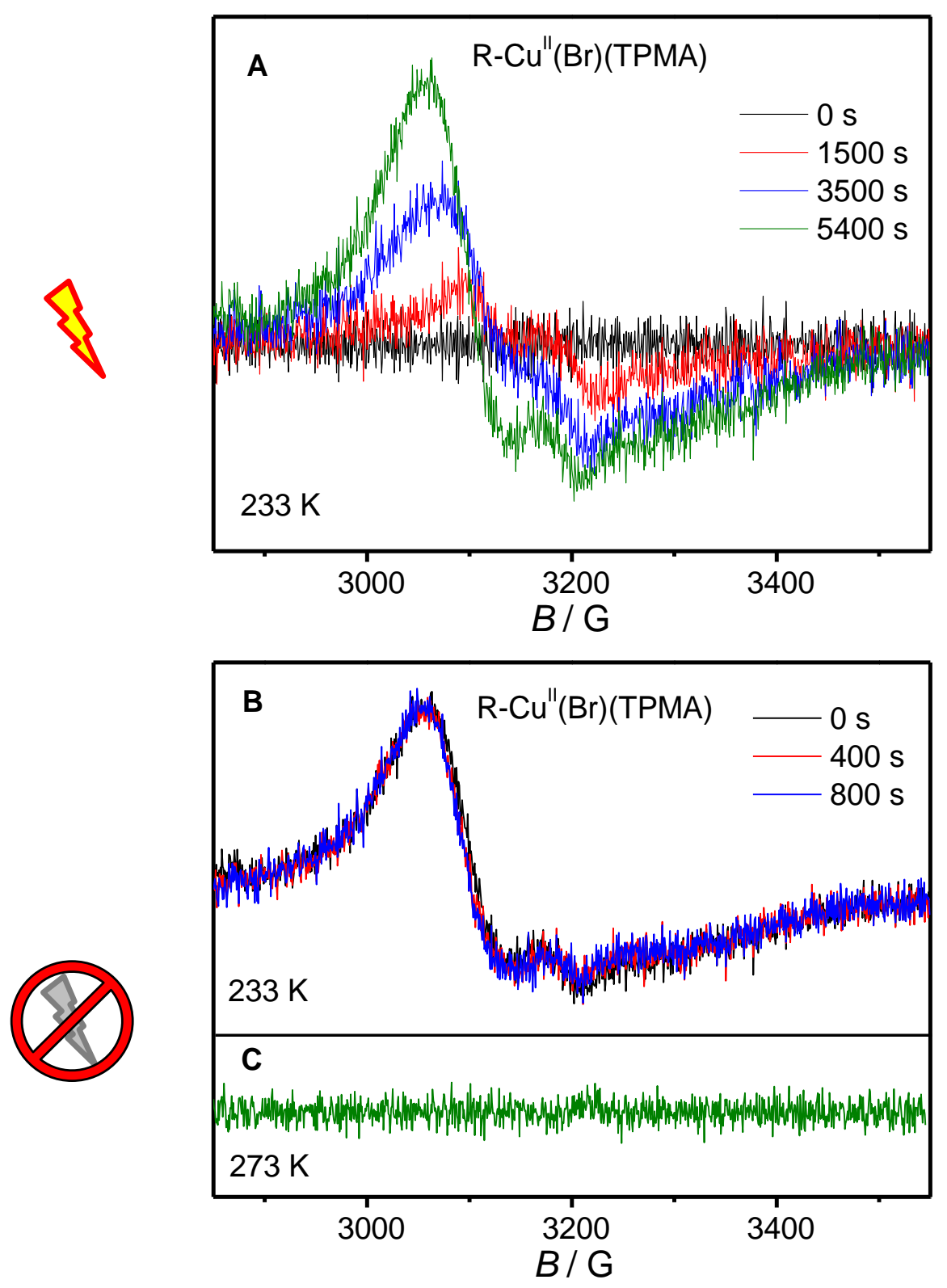

Figure 8.1. A: EPR spectrum of intermediate $\mathrm{R}-\mathrm{Cu}(\mathrm{Br})(\mathrm{TPMA})$ species prior to irradiation (black line) and after different irradiation times at a laser repetition rate of $0.2 \mathrm{~Hz}$ measured at $233 \mathrm{~K}$ in $\mathrm{BA}$ with $15 \mathrm{wt} \% \mathrm{MeCN}$. B: Constant EPR signal of the intermediate species measured at $233 \mathrm{~K}$ over a time period of $800 \mathrm{~s}$ without further irradiation. C: EPR spectrum measured at $293 \mathrm{~K}$ (green line). The observed signal in B has disappeared. 
The traces were recorded prior to irradiation (black line) and after laser pulsing at a repetition rate of $0.2 \mathrm{~Hz}$ for $1500 \mathrm{~s}$ (red line), $3500 \mathrm{~s}$ (blue line) and $5400 \mathrm{~s}$ (green line). During reaction, a broad signal between 2900 and $3500 \mathrm{G}$ emerged, which is assigned to a $\mathrm{Cu}^{\mathrm{II}}$ complex, because the field position exhibits the typical signature of these complexes. The higher the number of applied laser pulses, the higher is the accumulated amount of $\mathrm{Cu}^{\mathrm{II}}$.

After laser pulsing, the signal remains constant at $233 \mathrm{~K}$ for at least $800 \mathrm{~s}$ (Figure 8.1-B), implying that the complex is stable at this temperature. However, upon heating the sample to $293 \mathrm{~K}$, the signal disappeared (Figure 8.1-C), which demonstrates the limited stability of the intermediate $\mathrm{Cu}^{\mathrm{II}}$ species. No further irradiation occurred and thus no radials were photochemically produced, which indicates that dissociation occurs at higher temperature.

In the laser-induced BA polymerization, two types of radicals are present, i.e., primary radicals produced by decomposition of the photoinitiator and BA radicals generated after addition of monomer. To distinguish which of these two radicals predominantly reacts with $\mathrm{Cu}^{\mathrm{I}}(\mathrm{Br})(\mathrm{TPMA})$, the experiment was repeated in the absence of monomer. Therefore, BA was replaced by butyl propionate (BP), the saturated analogue of BA, acting as the solvent. Since BP does not possess a $\mathrm{C}-\mathrm{C}$ double bond, no propagation occurs and $\mathrm{Cu}^{\mathrm{I}}(\mathrm{Br})(\mathrm{TPMA})$ may only react with initiator fragments.

Shown in Figure 8.2-A is the EPR spectrum observed for the laser-induced decomposition of MMMP in BP at $233 \mathrm{~K}$. The black line represents the spectrum prior to irradiation. As compared to the measurements in BA, only two small peaks were observed in the same field range (red line). Moreover, the signal is not increasing with an additional number of laser pulses (blue line). After irradiation, the signal immediately disappeared even at $233 \mathrm{~K}$ (Figure 8.2-B).

For these reasons, the signals shown in Figure 8.1 should be predominately due to the reaction of $\mathrm{BA}$ radicals with the $\mathrm{Cu}^{\mathrm{I}}(\mathrm{Br})(\mathrm{TPMA})$ complex. 


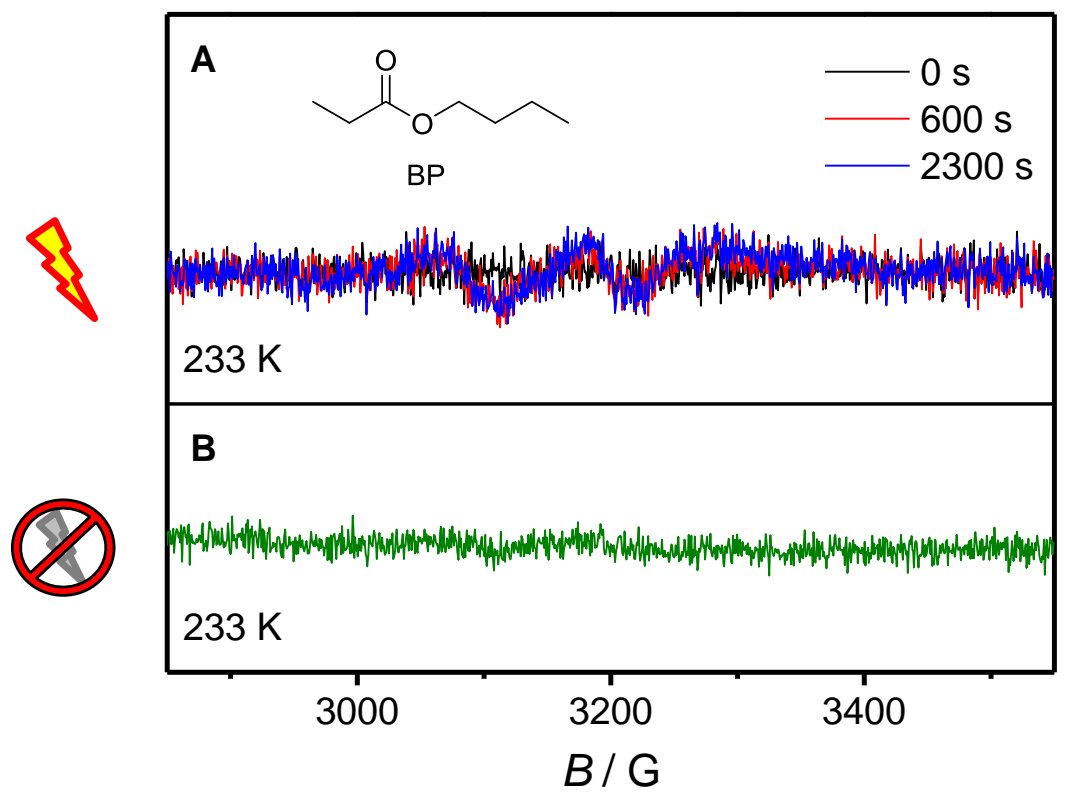

Figure 8.2. A: EPR spectrum prior to irradiation (black line) and after different irradiation times at a laser repetition rate of $0.2 \mathrm{~Hz}$ measured at $233 \mathrm{~K}$ in butyl propionate $(\mathrm{BP}) / \mathrm{MeCN}(85: 15 \mathrm{wt} \%)$. A signal emerged (red line), which is not significantly accumulated over time (blue line) B: The signal immediately disappeared in the absence of irradiation.

Instead of $\mathrm{Cu}^{\mathrm{I}}(\mathrm{Br})(\mathrm{TPMA}), \mathrm{Cu}^{\mathrm{I}}\left(\mathrm{PF}_{6}\right)$ (TPMA) was used in $\mathrm{BA}$ polymerization to avoid the presence of halogen atoms and thus formation of any $\mathrm{Br}-\mathrm{Cu}^{\mathrm{II}}$ ATRP-type complexes. During irradiation of the sample, an EPR spectrum of a similar $\mathrm{Cu}^{\mathrm{II}}$ species was observed at $233 \mathrm{~K}$ (cf. green line, Figure 8.2). The associated intermediate $\mathrm{Cu}^{\mathrm{II}}$ complex is also stable at $233 \mathrm{~K}$ and dissociates at higher temperatures.

Figure 8.3 illustrates the EPR spectra of $\mathrm{R}-\mathrm{Cu}^{\mathrm{II}}(\mathrm{Br})(\mathrm{TPMA})$ (blue line) and $\mathrm{R}-$ $\mathrm{Cu}^{\mathrm{I}}\left(\mathrm{PF}_{6}\right)$ (TPMA) (green line) as compared to the spectrum of $\mathrm{Cu}^{\mathrm{II}}(\mathrm{Br})_{2}(\mathrm{TPMA})$ (red line) measured at $233 \mathrm{~K}$. All three spectra are characterized by a broad signal between 2900 and $3500 \mathrm{G}$. This similarity demonstrates the formation of an organometallic $\mathrm{Cu}^{\mathrm{II}}$ intermediate and the interaction of the $\mathrm{Cu}^{\mathrm{I}}$ species with radicals. Unfortunately, it is not possible to determine whether the observed signals of the intermediate species belong to $\mathrm{R}-\mathrm{Cu}^{\mathrm{II}}(\mathrm{Br})(\mathrm{TPMA})$ or $\mathrm{H}-\mathrm{Cu}^{\mathrm{II}}(\mathrm{Br})(\mathrm{TPMA})$ because of the poor quality of the spectra. 


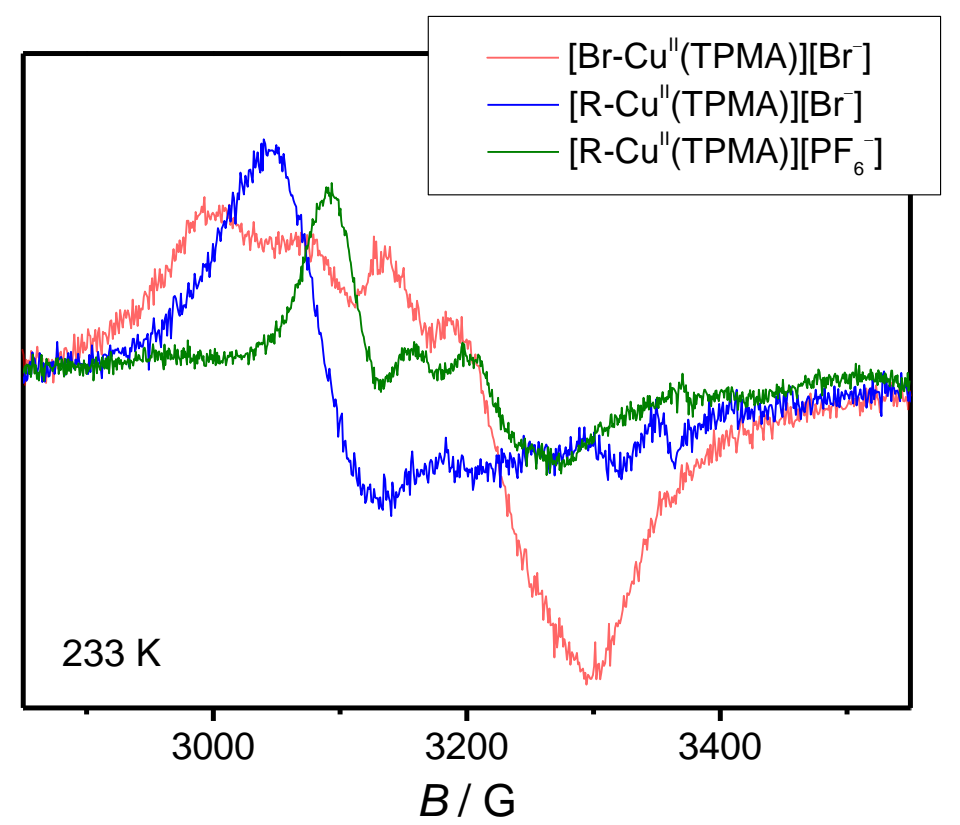

Figure 8.3. EPR spectra of $\mathrm{R}-\mathrm{Cu}^{\mathrm{II}}(\mathrm{Br})(\mathrm{TPMA})$ (blue line) and $\mathrm{R}-$ $\mathrm{Cu}^{\mathrm{I}}\left(\mathrm{PF}_{6}\right)$ (TPMA) (green line) as compared to the spectrum of $\mathrm{Cu}^{\mathrm{II}}(\mathrm{Br})_{2}$ (TPMA) (red line) measured at $233 \mathrm{~K}$. In all cases a broad signal between 2900 and $3500 \mathrm{G}$ appeared.

For a more precise analysis of the dissociation process of the $\mathrm{Cu}^{\mathrm{II}}$ intermediates, single pulse experiments of $\mathrm{BA}$ in $15 \mathrm{wt} \% \mathrm{MeCN}$ were performed at $233 \mathrm{~K}$ in the presence of $1 \mathrm{mM} \mathrm{Cu}(\mathrm{Br})($ TPMA) with MMMP as the photoinitiator.

First, the sample was irradiated at $233 \mathrm{~K}$ and the time-resolved spectra of around 20 single pulses were co-added (black line, Figure 8.4). The decay in radical concentration is faster based on the additional $\mathrm{Cu}^{\mathrm{I}}$-induced termination as compared to the experiment in the absence of $\mathrm{Cu}$ (dashed line). After the first sequence of SP, the sample was further irradiated by around 100 laser pulses at a repetition rate of $0.2 \mathrm{~Hz}$ without EPR detection. Subsequently, the $c_{\mathrm{R}}(t)$ traces of $20 \mathrm{SP}$ were recorded (blue line). The decay of the signal is significantly slower due to the lower $\mathrm{Cu}^{\mathrm{I}}$ concentration and the associated formation of stable $\mathrm{Cu}^{\mathrm{II}}$ intermediates.

Following the second SP sequence, the sample was heated to $293 \mathrm{~K}$ for 2 minutes and afterwards cooled down to the prior reaction temperature of $233 \mathrm{~K}$. Then a third sequence of $20 \mathrm{SP}$ was applied. As illustrated by the red line in Figure 8.4, the termination is 
accelerated and the decay is almost as fast as compared to the beginning of the experiment. This shows that, by dissociation of the $\mathrm{Cu}^{\mathrm{II}}$ intermediate at higher temperatures, $\mathrm{Cu}^{\mathrm{I}}$ is regenerated. The associated higher $\mathrm{Cu}^{\mathrm{I}}$ concentration leads to the faster decay in radical concentration.

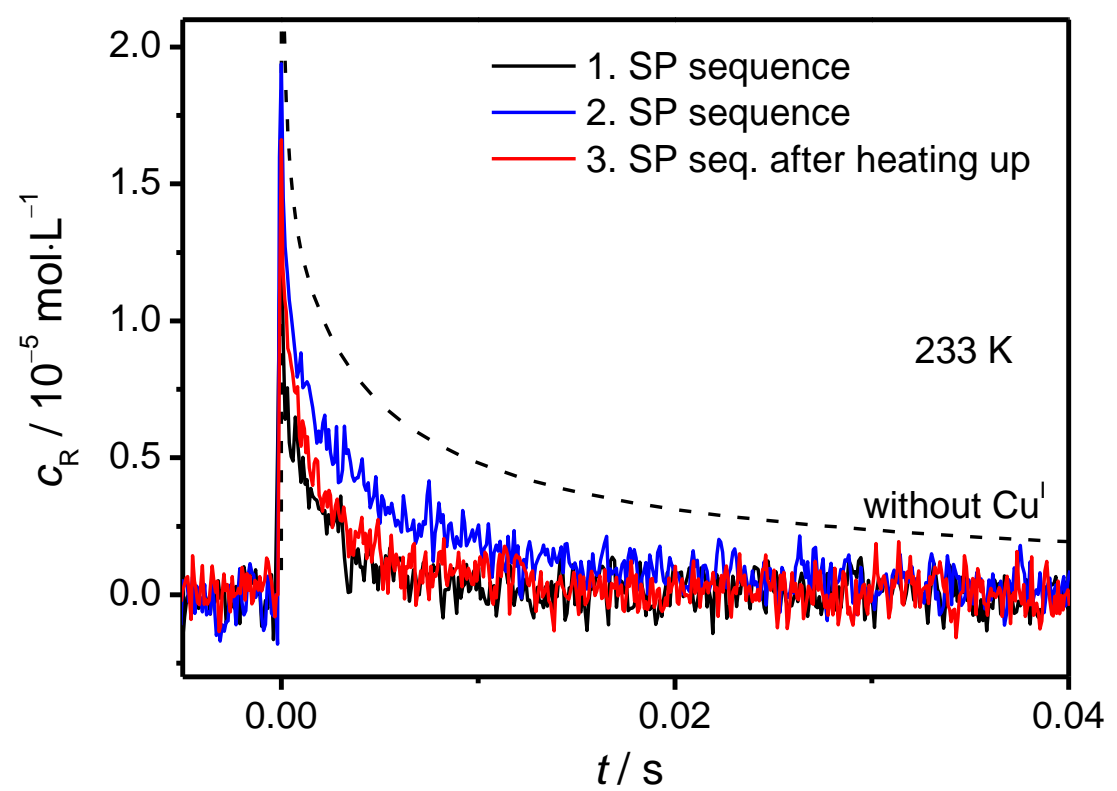

Figure 8.4. Time-resolved EPR spectra of BA polymerization in $15 \mathrm{wt} \%$ $\mathrm{MeCN}$ in the presence of different amounts of $\mathrm{Cu}^{\mathrm{I}}$ measured at $233 \mathrm{~K}$. The first spectrum was recorded with $1 \mathrm{mMCu}^{\mathrm{I}}(\mathrm{Br})(\mathrm{TPMA})$ (black line). By formation of a stable intermediate and a lower $\mathrm{Cu}^{\mathrm{I}}$ concentration, the decay in radical concentration is slower (blue line). After heating to $293 \mathrm{~K}, \mathrm{Cu}^{\mathrm{I}}$ is regenerated and the decay is accelerated (red line). A reference spectrum without $\mathrm{Cu}$ is illustrated by the dashed line. 


\subsection{Determination of Rate Coefficients for the Formation of R-Cu"}

Scheme 8.2 illustrates the reaction pathways of the $\mathrm{Cu}^{\mathrm{I}}$-induced termination. The equilibrium of formation and dissociation of the $\mathrm{R}-\mathrm{Cu}^{\mathrm{II}}$ species is described by the rate coefficients $k_{\text {add }}$ and $k_{\text {dis. }}$. The consecutive reaction to regenerate $\mathrm{Cu}^{\mathrm{I}}$ and to form dead chains is characterized by $k_{\mathrm{t}}^{\mathrm{OM}}$.

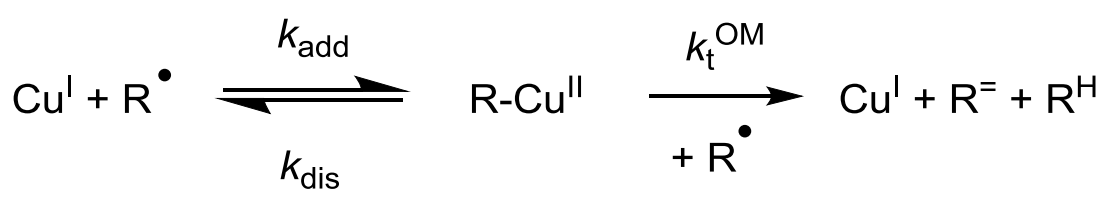

Scheme 8.2. $\mathrm{Cu}^{\mathrm{I}}$-induced termination in ATRP. Rate coefficients $k_{\text {add }}$ and $k_{\text {dis }}$ describe the formation and dissociation of the $\mathrm{R}-\mathrm{Cu}^{\mathrm{II}}$ intermediate, respectively. The reaction between the $\mathrm{R}-\mathrm{Cu}^{\mathrm{II}}$ species and a second radical with the associated coefficient $k_{\mathrm{t}}{ }^{\mathrm{OM}}$ leads to regeneration of $\mathrm{Cu}^{\mathrm{I}}$ and dead chains.

To determine the rate coefficient $k_{\text {add, }}$ SP-PLP-EPR experiments of BA with $15 \mathrm{wt} \%$ $\mathrm{MeCN}$ being present were performed at $233 \mathrm{~K}$. It was shown in the previous chapter that at this temperature the intermediate is stable and the dissociation is thus negligible. The consecutive reaction with the associated rate coefficient $k_{\mathrm{t}}{ }^{\mathrm{OM}}$ is assumed to be small as compared to the formation, since the intermediate is accumulated (cf. chapter 8.2). Therefore, the rate law of $\mathrm{R}-\mathrm{Cu}^{\mathrm{II}}$ formation may be described to a good approximation by eq. 8.2.

$$
\frac{\mathrm{d}\left[\mathrm{RCu}^{\mathrm{II}}\right]}{\mathrm{d} t}=k_{\text {add }} \cdot\left[\mathrm{Cu}^{\mathrm{I}}\right] \cdot\left[\mathrm{R}^{\bullet}\right]
$$


The decay in radical concentration depends on termination between two radicals and formation of the $\mathrm{R}-\mathrm{Cu}^{\mathrm{II}}$ species. The recorded $c_{\mathrm{R}}(t)$ traces were modeled with PREDICI to determine $k_{\text {add }}$ (cf. chapter 6.4).

Shown in Figure 8.5 is the absolute concentration of BA radicals measured after laser single pulse initiation. The upper curve (brown) refers to the experiment without copper, whereas the curves in blue and orange have been measured in the presence of 0.3 and $1 \mathrm{mM} \mathrm{Cu}(\mathrm{Br})(\mathrm{TPMA})$, respectively. The decay of $c_{\mathrm{R}}(t)$ is significantly faster with $\mathrm{Cu}^{\mathrm{I}}$ being present. The full lines illustrate the modeled data.

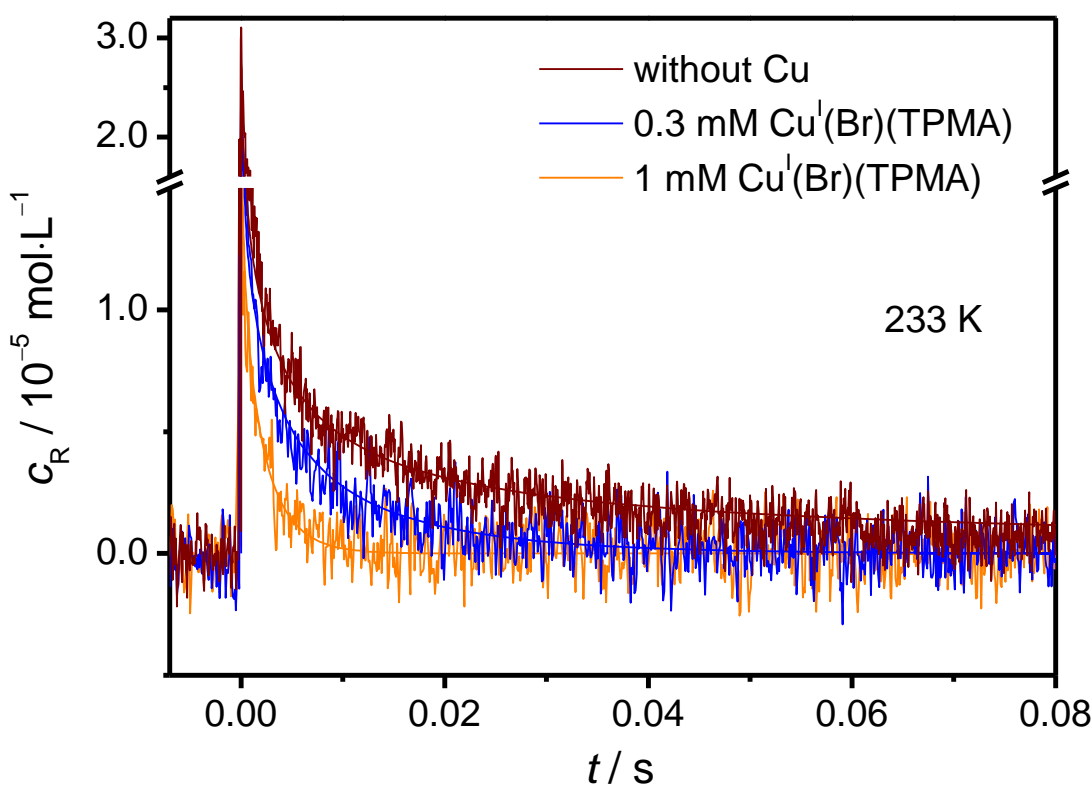

Figure 8.5. Time-resolved concentration of BA radicals after single laser pulse initiation in the presence of $15 \mathrm{wt} \% \mathrm{MeCN}$. The upper curve was measured in the absence of copper (brown), both lower curves (blue, orange) were recorded in the presence of $1 \mathrm{mM}$ and $0.3 \mathrm{mM} \mathrm{Cu}(\mathrm{Br})(\mathrm{TPMA})$, respectively. The full lines represent the modeled data with PREDICI.

The rate coefficient $k_{\text {add }}$ for $\mathrm{Cu}^{\mathrm{I}}(\mathrm{Br})(\mathrm{TPMA})$ was determined to $(3.0 \pm 0.8) \cdot 10^{5} \mathrm{~L} \cdot \mathrm{mol}^{-1} \cdot \mathrm{s}^{-1}$. This coefficient is by a factor of 20 higher than $k_{\text {add }}$ in the Fe-catalyzed system (Table 8.1), where a CRT mechanism also operates. ${ }^{118}$ It should be noted that in case of $\mathrm{Cu}$, the 
intermediate species is stable at $233 \mathrm{~K}$, whereas for $\mathrm{Fe}$, the intermediate is predominantly decomposed via the CRT pathway.

In Fe-mediated ATRP, the organometallic reaction is also first order in the radical concentration at high temperatures. However for $\mathrm{Cu}$-catalyzed systems, the kinetics is more complex. The reverse reaction being operative results in an effective lowering of the apparent $\mathrm{Cu}-\mathrm{CRT}$. Due to this mechanistic interplay, the reported values measured at $313 \mathrm{~K}$ are by more than a factor of 25 lower than the observed values at $233 \mathrm{~K} .{ }^{59}$

The preceding measurements for $\mathrm{Cu}$ were carried out with TPMA as the ligand. To investigate the influence of the ligand on interactions with $\mathrm{Cu}^{\mathrm{I}}$, SP-PLP-EPR experiments of BA polymerization were also performed with PMDETA as the ligand.

Shown in Figure 8.6 are the $c_{\mathrm{R}}(t)$ traces for the BA polymerization in the presence of $15 \mathrm{wt} \% \mathrm{MeCN}$ and with $3 \mathrm{mMCu}^{\mathrm{I}}(\mathrm{Br})(\mathrm{PMDETA})$ (green line) as well as the reference without $\mathrm{Cu}$ (brown line), respectively. The decay in radical concentration with even higher concentration of $\mathrm{Cu}^{\mathrm{I}}$ is much slower as compared to the spectra shown in Figure 8.5. The full lines represent the modeled data from PREDICI according to eq. 8.2, which is based on the assumption that only the formation of $\mathrm{R}-\mathrm{Cu}^{\mathrm{II}}$ occurs. However, the concentration of the $\mathrm{R}-\mathrm{Cu}^{\mathrm{II}}$ intermediate was too small and could not be monitored. Therefore, further reactions of $\mathrm{R}-\mathrm{Cu}^{\mathrm{II}}$ cannot be completely ruled out.

But, the green curve in Figure 8.6 is well modeled via first order kinetics in the radical concentration. Since a dissociation of the organometallic species would lead to second order in $\left[\mathrm{R}^{\cdot}\right]$, this process may be negligible. A decomposition of $\mathrm{R}-\mathrm{Cu}^{\mathrm{II}}$ via the $\mathrm{CRT}$ pathway may, in principle, occur. However, the determined value from the modeled data is in case of a fast consecutive reaction at worst a factor of 2 below the actual value. The following statements are based on assuming only the formation of $\mathrm{R}-\mathrm{Cu}^{\mathrm{II}}$. 


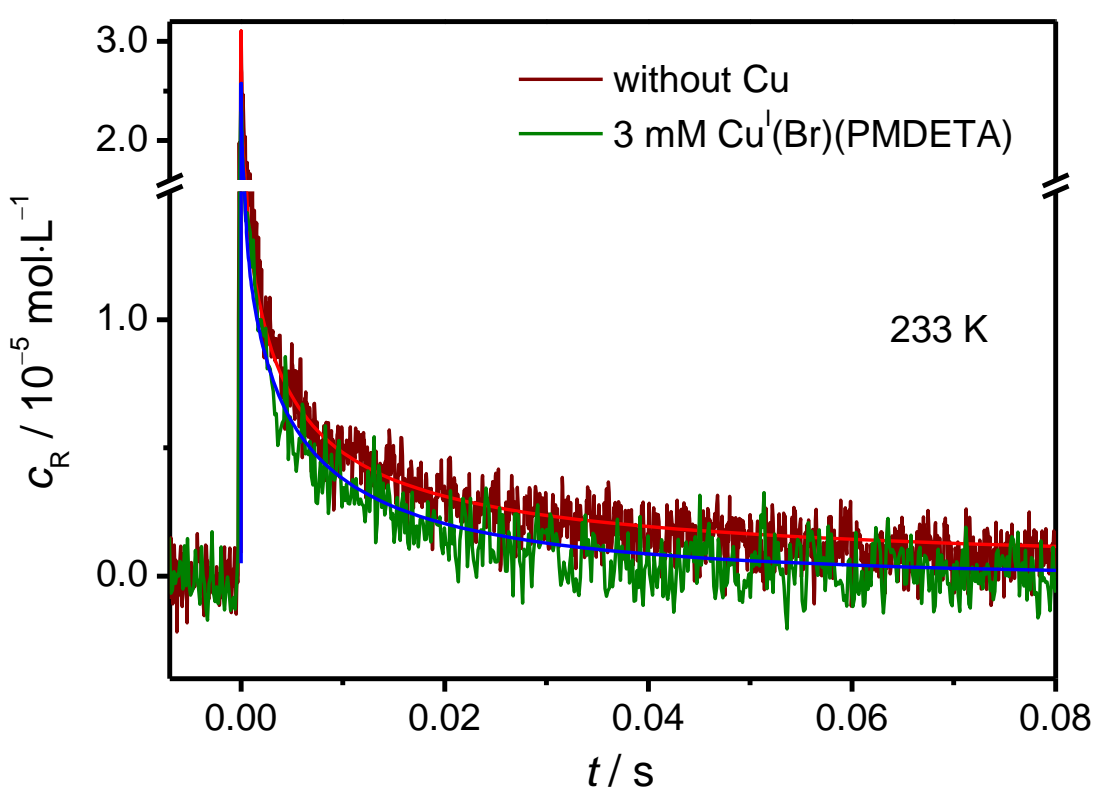

Figure 8.6. Time-resolved EPR spectrum for BA polymerization in the presence of $15 \mathrm{wt} \% \mathrm{MeCN}$ with $3 \mathrm{mM} \mathrm{Cu}^{\mathrm{I}}(\mathrm{Br})(\mathrm{PMDETA})$ measured at $233 \mathrm{~K}$ (green line). The reference spectrum is recorded in the absence of $\mathrm{Cu}$ (brown line). The full lines represent the modeled data with PREDICI.

The value for the formation of a $\mathrm{R}-\mathrm{Cu}^{\mathrm{II}}$ species with PMDETA as the ligand was determined to be $k_{\text {add }}=(9 \pm 3) \cdot 10^{3} \mathrm{~L} \cdot \mathrm{mol}^{-1} \cdot \mathrm{s}^{-1}$ which is far below the value obtained for TPMA, $k_{\text {add }}=(3.0 \pm 0.8) \cdot 10^{5} \mathrm{~L} \cdot \mathrm{mol}^{-1} \cdot \mathrm{s}^{-1}$. In previous studies it was shown that the stability of $\mathrm{Cu}^{\mathrm{II}}$ complexes with TPMA as the ligand is higher and the associated redox potential is lower as for complexes with PMDETA. ${ }^{55,92}$ Therefore it is reasonable to assume that the formation of $\mathrm{R}-\mathrm{Cu}^{\mathrm{II}}$ species is favored for TPMA und thus $k_{\text {add }}$ is increased. For weaker ligands like PMDETA, organometallic intermediates may play only a minor role.

The difference in $k_{\text {add }}$ (Table 8.1) between TPMA and PMDETA is around a factor of 33. The rate coefficients for activation in an ATRP model system of MBrP are $k_{\text {act }}($ TPMA $)=3.8 \mathrm{~L} \cdot \mathrm{mol}^{-1} \cdot \mathrm{s}^{-1}$ and $k_{\text {act }}($ PMDETA $)=0.17 \mathrm{~L} \cdot \mathrm{mol}^{-1} \cdot \mathrm{s}^{-1}$, which show a similar difference by a factor of $23 .{ }^{89}$ Therefore, it may be assumed that $k_{\text {add }}$ correlates with $k_{\text {act }}$ and is even higher for very active catalysts. However, the application of ATRP systems with a catalyst concentration at a ppm level, as with ICAR and ARGET ATRP, reduces or may compensate the effect of organometallic 
reactions, because of the lower $\mathrm{Cu}^{\mathrm{I}}$ concentration. Moreover, highly active catalysts are required for effective and successful polymerization of monomers with weaker stabilizing substituents such as vinyl acetate. ${ }^{119}$

Table 8.1. Rate coefficients $k_{\text {add }}$ at $233 \mathrm{~K}$ for BA polymerization in MeCN and 2-butanone, respectively.

\begin{tabular}{ccc}
\hline metal/ligand & monomer/solvent & $\boldsymbol{k}_{\text {add }} / \mathbf{L} \cdot \mathbf{m o l}^{-\mathbf{1}} \cdot \mathbf{s}^{\mathbf{- 1}}(\mathbf{2 3 3 ~ K})$ \\
\hline $\mathrm{Cu} / \mathrm{TPMA}$ & $\mathrm{BA} / \mathrm{MeCN}$ & $(3.0 \pm 0.8) \cdot 10^{5}$ \\
$\mathrm{Cu}^{\mathrm{I} / \mathrm{PMDETA}}$ & $\mathrm{BA} / \mathrm{MeCN}$ & $(9 \pm 3) \cdot 10^{3 b}$ \\
$\mathrm{Fe}^{\mathrm{II}}$ & $\mathrm{BA} / 2-$ butanone & $(1.5 \pm 0.2) \cdot 10^{4 a}$ \\
\hline
\end{tabular}

${ }^{a}$ calculated from ref. ${ }^{118}$ via $k_{\mathrm{t}}^{\mathrm{Fe}}=2 \cdot k_{\text {add }}$

${ }^{b}$ assuming only formation of $\mathrm{R}-\mathrm{Cu}^{\mathrm{II}}$ according to eq. 8.2

The interaction of radicals with $\mathrm{Cu}^{\mathrm{I}}$ was also investigated by SP-PLP-EPR for DMA polymerization in the presence of $15 \mathrm{wt} \% \mathrm{MeCN}$ at $273 \mathrm{~K}$. Figure 8.7 illustrates the decay in radical concentration in the absence (black line) and in the presence of $3 \mathrm{mMCu}(\mathrm{Br})(\mathrm{TPMA})$ (orange line). The $c_{\mathrm{R}}(t)$ traces show no significant difference. Thus, it may be concluded that $\mathrm{Cu}^{\mathrm{I}}$-induced termination is negligible in DMA polymerization. This is in full agreement with the observations from ATRP polymerizations of MMA where no increase in termination above the value predicted for exclusive termination between two radicals was found.

In ATRP of methacrylates, the formation of organometallic $\mathrm{R}-\mathrm{Cu}^{\mathrm{II}}$ intermediates may be sterically hindered by the $\alpha$-methyl group of the monomer. Moreover, the methyl group may reduce the electrophilicity of the radical and thus the stability of a formed complex. 


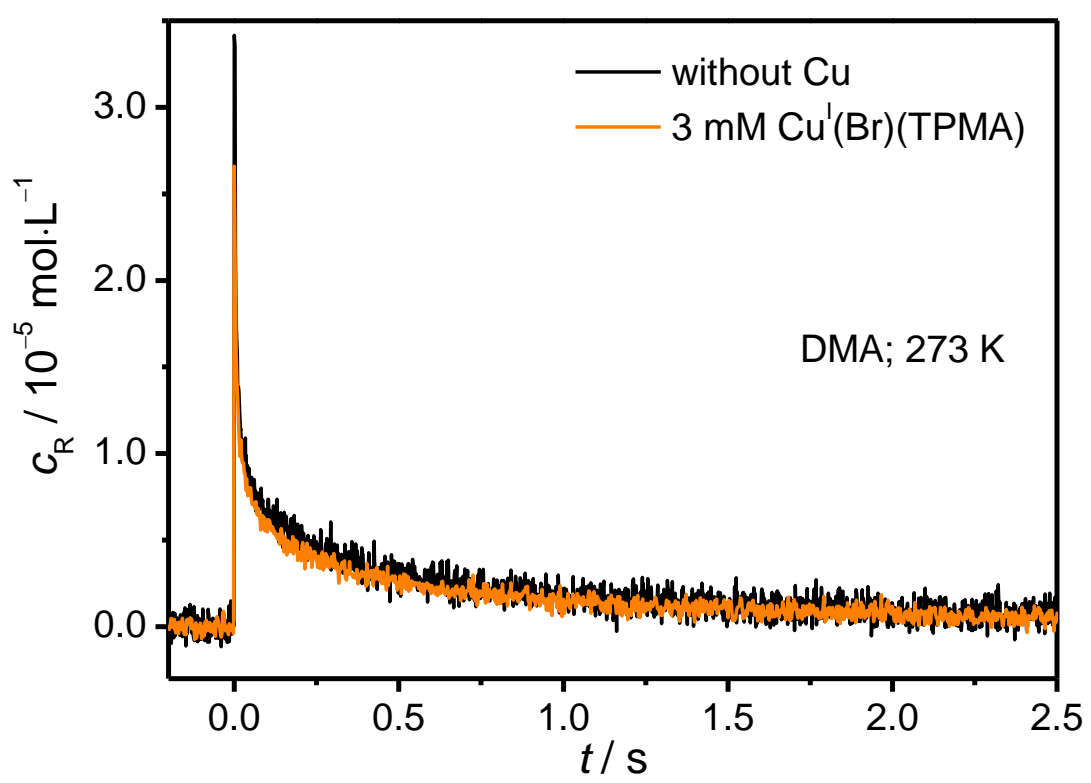

Figure 8.7. Time-resolved EPR spectra for DMA polymerization in $15 \mathrm{wt} \%$ $\mathrm{MeCN}$ measured at $273 \mathrm{~K}$. The black line refers to the experiment in the absence of $\mathrm{Cu}$, whereas the orange line is recorded in the presence of $3 \mathrm{mM}$ $\mathrm{Cu}^{\mathrm{I}}(\mathrm{Br})(\mathrm{TPMA})$. The traces show no significant difference.

In this chapter, the SP-PLP-EPR technique has been used to study whether and to which extent organometallic reactions of radicals and $\mathrm{Cu}^{\mathrm{I}}$ take place. It was shown that in the polymerization of methacrylates, such side reactions play no significant role. However in acrylate polymerization, the formation of $\mathrm{R}-\mathrm{Cu}^{\mathrm{II}}$ species was spectroscopically demonstrated. It seems that toward stronger complexation of the catalyst, the probability for $\mathrm{Cu}^{\mathrm{I}}$-induced termination in ATRP is higher. However, ATRP systems with a low concentration of the catalyst such as ICAR ATRP may minimize the occurrence of organometallic reactions. 


\section{$9 \quad$ Closing Remarks}

Kinetic coefficients of radical polymerization both in the presence and in the absence of an ATRP Cu catalyst were investigated via the SP-PLP-EPR technique. In the first part, the termination kinetics of DMA and EHMA polymerization in a $\mathrm{Cu}$-free monomer system was investigated. The main focus was hereby on the dependency of the compositemodel parameters, $k_{\mathrm{t}}{ }^{1,1}, \alpha_{\mathrm{s}}, \alpha_{\mathrm{l}}$ and $i_{\mathrm{c}}$, on temperature.

The activation energy of $k_{\mathrm{t}}{ }^{1,1}$ was determined for both monomers and correlates to the activation energy of the fluidity of the solution. This similarity of $E_{\mathrm{A}}$ confirms the expectation that termination for DMA and EHMA polymerization is a diffusion controlled process. However, the values of $k_{\mathrm{t}}^{1,1}$ were approximately one order of magnitude lower than the diffusion limit which indicates a stronger shielding of the radical site as compared to methacrylate monomers with shorter side chains. The numbers for the power-law exponents $\alpha_{\mathrm{s}}$ and $\alpha_{1}$ showed no significant temperature effect and were in good agreement with reported numbers for other methacrylates.

In contrast, the crossover chain lengths $i_{\mathrm{c}}$ of DMA and EHMA showed a strong decrease toward higher $T$. This observation is particularly remarkable, since it is the first time that such a temperature dependence of $i_{\mathrm{c}}$ was observed. However, to confirm this effect, measurements of $i_{\mathrm{c}}$ with other methacrylate monomers may be performed. Thereby, it may be investigated whether there is a stepwise increase in the temperature dependence from BMA to DMA. Moreover, monomers with larger alkyl groups than DMA such as stearyl methacrylate may show an even stronger dependence.

Within the second part, the ATRP kinetics were examined, in particular the deactivation rate coefficient $k_{\text {deact }}$. Therefore, a method for the direct determination of $k_{\text {deact }}$ has been developed which is based on the SP-PLP-EPR technique. In the presence of a $\mathrm{Cu}^{\mathrm{II}}$ deactivating species, the decay of radical concentration after instantaneous laser-induced production of an intense burst of radicals occured as a consequence of both deactivation and radical-radical termination. The recorded $c_{\mathrm{R}}(t)$ traces were modeled to achieve $k_{\text {deact. }}$. 
The required rate coefficients and concentrations for this modeling were deduced from separate (SP-PLP-)EPR and PLP-SEC measurements. This novel strategy has been applied to homopolymerizations of BA and DMA. HMTETA, PMDETA and TPMA were selected as ligands of $\mathrm{Cu}^{\mathrm{II}}$.

In case of DMA polymerization with TPMA, $k_{\text {deact }}$ was found in close agreement with the number for the monomer-free model systems, whereas with HMTETA and PMDETA, $k_{\text {deact }}$ for the polymerizing system was lower by about one order of magnitude. This effect is assigned to steric strain on the polymer chain due to the $\alpha$-methyl group (back strain effect).

The values of $k_{\text {deact }}$ for BA polymerization are close to the ones determined for the model system. As a back strain effect is not operative in BA polymerization, both the reported data for the ATRP model systems and for the polymerizing system from the SP-PLPEPR approach are in close agreement. Because of the close similarity of $k_{\text {deact }}$, data from model systems are suitable to describe the kinetics in acrylate polymerization to a good approximation.

This novel strategy to determine deactivation rate coefficients directly from the recorded EPR spectra may be extended to $\mathrm{Cu}$-mediated ATRP in aqueous solution, which appears to be attractive, since water is cheap, nontoxic and environmentally benign. However, EPR measurements in aqueous solution are more difficult due to the polarity of water and the dielectric loss of microwave radiation. This problem may be overcome by using EPR flat cells.

SP-PLP-EPR for measuring $k_{\text {deact }}$ may also be applied for Fe-mediated ATRP. ATRP with $\mathrm{Fe}$ as a catalyst is an alternative to $\mathrm{Cu}$ due to the broad availability and the low potential toxicity. EPR measurements on Fe catalysts are more challenging, since Fe ${ }^{\mathrm{III}}$ possesses two possible states, a high spin and a low spin state. High-spin $\mathrm{Fe}^{\mathrm{III}}$ exhibits a welldetectable signal, whereas low-spin Fe ${ }^{\mathrm{III}}$ is only weakly EPR-active.

In the last part, the SP-PLP-EPR technique has been used to study whether and to which extent organometallic reactions of radicals and $\mathrm{Cu}^{\mathrm{I}}$ take place. Therefore, the decay in radical concentration was measured with an ATRP $\mathrm{Cu}^{\mathrm{I}}$ catalyst being present. The decay depends on termination between two radicals and on the formation of the $\mathrm{R}-\mathrm{Cu}^{\mathrm{II}}$ species. 
In the polymerization of DMA, such side reactions play no significant role, since the $c_{\mathrm{R}}(t)$ traces showed no significant difference in the absence and in the presence of $\mathrm{Cu}^{\mathrm{I}}$. In case of $\mathrm{BA}$ polymerization, the resulting $\mathrm{R}-\mathrm{Cu}^{\mathrm{II}}$ intermediate was spectroscopically detected and the rate coefficient for the formation, $k_{\text {add }}$, was determined. With TPMA as the ligand, $k_{\text {add }}$ is about a factor of 20 higher than for PMDETA. The results indicate that the formation of organometallic species mainly depends on the ligand of the $\mathrm{Cu}$ complex and is apparently enhanced for highly active catalysts. However, ATRP systems with a low concentration of the catalyst such as ICAR ATRP may minimize the occurrence of organometallic reactions.

Investigations of the interaction of $\mathrm{Cu}^{\mathrm{I}}$ with radicals should be applied to further ligands to verify the correlation between activation rate coefficient $k_{\text {act }}$ and the coefficient for the formation of organometallic species, $k_{\text {add }}$. Thereby, the ability toward organometallic reactions of $\mathrm{Cu}$ complexes may be predicted only by measuring $k_{\text {act. }}$. 



\section{Appendix}

Table 1. Individual values of viscosities for bulk DMA, bulk EHMA and DMA in $15 \mathrm{wt} \%$ $\mathrm{MeCN}$.

\begin{tabular}{c|cc|cc|cc} 
& $\boldsymbol{T} / \mathbf{K}$ & $\boldsymbol{\eta}$ (DMA bulk) / & $\boldsymbol{T} / \mathbf{K}$ & $\begin{array}{c}\boldsymbol{\eta} \text { (EHMA bulk) } / \\
\mathbf{m P a s}\end{array}$ & $\boldsymbol{T} / \mathbf{K}$ & $\begin{array}{c}\boldsymbol{\eta} \text { (DMA MeCN) } \\
\text { / } \mathbf{m P a s}\end{array}$ \\
\hline 1 & 283 & 6.2871 & 283 & 2.5167 & 293 & 2.3549 \\
2 & 283 & 6.2842 & 283 & 2.51 & 293 & 2.3566 \\
3 & 288 & 5.371 & 283 & 2.5081 & 293 & 2.3553 \\
4 & 288 & 5.3708 & 293 & 1.9685 & 293 & 2.355 \\
5 & 293 & 4.6377 & 293 & 1.9277 & 293 & 2.3563 \\
6 & 293 & 4.6386 & 293 & 1.9454 & 293 & 2.3563 \\
7 & 298 & 4.0469 & 293 & 1.9577 & 298 & 2.1057 \\
8 & 298 & 4.0431 & 293 & 1.9649 & 298 & 2.1062 \\
9 & 303 & 3.5584 & 293 & 1.9624 & 298 & 2.1057 \\
10 & 303 & 3.5558 & 303 & 1.5772 & 303 & 1.8974 \\
11 & 303 & 3.5565 & 303 & 1.5757 & 303 & 1.8958 \\
12 & 308 & 3.1618 & 303 & 1.5803 & 303 & 1.8958 \\
13 & 308 & 3.1571 & 313 & 1.3138 & 303 & 1.8969 \\
14 & 313 & 2.816 & 313 & 1.3119 & 308 & 1.7165 \\
15 & 313 & 2.8155 & 313 & 1.3122 & 308 & 1.7147 \\
16 & 313 & 2.8175 & 313 & 1.3094 & 308 & 1.7144 \\
17 & 318 & 2.5371 & 313 & 1.3098 & 313 & 1.5639 \\
18 & 318 & 2.5345 & 313 & 1.3122 & 313 & 1.562 \\
19 & 323 & 2.2903 & 323 & 1.107 & 313 & 1.5595 \\
20 & 323 & 2.2916 & 323 & 1.111 & 313 & 1.5592 \\
21 & 323 & 2.2925 & 323 & 1.1052 & 313 & 1.5624 \\
22 & 328 & 2.0866 & 333 & 0.9524 & 313 & 1.5595 \\
23 & 328 & 2.0867 & 333 & 0.95272 & 318 & 1.4275 \\
24 & 328 & 2.0859 & 333 & 0.95253 & 318 & 1.4272 \\
25 & 333 & 1.9043 & 333 & 0.95339 & 323 & 1.3146 \\
26 & 333 & 1.9087 & 333 & 0.95311 & 323 & 1.3141 \\
27 & 333 & 1.9062 & 333 & 0.94958 & 323 & 1.3139 \\
28 & 338 & 1.7501 & 343 & 0.83098 & 323 & 1.313 \\
29 & & & 343 & 0.83129 & 323 & 1.3128 \\
30 & & & 343 & 0.8307 & 323 & 1.3124 \\
& & & & & &
\end{tabular}




\begin{tabular}{|c|c|c|c|c|}
\hline 31 & 353 & 0.73095 & 328 & 1.2127 \\
\hline 32 & 353 & 0.73197 & 328 & 1.2131 \\
\hline 33 & 353 & 0.73161 & 328 & 1.2124 \\
\hline 34 & 353 & 0.73184 & 333 & 1.1252 \\
\hline 35 & 353 & 0.73139 & 333 & 1.1253 \\
\hline 36 & & & 333 & 1.125 \\
\hline 37 & & & 333 & 1.1252 \\
\hline 38 & & & 333 & 1.1253 \\
\hline 39 & & & 333 & 1.1257 \\
\hline
\end{tabular}

Table 2. Viscosities of bulk MMA and bulk BMA.

\begin{tabular}{c|cc|cc} 
& $\boldsymbol{T} / \mathbf{K}$ & $\boldsymbol{\eta} \begin{array}{c}\text { (MMA bulk) } \\
\text { mPas }\end{array}$ & $\boldsymbol{T} / \mathbf{K}$ & $\begin{array}{c}\boldsymbol{\eta} \text { (BMA bulk) / } \\
\text { mPas }\end{array}$ \\
& & & & \\
\hline 1 & 283 & 0.67084 & 283 & 1.133 \\
2 & 283 & 0.67055 & 283 & 1.1322 \\
3 & 288 & 0.62376 & 283 & 1.1324 \\
4 & 288 & 0.62293 & 283 & 1.131 \\
5 & 293 & 0.58149 & 293 & 0.95127 \\
6 & 293 & 0.58128 & 293 & 0.95228 \\
7 & 293 & 0.58119 & 293 & 0.95351 \\
8 & 293 & 0.58137 & 293 & 0.9507 \\
9 & 298 & 0.54709 & 298 & 0.87863 \\
10 & 298 & 0.54492 & 298 & 0.87765 \\
11 & 303 & 0.51135 & 298 & 0.87767 \\
12 & 303 & 0.5102 & 303 & 0.80843 \\
13 & 313 & 0.45288 & 313 & 0.70325 \\
14 & 313 & 0.45257 & 313 & 0.70322 \\
15 & 323 & 0.40607 & 313 & 0.70314 \\
16 & 323 & 0.40595 & 323 & 0.61777 \\
17 & 333 & 0.36811 & 323 & 0.61798 \\
18 & 333 & 0.36808 & 323 & 0.61782 \\
19 & & & 333 & 0.54927 \\
20 & & & 333 & 0.54887 \\
\hline & & & &
\end{tabular}


Table 3. Values of $k_{\mathrm{t}}^{1,1}$ for bulk DMA, bulk EHMA and DMA/MeCN.

\begin{tabular}{|c|c|c|c|}
\hline$T / \mathbf{K}$ & $\begin{array}{c}k_{\mathrm{t}}^{1,1}(\text { DMA bulk) } / \\
\text { Lmol }^{-1} \mathbf{s}^{-1}\end{array}$ & $\begin{array}{c}k_{\mathrm{t}}^{1,1}(\text { EHMA bulk) } \\
\mathrm{Lmol}^{-1} \mathrm{~s}^{-1}\end{array}$ & $\begin{array}{c}k_{\mathrm{t}}^{1,1}(\mathrm{DMA} / \mathrm{MeCN}) / \\
\mathrm{Lmol}^{-1} \mathbf{s}^{-1}\end{array}$ \\
\hline 233 & & $5.13 \mathrm{E}+06$ & \\
\hline 253 & & $1.08 \mathrm{E}+07$ & \\
\hline 263 & & & $4.75 \mathrm{E}+07$ \\
\hline 273 & $1.13 \mathrm{E}+07$ & $1.77 \mathrm{E}+07$ & $5.57 \mathrm{E}+07$ \\
\hline 283 & & & $1.21 \mathrm{E}+08$ \\
\hline 293 & $2.85 \mathrm{E}+07$ & $2.81 \mathrm{E}+07$ & $6.34 \mathrm{E}+07$ \\
\hline 313 & $3.39 \mathrm{E}+07$ & $4.89 \mathrm{E}+07$ & $1.22 \mathrm{E}+08$ \\
\hline 333 & $5.56 \mathrm{E}+07$ & & $1.73 \mathrm{E}+08$ \\
\hline 353 & $8.74 \mathrm{E}+07$ & & \\
\hline 373 & $1.39 \mathrm{E}+08$ & & \\
\hline
\end{tabular}

Table 4. Power-law exponent $\alpha_{\mathrm{s}}$ for bulk DMA, bulk EHMA and DMA/MeCN.

\begin{tabular}{c|ccc}
$\boldsymbol{T} / \mathbf{K}$ & $\boldsymbol{\alpha}_{\mathbf{s}}$ (DMA) & $\boldsymbol{\alpha}_{\mathrm{s}}$ (EHMA) & $\begin{array}{c}\boldsymbol{\alpha}_{\mathrm{s}} \\
(\mathbf{D M A} / \mathbf{M e C N})\end{array}$ \\
\hline 233 & & 0.65 & \\
253 & & 0.61 & 0.78 \\
263 & & & 0.73 \\
273 & 0.67 & 0.63 & 0.78 \\
283 & & & 0.72 \\
293 & 0.70 & 0.56 & 0.71 \\
313 & 0.65 & 0.60 & 0.64 \\
333 & 0.66 & & \\
353 & 0.59 & & \\
373 & 0.63 & & \\
\hline
\end{tabular}


Table 5. Power-law exponent $\alpha_{1}$ for bulk DMA, bulk EHMA and DMA/MeCN.

\begin{tabular}{c|ccc}
$\boldsymbol{T} / \mathbf{K}$ & $\boldsymbol{\alpha}_{\mathbf{1}}$ (DMA) & $\boldsymbol{\alpha}_{\mathbf{1}}$ (EHMA) & $\begin{array}{c}\boldsymbol{\alpha}_{\mathbf{l}} \\
(\mathbf{D M A} / \mathbf{M e C N})\end{array}$ \\
\hline 233 & & 0.22 & \\
253 & & 0.15 & \\
263 & & & 0.13 \\
273 & 0.19 & 0.21 & 0.15 \\
283 & & & 0.24 \\
293 & 0.19 & 0.21 & 0.17 \\
313 & 0.19 & 0.17 & 0.17 \\
333 & 0.15 & 0.17 & 0.19 \\
353 & 0.13 & & \\
373 & 0.18 & & \\
\hline
\end{tabular}

Table 6. Crossover chain length $i_{\mathrm{c}}$ for bulk DMA, bulk EHMA and DMA/MeCN.

\begin{tabular}{c|ccc}
$\boldsymbol{T} / \mathbf{K}$ & $\boldsymbol{i}_{\mathbf{c}}(\mathbf{D M A})$ & $\boldsymbol{i}_{\mathbf{c}}(\mathbf{E H M A})$ & $\boldsymbol{i}_{\mathbf{c}}(\mathbf{D M A} / \mathbf{M e C N})$ \\
\hline 233 & & 287 & \\
253 & & 244 & 218 \\
263 & & & 175 \\
273 & 221 & 151 & 129 \\
283 & & & 144 \\
293 & 156 & 128 & 121 \\
313 & 103 & 86 & 97 \\
333 & 75 & 80 & \\
353 & 45 & & \\
373 & 36 & & \\
\hline
\end{tabular}


Table 7. Deactivation rate coefficient $k_{\text {deact }}$ for DMA polymerization in $15 \mathrm{wt} \% \mathrm{MeCN}$ in the presence of $\mathrm{Cu}^{\mathrm{II}}(\mathrm{Br})_{2}$ (HMTETA).

\begin{tabular}{cc}
$\boldsymbol{T} / \mathbf{K}$ & $\begin{array}{c}\boldsymbol{k}_{\text {deact }} \\
(\mathbf{D M A} / \mathbf{M e C N}) / \\
\mathbf{L m o l}^{-1} \mathbf{s}^{-\mathbf{1}}\end{array}$ \\
\hline 273 & $3.92 \mathrm{E}+05$ \\
283 & $4.50 \mathrm{E}+05$ \\
293 & $9.60 \mathrm{E}+05$ \\
313 & $1.20 \mathrm{E}+06$ \\
\hline
\end{tabular}





\section{Abbreviations}

A

$\alpha_{1}$

$\alpha_{\mathrm{s}}$

ATRP

B

BA

BMA

BzMA

$c_{\mathrm{M}}$

$c_{\mathrm{R}}$

$c_{\mathrm{R}}{ }^{0}$

$D^{i}$

DMA

DoBriB

$\mathrm{DP}_{\mathrm{T}}$

$E_{\mathrm{A}}$

EHMA

EPR

eq.

et al.

EtBriB

$f$

FT

G

$h_{1}, h_{2}, h_{3}$ preexponential factor

power-law exponent describing the chain-length dependence of $k_{\mathrm{t}}$ for long-chain radicals

power-law exponent describing the chain-length dependence of $k_{\mathrm{t}}$ for short-chain radicals

atom transfer radical polymerization

magnetic field

n-butyl acrylate

butyl methacrylate

benzyl methacrylate

monomer concentration

radical concentration

initial radical concentration

diffusion coefficient of chain length $i$

dodecyl methacrylate

dodecyl 2-bromoisobutyrate

targeted degree of polymerization

activation energy

2-ethylhexyl methacrylate

electron paramagnetic resonance

equation

and others

ethyl 2-bromoisobutyrate

initiator efficiency

Fourier-transformation

gauss

proportionality factor used for EPR calibration 


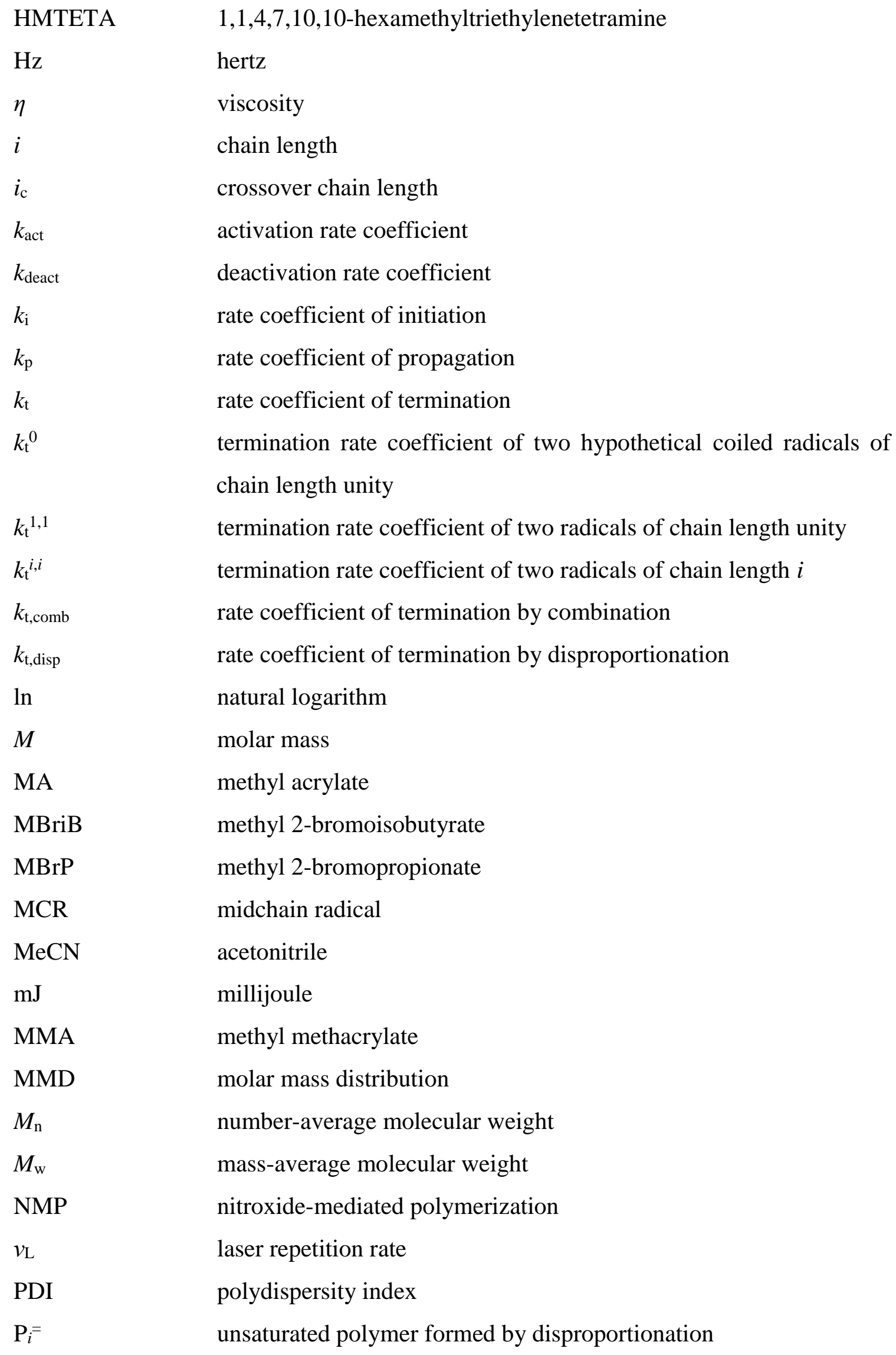


$\mathrm{P}_{i}^{\mathrm{H}}$

PMDETA

p.r.r.

RAFT

$R_{\mathrm{c}}$

RDRP

$\mathrm{R}_{i}$

$r_{i}$

RP

SEC

SP-PLP-EPR

SP-PLP-NIR

SPR

St

T

$t$

$t$ BMA

TPMA

VAc

VPi

wt \%

X saturated polymer formed by disproportionation

$N, N, N$ ', $N$ ' , $N$ ''-pentamethyldiethylenetriamine

pulse repetition rate

reversible addition-fragmentation chain transfer

capture radius

reversible-deactivation radical polymerization

radical of monomer chain length $i$

hydrodynamic radius

radical polymerization

size-exclusion chromatography

single pulse-pulsed laser polymerization-electron paramagnetic

resonance

single pulse-pulsed laser polymerization-near-infrared spectroscopy

secondary propagating radical

styrene

temperature

time

tert-butyl methacrylate

tris(2-pyridylmethyl(amine)

vinyl acetate

vinyl pivalate

weight per cent

monomer-to-polymer conversion 



\section{Bibliography}

(1) Baekeland, L. H. Chemiker-Zeitung 1909, 33, 317-318.

(2) Staudinger, H.; Fritschi, J. Helv. Chim. Acta 1922, 5, 785-806.

(3) PlasticsEurope. Plastics - the facts 2014/2015

http://issuu.com/plasticseuropeebook/docs/final_plastics_the_facts_2014_19122 (accessed Apr 21, 2015).

(4) Matyjaszewski, K. Controlled and Living Polymerization; WILEY-VCH Verlag: Weinheim, 2009; pp. 103-166.

(5) Wang, J.; Matyjaszewski, K. J. Am. Chem. Soc. 1995, 117, 5614-5615.

(6) Kamigaito, M.; Ando, T.; Sawamoto, M. Chem. Rev. 2001, 101, 3689-3745.

(7) Hawker, C. J.; Bosman, A. W.; Harth, E. Chem. Rev. 2001, 101, 3661-3688.

(8) Chiefari, J.; Chong, Y. K. (Bill); Ercole, F.; Krstina, J.; Jeffery, J.; Le, T. P. T.; Mayadunne, R. T. A.; Meijs, G. F.; Moad, C. L.; Moad, G.; Rizzardo, E.; Thang, S. H. Macromolecules 1998, 31, 5559-5562.

(9) Barner-Kowollik, C.; Davis, T. P.; Heuts, J. P. a; Stenzel, M. H.; Vana, P.; Whittaker, M. J. Polym. Sci. Part A Polym. Chem. 2003, 41, 365-375.

(10) Matyjaszewski, K.; Xia, J. Chem. Rev. 2001, 101, 2921-2990.

(11) Patten, T. E.; Matyjaszewski, K. Adv. Mater. 1998, 901-915.

(12) Patten, T. E.; Matyjaszewski, K. Acc. Chem. Res. 1999, 32, 895-903.

(13) Barth, J.; Buback, M. Macromol. React. Eng. 2010, 4, 288-301.

(14) Buback, M. Macromol. Symp. 2009, 275-276, 90-101.

(15) Olaj, O. F.; Bitai, I.; Hinkelmann, F. Makromol. Chem. 1987, 188, 1689-1702.

(16) Beuermann, S.; Buback, M.; Davis, T. P.; Gilbert, R. G.; Hutchinson, R. a.; Olaj, O. F.; Russell, G. T.; Schweer, J.; van Herk, A. M.; Beuermannb, S.; Davisd, T. I.; Hutchinsonc, R. a; Friedrich, O.; Gregory, O. Macromol. Chem. Phys. 1997, $198,1545-1560$. 
(17) Beuermann, S.; Buback, M.; Davis, T. P.; Gilbert, R. G.; Hutchinson, R. a.; Kajiwara, A.; Klumperman, B.; Russell, G. T. Macromol. Chem. Phys. 2000, 201, 1355-1364.

(18) Asua, J. M.; Beuermann, S.; Buback, M.; Castignolles, P.; Charleux, B.; Gilbert, R. G.; Hutchinson, R. a.; Leiza, J. R.; Nikitin, A. N.; Vairon, J. P.; Van Herk, A. M. Macromol. Chem. Phys. 2004, 205, 2151-2160.

(19) Buback, M.; Hippler, H.; Schweer, J.; Vögele, H.-P. Die Makromol. Chemie, Rapid Commun. 1986, 7, 261-265.

(20) Buback, M.; Kuchta, F.-D. Macromol. Chem. Phys. 1997, 198, 1455-1480.

(21) Buback, M.; Egorov, M.; Gilbert, R. G.; Kaminsky, V.; Olaj, O. F.; Russell, G. T.; Vana, P.; Zifferer, G. Macromol. Chem. Phys. 2002, 2570-2582.

(22) Buback, M.; Müller, E.; Russell, G. T. J. Phys. Chem. A 2006, 110, 3222-3230.

(23) Buback, M.; Egorov, M.; Junkers, T.; Panchenko, E. Macromol. Chem. Phys. 2005, 206, 333-341.

(24) Kattner, H.; Buback, M. Macromol. Symp. 2013, 333, 11-23.

(25) Kattner, H.; Buback, M. Macromolecules 2015, 48, 309-315.

(26) Kattner, H.; Buback, M. Macromol. Chem. Phys. 2014, 215, 1180-1191.

(27) Barth, J.; Buback, M. Macromolecules 2011, 44, 1292-1297.

(28) Barth, J.; Buback, M.; Hesse, P.; Sergeeva, T. Macromol. Rapid Commun. 2009, 30, 1969-1974.

(29) Barth, J.; Buback, M.; Hesse, P.; Sergeeva, T. Macromolecules 2009, 42, 481488.

(30) Barth, J.; Buback, M.; Hesse, P.; Sergeeva, T. Macromolecules 2010, 43, 4023 4031.

(31) Meiser, W.; Buback, M. Macromol. Rapid Commun. 2012, 33, 1273-1279.

(32) Meiser, W.; Buback, M.; Barth, J.; Vana, P. Polymer (Guildf). 2010, 51, 59775982.

(33) Elias, H.-G. Makromoleküle; 6th ed.; WILEY-VCH Verlag, 1999; p. 317ff.

(34) Bamford, C. H.; Dyson, R. W.; Eastmond, G. C. Polymer (Guildf). 1969, 10, 885899. 
(35) Roedel, M. J. J. Am. Chem. Soc. 1953, 75, 6110-6112.

(36) Hesse, P. Studies into the Radical Polymerization Kinetics in Homogeneous Aqueous Solution and into Systems with Secondary and Tertiary Macroradicals by Novel Pulsed-Laser Polymerization Techniques; Ph.D. thesis, Göttingen, 2008.

(37) Norrish, R. G. W.; Smith, R. R. Nature 1942, 150, 336-337.

(38) Smoluchowski, M. von. Z. Phys. Chem. 1917, 92, 129.

(39) Methodology, F. P. M.; Russell, G. T. Macromolecules 1993, 26, 3538-3552.

(40) Porter, F. Society 1983, 200-207.

(41) Smith, G. B.; Russell, G. T.; Heuts, J. P. a. Macromol. Theory Simulations 2003, $12,299-314$.

(42) Arrhenius, S. Z. Phys. Chem. 1889, 4, 226.

(43) Matyjaszewski, K.; Spanswick, J. Mater. Today 2005, 8, 26-33.

(44) Kharasch, M. Science (80-. ). 1945, 102, 128.

(45) Kato, M.; Kamigaito, M.; Sawamoto, M.; Higashimuras, T. Macromolecules 1995, 28, 1721-1723.

(46) Ashford, E. J.; Naldi, V.; O’Dell, R.; Billingham, N. C.; Armes, S. P. Chem. Commun. 1999, 1285-1286.

(47) Tang, W.; Matyjaszewski, K. Macromolecules 2007, 40, 1858-1863.

(48) Paik, H.; Horwitz, C. P. Macromolecules 2001, 34, 430-440.

(49) Matyjaszewski, K.; Wei, M.; Xia, J.; Mcdermott, N. E. Macromolecules 1997, 30, 8161-8164.

(50) Wang, Y.; Matyjaszewski, K. Macromolecules 2010, 43, 4003-4005.

(51) Tsarevsky, N. V.; Pintauer, T.; Matyjaszewski, K. Macromolecules 2004, 37, 9768-9778.

(52) Tang, W.; Matyjaszewski, K. Macromol. Theory Simulations 2008, 17, 359-375.

(53) Kwak, Y.; Matyjaszewski, K. Polym. Int. 2009, 58, 242-247.

(54) Matyjaszewski, K.; Jakubowski, W.; Min, K.; Tang, W.; Huang, J.; Braunecker, W. a; Tsarevsky, N. V. Proc. Natl. Acad. Sci. U. S. A. 2006, 103, 15309-15314. 
(55) Tsarevsky, N. V.; Braunecker, W. a.; Vacca, A.; Gans, P.; Matyjaszewski, K. Macromol. Symp. 2007, 248, 60-70.

(56) Braunecker, W. a.; Tsarevsky, N. V.; Pintauer, T.; Gil, R. R.; Matyjaszewski, K. Macromolecules 2005, 38, 4081-4088.

(57) Smolne, S.; Buback, M. Macromol. Chem. Phys. 2015, 216, 894-902.

(58) Matyjaszewski, K.; Woodworth, B. Macromolecules 1998, 31, 4718-4723.

(59) Wang, Y.; Soerensen, N.; Zhong, M.; Schroeder, H.; Buback, M.; Matyjaszewski, K. Macromolecules 2013, 46, 683-691.

(60) Morick, J.; Buback, M.; Matyjaszewski, K. J. Chem. Phys. 2011, 212, 24232428.

(61) Buback, M.; Morick, J. Macromol. Chem. Phys. 2010, 211, 2154-2161.

(62) Matyjaszewski, K.; Paik, H.; Zhou, P.; Diamanti, S. J. Macromolecules 2001, 34, 5125-5131.

(63) Soerensen, N.; Barth, J.; Buback, M.; Morick, J.; Schroeder, H.; Matyjaszewski, K. Macromolecules 2012, 45, 3797-3801.

(64) Fischer, H.; Universität, P. I. Der; Zürich, C.-. J. Chem. Soc. Perkin Trans. 1998, $1553-1559$.

(65) Schrooten, J. Investigations into the Propagation and Termination Kinetics of the Radical Polymerization of Polar Monomers in Aqueous Solution; Ph.D. thesis, Göttingen, 2012.

(66) Hutchinson, R. a; Beuermann, S.; Paquet, D. a; McMinn, J. H.; Jackson, C. Macromolecules 1998, 31, 1542-1547.

(67) Barth, J.; Buback, M. Macromol. Rapid Commun. 2009, 30, 1805-1811.

(68) Kamachi, M. J. Polym. Sci. Part A Polym. Chem. 2002, 40, 269-285.

(69) Barth, J.; Siegmann, R.; Beuermann, S.; Russell, G. T.; Buback, M. Macromol. Chem. Phys. 2012, 213, 19-28.

(70) Friedman, B.; O’Shaughnessy, B. Macromolecules 1993, 26, 5726-5739.

(71) Barner-Kowollik, C.; Russell, G. T. Prog. Polym. Sci. 2009, 34, 1211-1259.

(72) Johnston-Hall, G.; Theis, A.; Monteiro, M. J.; Davis, T. P.; Stenzel, M. H.; Barner-Kowollik, C. Macromol. Chem. Phys. 2005, 206, 2047-2053. 
(73) Barth, J.; Buback, M.; Russell, G. T.; Smolne, S. Macromol. Chem. Phys. 2011, 212, 1366-1378.

(74) Strukelj, M.; Martinho, J. M. G.; Winnik, M. a; Quirk, R. P. Macromolecules 1991, 24, 2488-2492.

(75) Khokhlov, A. Die Makromol. Chemie, Rapid Commun. 1981, 2, 633-636.

(76) Mahabadi, H. K.; O’Driscoll, K. F.; Stages, I.; Polymerization, F. R. Macromolecules 1977, 10, 55-58.

(77) Griffiths, M. C.; Strauch, J.; Monteiro, M. J.; Gilbert, R. G. Macromolecules 2006, 2, 7835-7844.

(78) Fan, W.; Zhou, Q.; Sun, J.; Zhang, S. J. Chem. Eng. Data 2009, 54, 2307-2311.

(79) Buback, M.; Junkers, T. Macromol. Chem. Phys. 2006, 207, 1640-1650.

(80) Chen, J.; Weng, W.; Chu, H. J. Chem. Eng. Data 2006, 51, 1441-1445.

(81) Müller, E. Detailed Investigations into the Propagation and Termination Kinetics of Bulk Homo- and Copolymerization of (Meth)Acrylates; Ph.D. thesis, Göttingen, 2005.

(82) Morick, J. Kinetik von Atom-Transfer Radikalischen Polymerisationen bis zu hohen Drücken; Ph.D. thesis, Göttingen, 2012.

(83) Chambard, G.; Klumperman, B.; German, A. L. Macromolecules 2002, 35, 34203425.

(84) Buback, M.; Kollowik, C.; Kamachi, M.; Kajiwara, A. Macromolecules 1998, 31, 7208-7212.

(85) Schno, I. Monatshefte 1999, 740, 731-740.

(86) Suddaby, K. G.; Maloney, D. R.; Haddleton, D. M. Macromolecules 1997, 30, 702-713.

(87) Pintauer, T.; Matyjaszewski, K. Coord. Chem. Rev. 2005, 249, 1155-1184.

(88) Yordanov, N. D.; Shopov, D. EPR spectra of mixed-ligand copper(II) complexes in solution. Journal of Inorganic and Nuclear Chemistry, 1976, 38, 137-140.

(89) Tang, W.; Kwak, Y.; Braunecker, W.; Tsarevsky, N. V.; Coote, M. L.; Matyjaszewski, K. J. Am. Chem. Soc. 2008, 130, 10702-10713. 
(90) Tang, W.; Tsarevsky, N. V; Matyjaszewski, K. J. Am. Chem. Soc. 2006, 128, $1598-1604$.

(91) Kickelbick, G.; Pintauer, T.; Matyjaszewski, K. New J. Chem. 2002, 26, 462-468.

(92) Qiu, J.; Matyjaszewski, K.; Thouin, L.; Amatore, C. Macromol. Chem. Phys. 2000, 201, 1625-1631.

(93) Kumar, A.; Matyjaszewski, K. Macromolecules 2003, 36, 8222-8224.

(94) Matyjaszewski, K.; Wang, J.-L.; Grimaud, T.; Shipp, D. a. Macromolecules 1998, $31,1527-1534$.

(95) Mayr, H.; Roth, M.; Faust, R. Reactions 1996, 9297, 6110-6113.

(96) Lin, C. Y.; Coote, M. L.; Petit, A.; Richard, P.; Poli, R.; Matyjaszewski, K. Macromolecules 2007, 40, 5985-5994.

(97) Nanda, A. K.; Matyjaszewski, K. Macromolecules 2003, 36, 1487-1493.

(98) Lacík, I.; Beuermann, S.; Buback, M. Macromolecules 2003, 36, 9355-9363.

(99) Lin, C. Y.; Coote, M. L.; Gennaro, A. J. Am. Chem. Soc. 2008, 130, $12762-$ 12774.

(100) Morick, J.; Buback, M.; Matyjaszewski, K. Macromol. Chem. Phys. 2012, 213, 2287-2292.

(101) Isse, A. a.; Gennaro, A.; Lin, C. Y.; Hodgson, J. L.; Coote, M. L.; Guliashvili, T. J. Am. Chem. Soc. 2011, 133, 6254-6264.

(102) Buback, M.; Egorov, M.; Feldermann, A. Macromolecules 2004, 37, 1768-1776.

(103) Lyons, R. a; Hutovic, J.; Piton, M. C.; Christie, D. I.; Clay, P. a; Manders, B. G.; Kable, S. H.; Gilbert, R. G. Macromolecules 1996, 29, 1918-1927.

(104) Willemse, R. X. E.; Van Herk, A. M.; Panchenko, E.; Junkers, T.; Buback, M. Macromolecules 2005, 38, 5098-5103.

(105) Nikitin, A. N.; Hutchinson, R. a. Macromol. Rapid Commun. 2005, 38, 15811590 .

(106) Barner-Kowollik, C.; Günzler, F.; Junkers, T. Macromolecules 2008, 41, 89718973.

(107) Kajiwara, A.; Nanda, A. K.; Matyjaszewski, K. Macromolecules 2004, 37, 13781385. 
(108) Kajiwara, A. Macromol. Symp. 2007, 248, 50-59.

(109) Nikitin, A. N.; Hutchinson, R. a.; Buback, M.; Hesse, P. Macromolecules 2007, $40,8631-8641$.

(110) Couvreur, L.; Piteau, G.; Castignolles, P.; Tonge, M.; Coutin, B.; Charleux, B.; Vairon, J. P. Macromol. Symp. 2001, 174, 197-207.

(111) Beuermann, S.; Paquet, D. a.; McMinn, J. H.; Hutchinson, R. a. Macromolecules 1996, 29, 4206-4215.

(112) Navon, N.; Golub, G.; Cohen, H.; Meyerstein, D. Organometallics 1995, 14, $5670-5676$.

(113) Schröder, K.; Konkolewicz, D.; Poli, R.; Matyjaszewski, K. Organometallics 2012, 31, 7994-7999.

(114) Zhong, M.; Matyjaszewski, K. Macromolecules 2011, 44, 2668-2677.

(115) Wang, Y.; Zhong, M.; Zhang, Y.; Magenau, A. J. D.; Matyjaszewski, K. Macromolecules 2012, 45, 8929-8932.

(116) Nyström, F.; Soeriyadi, A. H.; Boyer, C.; Zetterlund, P. B.; Whittaker, M. R. J. Polym. Sci. Part A Polym. Chem. 2011, 49, 5313-5321.

(117) Nguyen, N. H.; Levere, M. E.; Kulis, J.; Monteiro, M. J.; Percec, V. Macromolecules 2012, 45, 4606-4622.

(118) Schroeder, H.; Buback, M. Macromolecules 2014, 47, 6645-6651.

(119) Matyjaszewski, K. J. Macromol. Sci. Appl. Chem. 1997, A34, 1785-1801. 

